ANA CAROLINA RIEKSTIN

MODELO DE GOVERNANÇA DE TECNOLOGIA DA INFORMAÇÃO DO ESCRITÓRIO AO CHÃO DE FÁBRICA

São Paulo - SP 


\title{
MODELO DE GOVERNANÇA DE TECNOLOGIA DA INFORMAÇÃO DO ESCRITÓRIO AO CHÃO DE FÁBRICA
}

\author{
Dissertação apresentada à Escola \\ Politécnica da Universidade de São Paulo \\ para obtenção do título de Mestre em \\ Engenharia.
}

São Paulo - SP 


\title{
MODELO DE GOVERNANÇA DE TECNOLOGIA DA INFORMAÇÃO DO ESCRITÓRIO AO CHÃO DE FÁBRICA
}

\author{
Dissertação apresentada à Escola \\ Politécnica da Universidade de São Paulo \\ para obtenção do título de Mestre em \\ Engenharia.
}

Área de Concentração:

Sistemas Digitais

Orientadora:

Profa. Dra Tereza Cristina Melo de Brito Carvalho 


\section{DEDICATÓRIA}

Ao Carlos Eduardo, noivo e companheiro.

Aos meus pais.

Aos meus irmãos.

A Deus. 


\section{AGRADECIMENTOS}

A Deus, por esta e todas as outras oportunidades em minha vida.

Ao Carlos Eduardo, sempre companheiro, pelo apoio constante desde o momento da inscrição no programa de mestrado até a conclusão.

Aos meus pais, Mario e Fatima, meus exemplos, e aos meus irmãos Ana Cláudia e Fernando que estão sempre presentes, mesmo distantes.

Aos meus amigos pelo apoio costumeiro.

Aos profissionais que dispensaram seu tempo nas entrevistas, colaborando decisivamente para a consecução deste trabalho.

À PromonLogicalis pelo apoio no início do programa de mestrado.

À Profa. Dra. Tereza Cristina Melo de Brito Carvalho pela dedicação de seu precioso tempo, em revisões e comentários, fundamentais para a consecução deste trabalho. 


\section{RESUMO}

A informação exerce um papel cada vez mais importante nas empresas e a Tecnologia da Informação (TI) vem sendo largamente utilizada para permitir a geração de informações úteis para a tomada de decisões, bem como agilizar ou até mesmo viabilizar diversos processos. No complexo ambiente industrial (manufatura), a TI está presente no escritório, nas áreas de desenvolvimento de produtos e processos e na linha de produção propriamente dita. Em função disto, é importante uma abordagem corporativa e sistêmica tanto para sistemas utilizados em escritório, quanto para sistemas utilizados em chão de fábrica, buscando o alinhamento da TI em todos estes ambientes com o negócio. Como forma de gerar valor ao negócio, atuando de forma alinhada, existe a Governança de TI. É possível estendê-la para as diversas funções de uma organização, mas ainda são poucas as iniciativas para tal. Neste contexto, o trabalho tem por objetivo propor uma abordagem conjunta de Governança de TI para todos os ambientes nos quais a TI está inserida em uma indústria, desde os sistemas corporativos até os sistemas de chão de fábrica. É proposto um modelo de governança de $\mathrm{TI}$ que busca integrar os diferentes requisitos, estabelecendo uma estrutura única e uma linguagem comum, agregando diferentes modelos e melhores práticas de mercado. Com o objetivo de validar o modelo proposto, este modelo foi aplicado em uma importante indústria do setor automobilístico realizando-se análises documentais, observações e diversas entrevistas. $O$ estudo de caso realizado para a referida indústria permitiu validar o modelo, considerando o atendimento aos requisitos especificados, além da análise crítica da sua aplicação. Pode-se dizer, então, que o produto final deste trabalho é um modelo integrado de governança de TI aplicável a empresas de manufatura de diferentes ramos.

Palavras chave: tecnologia da informação (administração) 


\begin{abstract}
Information plays an increasingly important role in business. Consequently, Information Technology (IT) has been widely used to allow the generation of useful information for decision-making, as well as speed up or even enable several processes. In the complex industrial environment (manufacturing), IT is present in the office, in the areas of product and processes development and on the shop floor. Because of this, a corporate and systemic approach is important for both systems used at the office and systems used in the shop floor, aiming at aligning IT in all these environments with the business. In order to generate value to the business, acting in a aligned way, there is the IT Governance. It is posible to extend it to the various functions of an organization, but there are few initiatives to do so. In this context, this work aims to propose a joint approach for IT Governance for all environments in which IT is present in an industry, from corporate systems to the shop floor systems. It is proposed an IT governance model that aims to integrate the different requirements, establishing a unique structure and a common language, consolidating different models and market best practices. In order to validate the proposed model, the model was applied in an important industry in the automotive sector by doing document analysis, observations and several interviews. The case study for that industry has made posible the model validation, considering the specified requirements, and also the critical analysis of its application. It is posible to state that the final product of this work is an integrated IT governance model applicable to manufacturing companies of different sectors.
\end{abstract}

Keywords: information technology (administration) 


\section{LISTA DE ILUSTRAÇÕES}

Figura 1 - Trabalhos relacionados .24

Figura 2 - Estágios da TI dentro de uma empresa (FERNANDES; ABREU, 2008) ..29 Figura 3 - Modelo de alinhamento estratégico (HENDERSON; VENKATRAMAN, 1993) .30

Figura 4 - Alternativas de estrutura (RAMIREZ; ZUCARELLI, s.d.) ….....................34

Figura 5 - Processo físico (SOUZA; PEREIRA, 2008) ..........................................38

Figura 6 - Modelo MES proposto pela MESA (MESA, 1997 apud SILVA, 2009)......41

Figura 7 - ISA Hierarquia Funcional (ISA, 2000 apud SILVA, 2009) .......................41

Figura 8 - Modelo ISA 95 (ISA, 2000 apud SILVA, 2009)........................................ 43

Figura 9 - Escopo dos padrões de segurança (SINGER, 2006) .............................44

Figura 10 - Visão Funcional CPAS (HOLLENDER, 2009) .......................................45

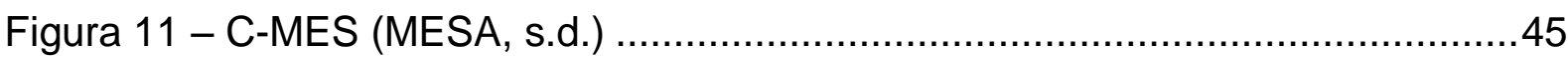

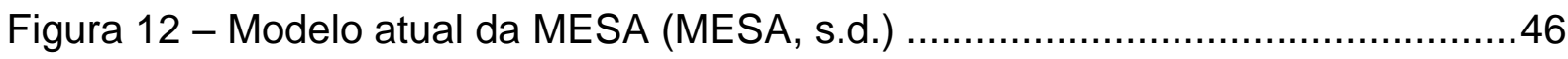

Figura 13 - Governança corporativa e dos principais ativos (WEILL; ROSS, 2006)... 49

Figura 14 - Ciclo de Governança de TI (FERNANDES; ABREU, 2008) ...................56

Figura 15- Framework de Governança de TI (MIT CISR, 2003 apud WEILL; ROSS,

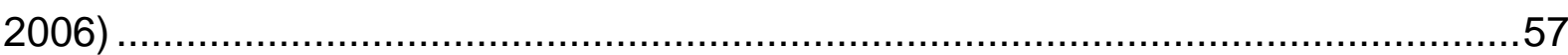

Figura 16- Modelo de Governança de TI (FERNANDES; ABREU, 2008) ..................58

Figura 17- Modelo de Governança de TI (GREMBERGEN; DE HAES, 2008) ...........59

Figura 18- Estrutura de Governança de TI (ALBERTIN; ALBERTIN, 2010) ..............60

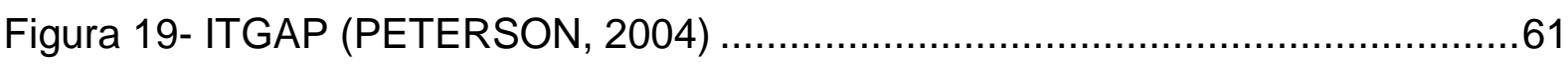

Figura 20 - Práticas atuais de governança (ITGI; PRICEWATERHOUSECOOPERS, 2008)

Figura 21 - Os quatro domínios do CobIT inter-relacionados (adaptado de ITGI, 2007) 64

Figura 22 - Domínios e processos do VAL IT (adaptado de ISACA, 2009a)

Figura 23: Processos ISO/IEC 20000 (adaptado de ISO, 2005 apud FERNANDES;

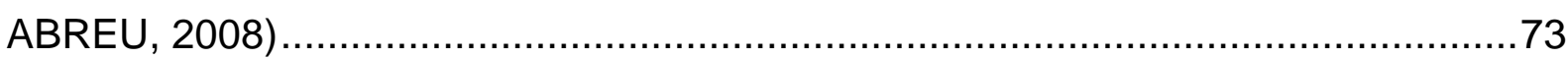

Figura 24 - PDCA (Adaptado de Fernandes e Abreu, 2008) ….............................74

Figura 25 - Mapeamento entre os processos de gerenciamento de projetos e os grupos de processos de gerenciamento de projetos e as áreas de conhecimento (PMI, 2004)..... 
Figura 26 - Relacionamento entre processos e componentes na PRINCE2

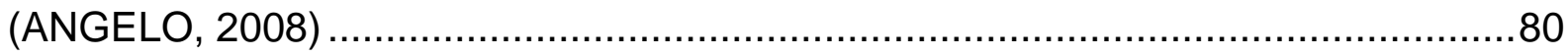

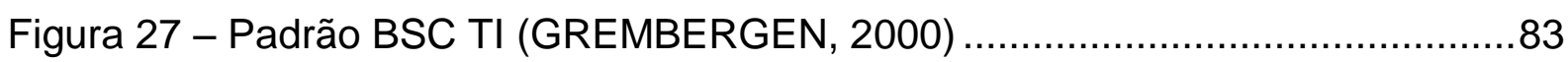

Figura 28 - TOGAF Architecture Development Method (adaptado de THE OPEN GROUP, 2009)

Figura 29 - Modelo do ciclo Avaliar-Dirigir-Monitorar para a Governança de TI de acordo com a ISO 38500 (TEIXEIRA, 2010) . .89

Figura 30 - Análise do âmbito de aplicação de cada melhor prática .91

Figura $31-$ Modelos de governança utilizados (ITGl;

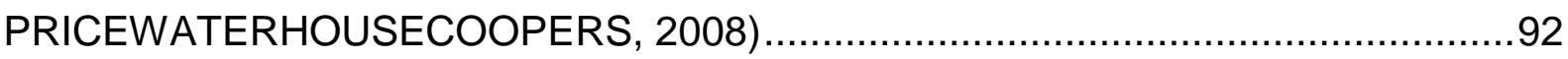

Figura 32 - Estruturas / processos de gestão (RODRIGUES et al., 2009) ..............92

Figura 33 - Método de criação e estrutura do modelo proposto por Clementi

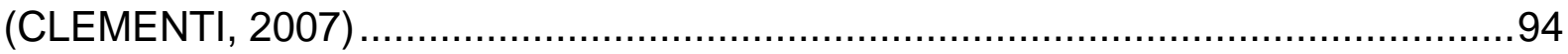

Figura 34 - Exemplo de mapeamento COBIT - ITIL - ISO 27001 (ITGI, 2008) .......95

Figura 35 - Os domínios e papeis da ITIL e TOGAF dentro de uma organização (RADHAKRISHNAN, 2008 apud VAN SANTE; ERMERS, 2009)............................95

Figura 36 - Escopos da ITIL V3 e do TOGAF (VAN SANTE; ERMERS, 2009) ........95

Figura 37 - COBIT e Val IT (VOON; SALIDO, 2009) ……....................................

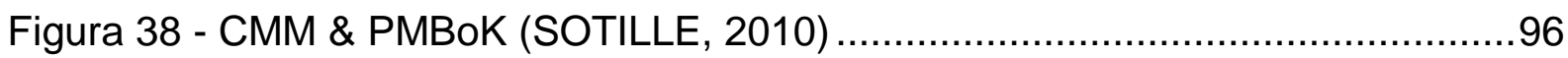

Figura 39 - Sistema de governança que integra supervisão da diretoria da empresa e

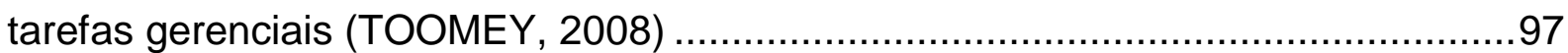

Figura 40 - Melhores práticas em Governança de TI (JESUS, 2007)......................97

Figura 41 - Framework Calder-Moir (CALDER, 2008a) ......................................98

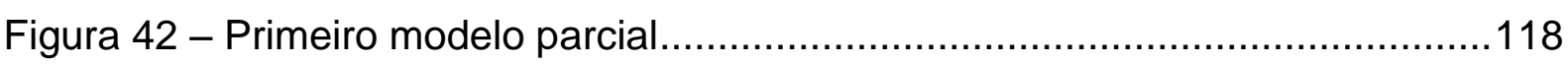

Figura 43 - Detalhamento das etapas para desenvolvimento do modelo ...............119

Figura 44 - Modelo parcial de Governança de TI, envolvendo COBIT, Val IT e outros

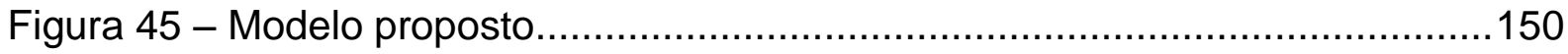

Figura 46 - Protocolo utilizado nas entrevistas ..............................................153

Figura 47 - Perguntas para avaliar a Governança de TI (WEILL; ROSS, 2006).....154 


\section{LISTA DE TABELAS}

Tabela 1- Estágios de evolução da informática, segundo Nolan (LAURINDO, 2000) .32

Tabela 2 - Arquétipo da Governança de TI (Adaptado de WEILL; ROSS, 2006) ......53

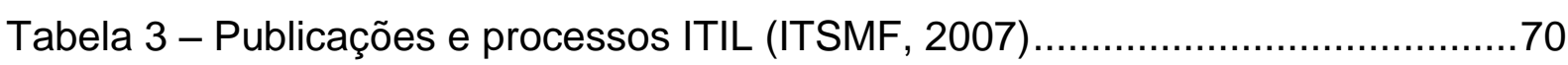

Tabela 4 - Modelos e melhores práticas de mercado: descrição e aplicabilidade .....90

Tabela 5 - Domínios e processos do COBIT e o que é necessário incluir no modelo em construção.

Tabela 6 - Domínio "Investment Management" (IM) e respectivos processos do VAL IT e o que é necessário incluir no modelo. 123

Tabela 7 - Domínio "Portfolio Management" (PM) e respectivos processos do VAL IT e o que é necessário incluir no modelo 125

Tabela 8 - Domínio "Value Governance" (VG) e respectivos processos do VAL IT e o que é necessário incluir no modelo 126

Tabela 9 - Atendimento aos requisitos 147

Tabela 10 - Entrevistados e respectivas áreas 151

Tabela 11 - Síntese do estudo de caso da Carros 187

Tabela 12 - Validação dos requisitos 193 


\section{LISTA DE ABREVIATURAS E SIGLAS}

AMT

APS

ARC

AS/RS

BSC

CAD

CAE

CAM

CAPP

CEO

CIM

$\mathrm{CIO}$

CISR

C-MES

CMMi

CMMi-ACQ

CMMi-DEV

CMMi-SVC

CNC

COBIT

COO

CPAS

DNC

EAM

ERP

eSCM

eSCM-CL

eSCM-SP

FCS

ISA

ISACA

ITGAP
Advanced Manufacturing Technology

Advanced Planning Schedule

Advisory Group

Automatic Storage/Retrieval Systems

Balanced Scorecard

Computer Aided Design

Computer Aided Engineering

Computer Aided Manufacturing

Computer Aided Process Planning

Chief Executive Officer

Computer Integrated Manufacturing

Chief Information Officer

Center for Information Systems Research

Collaborative MES (Manufacturing Execution Systems)

Capability Maturity Model Integration

Capability Maturity Model Integration - for Acquisition

Capability Maturity Model Integration - for Development

Capability Maturity Model Integration - for Services

Computer Numerical Control

Control Objectives for Information and related Technology

Chief Operations Officer

Collaborative Process Automation System

Distributed Numerical Control

Enterprise Asset Management

Enterprise Resource Planning

The eSourcing Capability Model

The eSourcing Capability Model for Client Organization

The eSourcing Capability Model for Service Providers

Fatores Críticos de Sucesso

International Society of Automation

Information Systems Audit and Control Association

IT Governance Assessment Process 
IT Governance Institute

ITIL

Information Technology Infrastructure Library

LAN

Local Area Network

MES

Manufacturing Execution Systems

MESA

Manufacturing Enterprise Solution Association

MIT

Massachusetts Institute of Technology

MPS.BR

Melhoria de Processos do Software Brasileiro

MRP

Materials Requirement Planning

MRP II

NC

Manufacturing Resources Planning

OCDE

Numerical Control

OPM3

Organização para Cooperação e Desenvolvimento Econômico

P3M3

Organizational Project Management Maturity Model

PIMS

Portfolio, Programme \& Project Management Maturity Model

PLC

Plant Information Management

PLM

Programmable Logical Controller

PMBOK

Product Lifecycle Management

PRINCE2

Project Management Body of Knowledge

SCADA

Project in Controlled Environments

SME

Supervisory Control and Data Acquisition

SOFTEX

Society of Manufacturing Engineers

TOGAF

Sociedade para Promoção da Excelência do Software Brasileiro

WAN

The Open Group Architecture Framework

Wide Area Network 


\section{SUMÁRIO}

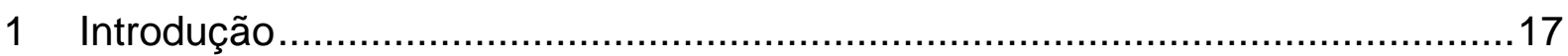

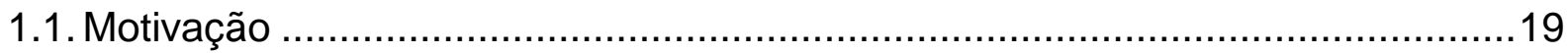

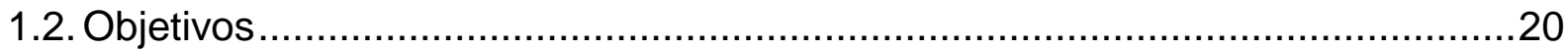

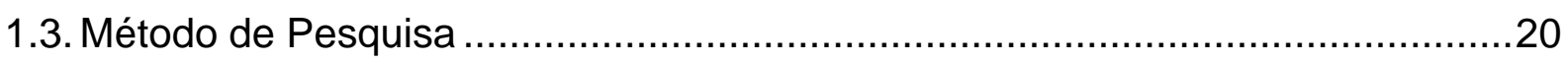

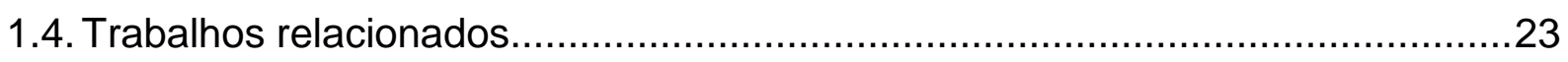

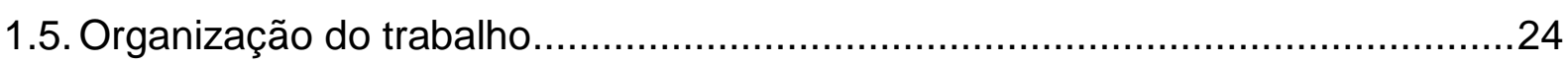

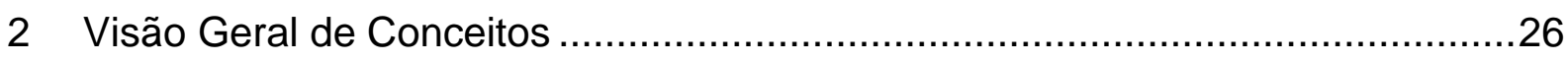

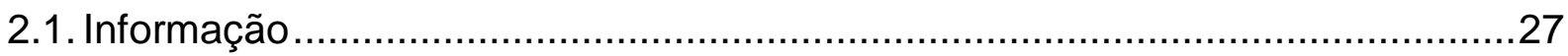

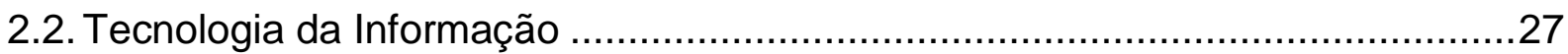

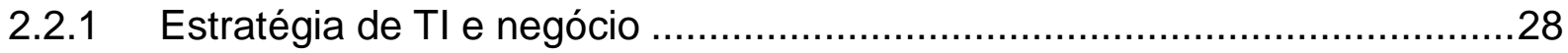

2.2.2 Entendimento da posição da TI dentro da empresa.....................................31

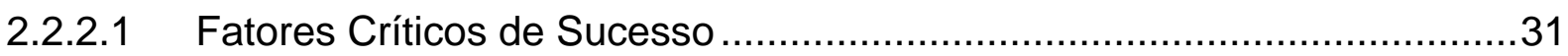

2.2.2.2 Estágio de Informatização da Empresa ...............................................32

2.2.2.3 Centralização ou Descentralização de TI.............................................32

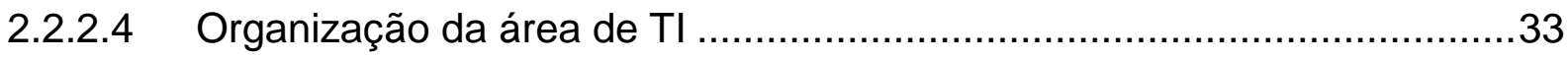

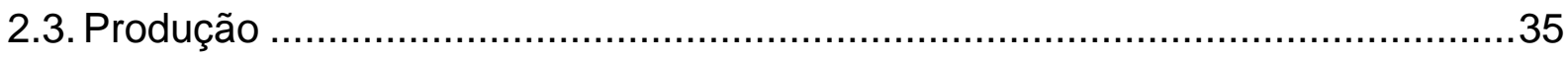

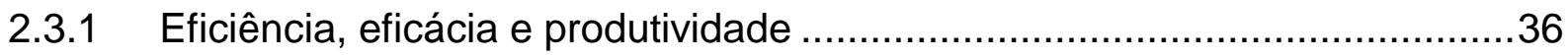

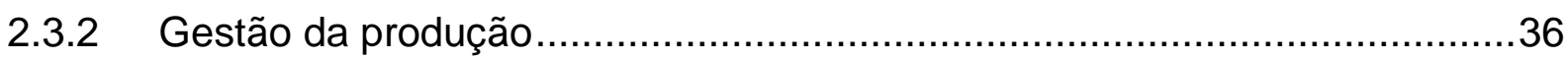

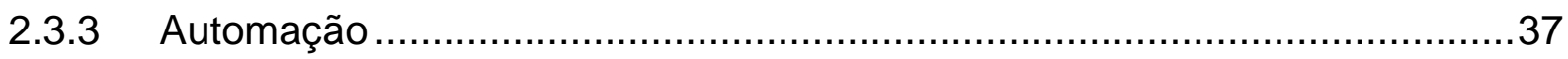

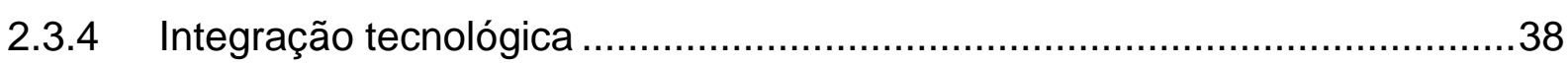

2.3.4.1 Modelos para integração tecnológica .................................................40

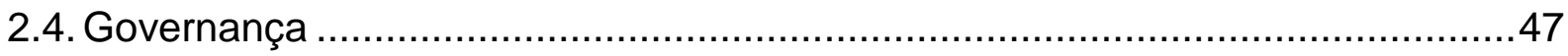

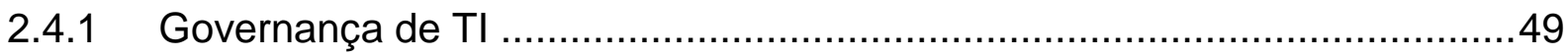

2.4.1.1 Modelos de Governança de TI..........................................................

2.4.1.2 Modelos e melhores práticas que apoiam a Governança de TI ................61

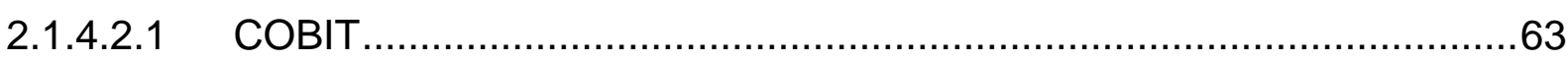

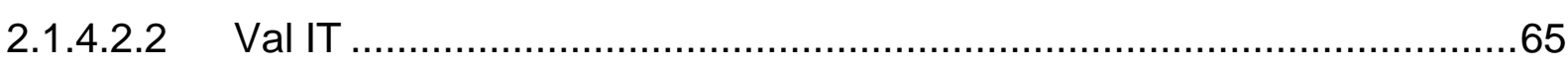

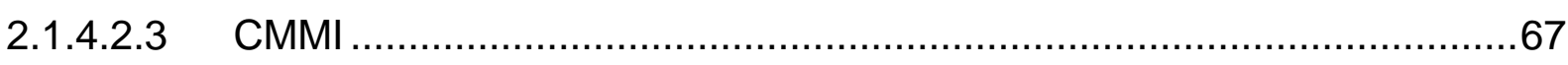

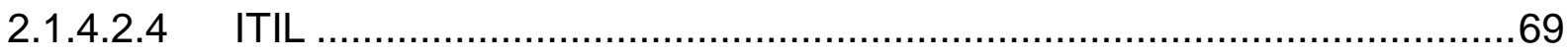

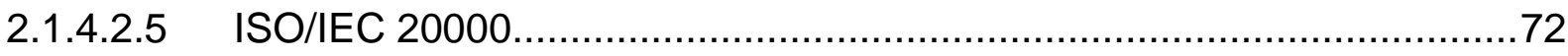

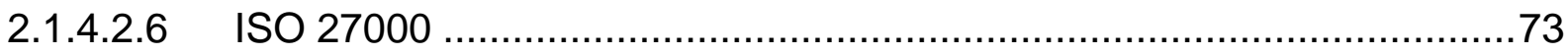

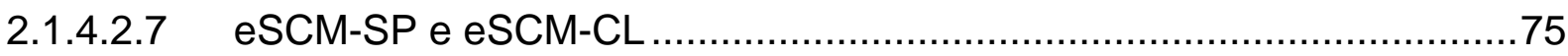




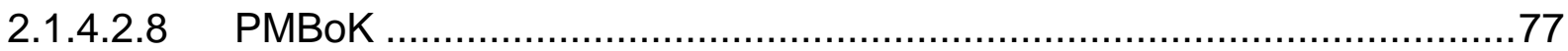

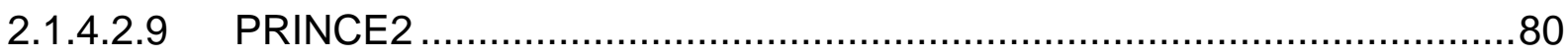

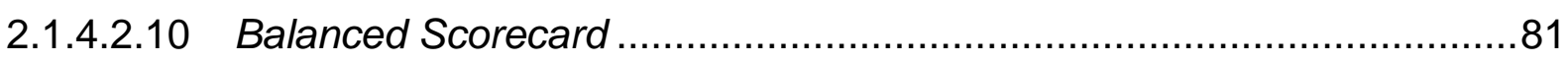

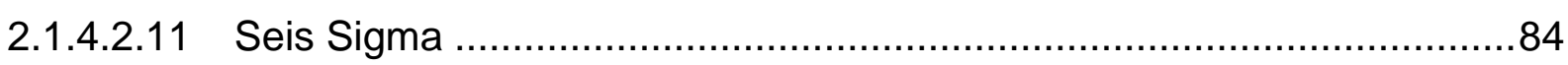

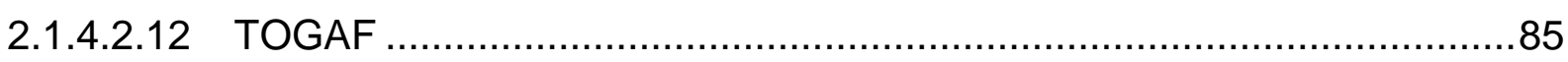

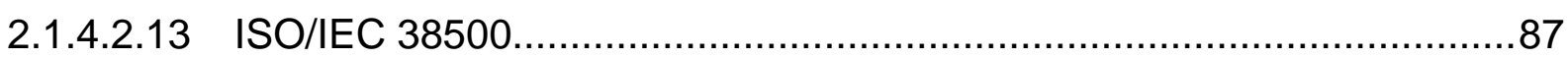

2.1.4.2.14 Analise Comparativa Geral dos Modelos de Governança ....................90

2.4.1.3 Combinação de modelos de governança de $\mathrm{Tl}$ e melhores práticas ........93

2.5. Alinhamento entre tecnologia aplicada à produção e negócio e Governança de

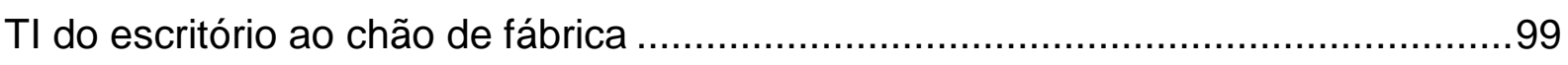

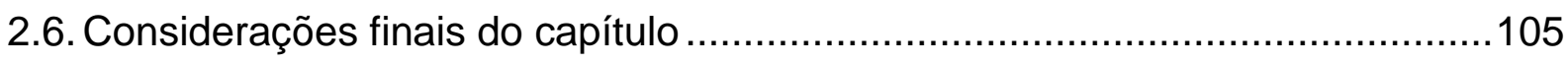

3 Descrição do Problema e Especificação de Requisitos ...................................106

3.1. Classificação das ferramentas utilizadas em manufatura ..............................107

3.2. Requisitos para um modelo de Governança de TI aplicado à manufatura .......107

3.3. Considerações finais do capítulo .............................................................111

4 Modelo de Governança de TI Proposto ....................................................112

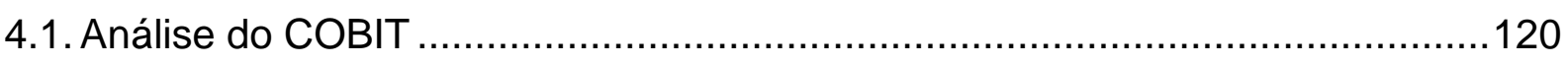

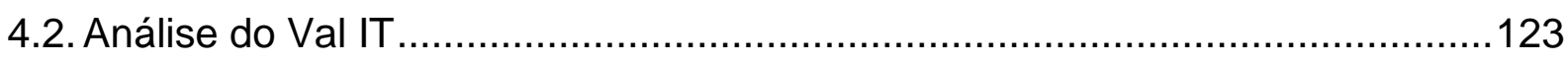

4.3. Detalhamento de acordo com ITIL, ISO 27000, PMBoK, PRINCE2 e TOGAF.128

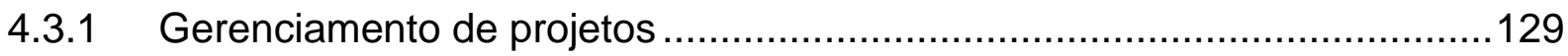

4.3.2 Transição e Operações ................................................................130

4.3.2.1 Gerenciamento de níveis de serviço .................................................131

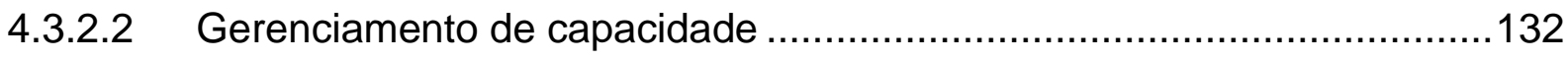

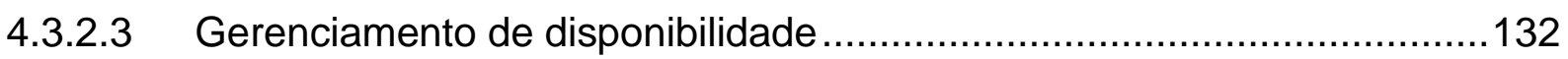

4.3.2.4 Gerenciamento de continuidade …..............................................133

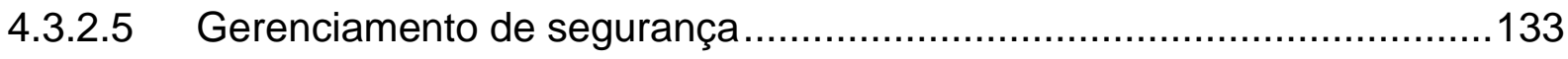

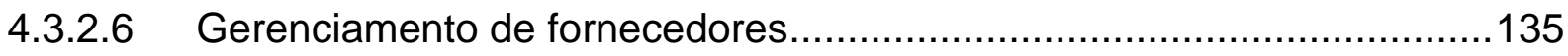

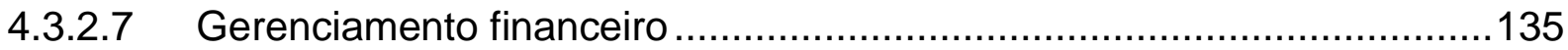

4.3.2.8 Gerenciamento de mudanças .....................................................135

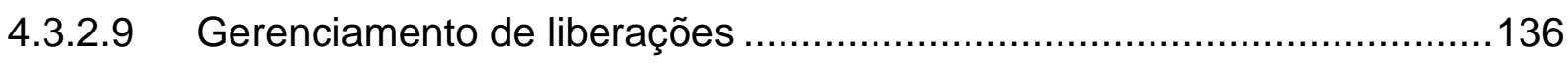

4.3.2.10 Gerenciamento de configuração .....................................................137

4.3.2.11 Gerenciamento de eventos .......................................................137

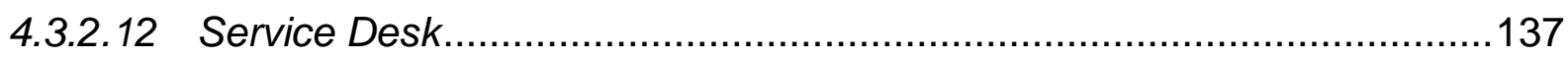

4.3.2.13 Gerenciamento de incidentes ...................................................138 
4.3.2.14 Gerenciamento de requisições .................................................138

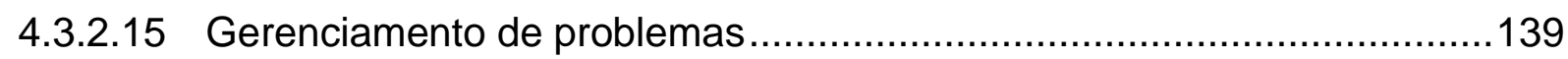

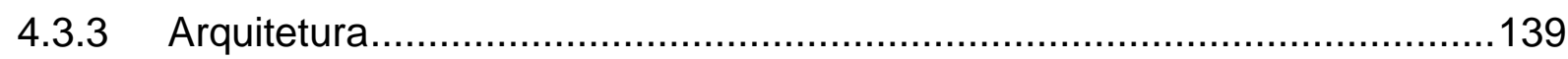

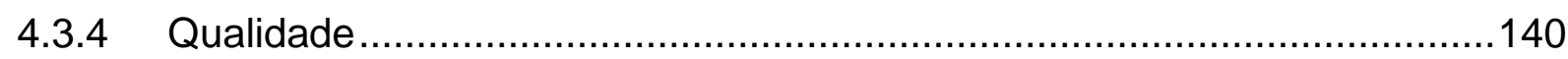

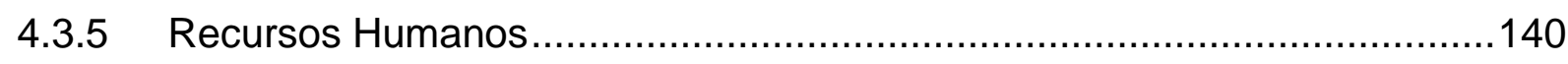

4.4. Detalhamento de acordo com eSCM-SP / eSCM-CL e CMMi .........................141

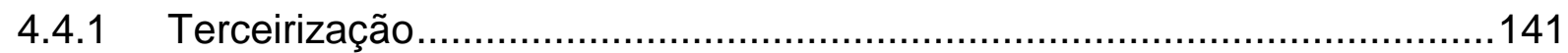

4.5. Detalhamento dos mecanismos relacionais e abordagens de comunicação....143

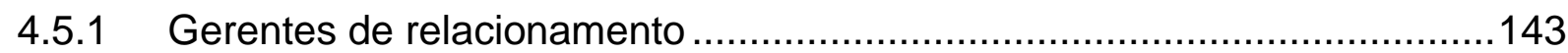

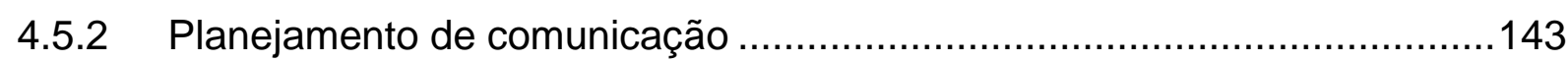

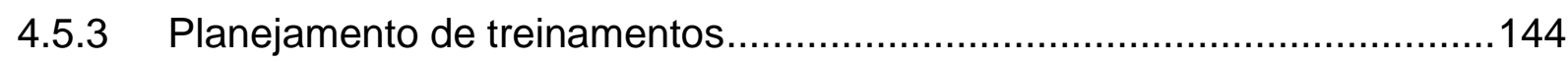

4.5.4 Documentação de sistemas e processos ..............................................145

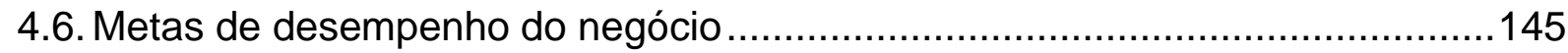

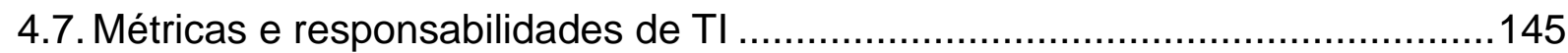

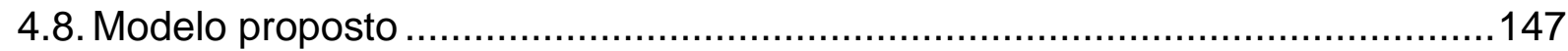

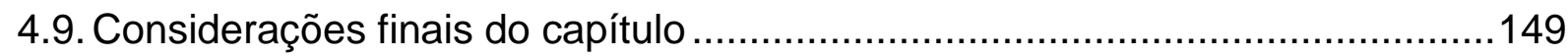

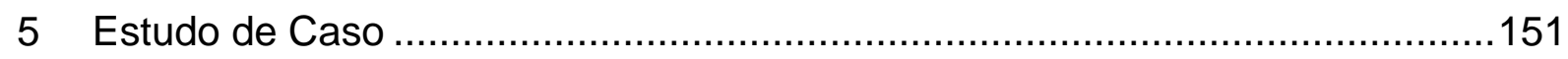

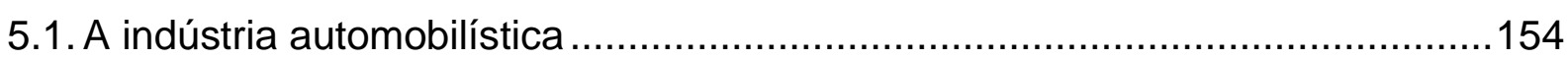

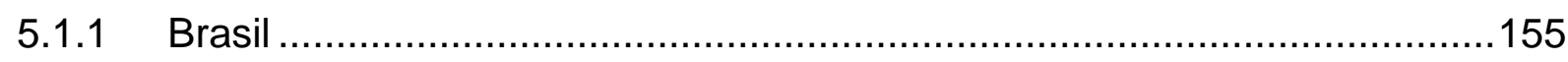

5.2. A Tecnologia da Informação na indústria automobilística...............................156

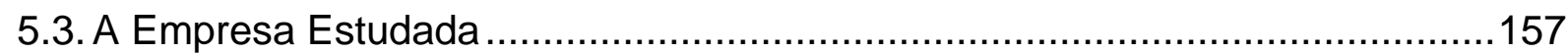

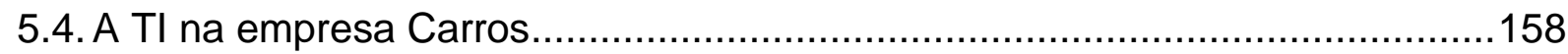

5.5. Estado atual da Governança de TI na empresa estudada.............................158

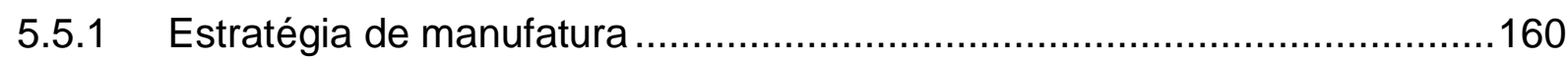

5.5.2 Organização de Tl e comportamentos desejáveis ...................................160

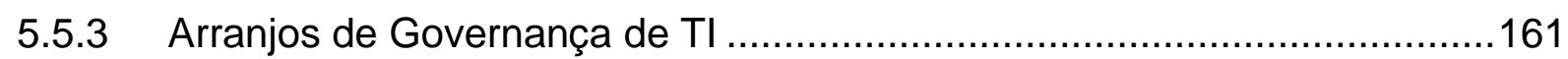

5.5.4 Mecanismos de Governança de TI - Estruturas organizacionais ..............162

5.5.5 Mecanismos de Governança de TI - Processos de alinhamento ...............164

5.5.5.1 Mecanismos de Governança de TI - Processos de alinhamento -

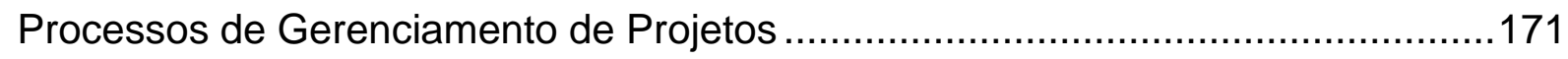

5.5.5.2 Mecanismos de Governança de TI - Processos de alinhamento -

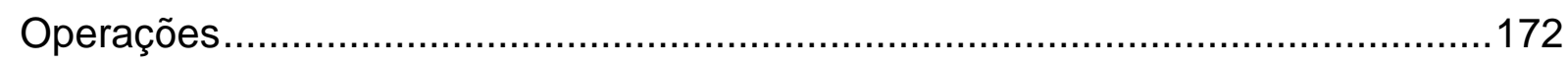

5.5.5.3 Mecanismos relacionais e abordagens de comunicação ........................181

5.5.5.4 Metas de desempenho do negócio ..................................................182 
5.5.5.5 Métricas e responsabilidades de TI

5.6. Estado desejado da Governança de TI na empresa estudada e como a empresa pretende alcançá-lo 184

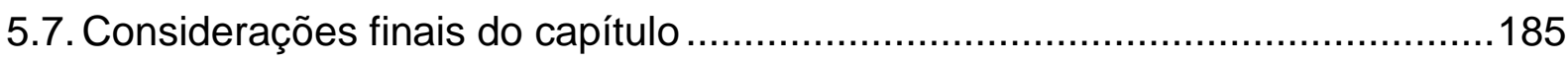

6 Validação do Modelo proposto ……………….....................................186

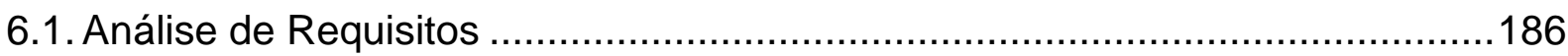

6.2. Análise do Uso do Modelo Proposto para o Estudo de Caso ..........................187

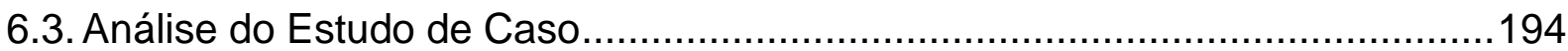

6.4. Análise da Aplicabilidade do Modelo de Governança Proposto para Outros

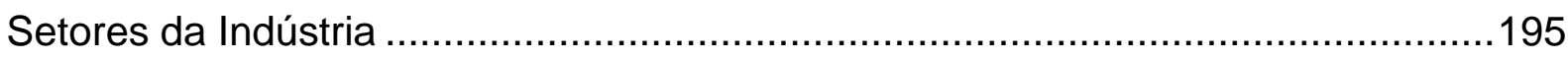

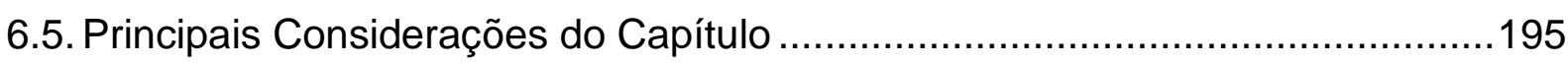

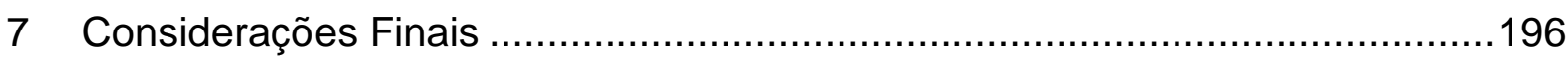

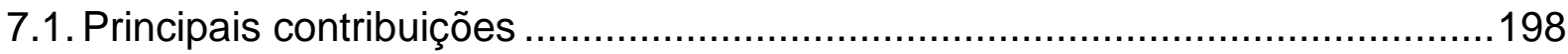

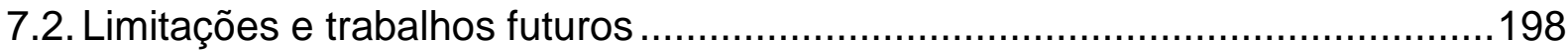

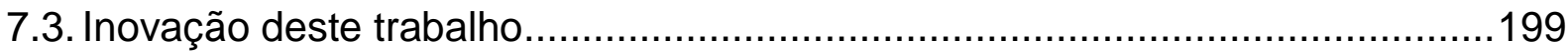

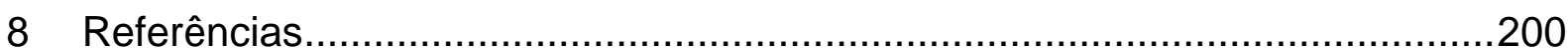




\section{INTRODUÇÃO}

A informação exerce um papel cada vez mais importante nas organizações (SOUZA; PEREIRA, 2008) e, conforme, se torna um ativo mais estratégico, o papel da Tecnologia da Informação (TI) tende a assumir posições mais importantes dentro da empresa, devendo ser administrada como são os negócios, com processos, metas e métricas de controle.

Quanto mais estratégico é o papel da TI, e quanto mais estratégica é a TI, mais importante é o alinhamento estratégico entre ela e os negócios.

De acordo com o COBIT (ITGI, 2007, p. 09), o alinhamento trata de:

"Garantir a ligação entre os planos de negócios e de TI, definindo, mantendo e validando a proposta de valor de $\mathrm{TI}$, alinhando as operações de TI com as operações da organização".

Este alinhamento, de acordo com Henderson e Venkatraman (1993) pode ter a estratégia do negócio como fator motivador ou a estratégia de TI como habilitador, buscando explorar como a TI pode criar ou melhorar a estratégia do negócio.

Dentro do cenário altamente competitivo de hoje, a demanda por produtos de alta qualidade e baixo custo com tempos baixos de desenvolvimento levou as indústrias a considerarem novas estratégias de desenvolvimento de produtos, processos e gestão do negócio e, com estas estratégias, a TI se desenvolveu buscando a integração das atividades, eficiência e eficácia (VERNADAT, 1996).

Desta forma, o mundo industrial tem passado por muitas mudanças e o cenário de $\mathrm{TI}$ tornou-se complexo, composto por diferentes ambientes, inclusive o de produção ${ }^{1}$, cujo o objetivo é a fabricação de bens manufaturados, a prestação de serviços ou o fornecimento de informações (MARTINS; LAUGENI, 2006).

\footnotetext{
${ }^{1}$ Produção é o processo de transformação pelo qual insumos são transformados em produtos ou serviços com maior valor econômico que os insumos (MORORÓ, 2008)
} 
$\mathrm{Na}$ grande maioria das indústrias, a TI está presente no escritório, nas áreas de desenvolvimento de produtos e processos e na linha de produção propriamente dita $\left(\right.$ automação $^{2}$ ). Em busca de maior competitividade e do atendimento das necessidades sociais, econômicas e ambientais, a indústria vem empregando cada vez mais automação (GUEDES et al., 2008), cujo principal objetivo é acelerar o processo de produção e obter produtos com qualidade.

No início, os sistemas de automação limitavam-se ao monitoramento e controle de partes específicas do processo, em busca de viabilizar operações remotas não assistidas (SOUZA; PEREIRA, 2008). Este campo de atuação foi expandido e os sistemas passaram a lidar com grandes quantidades de dados. (GUEDES et al., 2008). A automação, presente nas várias etapas do negócio, permite a geração de informações úteis à operação e manutenção, suportando a tomada de decisões (SOUZA; PEREIRA, 2008).

É importante uma abordagem corporativa e sistêmica tanto para sistemas utilizados em escritório, quanto para sistemas utilizados em chão de fábrica (SOUZA; PEREIRA, 2008). A TI deve andar lado a lado com os processos de negócio, de forma que os investimentos em tecnologia sejam voltados à geração de valor para o negócio.

Como forma de gerar valor ao negócio, atuando de forma alinhada, existe a Governança de TI. É possível estendê-la para as diversas funções de uma organização (SILVA, 2009). No entanto, ainda são poucas as iniciativas como a de Silva (2009), que buscam estender a Governança de TI para o chão de fábrica, proporcionando uma estrutura decisória, de processos e mecanismos relacionais integrados.

No complexo âmbito industrial, a TI é capaz de influir no ganho de produtividade, pois permite o desenvolvimento de produtos e de processos de forma mais eficiente, facilita a difusão de inovações e possibilita economias de escala através da cadeia

\footnotetext{
${ }^{2}$ Groover (2008) define automação como a tecnologia pela qual um processo ou procedimento é realizado sem intervenção humana. É implementada usando um conjunto de instruções e um sistema de controle que as executa.
} 
produtiva. Ambientes integrados tecnologicamente podem trazer diversas vantagens competitivas por prover informações confiáveis e suportar a manufatura "lean" (enxuta), ágil e concorrente (NAGALINGAM, 2008).

Apesar desta complexidade, já existem iniciativas de integração (arquitetura de automação) e governança unindo estes diferentes ambientes (SILVA, 2009; HOLLENDER, 2009; MESA, s.d). As indústrias que têm alcançado os maiores benefícios estão convergindo suas estruturas nas áreas de arquitetura e infraestrutura de $\mathrm{Tl}$ e de automação, estruturas para projetos destas áreas e novas estruturas organizacionais (FRASER; ZIMMERMANN, 2007).

\subsection{Motivação}

Unir as diferentes subáreas de $\mathrm{Tl}$ existentes em diferentes departamentos ou divisões de uma indústria pode trazer benefícios para o negócio como um todo, como:

- Aumento da eficiência e lucratividade;

- Redução de custos;

- Redução de erros por entrada manual de dados;

- Redução de esforço duplicado de manter equipamentos e serviços em departamentos separados (mão de obra e equipamentos) (FRASER; ZIMMERMANN, 2007; MIKLOVIC, 2008; SOMMER, 2008).

As indústrias que têm alcançado os maiores benefícios estão convergindo os ambientes não apenas através de estruturas para projetos, mas criando novas estruturas organizacionais e processos, expandindo a Governança de TI - a Governança de $\mathrm{Tl}$ é motivada por diversos fatores, como a dependência do negócio em relação a $\mathrm{TI}$, os marcos regulatórios, a necessidade de segurança da informação, o próprio contexto de negócios e a necessidade de integração tecnológica (FERNANDES; ABREU, 2008). 
Albertin e Albertin (2010) comentam que o tema de Governança de TI encontra-se em fase de amadurecimento e de consolidação, além de ser um mercado ainda carente de projetos implantados e com muitas divergências sobre o que é ter um modelo de Governança de $\mathrm{TI}$, que muitas vezes fica restrito à implementação de melhores práticas como COBIT ou ITIL.

Brown e Grant (2005) comentam que ainda há espaço para estudos empíricos em Governança de TI. Larsen et al. (2006) comentam que estudos de caso em profundidade e uma visão geral das ferramentas de governança são necessárias. Além disto, Panetto e Molina (2008) comentam que existem diversos desafios de pesquisa no campo da integração em manufatura, como a pesquisa alinhada entre estratégia de negócios e tecnologia, reuso de boas práticas e teorias neste ambiente e interoperabilidade entre arquiteturas de TI e de automação.

\subsection{Objetivos}

Dentro deste contexto, é proposto neste trabalho um modelo de governança para todos os ambientes nos quais a TI está presente nas indústrias e tem por objetivo responder "como integrar a Governança de TI através de um modelo, considerando sua utilização em processos corporativos e de produção?", levando em conta os requisitos de cada ambiente dentro do ramo industrial, um claro exemplo de ambiente em que a infraestrutura de tecnologia para processos administrativos e de produção convivem no dia-a-dia.

\subsection{Método de Pesquisa}

O presente trabalho tem como tema a Governança de TI englobando pessoas, processos e ferramentas corporativas, bem como ferramentas utilizadas para a automação de processos industriais. Para tal, foi realizado um extenso levantamento bibliográfico sobre sistemas de produção, automação, tecnologia da informação, Governança da Tecnologia da Informação, modelos de mercado e sobre a união da automação com a tecnologia da informação. Foi proposto, então, um modelo de 
governança que busca alinhar estes dois mundos, considerando as melhores práticas estudadas.

A pergunta de pesquisa pode ser descrita da seguinte forma: "como integrar a Governança de TI através de um modelo, considerando sua utilização em processos corporativos e de produção?".

Para testar o modelo proposto, a questão será tratada de forma descritiva e qualitativa, empregando como abordagem metodológica um estudo de caso ${ }^{3}$. Quando a questão de pesquisa é "como" ou "porque", quando o pesquisador tem pouco controle sobre os eventos e quando o foco é um acontecimento contemporâneo, Yin (2005) comenta que os estudos de caso são a estratégia preferida. Palena et al.(2006) comenta que um estudo de caso é apropriado quando existe uma história única e interessante a ser contada, sendo uma metodologia capaz de oferecer um panorama completo sobre o que acontece e por quê.

De acordo com Clever (2000) et al. apud Laurindo (2000), os estudos de caso têm sido bastante usados nas pesquisas em TI. De acordo com Albertin e Albertin (2010), a estratégia de pesquisa de estudo de caso tem contribuído para a compreensão de fenômenos organizacionais, além de ser muito utilizada nas áreas de administração, pois permite um estudo que preserva as características holísticas de processos organizacionais e administrativos.

Dentro do contexto do presente trabalho, foi realizado um estudo de caso aplicado a uma única empresa, permitindo um maior aprofundamento no assunto da Governança de TI aplicada do escritório ao chão de fábrica. Foi possível investigar o modelo de um exemplo representativo que oferece um panorama completo de como é a governança em uma indústria.

${ }^{3}$ Estudos de casos podem ser caracterizados como pesquisas exploratórias, por prover ao pesquisador e sua audiência um maior conhecimento sobre o tema, relacionando um caso real às teorias do assunto (MIGUEL, 2007). 
Para o levantamento dos dados, foram realizadas entrevistas semi-estruturadas ${ }^{4}$ com diferentes profissionais dentro da empresa estudada, possibilitando uma maior flexibilidade na formulação das perguntas, além de análises documentais e observações diretas.

De acordo com Yin (2005), a vulnerabilidade em potencial de um caso único é que o mesmo pode acabar não sendo o caso que se pensava no início, de forma que se exige uma investigação inicial para minimizar as chances de uma representação equivocada.

O processo de condução de um estudo de caso segue o mesmo processo geral que outros métodos de pesquisa, incluindo as fases de: planejamento, coleta de dados, análise dos dados e conclusões (PALENA et al., 2006).

Neste trabalho, é considerado o seguinte roteiro:

1. Planejamento: identificar as pessoas envolvidas e locais a serem visitados; identificar as informações necessárias e fontes; identificar documentos importantes; listar as pessoas a serem entrevistadas.

2. Desenvolvimento dos protocolos para entrevistas: o que perguntar - listar perguntas para os diferentes envolvidos, buscando questões que verifiquem a consistência das respostas; o que dizer aos entrevistados no início, durante e para encerrar a conversa; o que fazer durante a entrevista (anotações, gravação); o que fazer após a entrevista.

3. Investigação inicial: trocar informações sobre o estudo com os futuros entrevistados para minimizar as chances de uma representação equivocada.

\footnotetext{
${ }^{4}$ Uma entrevista semi-estruturada possui um roteiro com perguntas básicas e principais que pode ser complementado com novos questionamentos que surgirem durante a interação com o entrevistado para atingir o objetivo da pesquisa, de forma que o pesquisador possui um planejamento, mas novas informações podem emergir de forma mais livre (MANZINI, 2004).
} 
4. Agendamento e estimativa de tempo de cada encontro necessário, entrevistando o número adequado de pessoas envolvidas em diferentes funções de Tl e de áreas de negócio.

5. Coleta de dados: conduzir as entrevistas; coletar documentos.

6. Análise dos dados: revisar dados coletados; analisar modelo proposto versus situação estudada.

7. Conclusão: escrever relatório do estudo; solicitar feedback aos envolvidos; revisar modelo proposto.

\subsection{Trabalhos relacionados}

Discussões acerca da integração dos diferentes ambientes de TI na área de manufatura têm sido realizadas por pesquisadores, institutos e empresas do ramo. Estes trabalhos são discutidos na seção 2.3.4 (Integração tecnológica).

A TI tem se tornado mais estratégica e o tema Governança de TI está amadurecendo e sendo consolidado. Diversos trabalhos acadêmicos buscaram definições, formas de alinhamento entre o negócio e TI, modelos, combinações de modelos e aplicações. O assunto é tratado na seção 2.4.1 (Governança de TI).

Os trabalhos publicados por Fraser e Zimmermann (2007), Miklovic (2008) e Sommer (2008) buscaram entender o estado atual de integração entre as áreas de TI e automação, bem como a forma com que está sendo realizada a integração dos trabalhos entre as áreas, através de processos, estruturas e tecnologias. Os resultados dos estudos são detalhados na seção 2.5 .

Unindo os dois mundos, aplicando a Governança de $\mathrm{Tl}$ aos diferentes ambientes de manufatura, Silva (2009) propõe um mecanismo para estender a Governança de TI até o chão de fábrica em indústrias trabalhando com a camada MES (Manufacturing Execution Systems). A proposta do modelo MES é integrar os sistemas de automação do chão de fábrica aos sistemas de gestão através de um conjunto de funcionalidades. Por conta desta característica, o autor defende a extensão da 
Governança TI até o chão-de-fábrica iniciando pelo estabelecimento de processos para suportar o planejamento dos investimentos em sistemas, considerando o alinhamento entre $\mathrm{TI}$ e negócio como um aspecto chave.

O trabalho utiliza o modelo de alinhamento de Rockhart e sugere os seguintes passos: executivos identificam aspectos fundamentais para o negócio (fatores críticos de sucesso), definem indicadores para os fatores identificados e derivam requisitos e necessidades do MES. Desta forma, busca-se estender os limites da Governança de TI em indústrias desde o nível administrativo até o chão de fábrica endereçando o processo de planejamento de investimentos na camada MES.

A Figura 1 descreve a relação entre os trabalhos conforme descrito acima.

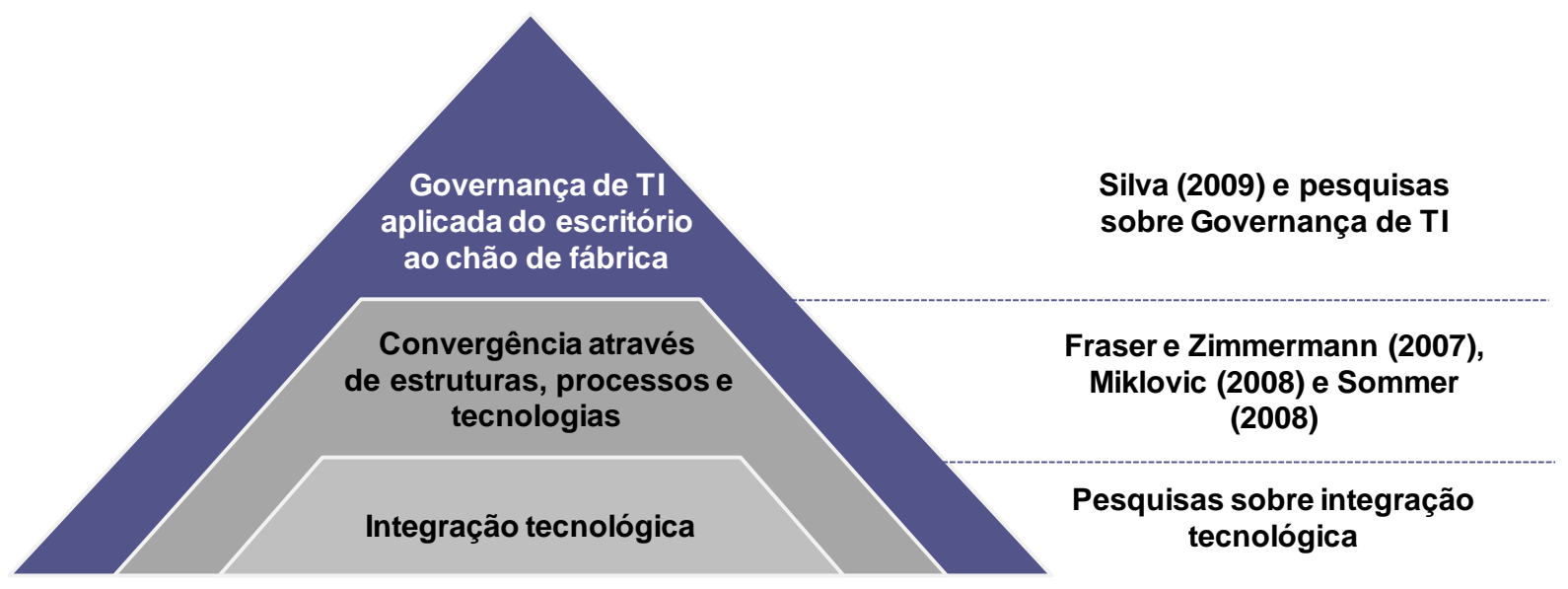

Figura 1 - Trabalhos relacionados

\subsection{Organização do trabalho}

Este trabalho está organizado da seguinte forma:

- Capítulo 1 - Introdução: capítulo corrente que trata da contextualização, motivação, objetivos, método de pesquisa, trabalhos relacionados, organização do presente trabalho e cronograma;

- Capítulo 2 - Referencial teórico: capítulo que discorre a respeito de: tecnologia da informação e seu alinhamento com o negócio, a respeito de 
conceitos de produção, incluindo gestão da produção e automação, sobre a convergência entre sistema de informação e automação em um ambiente de produção e a respeito da Governança de TI, conceitos, principais modelos, combinações entre eles e formas de implementação;

- Capítulo 3 - Modelo proposto: apresenta o modelo de governança proposto para a convergência entre todos os sistemas de $\mathrm{Tl}$ existentes em um ambiente de produção;

- Capítulo 4 - Apresentação do estudo de caso: descreve o estudo de caso realizado;

- Capítulo 5 - Análise do estudo de caso: análise das informações levantadas e comparação com o modelo sugerido;

- Capítulo 6 - Considerações finais: neste capítulo é apresentada uma avaliação dos resultados obtidos, as contribuições e limitações deste trabalho e possíveis trabalhos a serem desenvolvidos futuramente. 


\section{VISÃO GERAL DE CONCEITOS}

O desenvolvimento de um modelo de governança de Tecnologia da Informação que abranja os diferentes ambientes de uma indústria, demanda o estudo de diversos tópicos, incluindo a tecnologia da informação em si, aspectos de produção e Governança de TI.

Este capítulo discorre a respeito de aspectos relevantes destes tópicos, fornecendo o suporte necessário para o desenvolvimento do modelo. Os tópicos abordados neste capítulo são os seguintes:

- Informação: importância da informação dentro das empresas;

- Tecnologia da Informação: dada a importância da informação para as empresas, a tecnologia da informação tem se desenvolvido muito, sendo importante entender seu posicionamento dentro da empresa e buscar o alinhamento da TI com o negócio;

- Produção: como o trabalho trata da elaboração de um modelo que englobe as tecnologias de todos os ambientes dentro de uma indústria, é importante entender o que há de tecnologia no ambiente de produção e como se dá a integração das informações geradas neste ambiente ao ambiente de escritório;

- Governança de TI: tendo definidos os conceitos de TI e produção, é necessário entender as definições, modelos e melhores práticas, além da combinação entre melhores práticas de Governança de TI para o desenvolvimento de um modelo que englobe os diferentes ambientes de uma indústria;

- Alinhamento entre tecnologia aplicada à produção e negócio e Governança de TI do escritório ao chão de fábrica: por fim, é importante entender o que tem sido desenvolvido para a união dos diferentes ambientes de uma indústria em um único modelo de governança, suas dificuldades e melhores práticas. 


\subsection{Informação}

A informação ${ }^{5}$ exerce um papel cada vez mais importante nas organizações (SOUZA; PEREIRA, 2008), tendo se tornado um dos ativos mais valiosos para as empresas. Ela é organizada, analisada e interpretada para possuir um significado dentro das práticas de trabalho nas quais está inserida. A informação ganha valor dentro da execução do trabalho para explorar oportunidades ou resolver problemas (BROWN; DUGUID, 1991).

A revolução da informação, de acordo com Porter e Millar (1985), é inevitável e tem alterado a forma de competir das empresas de três maneiras:

- Muda a estrutura da indústria e altera as regras de competição;

- Permite que as empresas criem outras formas de superar seus competidores, gerando vantagens competitivas e

- Possibilita a criação de novos negócios, partindo de operações já existentes nas empresas.

\subsection{Tecnologia da Informação}

Conforme a informação torna-se um ativo mais estratégico, o papel da Tecnologia da Informação (TI) tende a assumir posições mais relevantes dentro da empresa.

Carr (2005) comenta que o termo "Tecnologia da Informação" é bastante amplo. De acordo com o senso comum atual, tecnologia da informação denota as tecnologias usadas para processar, armazenar e transportar informação em meio digital.

De acordo com Souza e Pereira (2008), o termo TI refere-se ao "conjunto de recursos tecnológicos e computacionais para geração e uso da informação", estando fundamentada nos seguintes componentes:

\footnotetext{
${ }^{5}$ Informação é o que as pessoas e os sistemas devem possuir para executar as tarefas necessárias em uma organização (BRAGANZA, 2004).
} 
- Hardware e seus dispositivos periféricos;

- Software e seus recursos;

- Sistemas de telecomunicações e;

- Gestão de dados e informações.

Laurindo (2000), por sua vez, adota um conceito mais amplo, incluindo o uso de hardware e software, telecomunicações, automação, recursos multimídia e todos os outros recursos materiais/computacionais e de pessoal, centralizados ou não, considerando também sistemas de informação, serviços, negócios, usuários e relações envolvidas. O autor comenta, ainda, que alguns autores fazem distinção entre Tecnologia da Informação (TI) e Sistemas de Informação (SI) da seguinte forma:

- Tecnologia da Informação: corresponde a aspectos técnicos;

- Sistemas de informação: envolvem fluxo de trabalho, pessoas e informações.

Henderson e Venkatraman (1993) usam o termo Tecnologia da Informação abrangendo ambos os aspectos. Porter e Millar (1985) também consideram a Tecnologia da Informação como um conceito mais amplo, sendo mais que apenas computadores, devendo incluir as informações que o negócio gera e usa, bem como as novas tecnologias utilizadas para processar as informações.

\subsubsection{Estratégia de Tl e negócio}

Quanto mais as operações diárias e as estratégias corporativas dependem da TI, mais importante é o papel estratégico dela. Este papel pode variar desde o suporte administrativo (em que o uso da TI não influi nas estratégias de negócio) até uma posição estratégica (em que as estratégias de TI e de negócio são tratadas conjuntamente) (MORAES; LAURINDO, 2003). 
O quadrante representado na Figura 2 descreve os diferentes estágios em que a TI pode estar dentro de uma empresa (FERNANDES; ABREU, 2008).

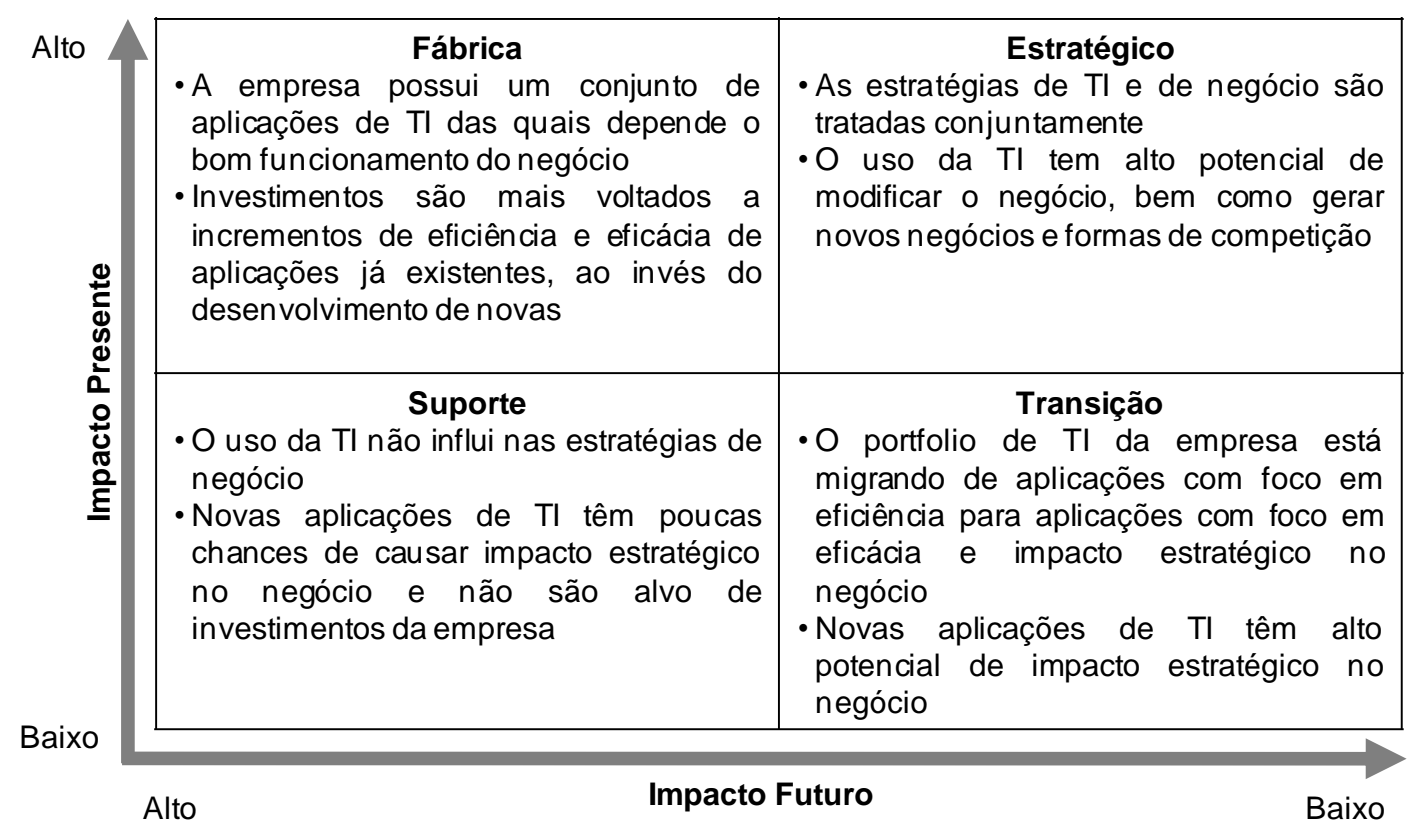

Figura 2 - Estágios da TI dentro de uma empresa (FERNANDES; ABREU, 2008)

Quanto mais estratégica é a TI, mais importante é o alinhamento estratégico entre ela e os negócios. Alinhamento é o grau de compromisso do grupo de TI para com as prioridades do negócio, a alocação de recursos e a realização, tanto de projetos, quanto a entrega de soluções, consistentes com os objetivos do negócio (RODRIGUES et al., 2009). De acordo com o COBIT (ITGI, 2007, p. 09), alinhamento trata de:

"Garantir a ligação entre os planos de negócios e de TI, definindo, mantendo e validando a proposta de valor de TI, alinhando as operações de TI com as operações da organização".

Fernandes e Abreu (2008) definem alinhamento como o processo de transformar a estratégia do negócio em estratégias e ações de TI que garantam que os objetivos de negócio sejam apoiados. O alinhamento estratégico pode ser bidirecional, ou seja, da estratégia do negócio para a estratégia de TI e da estratégia de TI para a estratégia do negócio, pois a estratégia de TI pode potencializar estratégias de negócio ou mesmo viabilizar partes dela. 
Henderson e Venkatraman (1993), cujo trabalho sobre alinhamento entre TI e o negócio é bastante reconhecido na área, propuseram um esquema de alinhamento que contempla esta via de mão dupla, como representa a Figura 3.

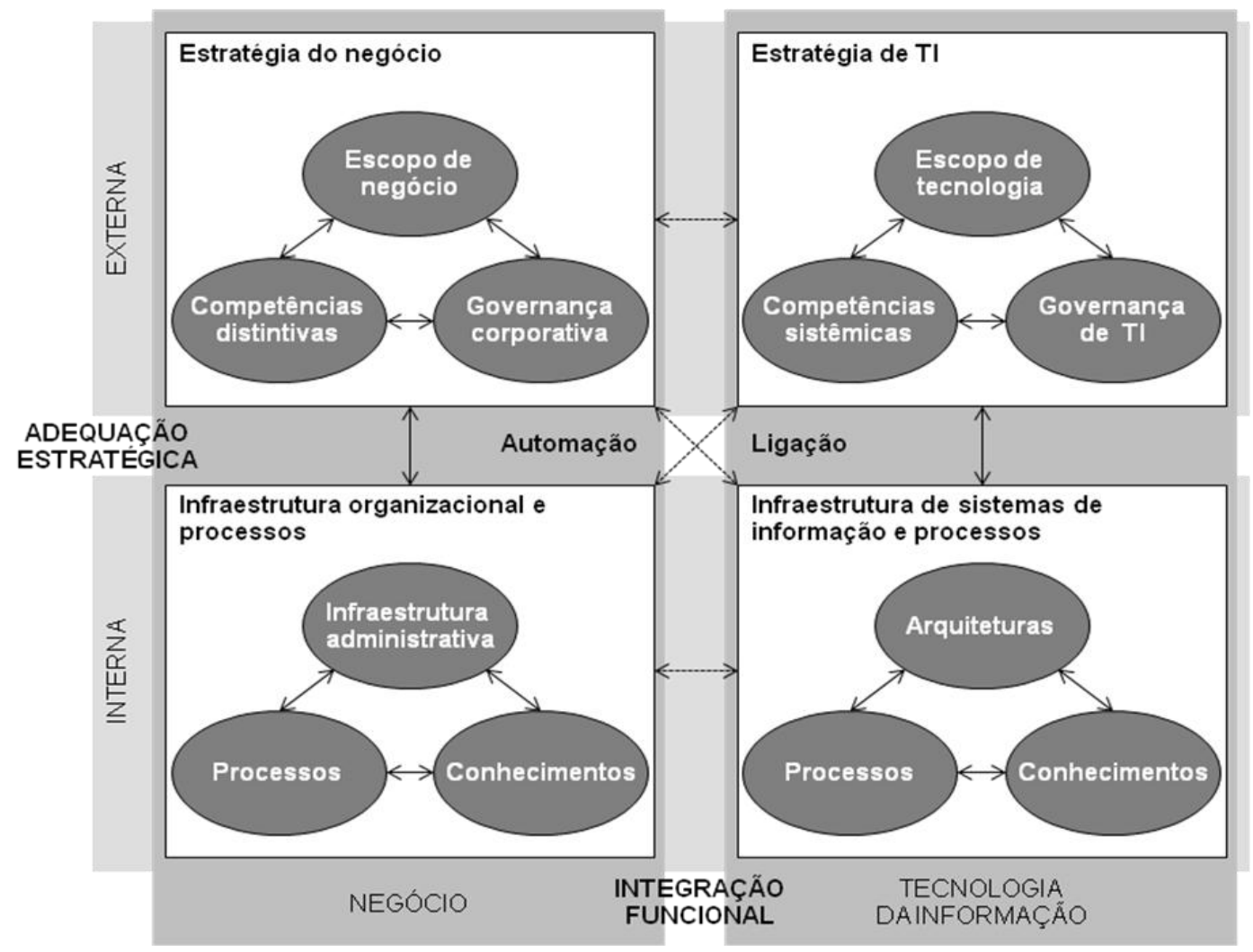

Figura 3 - Modelo de alinhamento estratégico (HENDERSON; VENKATRAMAN, 1993)

De acordo com os autores, existem quatro perspectivas de alinhamento dominantes. As duas primeiras têm a estratégia de negócio como fator motivador. A primeira perspectiva chama-se "execução da estratégia", em que a estratégia do negócio influencia a infraestrutura organizacional que, por sua vez, influencia a infraestrutura de TI. É a perspectiva mais usual.

A segunda perspectiva é chamada de "transformação tecnológica" em que a TI surge como viabilizadora de estratégias de negócio. Neste caso, a empresa busca as melhores competências de $\mathrm{TI}$, como o caso de uma empresa tradicional que passe a atuar na Internet. 
As outras duas perspectivas têm a estratégia de $\mathrm{TI}$ como habilitador, buscando explorar como a TI pode criar ou melhorar a estratégia do negócio. A terceira perspectiva é chamada de "potencial competitivo" e trata do uso da TI para criar novas estratégias de negócio, como no caso de uma empresa puramente virtual.

A quarta perspectiva é chamada "nível de serviço" e foca em como construir uma organização de serviços de TI de alto nível para atender a demandas do cliente. Neste caso, a estratégia do negócio tem um papel indireto e busca identificar formas de estimular a demanda por parte do cliente.

Alinhamento estratégico não é um evento, mas um processo contínuo de mudança e adaptação (ADACHI, 2008). O ITGI (2005) enfatiza que as organizações precisam realizar o alinhamento entre a $\mathrm{TI}$ e o negócio para evitar um descompasso entre as estratégias.

\subsubsection{Entendimento da posição da TI dentro da empresa}

Para entender a relação da $\mathrm{TI}$ com o negócio levando em conta os fatores estruturais da empresa e da organização de $\mathrm{TI}$ existem diversas ferramentas, como estudado por Laurindo (2000) para definir o modelo que o autor denominou MAN/TI, um modelo de análise da organização e estruturação da TI nas empresas, que concatena diversas dessas ferramentas:

1. Fatores críticos de sucesso da empresa;

2. Estágio de informatização da empresa;

3. Centralização ou descentralização da Tl;

4. Organização da área de Tl;

\subsubsection{Fatores Críticos de Sucesso}

O método dos FCS (Fatores Críticos de Sucesso) proposto por Rockhart sugere a análise do ramo de atuação da empresa (ou da área avaliada), a identificação dos 
Fatores Críticos de Sucesso (FCS), a definição de metas para estes FCS e sistemas de informação que controlarão estas medidas, sendo, por isto, uma forma de avaliar a eficácia de $\mathrm{TI}$ na empresa. Uma alternativa a este método seria o Balanced ScoreCard (BSC) de Kaplan e Norton (1996), descrito na seção 2.4.1.2.

\subsubsection{Estágio de Informatização da Empresa}

Quanto ao estágio de informatização da empresa, o modelo mais conhecido é o de Nolan. O modelo é ilustrado pela Tabela 1.

Tabela 1- Estágios de evolução da informática, segundo Nolan (LAURINDO, 2000)

\begin{tabular}{|c|c|c|c|c|c|c|}
\hline $\begin{array}{l}\text { Portfólio de } \\
\text { aplicações }\end{array}$ & $\begin{array}{l}\text { Mecanização } \\
\text { e Redução } \\
\text { de Custos }\end{array}$ & Proliferação & Consolidação & $\begin{array}{l}\text { Sistemas } \\
\text { Gerenciais }\end{array}$ & $\begin{array}{l}\text { Conversão } \\
\text { de aplicações } \\
\text { para } \\
\text { aplicações de } \\
\text { banco de } \\
\text { dados }\end{array}$ & $\begin{array}{l}\text { Integração } \\
\text { aplicações } \\
\text { espelhando } \\
\text { fluxo de } \\
\text { informações }\end{array}$ \\
\hline $\begin{array}{l}\text { Organização } \\
\text { das funções } \\
\text { da } \\
\text { informática }\end{array}$ & $\begin{array}{l}\text { Aprendizado } \\
\text { tecnológico }\end{array}$ & $\begin{array}{l}\text { Reorientação } \\
\text { funcional }\end{array}$ & $\begin{array}{l}\text { Atendimento } \\
\text { à média } \\
\text { gerência }\end{array}$ & $\begin{array}{l}\text { Estratificação } \\
\text { e adaptação }\end{array}$ & $\begin{array}{l}\text { Administrador } \\
\text { de dados }\end{array}$ & $\begin{array}{ll}\text { Gerência } & \text { de } \\
\text { recursos } & \text { de } \\
\text { dados } & \end{array}$ \\
\hline $\begin{array}{l}\text { Planejamen- } \\
\text { to e controle } \\
\text { da } \\
\text { informática }\end{array}$ & $\begin{array}{l}\text { Orçamento } \\
\text { flexível }\end{array}$ & $\begin{array}{l}\text { Orçamento } \\
\text { muito flexível }\end{array}$ & $\begin{array}{l}\text { Planejamento } \\
\text { e controle } \\
\text { formalizados }\end{array}$ & $\begin{array}{l}\text { Sistemas de } \\
\text { planejamento } \\
\text { e controle } \\
\text { "sob medida" }\end{array}$ & \begin{tabular}{lr}
\multicolumn{2}{l}{ Compartilha- } \\
mento de \\
dados \\
sistemas \\
comuns
\end{tabular} & $\begin{array}{l}\text { Planejamento } \\
\text { estratégico } \\
\text { de recursos } \\
\text { de dados }\end{array}$ \\
\hline $\begin{array}{l}\text { Papel dos } \\
\text { usuários }\end{array}$ & $\begin{array}{l}\text { "Por fora do } \\
\text { jogo" }\end{array}$ & $\begin{array}{l}\text { Entusiasmo } \\
\text { superficial }\end{array}$ & $\begin{array}{l}\text { Forçado a } \\
\text { ser } \\
\text { responsável }\end{array}$ & $\begin{array}{l}\text { Aprendendo } \\
\text { a ser } \\
\text { responsável }\end{array}$ & $\begin{array}{l}\text { Efetivamente } \\
\text { responsável }\end{array}$ & $\begin{array}{l}\text { Aceitação da } \\
\text { responsabili- } \\
\text { dade } \\
\text { conjunta } \\
\text { entre } \\
\text { usuários e TI }\end{array}$ \\
\hline Estágios & $\begin{array}{l}\text { Estágio } 1 \\
\text { Iniciação }\end{array}$ & $\begin{array}{l}\text { Estágio } 2 \\
\text { Contágio }\end{array}$ & $\begin{array}{l}\text { Estágio } 3 \\
\text { Controle }\end{array}$ & $\begin{array}{l}\text { Estágio } 4 \\
\text { Integração }\end{array}$ & $\begin{array}{l}\text { Estágio } 5 \\
\text { Administra- } \\
\text { ção }\end{array}$ & $\begin{array}{l}\text { Estágio } 6 \\
\text { Maturidade }\end{array}$ \\
\hline
\end{tabular}

\subsubsection{Centralização ou Descentralização de TI}

Quanto à centralização ou descentralização, a análise da TI e de como a área está organizada relaciona-se a pressões por diferenciação, desejo de controle direto e ligação do suporte da informática ao poder (BUCHANAN; LINOWES, 1980 apud LAURINDO, 2000). Existe uma tendência à centralização das estruturas de TI, formando os chamados Centros de Serviços Compartilhados para funções de suporte, com o objetivo de reduzir custos e alavancar competências críticas 
(RAMIREZ; ZUCARELLI, s.d.). Algumas funções cuja centralização pode ser interessante são:

- Planejamento e controle da arquitetura de TI, buscando oportunidades de padronização, otimizando investimentos, garantindo integração e reduzindo custos de suporte;

- Controle da qualidade do serviço, buscando garantir aos usuários que a centralização não prejudique a qualidade e o tempo de atendimento, definindo os serviços prestados, medindo indicadores e alocando os custos dos serviços às unidades de negócio;

- Gestão dos contratos com terceiros, buscando administrar os contratos de terceirização, controlando o nível de serviços, gerenciando as exceções e condições para aplicação de multas etc.;

- Definição e divulgação de métodos para realização de atividades críticas como gerenciamento de projetos, redesenho de processos de negócio, desenvolvimento e testes de sistemas.

Grembergen et al. (2004) comentam que são candidatos à centralização a infraestrutura global, os processos para compras da empresa e a segurança. Candidatos à descentralização seriam as aplicações de negócios e as decisões sobre projetos específicos de unidades de negócios.

\subsubsection{Organização da área de TI}

No caso da organização da área de TI, deve-se tratar a estrutura organizacional, que deve estar de acordo com o negócio e com a estratégia de centralização ou descentralização. Existem, basicamente, três alternativas, como ilustra a Figura 4. 

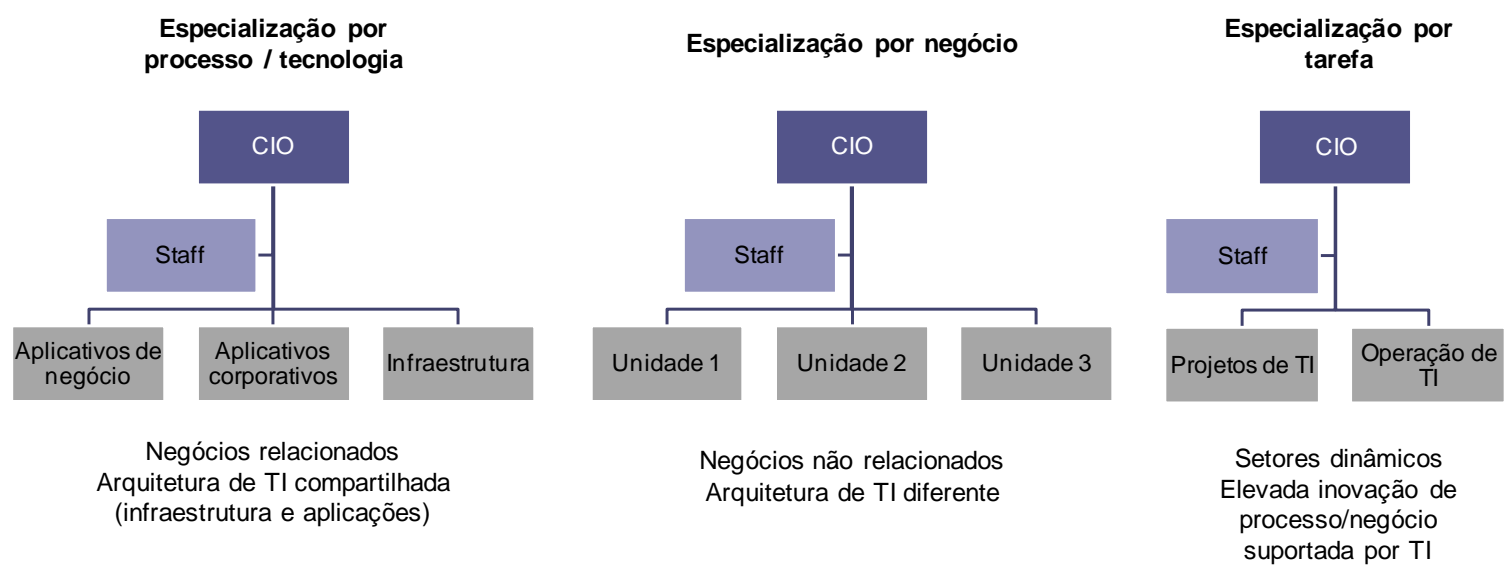

Figura 4 - Alternativas de estrutura (RAMIREZ; ZUCARELLI, s.d.)

O primeiro modelo, especialização por processo ou tecnologia, implica um grau de centralização elevado, devido ao compartilhamento de equipes entre as unidades de negócio. Este modelo é especialmente adequado quando os negócios da empresa estão relacionados e compartilham a mesma arquitetura de $\mathrm{Tl}$.

O segundo modelo, especialização por negócio, sofre uma maior descentralização e é adequado quando os negócios são pouco relacionados ou utilizam arquiteturas de TI diferentes. Neste caso pode-se ter, por exemplo, os aplicativos especializados por unidade de negócio e a infraestrutura compartilhada, centralizada.

O terceiro modelo, especialização por tarefa, separa a equipe responsável pela operação de $\mathrm{Tl}$ e a equipe responsável por projetos, dadas as diferenças entre estas duas competências. É um modelo menos comum, adequado para empresas que demandam elevada inovação de processo ou negócio suportados por TI.

Além destes modelos, existem estruturas matriciais ou híbridas, que combinam os critérios de especialização. Pode-se ter, por exemplo, uma estrutura especializada por tecnologia com pessoas chave que, em contato com as unidades de negócio, buscarão garantir o alinhamento com as necessidades do negócio. Outro exemplo seria a criação de equipes de projeto centralizadas para implementação de projetos comuns às unidades de negócios ou centros de competência especializados prestando serviços para as diferentes unidades de negócio (exemplo: tecnologias web) (RAMIREZ; ZUCARELLI, s.d.). 
O uso eficaz da TI e a integração entre sua estratégia e a estratégia do negócio vão além da ideia de ferramenta de produtividade. Hoje, o caminho para o sucesso não está mais relacionado somente com o hardware e o software utilizados, ou ainda com métodos de desenvolvimento, mas com o alinhamento da TI com a estratégia e as características da empresa e de sua estrutura organizacional.

De acordo com Henderson e Venkatraman, a falta de habilidade das empresas em obter retornos consideráveis dos investimentos em TI se deve (ainda que não totalmente) à falta de coordenação, de alinhamento, entre as estratégias de negócio e de TI (LAURINDO, 2000).

\subsection{Produção}

Produção é o processo de transformação de insumos em produtos ou serviços, com maior valor econômico que os insumos. (MORORÓ, 2008).

Um processo de produção é definido por um conjunto de parâmetros, dentre os quais estão:

- O que deve ser produzido?

- Como será produzido (considerando tecnologias, qualidade, mão de obra, meio ambiente)?

- Quando será produzido?

- Quanto deve ser produzido? (HUMPHREY; SCHMITZ, 2004).

Um sistema ${ }^{6}$ de produção é aquele que tem por objetivo a fabricação de bens manufaturados, a prestação de serviços ou o fornecimento de informações (MARTINS; LAUGENI, 2006).

\footnotetext{
${ }^{6}$ Sistema é um conjunto de elementos inter-relacionados com um objetivo comum composto por três elementos básicos: as entradas, as saídas e as funções de transformação.
} 
De acordo com Groover (2008), um sistema de produção é um conjunto de pessoas, equipamentos e procedimentos para executar as operações e manufatura de uma organização.

Quando se fala em sistema de produção, dois conceitos estão sempre associados: eficácia e eficiência.

\subsubsection{Eficiência, eficácia e produtividade}

A eficácia está relacionada a como as saídas atendem às metas estabelecidas (atingimento do objetivo) e a eficiência está relacionada ao desempenho com que as entradas são transformadas nas saídas (Laurindo, 2002 apud Clementi, 2007). Por exemplo, deseja-se fazer um bolo - a eficácia relaciona-se a conseguir fazer o bolo, enquanto a eficiência relaciona-se ao processo de elaboração ser executado da melhor forma possível, economizando recursos.

Produtividade é a relação entre o valor do produto e/ou serviço produzido e o custo dos insumos para produzi-lo (MARTINS; LAUGENI, 2006). Chiavenato (1983) define produtividade como o resultado da produção por um determinado período de tempo. A produtividade é conseqüência direta da eficiência, ou seja, quanto maior a eficiência, maior a produtividade.

De acordo com Martins e Laugeni (2006), uma das características da fábrica do futuro é a alta produtividade, com um elevado grau de automação, estando organizada em torno da tecnologia.

\subsubsection{Gestão da produção}

A gestão da produção envolve todos os processos relacionados à produção em uma empresa de manufatura. Um processo estruturado de gestão da produção é uma alternativa para a obtenção de uma boa posição competitiva (FAVARETTO, 2001). 
As principais atividades do processo de gestão da produção são o planejamento e a programação das atividades e o controle da produção (CORREA, 1997 apud FAVARETTO, 2001).

Os sistemas de gestão da produção devem gerir o que, quando, quanto e como produzir. Alguns problemas apresentados por este tipo de sistema referem-se à qualidade das informações de entrada (por exemplo, níveis de estoque), ao tempo necessário para que uma informação seja disponibilizada e ao processo de geração e coleta de dados (por exemplo, indicadores do que foi produzido), além da falta de integração com os sistemas do chão de fábrica. Dentro deste cenário, os sistemas de monitoramento de produção em tempo real são cada vez mais necessários. $A$ disponibilidade de informações em tempo real é um parâmetro de eficiência.

\subsubsection{Automação}

Groover (2008) define automação como a tecnologia pela qual um processo ou procedimento é realizado sem intervenção humana. É implementada usando um conjunto de instruções e um sistema de controle que as executa.

Em busca de maior competitividade e para atender a necessidades sociais, econômicas e ambientais, a indústria vem empregando cada vez mais tecnologia de automação (GUEDES et al., 2008), cujo principal objetivo é acelerar o processo de produção e obter produtos com qualidade.

No início, os sistemas de automação limitavam-se ao monitoramento e controle de partes específicas do processo, em busca de viabilizar operações remotas não assistidas (SOUZA; PEREIRA, 2008). Este campo de atuação foi expandido e os sistemas passaram a lidar com grandes quantidades de dados referentes a uma visão mais ampla dos processos.

Uma forma de representar de maneira integrada os sistemas envolvidos neste campo expandido de atuação é a pirâmide de automação representada na Figura 5 (SOUZA; PEREIRA, 2008). 
$\mathrm{Na}$ base da pirâmide é realizada a aquisição de dados dos processos e maquinário. Estes dados são utilizados em lógicas executadas no nível 2 por controladores lógico-programáveis. O nível 3 está relacionado ao monitoramento remoto de dados e à otimização do processo por sistemas de supervisão. O nível 4 trata da matemática envolvida no processo, permitindo avaliações. O nível 5 trata do planejamento estratégico, utilizando como ferramenta o Enterprise Resource Planning (ERP) (SILVA, 2009).

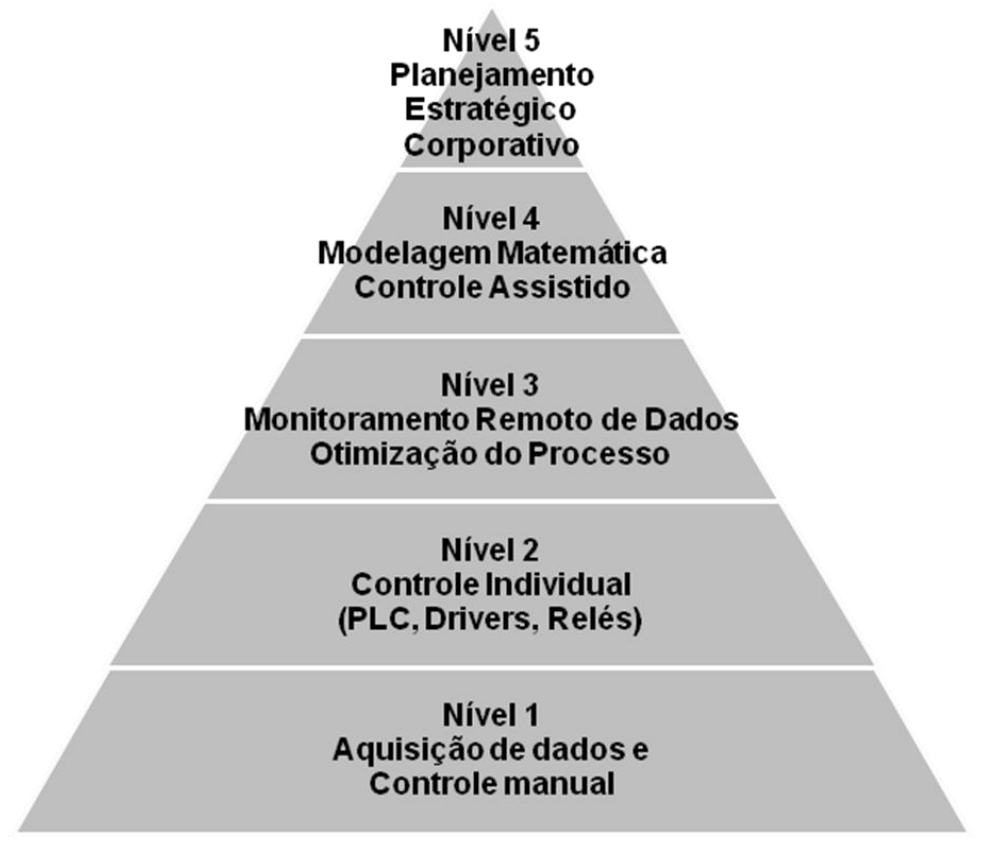

Figura 5 - Processo físico (SOUZA; PEREIRA, 2008)

A automação, presente nas várias etapas do negócio, permite a geração de informações úteis à operação e manutenção, suportando a tomada de decisões (SOUZA; PEREIRA, 2008).

\subsubsection{Integração tecnológica}

De acordo com Francalanci e Maggiolini (2002), a tecnologia dentro da indústria pode ser classificada nas seguintes categorias:

- Tl embutida nos processos produtivos, como robôs e automação; 
- TI embutida em produtos e serviços, como tecnologia embarcada em automóveis e caixas de banco;

- TI utilizada no gerenciamento do processo produtivo, como emails, planilhas eletrônicas e videoconferências;

Com o avanço da $\mathrm{TI}$, novos paradigmas de manufatura foram desenvolvidos, como o CIM (Computer Integrated Manufacturing). O termo CIM é utilizado para descrever as abordagens modernas para manufatura, sendo a principal característica a integração total das funções de manufatura como design, engenharia, planejamento, controle, fabricação (SUN, 2000). No modelo CIM da SME (Society of Manufacturing Engineers), há um componente de negócios e quatro componentes técnicos, descritos a seguir:

- Planejamento e controle, abrange softwares de MRP (Materials Requirement Planning) e MRP II (Manufacturing Resources Planning);

- Gestão da informação, inclui bases de dados compartilhadas e redes para compartilhamento de informações, como WAN (Wide Area Network) e LAN (Local Area Network);

- Definição de produto e processo, como CAD (Computer Aided Design), CAE (Computer Aided Engineering), CAPP (Computer Aided Process Planning) e

- Automação de fábrica como NC (Controle Numérico, Numerical Control), CNC (Controle Numérico Computacional, Computer Numerical Control) e DNC (Controle Numérico Distribuído, Distributed Numerical Control), robôs, e sistemas automáticos de armazenamento e recuperação (AS/RS - Automatic Storage/Retrieval Systems).

As chamadas AMT (Advanced Manufacturing Technology) são o principal componente técnico de um ambiente CIM e consistem em sistemas semi ou totalmente automatizados que podem ser usados em diversas unidades funcionais de uma empresa (Nagalingam, 2008). A implantação de um ambiente CIM requer a integração de diversas AMT. 


\subsubsection{Modelos para integração tecnológica}

Como referência para a integração de sistemas, o comitê "CIM Reference Model Committee" do International Purdue Workshop on Industrial Computer Systems criou um modelo de referência CIM - o Purdue Reference Model, uma ferramenta a ser utilizada na implantação de ambientes integrados de manufatura.

Atualmente, os esforços de integração na indústria estão focando na integração entre ERP (Enterprise Resource Planning), MES (Manufacturing Execution System) e sistemas de controle, tendo o MES sido incluído na hierarquia ilustrada na Figura 5.

O termo MES foi criado pela AMR Research na década de 1990 e se referia, a princípio, a um modelo funcional de integração. Atualmente, tornou-se uma classe de software com sobreposições com outras propostas (SILVA, 2009). A MESA (Manufacturing Enterprise Solution Association) propôs o MES como um modelo composto por onze funcionalidades reconhecidas como núcleo, como ilustra a Figura 6. 


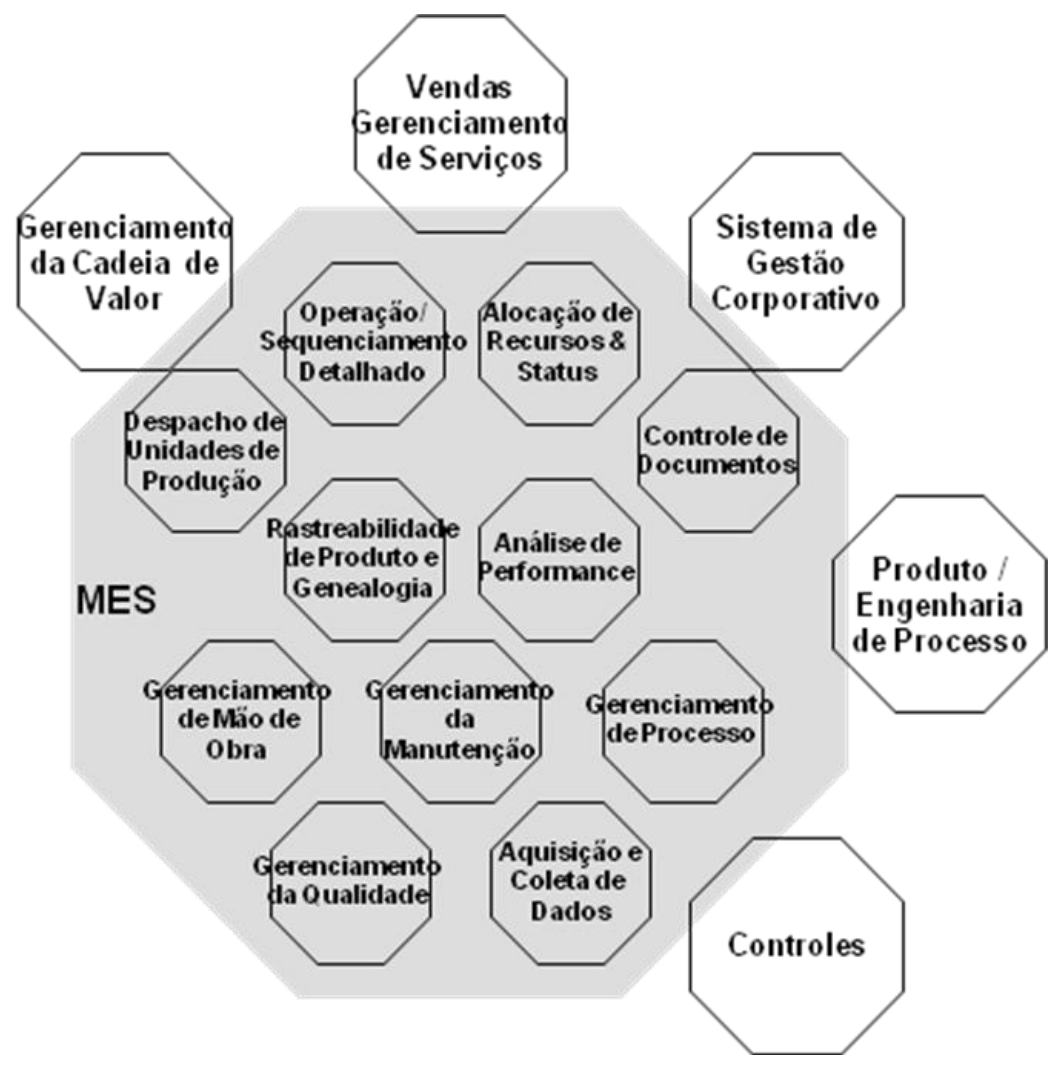

Figura 6 - Modelo MES proposto pela MESA (MESA, 1997 apud SILVA, 2009)

Na busca pela integração MES-ERP, a ISA (International Society of Automation) criou o padrão ISA 95, que define as interfaces entre as atividades corporativas e de controle. O padrão é um bom parâmetro para a definição dos requisitos para integração, inclui o modelo Purdue CIM e o modelo da MESA supracitados e define um conjunto de modelos e terminologias para reduzir riscos, custos e erros associados à implementação de interfaces entre os diferentes sistemas (UNGER, 2001). A Figura 7 ilustra a hierarquia funcional proposta pela ISA.

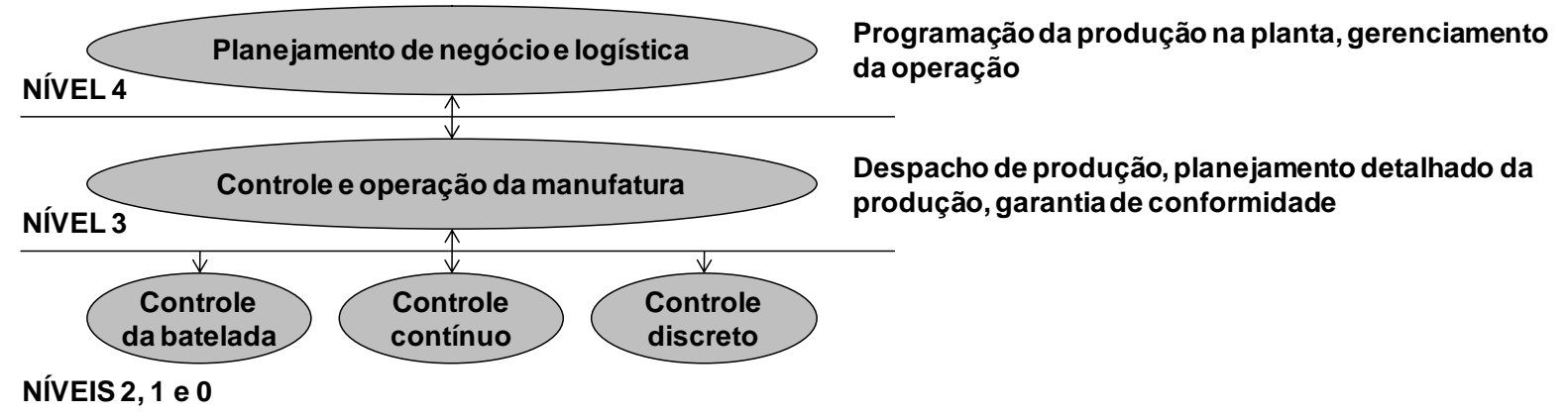

Figura 7 - ISA Hierarquia Funcional (ISA, 2000 apud SILVA, 2009) 
Os sistemas do nível 4 tratam das funções administrativas, contábeis, logísticas, de controladoria e funções de planejamento e de controle da produção. O nível 3 trata da integração do chão de fábrica com os sistemas de gestão, incluindo funções de análises de desempenho, histórico de produção, gerenciamento de manutenção, sequenciamento, alocação de recursos, gerenciamento da qualidade, controle de documentos, coleta e armazenamento de dados. O MES posiciona-se neste nível, realizando o acompanhamento de ordens de produção, mobilização de recursos, controle de fluxo de materiais e realizando a interface com demais sistemas e com automação do chão de fábrica. Neste nível, encontram-se, também, sistemas de:

- PLM (Product Lifecycle Management), que suportam os processos de desenvolvimento de produtos e criação de processos;

- EAM (Enterprise Asset Management) para gestão de ativos;

- APS (Advanced Planning Schedule), de otimização do planejamento de produção e

- PIMS (Plant Information Management) para registro histórico de variáveis de processo.

Por fim, os níveis 2, 1 e $\mathbf{0}$ tratam das funções de supervisão da linha ou processo, operação da linha ou processo e controle (SILVA, 2009).

O padrão passou por revisões em 2001 e 2006 e é dividido em cinco partes. As partes 1, 2 e 5 definem o intercâmbio de dados entre o negócio e o chão de fábrica. As partes 3 e 4 endereçam funções MES típicas e expandem o trabalho feito nas partes 1,2 e 5 definindo a troca de dados de manutenção, inventário e qualidade. A Figura 8 ilustra o modelo ISA 95. 


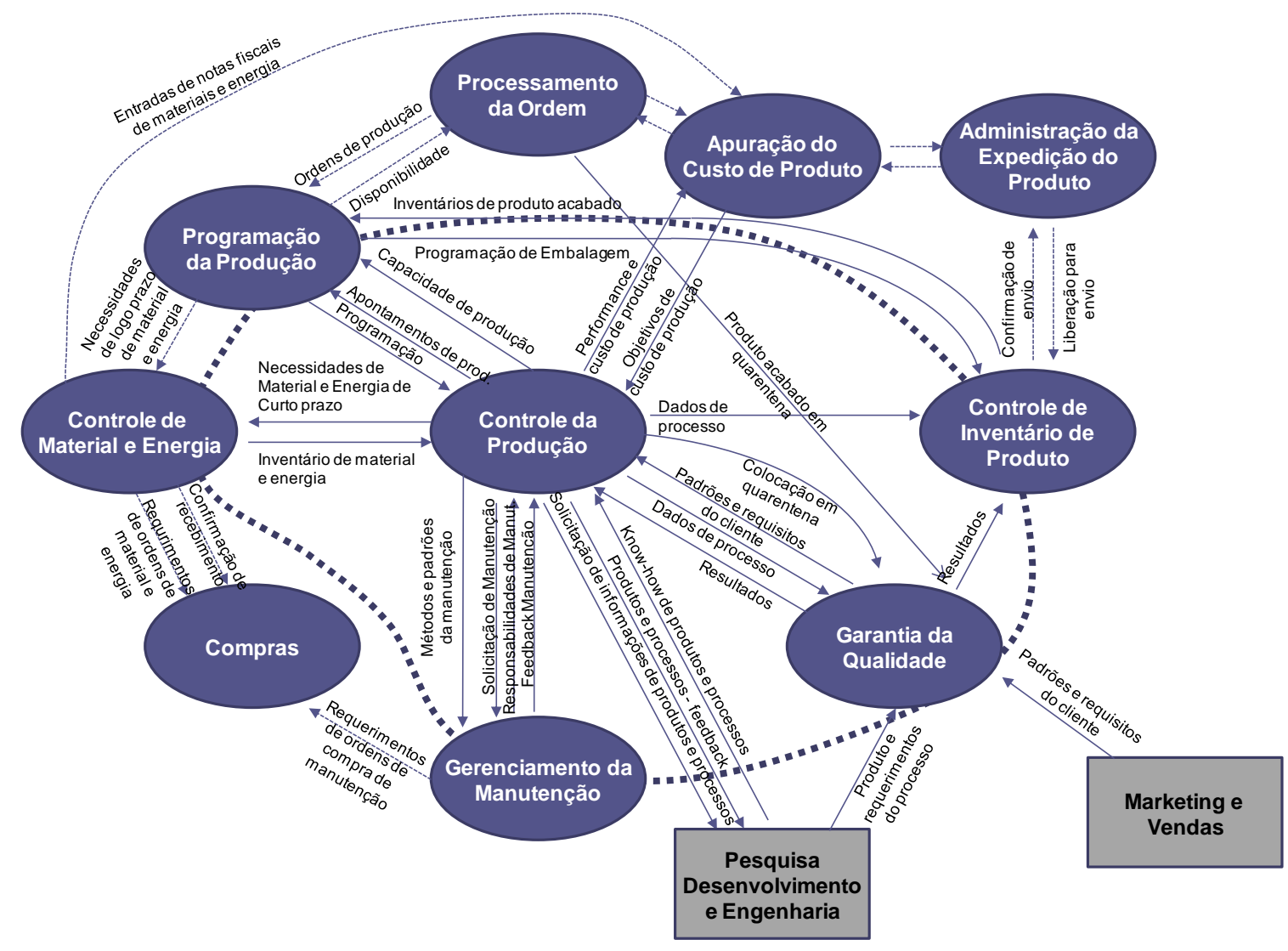

Figura 8 - Modelo ISA 95 (ISA, 2000 apud SILVA, 2009)

A ISA 95 deu origem à norma ISO/IEC 62264 (Enterprise Control Systems Integration) que define as interfaces entre as atividades corporativas e de controle. Esta norma inclui diversos aspectos de outros padrões, como a ISO 15531 (Industrial automation systems and integration - Industrial manufacturing management data) (ISO 15531-1, 2000 apud CHEN, 2005) e a ISO 15704 (Industrial automation systems - Requirements for enterprise-reference architectures and methodologies) (ISO 15704, 1998 apud CHEN, 2005).

Antes do desenvolvimento do padrão ISO/IEC 62264, outras iniciativas desenvolveram referências para arquitetura empresarial, como o TOGAF, apresentado na seção 2.4.1.2, mas não havia um padrão que tratasse da interface produção/controle para outros sistemas corporativos (CHEN, 2005).

A ISA também publicou a ISA-99, cujo objetivo é tratar da segurança do ambiente integrado de manufatura, propondo padrões para serem adotados em cada camada e na conexão entre elas. 
Mesmo existindo padrões e tecnologias de segurança para o ambiente de TI usual, o uso de medidas típicas de segurança de TI para levantamento da situação e mitigação pode levar os sistemas de controle a falhas. Além disto, muitos sistemas legados não conseguem suportar as medidas de mitigação de TI (SINGER, 2006). A ISA-99 foi criada com o objetivo de permitir que as redes de controle utilizem a tecnologia e experiência da segurança da informação através de soluções práticas que não causem problemas e inclui PLC (Programmable Logical Controller), SCADA (Supervisory Control and Data Acquisition) e outras aplicações. A Figura 9 ilustra os escopos dos padrões de segurança.

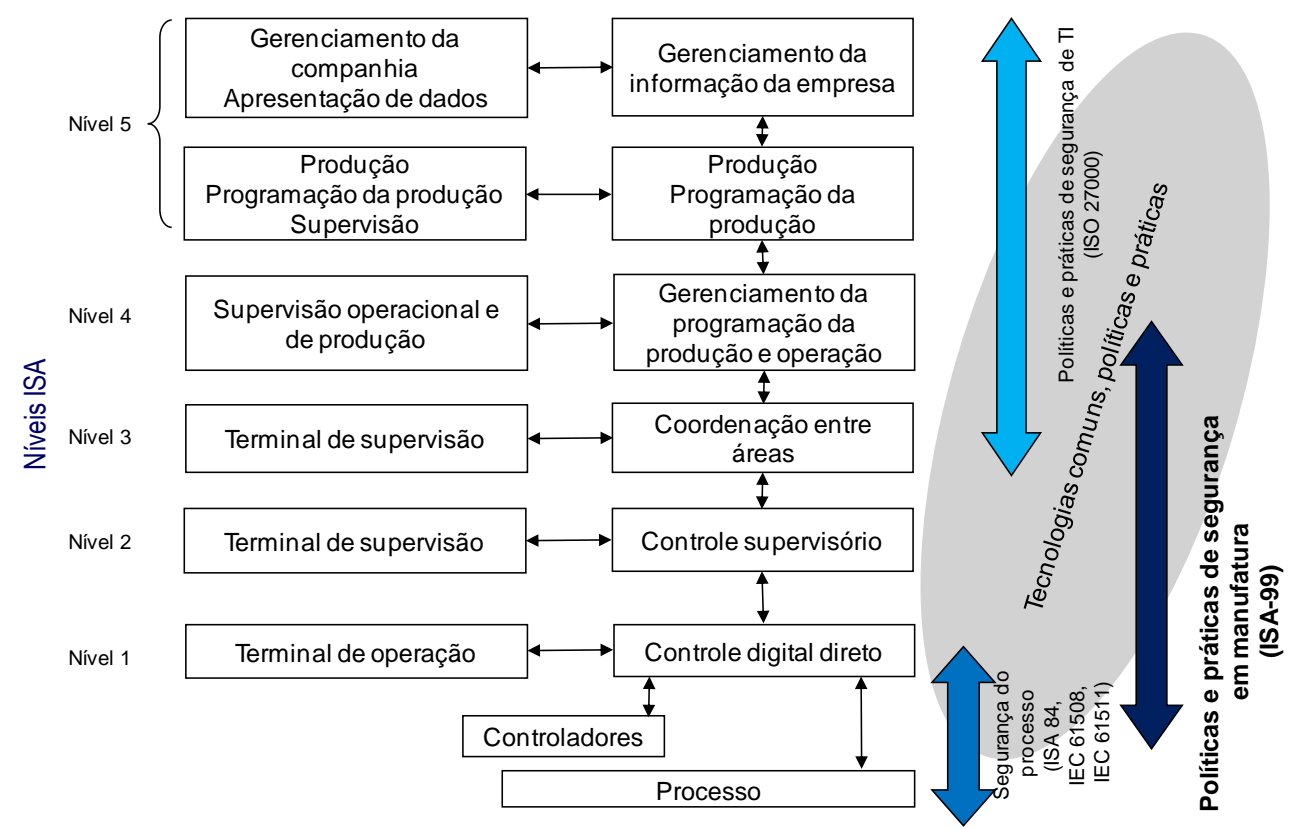

Figura 9 - Escopo dos padrões de segurança (SINGER, 2006)

Em 2002, o ARC (Advisory Group) desenvolveu o modelo CPAS (Collaborative Process Automation System) para arquitetura de sistemas de informação. O modelo trata de um ambiente unificado que busca apresentar a informação dentro de um contexto para as pessoas certas, no momento certo, a partir de qualquer ponto do sistema. O modelo, como ilustra a Figura 10, incorpora diversos padrões da indústria, como ISA 88, ISA 95, e Ethernet/IP. 


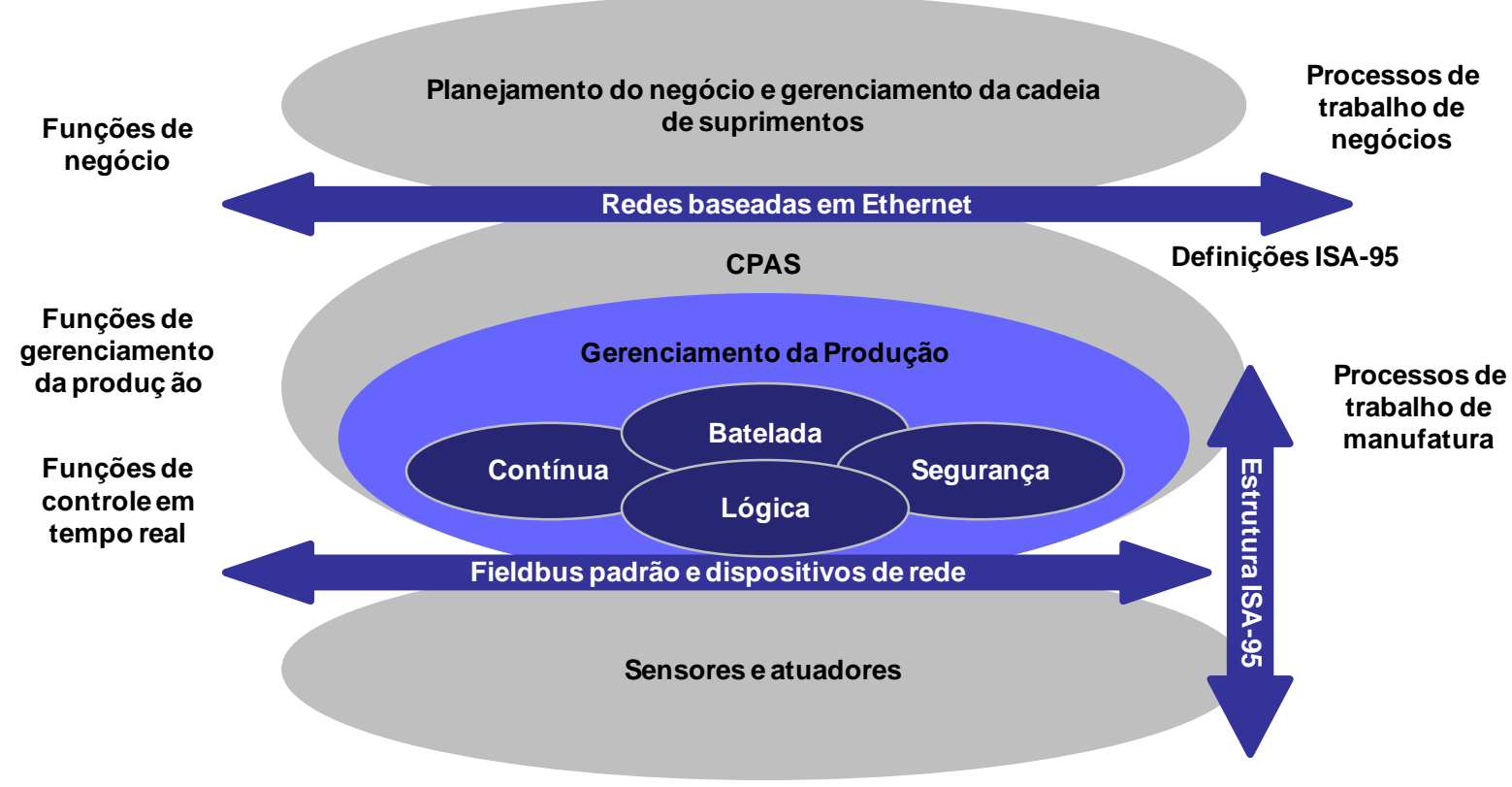

Figura 10 - Visão Funcional CPAS (HOLLENDER, 2009)

Em 2004 também, a MESA atualizou o modelo MES e passou a chamá-lo de C-MES (Collaborative MES), revisando as funcionalidades de onze para oito e evidenciando necessidades de integração com outros sistemas não existentes no modelo anterior, como ilustra a Figura 11.

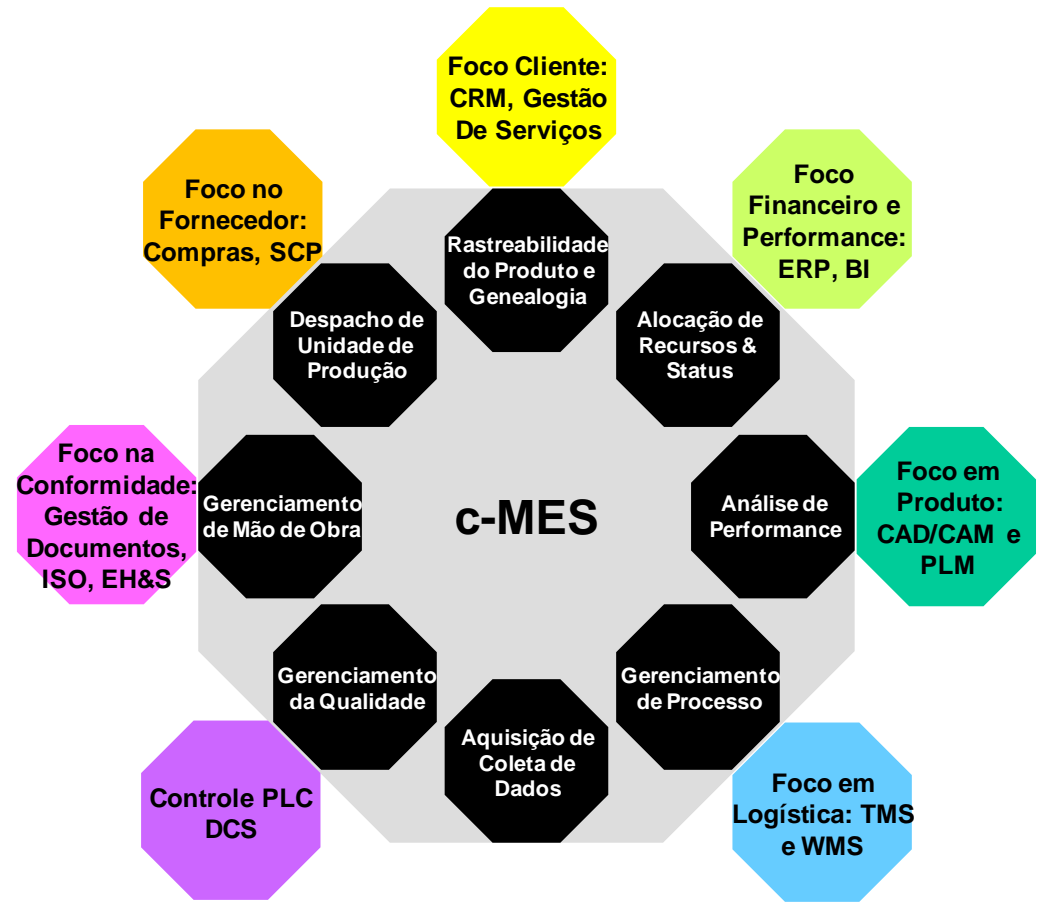

Figura 11 - C-MES (MESA, s.d.) 
Este modelo foca nas operações, representando, na parte interna do modelo, funções tipicamente encontradas dentro de produtos integrados MES oferecidos na época. O modelo faz interface com outras operações de negócio pelas áreas fora das arestas (MESA, s.d).

Em 2008, a MESA desenvolveu seu atual modelo, que mostra a interrelação entre estratégias e operações da planta, indo além de funcionalidades e interfaces, descrevendo iniciativas estratégicas. A Figura 12 ilustra este modelo.

O modelo descreve as ligações entre típicos módulos de software utilizados na operação de uma indústria e as estratégias corporativas. Os objetivos surgem na parte superior do modelo e afetam as camadas inferiores; os resultados são reportados das camadas inferiores para as superiores de acordo com os objetivos.

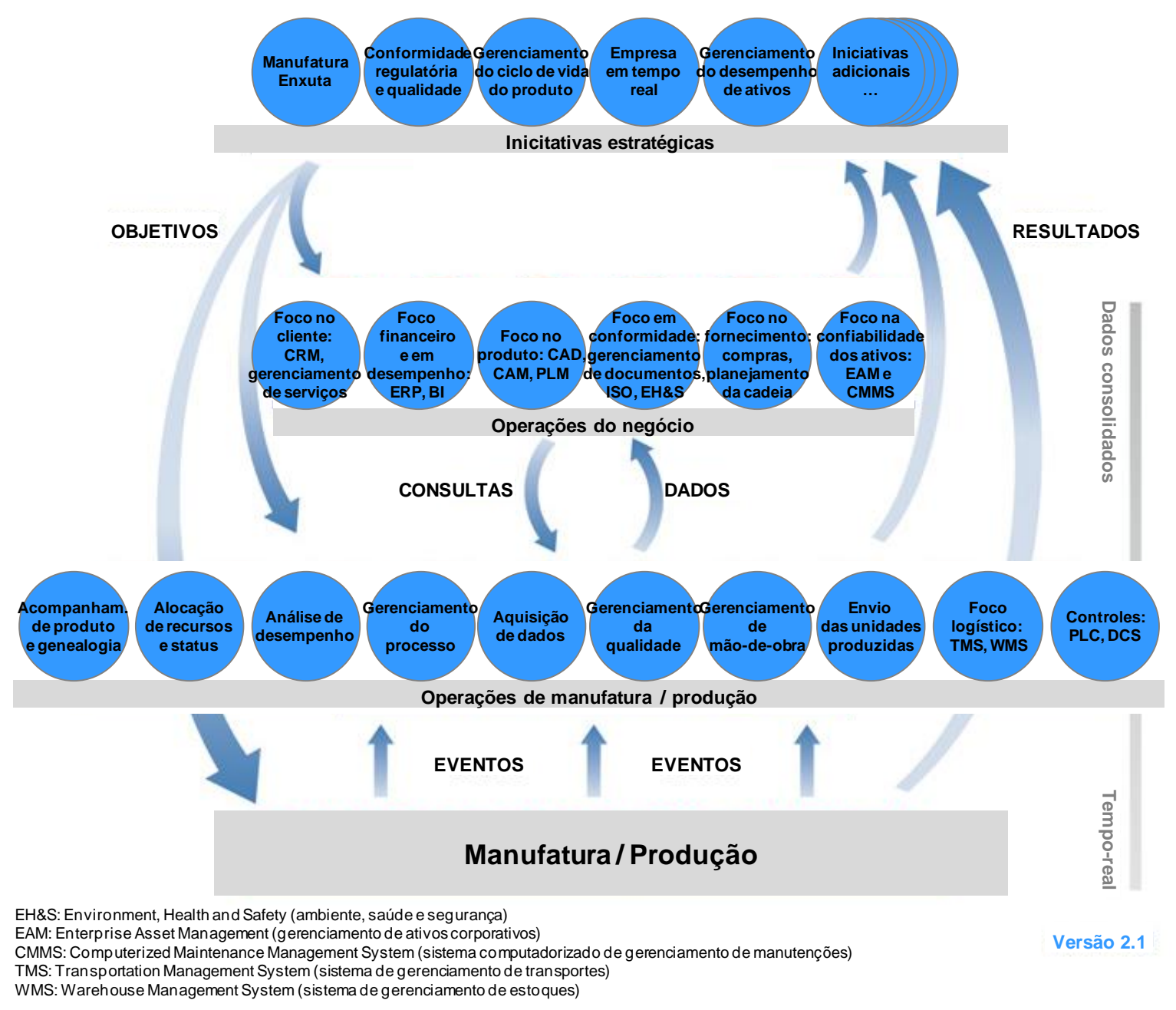

Figura 12 - Modelo atual da MESA (MESA, s.d.) 
A integração pode aumentar a disponibilidade de informações em tempo real, aumentando a vantagem competitiva da empresa (YUSUF, 1998 apud FAVARETTO, 2001). A falta de integração, por outro lado, compromete a otimização do uso de recursos envolvidos na implantação e manutenção de sistemas, com perdas de escala nos contratos de aquisição de equipamentos e serviços, bem como nos custos e complexidade decorrentes da manutenção de diferentes ambientes. Desta forma, é importante uma abordagem corporativa e sistêmica (SOUZA; PEREIRA, 2008) tanto para sistemas utilizados em escritório, quanto para sistemas utilizados em chão de fábrica.

\subsection{Governança}

"Governança corporativa é o sistema pelo qual as sociedades são dirigidas e monitoradas, envolvendo os relacionamentos entre Acionistas/Cotistas, Conselho de Administração, Diretoria, Auditoria Independente e Conselho Fiscal. As boas práticas de governança corporativa têm a finalidade de aumentar o valor da sociedade, facilitar seu acesso ao capital e contribuir para a sua perenidade" (IBGC, s.d.).

A governança corporativa tem, como princípios fundamentais, transparência, equidade, prestação de contas, cumprimento das leis e ética e ganhou força após os inúmeros escândalos corporativos a partir de 2002, como Enron, WorldCom e Tyco, entre outros (WEILL; ROSS, 2006). A gravidade dos impactos financeiros destes casos abalou a confiança dos investidores, o que contribuiu para a queda nos preços das ações e, em contrapartida, exigiu atitudes das empresas.

Os escândalos também motivaram a criação da lei Sarbanes-Oxley (também conhecida como SOX) em 2002, cujo objetivo é aperfeiçoar os controles financeiros e apresentar eficiência na governança corporativa, de forma a evitar outros escândalos e minimizar prejuízos. As empresas com ações listadas na Bolsa de Valores de Nova lorque e Nasdaq (a bolsa de valores eletrônica dos Estados Unidos) devem se adequar à lei e algumas empresas brasileiras, também, estão se adequando a ela, por estarem listadas em bolsa de valores norte-americana, por 
serem filiais de empresas estrangeiras ou porque enxergaram valor na implantação deste tipo de controle.

No Brasil, a Bolsa de Valores de São Paulo - BM\&FBOVESPA implantou em dezembro de 2000 os Níveis Diferenciados de Governança Corporativa. Os níveis 1 e 2 são segmentos especiais de listagem que foram desenvolvidos com o objetivo de proporcionar um ambiente de negociação que estimulasse, simultaneamente, o interesse dos investidores e a valorização das companhias. Empresas listadas nesses segmentos oferecem aos seus acionistas investidores melhorias nas práticas de governança corporativa que ampliam os direitos societários dos acionistas minoritários e aumentam a transparência das companhias, com divulgação de maior volume de informações e de melhor qualidade, facilitando o acompanhamento de seu desempenho. A adesão das Companhias ao Nível 1 ou ao Nível 2 (Nível 2 inclui Nível 1 e adiciona outras práticas) depende do grau de compromisso assumido e é formalizada por meio de um contrato, assinado pela Bolsa de Valores, pela Companhia, seus administradores, conselheiros fiscais e controladores (BM\&FBOVESPA, s.d.).

A Organização para Cooperação e Desenvolvimento Econômico (OCDE) desenvolveu em 1999 uma lista de princípios de Governança Corporativa - The OECD Principles of Corporate Governance que tem se tornado uma ferramenta de referência em diversos países, com foco em empresas com ações negociadas no mercado (KITAGAWA, 2007). Esta lista da OECD abrange as seguintes áreas chave da governança:

1. Bases para uma efetiva governança;

2. Direitos dos acionistas;

3. Tratamento equitativo dos acionistas;

4. Relacionamento com interessados (stakeholders);

5. Evidenciação e transparência;

6. Responsabilidades do Conselho de Administração (KITAGAWA, 2007). 
O conceito de governança corporativa surgiu para endereçar o "conflito de agência" que decorre da separação entre proprietário (acionista) e gestor (executivo) de uma empresa, pois os interesses nem sempre estão alinhados (IBGC, s.d.).

Meyer (2004) comenta que existem cinco influências sobre as pessoas em uma empresa que formam a governança: cultura, estrutura (organograma e processos de trabalho), economia interna, métodos e ferramentas, métricas e recompensas.

De acordo com Weill e Ross (2006), os ativos que devem ser considerados na governança corporativa incluem ativos humanos, financeiros, físicos (prédios, equipamentos), de propriedade intelectual, de informação e tecnologia da informação (TI) e de relacionamento (marca e reputação junto a clientes, fornecedores, concorrentes, revendas autorizadas etc.), como ilustra a Figura 13. Diversos mecanismos são utilizados para gerir estes ativos, como processos, estruturas, auditorias etc.

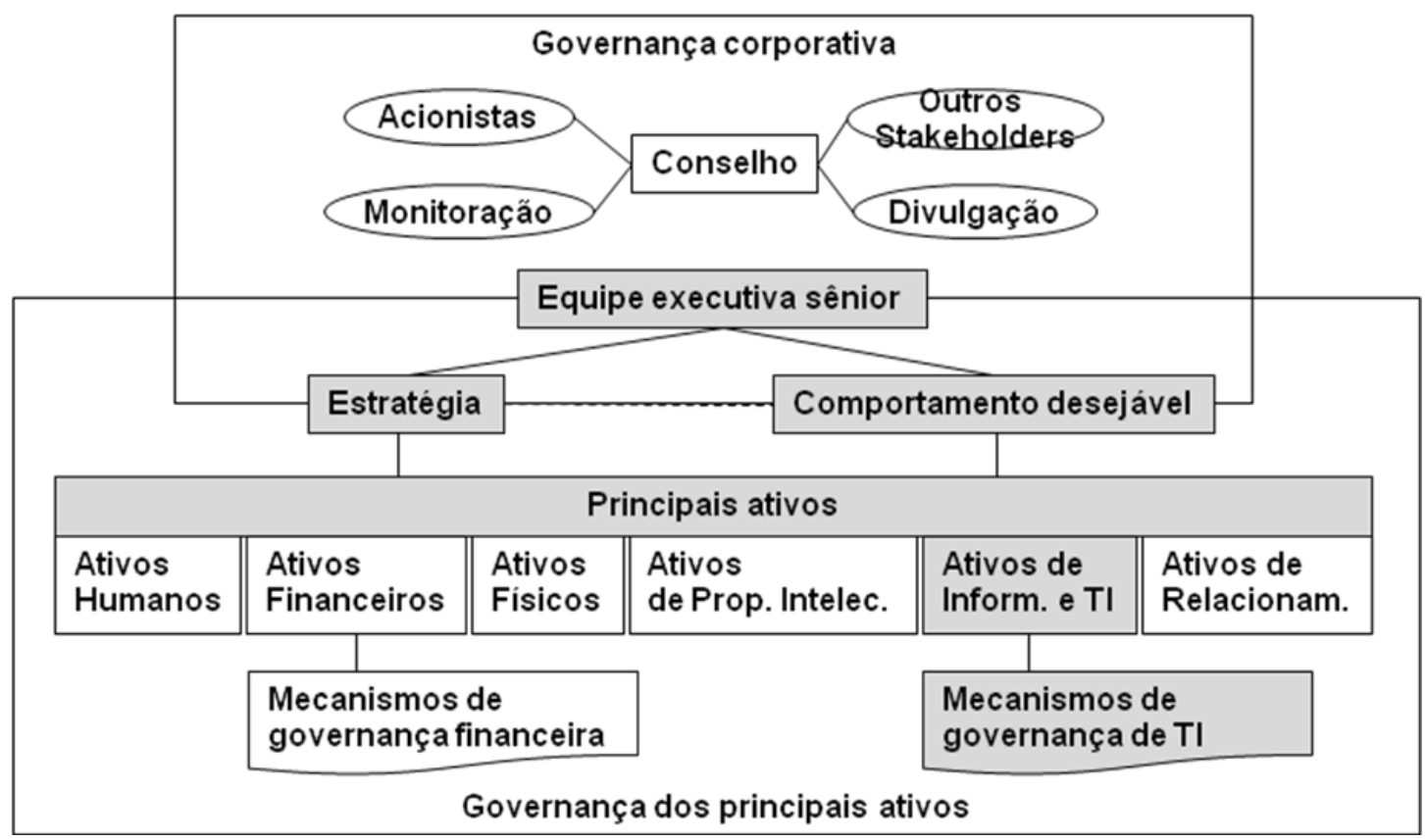

Figura 13 - Governança corporativa e dos principais ativos (WEILL; ROSS, 2006)

\subsubsection{Governança de TI}

O ITGI (2005) define a Governança de TI como liderança, estruturas organizacionais e processos que buscam garantir que a TI sustente e aprimore os 
objetivos e a estratégia da organização, sendo a Governança de TI de responsabilidade dos executivos e da alta direção.

Simonsson e Johnson (2006), baseando-se em um estudo de 60 diferentes trabalhos, definiram a Governança de TI como a preparação, o desenvolvimento e a implementação de decisões sobre metas, processos, pessoas e tecnologia em nível tático e estratégico.

Webb et al. (2006) definem a Governança de TI com base nas análises de outros trabalhos: a Governança de TI é o alinhamento estratégico da TI com o negócio de forma que seja obtido maior valor de $\mathrm{TI}$ para o negócio por meio de controle, responsabilidades, desempenho e gerenciamento de riscos em TI.

Weill e Ross (2006) definem a Governança de TI como a especificação dos direitos decisórios e do framework de responsabilidades para estimular comportamentos desejáveis na utilização da TI.

Já Grembergen e De Haes (2008) definem a Governança de TI como a capacidade organizacional exercida pelos executivos da empresa e de TI para controlar a formulação e a implementação da estratégia de TI e, desta forma, garantir o alinhamento entre TI e o negócio.

Carvalho (2009) define a Governança de TI como um mecanismo de acompanhamento e avaliação da execução do Plano Estratégico de TI, fundamental para o seu sucesso, viabilizando a realização dos ajustes necessários em resposta ao dinamismo do mercado e da própria organização.

Albertin e Albertin (2010, p.164) definem a Governança de TI como um "modelo de gestão, integrante da governança corporativa e da administração da TI, alinhado às estratégias, objetivos e metas organizacionais, que tem como função definir as diretrizes e efetivar o processo de decisão da TI, buscando uma entrega de valor, excelência operacional e otimização de resultados coerentes com as aspirações do negócio".

Estas definições estão alinhadas, de forma que podemos concluir que a Governança de TI é o sistema pelo qual a organização de TI é dirigida, incluindo direitos decisórios e responsabilidades, além de estruturas organizacionais, 
processos, mecanismos de relacionamento e mecanismos de monitoramento de métricas que suportam a tomada de decisões, de forma que a TI possa atuar de forma congruente com o negócio, agregando valor, sustentando e ampliando os objetivos e as estratégias organizacionais. Não se trata, portanto, apenas da implantação de modelos das chamadas melhores práticas de mercado.

É importante distinguir Governança de TI do gerenciamento de TI: governança trata de quem toma cada tipo de decisão, quem executa e quem é responsável, de forma alinhada à estratégia do negócio buscando atender a demandas atuais e futuras do negócio (internamente) e aos clientes do negócio (externamente), enquanto que o gerenciamento refere-se à entrega de serviços e produtos de $\mathrm{TI}$, buscando atender a demandas atuais, com foco interno (PETERSON, 2004).

Grembergen et al. (2004) chamam o gerenciamento de TI de "administração de TI" e complementam que está diretamente ligado ao bom funcionamento dos sistemas e das tecnologias que suportam as atividades organizacionais, buscando suprir internamente e de forma efetiva os serviços e produtos de TI.

A Governança de TI tem, basicamente, dois focos: o valor dos serviços de TI para o negócio, suportado pelo alinhamento estratégico entre TI e negócio, e a mitigação dos riscos de TI, suportado pela forma com que as responsabilidades são divididas.

Uma Governança de TI eficaz, o indicador mais importante do valor que a organização aufere com a TI, deve tratar de três questões (WEILL; ROSS, 2006):

1. Quais decisões devem ser tomadas para garantir a gestão e o uso eficazes de TI?

2. Quem deve tomar essas decisões?

3. Como essas decisões serão tomadas e monitoradas?

Cinco decisões inter-relacionadas devem ser tratadas pelas empresas: os princípios de $\mathrm{TI}$, a arquitetura de $\mathrm{TI}$, a infraestrutura de $\mathrm{TI}$, as necessidades de aplicações do negócio e os investimentos e a priorização da TI. Se a governança for bem concebida, as decisões se reforçarão mutuamente. 
Os princípios de $\mathrm{Tl}$ estabelecem diretrizes para todas as outras decisões e podem ser traduzidos em políticas, normas e diretrizes específicas. Os princípios devem esclarecer pelo menos três pontos:

1. Qual é o modelo operacional desejado pela empresa (como a empresa desenvolve e distribui produtos e serviços)?

2. Como a TI dará suporte ao modelo operacional desejado?

3. Como a TI será financiada?

A arquitetura de TI é a organização lógica dos dados, aplicações e infraestruturas, definida a partir de um conjunto de políticas, relacionamentos e opções técnicas que buscam padronização e integração técnica e de negócio. As decisões sobre arquitetura convertem os princípios em requisitos de integração e padronização.

A infraestrutura de TI é a base técnica e humana da capacidade planejada de TI disponível na forma de serviços compartilhados e utilizada por diversas aplicações. As decisões de infraestrutura partem dos princípios, da arquitetura e dos critérios de investimento para gerar as capacidades necessárias.

Por último, as necessidades de negócio identificam a necessidade de aplicações de $\mathrm{TI}$, que, por sua vez, geram novas demandas para a infraestrutura. A identificação das necessidades costuma ter objetivos conflitantes; a criatividade (maneiras novas e mais eficazes de gerar valor e suportar objetivos estratégicos) e a disciplina (integridade arquitetônica), requerendo pensadores criativos e gerentes de projeto disciplinados. As decisões referentes às necessidades de aplicações de negócio são as que geram valor diretamente.

As decisões sobre investimentos e priorização mobilizam recursos para converter princípios em sistemas e enfrentam três dilemas:

1. Quanto gastar;

2. Em que gastar;

3. Como conciliar as necessidades de diferentes grupos de interesse. 
Para definir quanto gastar, muitas vezes recorre-se a comparações com o mercado para determinar níveis apropriados de gastos. A alocação das verbas de TI é realizada por muitas empresas por meio de um portfólio de investimentos com indicadores estabelecidos pela administração do negócio e pela TI (WEILL; ROSS, 2006).

Para a definição de quem toma as decisões, os autores utilizam arquétipos políticos para descrever as combinações de pessoas que tomam decisões ou contribuem para a tomada de decisões de TI dentro das empresas. A Tabela 2 resume quem tem os direitos decisórios ou de contribuição em cada um dos modelos.

Tabela 2 - Arquétipo da Governança de TI (Adaptado de WEILL; ROSS, 2006)

\begin{tabular}{|l|l|}
\hline \multicolumn{1}{|c|}{ Estilo } & \multicolumn{1}{c|}{ Quem tem direitos decisórios ou de contribuição? } \\
\hline $\begin{array}{l}\text { Monarquia de } \\
\text { negócio }\end{array}$ & $\begin{array}{l}\text { Um grupo de executivos de negócios ou executivos individuais (CxOs). Inclui } \\
\text { comitês de executivos seniores de negócios, podendo incluir o CIO (Chief } \\
\text { Executive Officer). São aceitas contribuições de muitas fontes para as decisões. }\end{array}$ \\
\hline $\begin{array}{l}\text { Monarquia de } \\
\text { TI }\end{array}$ & $\begin{array}{l}\text { Indivíduos ou grupos de executivos de TI. Pode-se formar um comitê de TI } \\
\text { formado por profissionais de TI e de outras unidades de negócio. }\end{array}$ \\
\hline Feudalismo & $\begin{array}{l}\text { Líderes das unidades de negócio, detentores de processos-chave ou seus } \\
\text { delegados. }\end{array}$ \\
\hline Federalismo & $\begin{array}{l}\text { Executivos da diretoria e grupos de negócios, incluindo executivos de TI como } \\
\text { participantes adicionais. Equivalente à atuação conjunta dos governos federal e } \\
\text { estadual. }\end{array}$ \\
\hline Duopólio de TI & $\begin{array}{l}\text { Executivos de TI e algum outro grupo, como os CxOs ou os líderes de unidades de } \\
\text { negócio ou os líderes de processos. }\end{array}$ \\
\hline Anarquia & Cada usuário individual. \\
\hline
\end{tabular}

Na monarquia de negócio, os altos executivos tomam as decisões de TI, aceitando contribuições de muitas fontes para as decisões-chave.

$\mathrm{Na}$ monarquia de $\mathrm{Tl}$, os profissionais da $\mathrm{TI}$ tomam as decisões de $\mathrm{Tl}$. Esses profissionais podem ser de equipes corporativas ou de unidades de negócio.

O feudalismo tem como entidade típica a unidade de negócio, a região ou a função. É baseado nas tradições da antiga Inglaterra, em que os dirigentes tomavam as decisões localmente, otimizando suas necessidades. Este modelo dificulta as sinergias entre as unidades de negócio e não facilita a tomada de decisões da empresa como um todo.

federalismo é semelhante ao conhecido modelo dos governos com país e estados. É o arquétipo mais difícil para a tomada de decisões, pois os líderes da 
empresa têm preocupações diferentes das dos líderes das unidades de negócio. Além disso, os sistemas de incentivo levam os dirigentes a focarem os resultados da unidade de negócios o que, na maioria das vezes, dificulta ainda mais este relacionamento. Uma solução é a criação de equipes para resolver conflitos de interesses entre os grupos.

O duopólio é um arranjo entre duas partes: executivos de $\mathrm{TI}$ e algum outro grupo

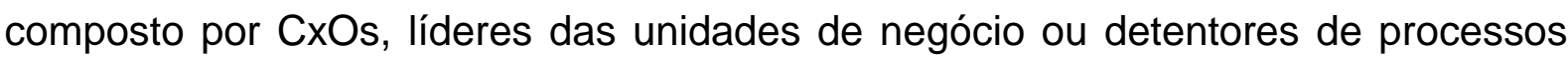
de negócios ou grupos dos principais usuários de sistemas.

O grupo de TI pode ter uma série de duopólios e, em muitos casos, é um dos poucos grupos que conhece a empresa como um todo, podendo procurar oportunidades de compartilhamento e reutilização (WEILL; ROSS, 2006).

As anarquias formalmente definidas são raras e acabam sendo adotadas quando se precisa de uma responsividade muito rápida a necessidades locais ou de clientes individuais.

Os autores identificaram em seu estudo que:

- Mais de um terço das empresas estudadas utilizava duopólios para tomar decisões nos três domínios menos técnicos: os princípios de $\mathrm{TI}$, as necessidades de aplicações de negócio e os investimentos em TI. Também eram frequentemente utilizados para contribuir em decisões sobre arquitetura e infraestrutura. Acredita-se que os duopólios sejam utilizados para os princípios de $\mathrm{TI}$ porque os administradores seniores sentiam que assim poderiam garantir o alinhamento entre $\mathrm{TI}$ e o negócio, além de ser um bom modelo para promover o comprometimento da unidade de $\mathrm{Tl}$ com os princípios de negócio;

- As decisões de arquitetura são, em sua maioria, tomadas por monarquias de TI. Acredita-se que isto ocorra por se ver a arquitetura como uma questão mais técnica. Uma parte significativa das empresas estudadas, porém, utilizam o duopólio, o que mostra o reconhecimento da dualidade técnica e de negócio das decisões sobre arquitetura; 
- Para infraestrutura, utiliza-se mais a monarquia de TI, talvez por se tratar de uma questão mais técnica e que provê serviços compartilhados para toda a empresa. Existe bastante contribuição de arranjos federalistas e duopolistas;

- As necessidades de aplicações de negócio são tratadas por diversos modelos, sendo que o federalismo apresenta pequena vantagem, buscando compartilhar expertise para toda a empresa, mas optando pelos benefícios das customizações locais. Duopólios em que a TI encontra-se no centro com uma série de relacionamentos bilaterais com as áreas de negócio também são bastante utilizados, conferindo maior poder à TI. Modelos feudais também são bastante utilizados, buscando maior autonomia para as unidades de negócio;

- Os investimentos em TI são determinados por: monarquias de negócio, permitindo que projetos de $\mathrm{TI}$ disputem fundos com outras necessidades organizacionais; esquemas federalistas, que permitem balancear prioridades da empresa como um todo e prioridades das unidades de negócio; duopólios em $\mathrm{T}$, que mostram o reconhecimento que a unidade de TI é apta para identificar riscos e oportunidades. Duopólios fortes podem agrupar projetos que requeiram novas capacidades de infraestrutura, adiando investimentos grandes em infraestrutura até que uma massa crítica os justifique.

As empresas implementam seus arranjos de governança por meio de um conjunto de mecanismos, como estruturas, processos, comunicações. Mecanismos bem concebidos, compreendidos e transparentes favorecem comportamentos desejáveis de TI.

Uma governança eficaz adota três tipos diferentes de mecanismos:

- Estruturas de tomadas de decisão, como comitês que envolvem pessoas de negócios e de TI;

- Processos de alinhamento, que buscam assegurar que os comportamentos cotidianos sejam consistentes com a política de Tl; 
- Abordagens de comunicação, para disseminar os princípios e as políticas da Governança de $\mathrm{TI}$, bem como os resultados dos processos decisórios (WEILL; ROSS, 2006).

Para uma Governança de Tl eficaz, Fernandes e Abreu (2008) sugerem o "Ciclo de Governança de TI" composto por quatro grandes etapas. Cada uma destas etapas possui uma série de mecanismos que permitem levar a estratégia de $\mathrm{TI}$ às operações dos produtos e serviços relacionados, como ilustra a Figura 14.

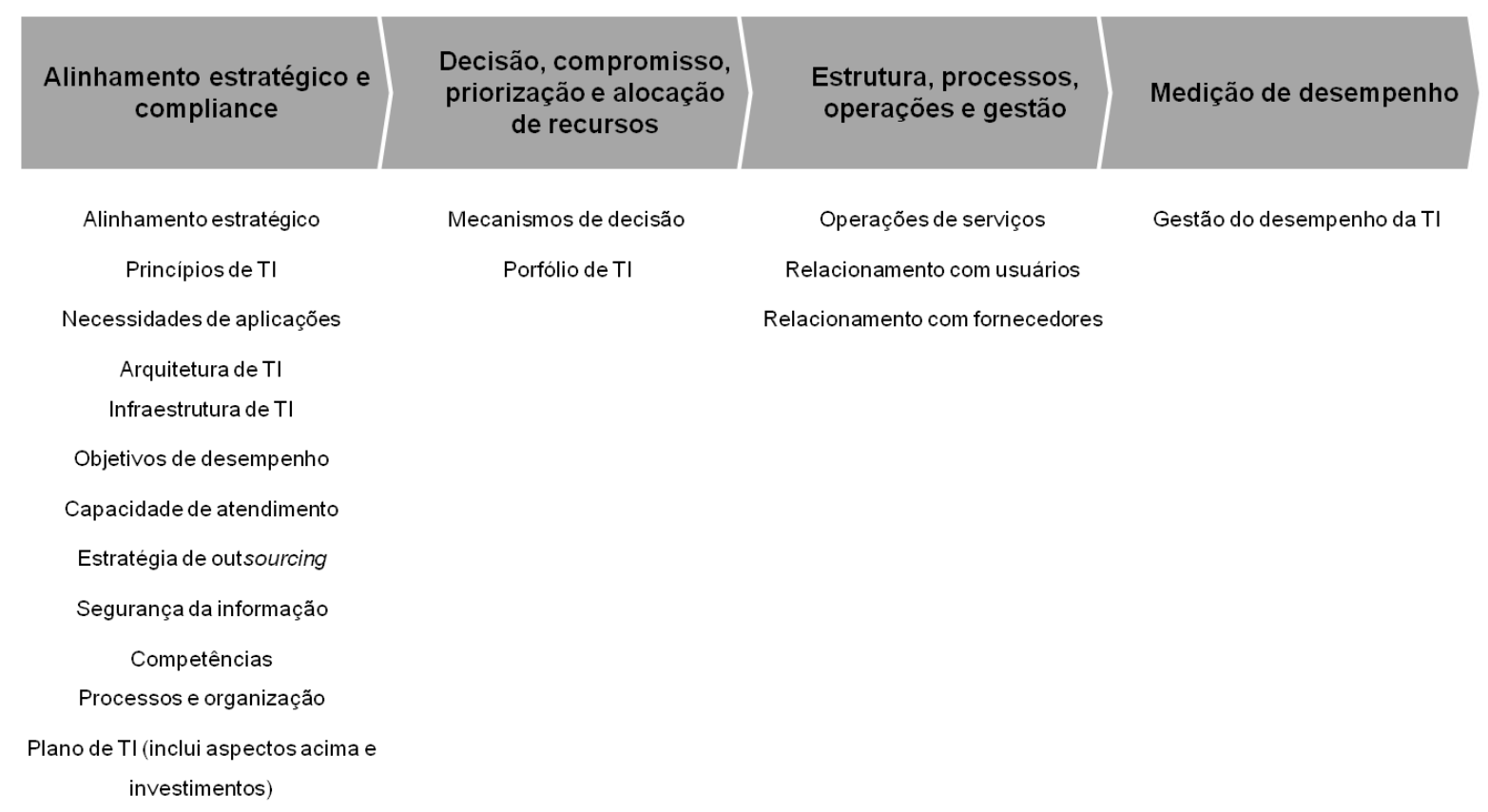

Figura 14 - Ciclo de Governança de TI (FERNANDES; ABREU, 2008)

\subsubsection{Modelos de Governança de TI}

Weill e Ross (2006) propõem um modelo de Governança de TI, conhecido como framework do MIT (Massachusetts Institute of Technology) CISR (Center for Information Systems Research), adaptável a qualquer empresa. Este modelo ilustra a necessidade de harmonização entre a estratégia e a organização da empresa, os arranjos de Governança de TI e as metas de desempenho do negócio que são postos em prática, respectivamente, pela organização de $\mathrm{TI}$ e comportamentos desejáveis, por mecanismos de Governança de TI e métricas e responsabilidades de TI. O modelo trata da necessidade de harmonizar a Governança de TI com as outras governanças dentro da organização, como demonstra a Figura 15. 


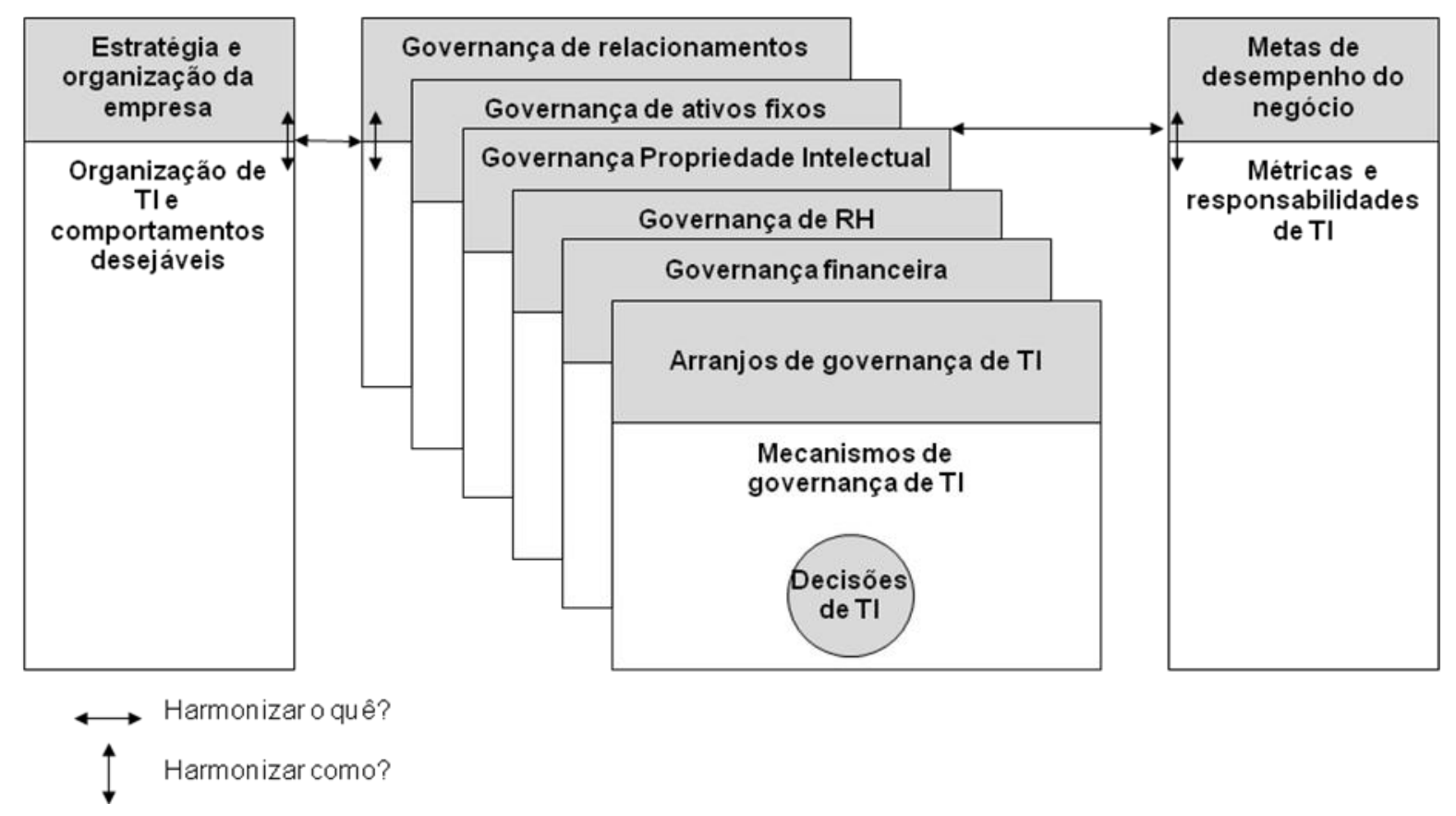

Figura 15- Framework de Governança de TI (MIT CISR, 2003 apud WEILL; ROSS, 2006)

A "estratégia e organização da empresa" determina os comportamentos desejáveis que motivam a governança corporativa. A "organização de TI e comportamentos desejáveis", por sua vez, colocam em prática a estratégia e a organização da empresa. Os "arranjos de Governança de TI" são concebidos como meio de habilitar e influenciar a estratégia e os direitos decisórios são atribuídos para as decisõeschave que governam cada ativo. Os mecanismos de Governança de TI devem estar em harmonia com as estruturas organizacionais de TI. Um exemplo de mecanismo seria a ITIL. As "metas de desempenho do negócio" determinam a eficácia esperada das estratégias da companhia e permitem avaliar o sucesso dos esforços de governança. As "métricas e responsabilidades de Tl" definem a contribuição de $\mathrm{TI}$ para as metas de desempenho da empresa e permitem avaliar a eficácia de TI de maneira separada (CLEMENTI, 2007).

Fernandes e Abreu (2008) sugerem um modelo estendido de governança baseado no "Ciclo da Governança de TI", considerando o alinhamento estratégico como ponto de partida, como ilustra a Figura 16. 


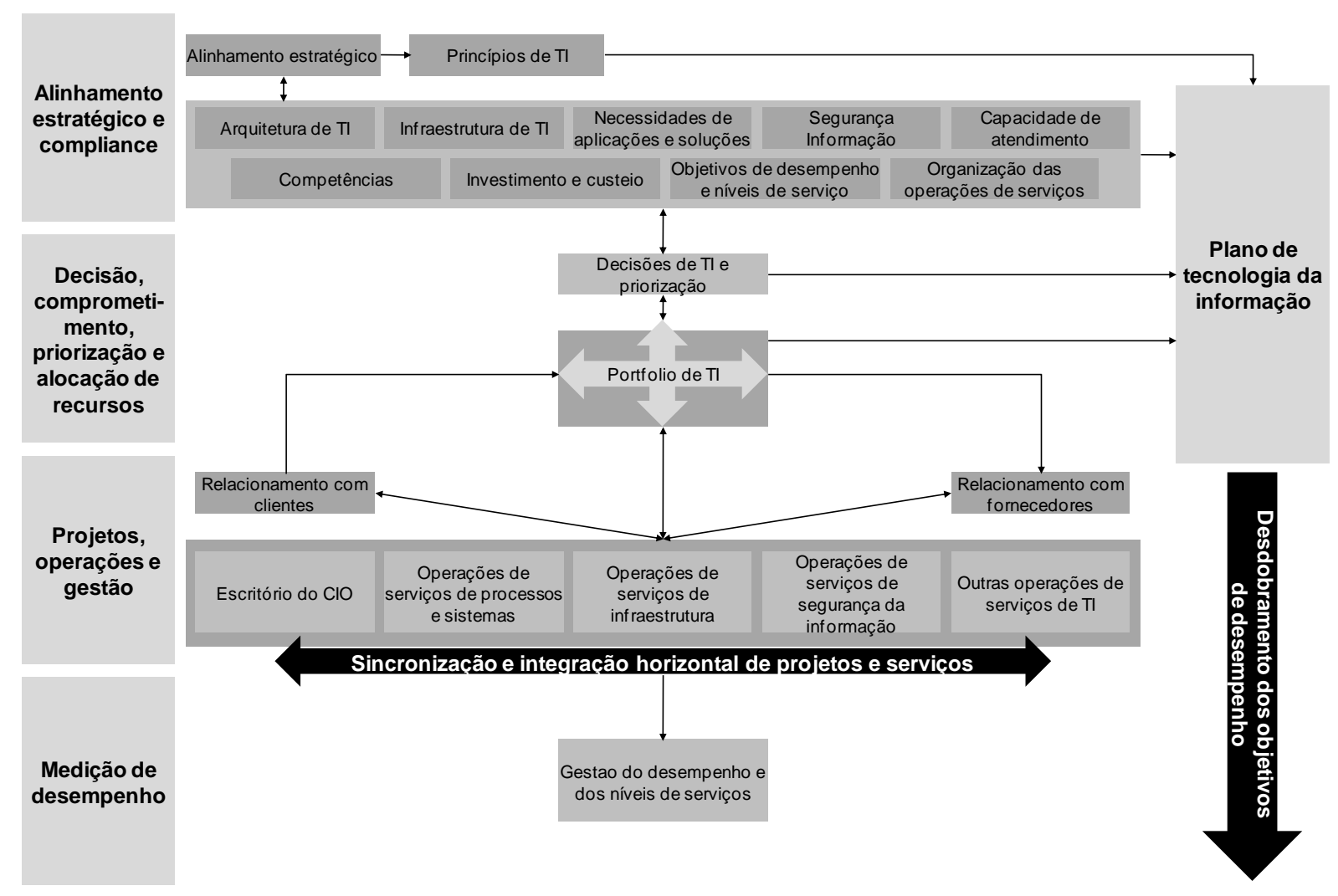

Figura 16- Modelo de Governança de TI (FERNANDES; ABREU, 2008)

Os autores classificam o alinhamento entre o negócio e a $\mathrm{TI}$ de duas formas: alinhamento estático, em que a estratégia de TI deriva do plano estratégico ou de negócios da empresa e alinhamento dinâmico, em que a estratégia de TI é alterada em função de mudanças na estratégia do negócio. O modelo de governança deve contemplar estes dois tipos de alinhamento.

A partir do alinhamento estratégico, definem-se as prioridades de $\mathrm{Tl}$, gerando um portfólio, que vai orientar as ações do dia-a-dia e o relacionamento com clientes e fornecedores, unindo estratégias de curto, médio e longo prazos à rotina diária das operações de serviços de TI.

O Plano de Tecnologia da Informação é derivado do alinhamento estratégico da organização e atualizado sempre que há mudanças na estratégia. O plano deve apoiar toda a operação e é também apoiado por outros planos da empresa, como de recursos humanos e investimentos. 
Objetivos de desempenho e níveis de serviço podem ser estabelecidos desde o plano de TI e devem ser medidos em intervalos de tempo pré-estabelecidos.

É importante deixar claro para os clientes quais serviços a área de TI realiza e quais não realiza. Dentro deste âmbito, um catálogo de serviços disponível a todos é um item importante, bem como a estrutura organizacional de operações.

Grembergen e De Haes (2008) sugerem que, para desenvolver um modelo de Governança de $\mathrm{TI}$ completo, é necessário considerar uma combinação de estruturas, processos e mecanismos relacionais, como ilustra a Figura 17.

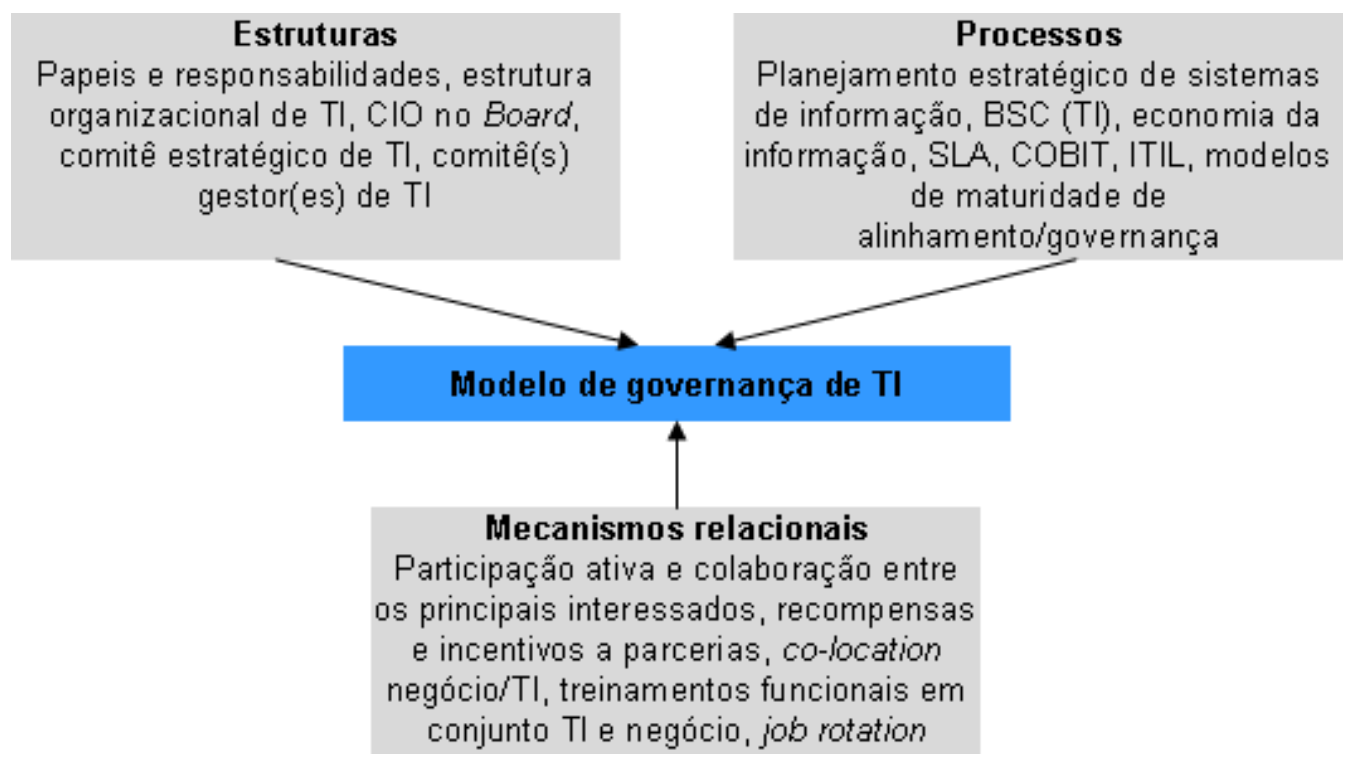

Figura 17- Modelo de Governança de TI (GREMBERGEN; DE HAES, 2008)

As estruturas incluem unidades organizacionais e papeis responsáveis por tomar as decisões em $\mathrm{Tl}$ e estabelecer o contato entre o negócio e a TI. Os processos referem-se à formalização e institucionalização de processos de tomada de decisão e monitoramento que buscam garantir que os comportamentos diários estejam consistentes com as políticas e criem novas entradas para tomadas de decisão. Os mecanismos relacionais tratam da participação ativa e do estabelecimento de um relacionamento colaborativo entre $\mathrm{TI}$ e o negócio e incluem os mecanismos de comunicação e esforços para treinamento. Diversos pesquisadores comentam que os mecanismos relacionais são cruciais para o modelo de governança da empresa e 
sua sustentabilidade, mesmo que já existam estruturas e processos estabelecidos (GREMBERGEN; DE HAES, 2008).

Albertin e Albertin (2010) comentam que a Governança de TI precisa ter uma estrutura que defina escopo, atuação e participantes, pois é multidisciplinar e envolve pessoas de diferentes áreas do negócio e de TI, tanto em nível, quanto em especialização. Com isto, propõem a estrutura de Governança de TI que contempla definições e relacionamentos da Figura 18.

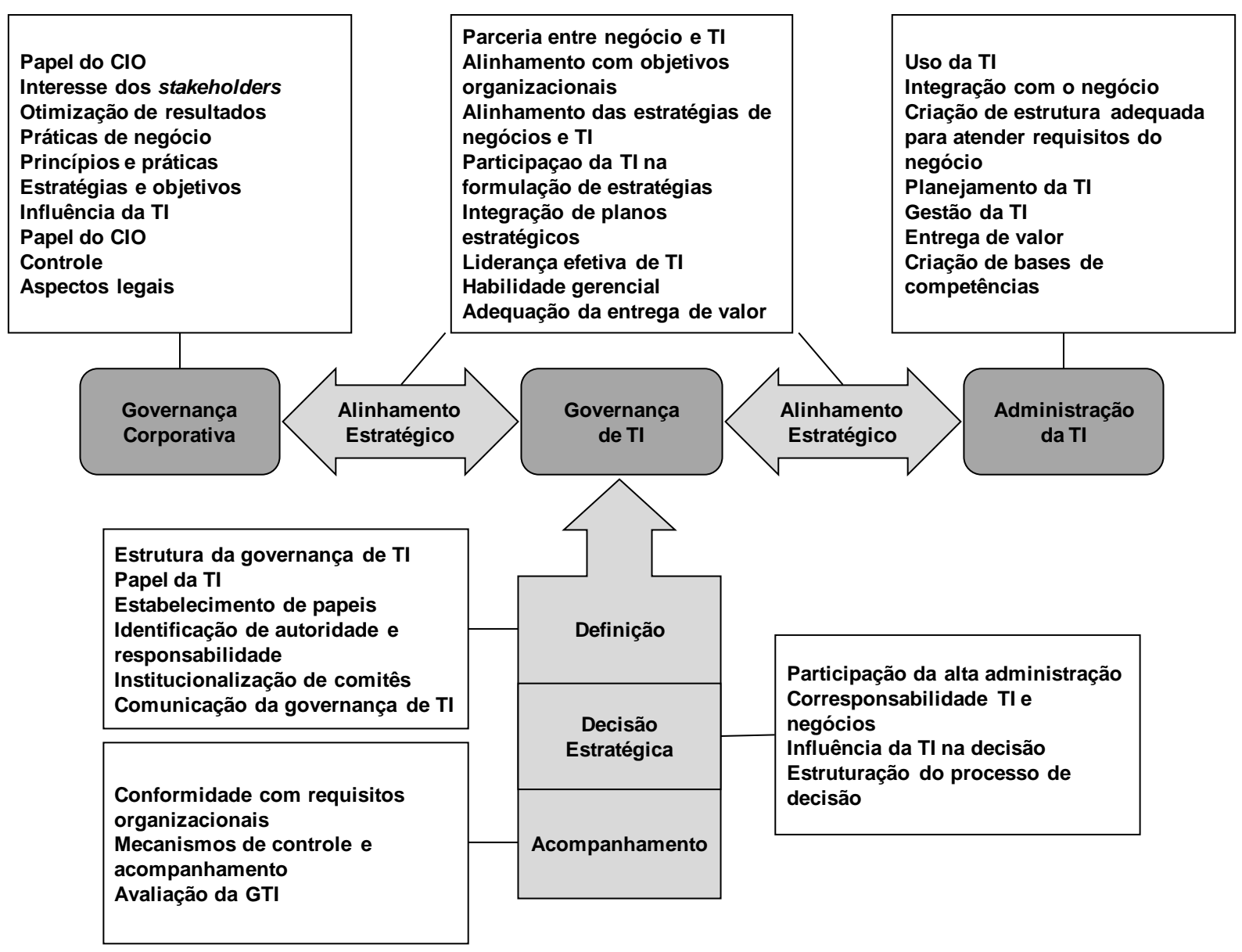

Figura 18- Estrutura de Governança de TI (ALBERTIN; ALBERTIN, 2010)

O modelo contempla os relacionamentos da Governança de TI com a organização e a administração de TI. Os autores definem os modelos de administração de TI como a implementação da Governança de TI. O COBIT e a ITIL seriam exemplos destes modelos (ALBERTIN; ALBERTIN, 2010). 
Além dos modelos de Governança de TI, é importante entender o estágio da governança antes de desenvolver um modelo ou melhorar o existente. Para isto, Peterson (2004) sugere um modelo, o ITGAP (IT Governance Assessment Process), ilustrado na Figura 19.

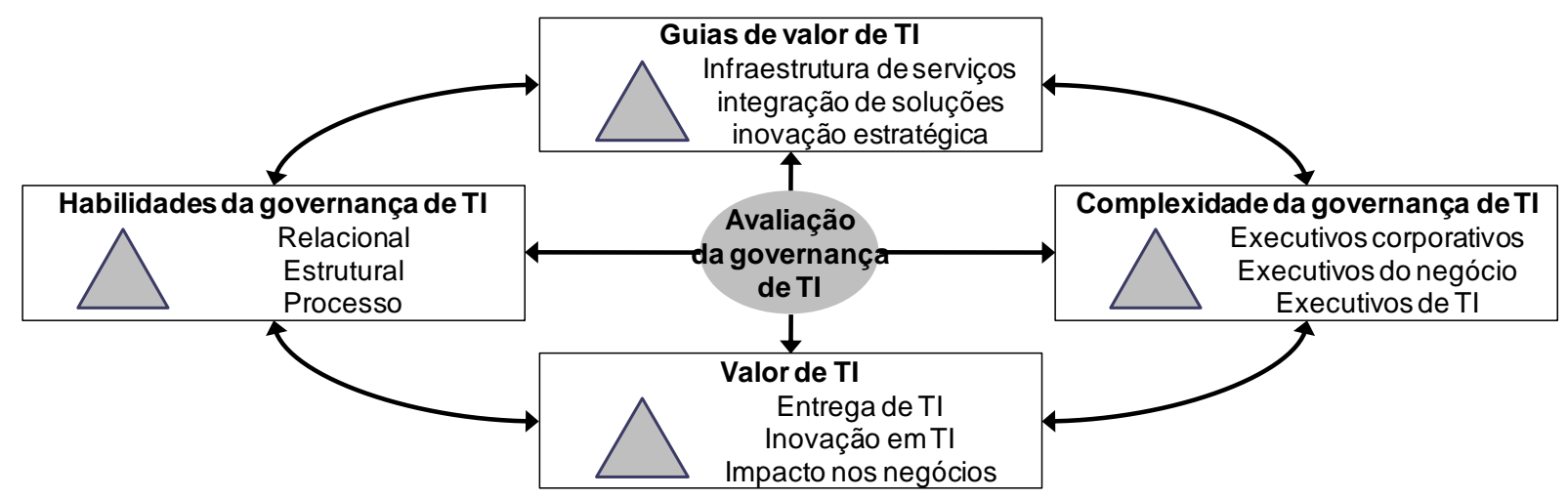

Figura 19- ITGAP (PETERSON, 2004)

\subsubsection{Modelos e melhores práticas que apoiam a Governança de TI}

Grande parte dos modelos de administração de $\mathrm{TI}$, conhecidos como "melhores práticas" surgiu há alguns anos, mas apenas recentemente os administradores têm dado foco para a necessidade de uma boa gestão das atividades de TI, visto o risco que uma TI mal gerenciada pode trazer para a empresa (FERNANDES; ABREU, 2008).

As organizações utilizam diferentes práticas, como ilustra a Figura 20 baseada no estudo "IT Governance Global Status Report - 2008", desenvolvido pela PricewaterhouseCoopers (PwC) em conjunto com o ITGI (IT Governance Institute), realizado em vinte e três países que identificou importantes aspectos da $\mathrm{TI}$ e da Governança de TI nas empresas estudadas. 


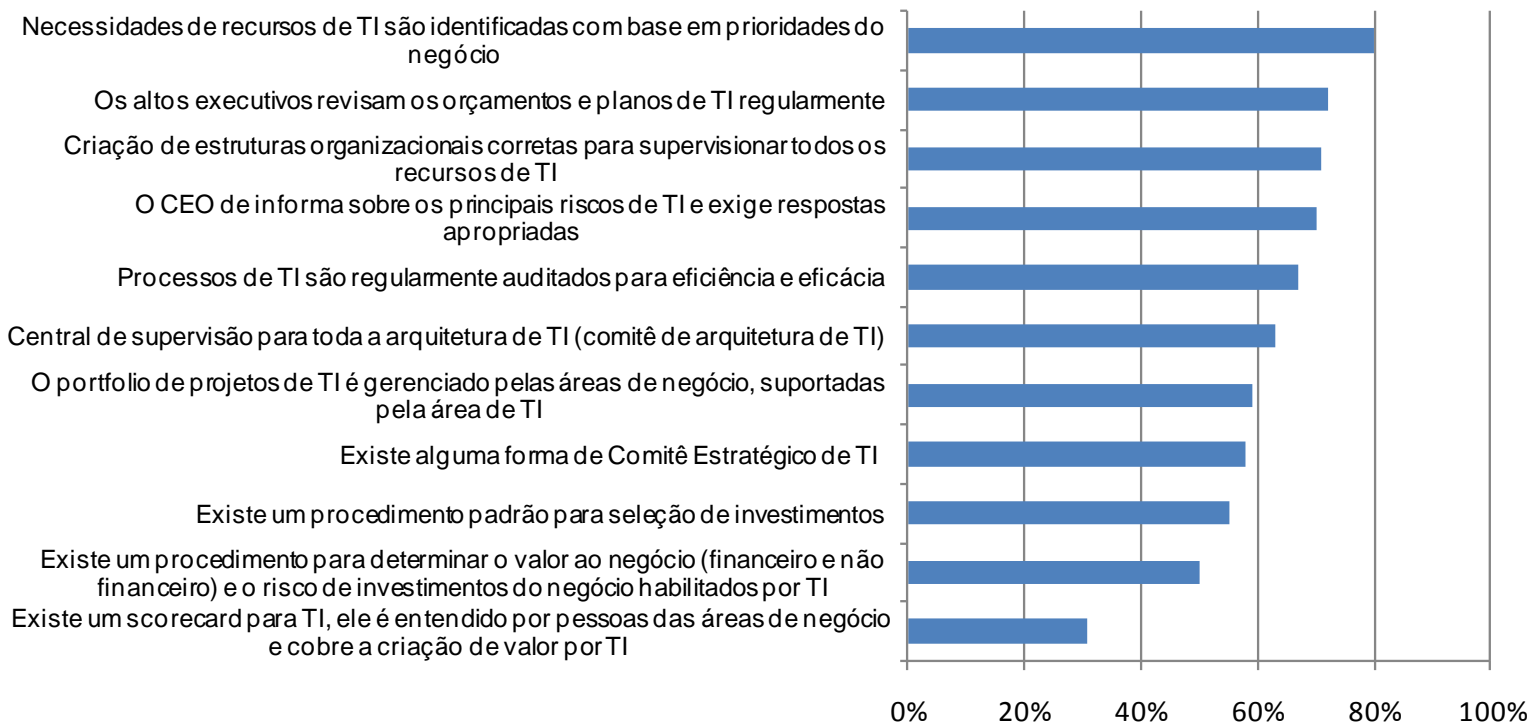

Figura 20 - Práticas atuais de governança (ITGI; PRICEWATERHOUSECOOPERS, 2008)

Outra pesquisa, realizada pelo instituto de pesquisa UAMS - ITAG (University of Antwerp Management School - IT Alignment and Governance Research Institute) identificou trinta e três melhores práticas aplicáveis a empresas intensivas em informação ${ }^{7}$, como muitas são hoje em dia. Grembergen e De Haes (2009) sugerem um subconjunto das práticas identificadas como o mínimo que as companhias deveriam adotar:

- Comitê gestor (Steering Committee), uma equipe para avaliar e priorizar investimentos;

- Participação do ClO no comitê executivo, uma equipe composta pelos altos gestores da empresa para tomar as principais decisões do negócio;

- Gerenciamento do portfólio utilizando Casos de Negócios e ferramentas para análise do retorno sobre o investimento;

- Controle e reporte do orçamento de TI;

\footnotetext{
${ }^{7}$ Empresas intensivas em informação são empresas que têm o processamento de informações como a principal atividade, por exemplo, bancos e outros serviços financeiros, consultoria, advocacia, engenharia, educação etc. (DRENNAN, 1989).
} 
- Comitê estratégico de TI no nível do Conselho Administrativo para discutir assuntos de $\mathrm{TI}$ junto a este conselho, responsável por auxiliar na elaboração das estratégias, orientar e supervisionar os executivos na definição dessas estratégias;

- Liderança de Tl;

- CIO reportando diretamente ao CEO (Chief Executive Officer) ou COO (Chief Operations Officer);

- Governança e métodos para gerenciamento de projetos (GREMBERGEN; DE HAES, 2009).

Rau (2004) também sugere um comitê responsável pelo direcionamento estratégico de $\mathrm{TI}$, reportando direto à alta direção da empresa. Além disto, sugere um "gerente de contas" para os clientes de $\mathrm{TI}$ e um escritório de projetos, uma estrutura organizacional para administrar de forma centralizada o portfólio de projetos.

Diversos modelos e métodos de mercado foram criados para auxiliar na implantação da Governança de TI. A seguir são descritos os principais modelos de mercado.

\subsection{COBIT}

O CoblT (Control Objectives for Information and related Technology) é um dos padrões mais abrangentes e mais conhecidos de Governança de TI. Apresenta um modelo de Governança que demonstra práticas geralmente aceitas na gestão de $\mathrm{TI}$, focado mais em controle e menos em execução. Estas práticas possibilitam a criação de um elo com os requisitos de negócios, a organização das atividades de TI em um processo de negócios geralmente aceito, a identificação da maioria dos recursos de $\mathrm{TI}$ e a definição de objetivos de controle gerenciais a serem considerados.

A missão do CoblT é "Pesquisar, desenvolver, publicar e promover um framework de controle de TI confiável, atualizado e internacionalmente aceito para ser adotado por empresas e no dia-a-dia dos gerentes de negócio, profissionais de $\mathrm{TI}$ e de 
segurança." (ITGI, 2007, p.13). A atual versão do modelo é a 4.1, mas já está sendo desenvolvida a versão 5, que trará uma série de melhorias, além de maior alinhamento com outros modelos de mercado.

O modelo sugere trinta e quatro grandes processos de trabalho agrupados em quatro domínios e é baseado em indicadores e modelos de maturidade. O relacionamento entre os domínios e algumas perguntas endereçadas em cada um deles é ilustrado na Figura 21. Para cada um dos processos é atribuído um nível de maturidade, cuja escala pode variar de zero a cinco.

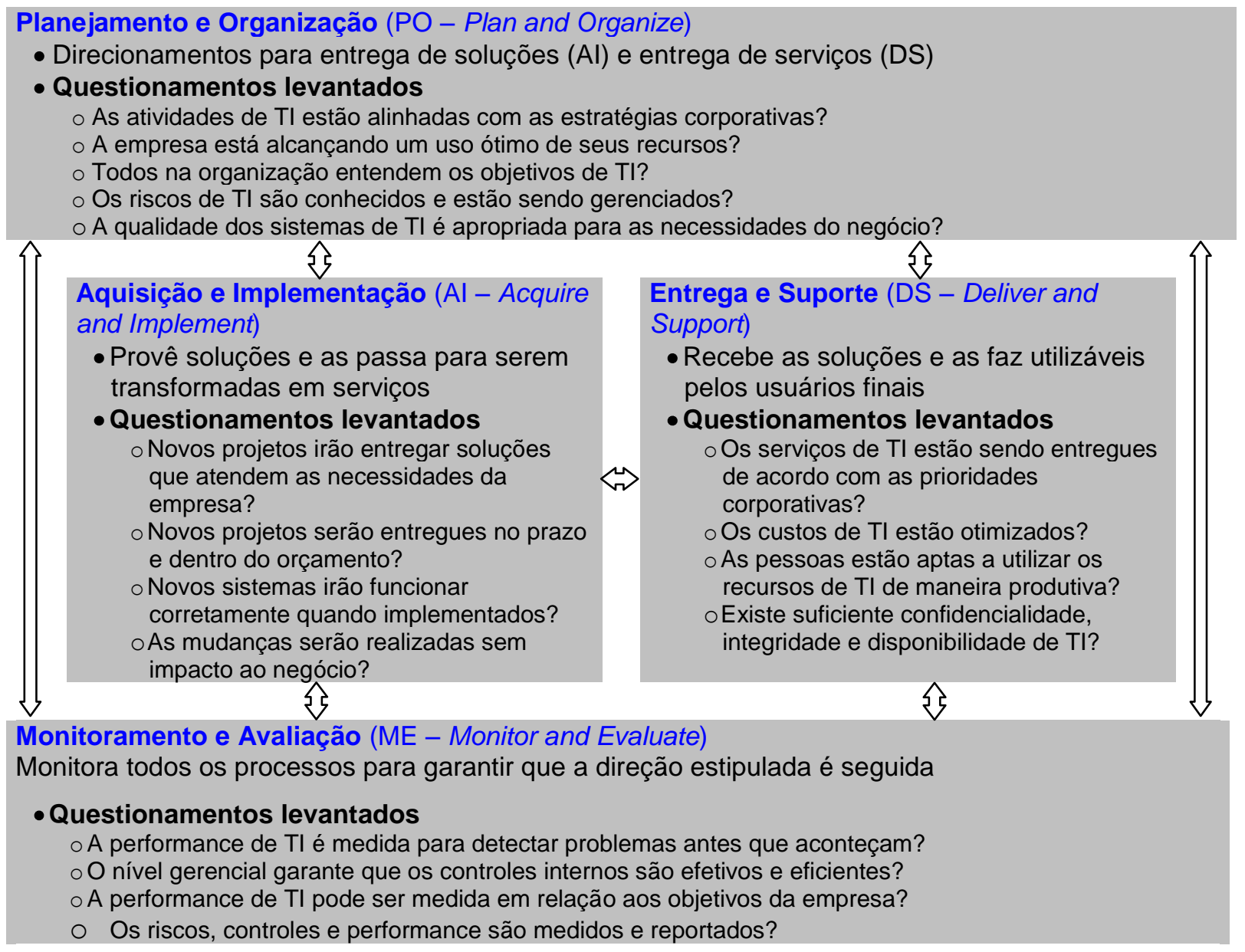

Figura 21 - Os quatro domínios do CoblT inter-relacionados (adaptado de ITGI, 2007)

Apesar de focar mais em controle e menos em execução, o COBIT permite analisar a maturidade dos processos, e indica um caminho para a evolução da Governança de TI, sendo um bom modelo para as empresas começarem a entender seu estágio de Governança de TI e o que podem fazer para melhorá-lo. 
Um dos benefícios primários do COBIT é que ele permite a integração de outros modelos. O uso combinado com outras ferramentas de mercado torna-se interessante para o desenvolvimento de estruturas completas de Governança de TI.

\subsection{Val IT}

O Val IT foi desenvolvido em 2006 como resposta à necessidade de demonstração do retorno que a $\mathrm{Tl}$ fornece para o negócio, tratando da gestão do valor e investimentos de $\mathrm{TI}$. O conceito de valor deriva da relação entre atender às expectativas do envolvidos com o negócio e os recursos utilizados para isto. A gestão do valor trata de combinar estes dois âmbitos, permitindo que as empresas definam internamente este conceito, selecionem e realizem investimentos e gerenciam seus ativos dentro de um nível adequado de utilização e um nível aceitável de risco (ITGI, 2008).

De acordo com a ISACA (Information Systems Audit and Control Association) (2009), o Val IT ajuda os executivos a responderem às seguintes questões, baseadas nas quatro questões levantadas por John Thorp em seu livro "O paradoxo da informação: "Estamos fazendo as coisas certas?", "Estamos conseguindo benefícios?", "Estamos fazendo de forma certa?", "Estamos conseguindo fazê-las bem?" (THORP, J, 2003 apud ISACA, 2009) . O ITGI (IT Governance Institute) (2008) comenta que as duas últimas questões são mais detalhadas pelo COBIT.

O modelo é baseado em sete princípios aplicados a processos de gerenciamento de valor (organizados em domínios, assim como no COBIT) que, por sua vez, são habilitados por práticas-chave e medidos por métricas de desempenho. A Figura 22 ilustra o modelo. Os princípios do Val IT são os seguintes:

- Os investimentos de TI serão gerenciados como um portfólio de investimentos;

- Os investimentos de TI incluirão o conjunto completo de atividades necessárias para atingir o valor para o negócio; 
- Os investimentos de TI serão gerenciados por meio do seu ciclo de vida econômico completo;

- As práticas de entrega de valor reconhecerão que há diferentes categorias de investimentos a serem avaliados e gerenciados de formas diferentes;

- As práticas de entrega de valor definirão e irão monitorar métricas chave e responderão rapidamente a qualquer mudança ou desvio;

- As práticas de entrega de valor envolverão todos os interessados (stakeholders) e atribuirão responsabilidades pelo resultado de forma apropriada para a entrega de capacidades e realização dos benefícios para o negócio e

- As práticas de entrega de valor serão continuamente monitoradas, avaliadas e melhoradas.

Uma importante ferramenta para criação de valor é o chamado Business Case, ou "Caso de Negócio", ferramenta de planejamento e suporte à decisão que projeta as prováveis consequências de determinado projeto (ou da falta dele), importante para justificar investimentos que agreguem valor para a empresa. Este documento deve incluir respostas às quatro perguntas que embasam o Val IT, listadas anteriormente. $O$ Val IT pode ser utilizado como guia para maximizar a qualidade destes casos de negócio, em especial na definição de indicadores financeiros e não financeiros (ITGI, 2006b). 


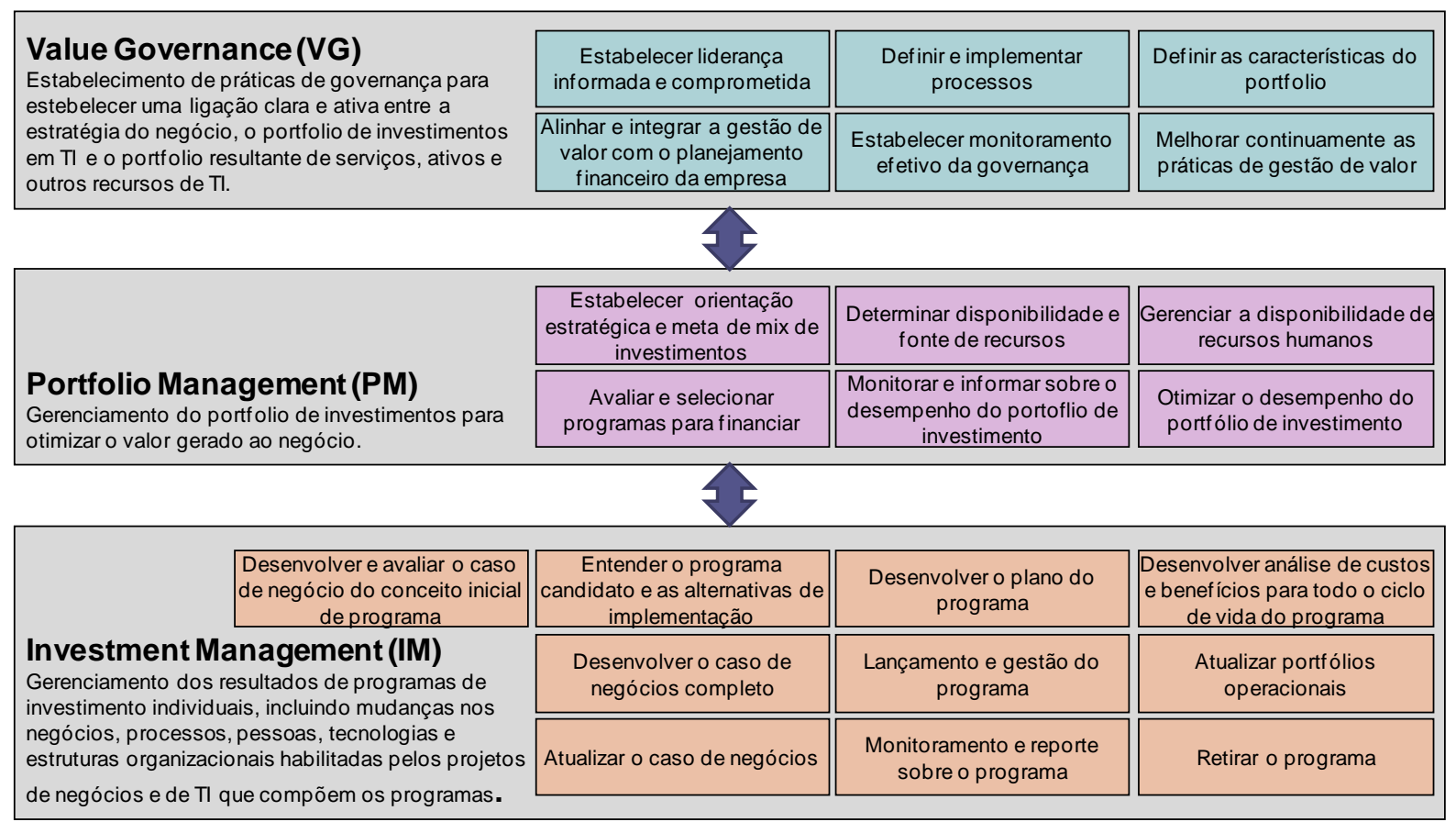

Figura 22 - Domínios e processos do VAL IT (adaptado de ISACA, 2009a)

O Val IT pode ser considerado extensão e complemento do COBIT, principalmente sob as perspectivas de negócios e financeira, uma vez que aborda a tomada de decisões em relação aos investimentos de $\mathrm{TI}$ e a realização efetiva dos benefícios sob a ótica da geração de valor, enquanto o COBIT foca no controle sob o ponto de vista da função de TI. No entanto, pode ser considerado muito burocrático e de alto nível para ser implementado, de forma que é importante selecionar quais processos são os mais importantes na visão da empresa para obter benefícios.

\subsection{CMMI}

O modelo CMMi (Capability Maturity Model Integration) fornece diretrizes baseadas em melhores práticas para a melhoria dos processos por todo o ciclo de vida de produtos e serviços, nas fases de concepção, desenvolvimento, aquisição, entrega e manutenção (FERNANDES; ABREU, 2008).

Os componentes do $\mathrm{CMMi}$, atendendo a requisitos de componentização, são agrupados nas chamadas "constelações": 
- CMMi-DEV (Capability Maturity Model Integration - for Development): para desenvolvimento de produtos e projetos de software;

- CMMi-ACQ (Capability Maturity Model Integration - for Acquisition): para suporte às decisões relacionadas a aquisições de produtos e serviços;

- CMMi-SVC(Capability Maturity Model Integration - for Services): para empresas que prestam serviços interna e externamente;

As três "constelações" são complementares entre si, com alguns processos em comum e outros específicos.

O CMMi-DEV não é um método de desenvolvimento de software, mas um conjunto de boas práticas para o processo de desenvolvimento. $O$ modelo sugere vinte e duas áreas de processo, agrupadas em quatro categorias de afinidade: Gestão do Processo, Gestão do Projeto, Engenharia e Suporte e possui duas abordagens para a sua implementação:

- Abordagem por estágios, que agrupa as áreas de processo em níveis de maturidade de forma que todos os processos de determinado nível devem ser implantados totalmente para que aquele nível de maturidade seja atingido;

- Abordagem contínua, que permite que cada área de processo seja implementada de forma independente e evolutiva, avaliando a maturidade processo a processo (SOTILLE, 2010).

No Brasil, existe o Programa MPS.BR (Melhoria de Processos do Software Brasileiro) para melhoria de processos, uma iniciativa envolvendo universidades, grupos de pesquisa e empresas, sob coordenação da Sociedade SOFTEX (Sociedade para Promoção da Excelência do Software Brasileiro). O objetivo do programa foi desenvolver e disseminar um modelo de processos de software (o modelo MPS) economicamente viável para que organizações de diferentes portes pudessem utilizar boas práticas da engenharia de software (KALINOWSKI et al., 2010).

As melhores práticas descritas no CMMi-DEV para desenvolvimento indicam como as empresas devem evoluir quando definem, implementam e controlam seus 
processos de software. É um conjunto indicado, principalmente, para empresas que desenvolvem softwares.

O CMMi-ACQ é um guia para aquisições de produtos e serviços (SEI, s.d.). É inevitável a associação com o eSCM-CL (The eSourcing Capability Model for Client Organizations), um modelo para terceirização sob a ótica do cliente. O CMMI-ACQ contém processos que estão relacionados à aquisição de produtos ou serviços de software e à avaliação dos mesmos. Já o eSCM-CL é um modelo de melhores práticas desenvolvido com os objetivos de prover orientação para as organizações em relacionamentos de terceirização, no sentido de melhorar sua capacidade em gerir provedores de serviços e prover às organizações critérios objetivos de avaliação de sua capacidade.

Já o CMMI-SVC, modelo para estabelecer, gerenciar e entregar serviços para organizações que os provêm (SEI, s.d.) possui um paralelo com o eSCM-SP (The eSourcing Capability Model for Service Providers). Ambos possuem propósitos semelhantes, mas o CMMI é mais amplo e o eSCM-SP, apesar de mais enxuto, detalha também a gestão de pessoas e do conhecimento. A escolha pelo uso depende do conhecimento prévio da empresa - se ela já possui CMMi, por exemplo, pode ser mais simples utilizar o CMMI-SVC. Por outro lado, o eSCM-SP, apesar de pouco utilizado no Brasil, é consolidado no mundo e não foi feito a partir de adaptações (ALMEIDA, 2009).

Além destes modelos, cujos objetivos referem-se à melhoria de processos, existe também o People CMM, destinado a prestadores de serviço (geralmente desenvolvimento de software) que desejam melhorar a forma com que gerenciam e desenvolvem seus funcionários através da adaptação do modelo de maturidade do CMMi (SEI, s.d).

\subsection{ITIL}

A ITIL (Information Technology Infrastructure Library) é uma biblioteca que apresenta uma estrutura de padrões e melhores práticas para gerenciar os serviços e infraestrutura de $\mathrm{TI}$ com o objetivo de fazer com que a $\mathrm{TI}$ foque no negócio da 
empresa e para que entregue os seus serviços aos clientes internos da melhor maneira possível e a um custo justificável (FERNANDES; ABREU, 2008). De acordo com Kumbakara (2008), é o padrão para gerenciamento de serviços de TI mais aceito.

Um serviço é um meio de entregar valor, sendo, sob a visão do cliente, função de duas variáveis: utilidade (possui o desempenho desejado ou redução das restrições de desempenho) e a garantia (disponibilidade, capacidade, continuidade e segurança suficientes para o uso).

A Tabela 3 descreve as publicações da ITIL e seus respectivos processos.

Tabela 3 - Publicações e processos ITIL (ITSMF, 2007)

\begin{tabular}{|c|c|c|c|}
\hline Livro & Descrição & Processo & crição \\
\hline \multirow{3}{*}{$\begin{array}{l}\text { Estratégia } \\
\text { do Serviço }\end{array}$} & \multirow{3}{*}{$\begin{array}{l}\text { Publicação } \\
\text { considerada uma } \\
\text { das grandes } \\
\text { novidades da ITIL } \\
\text { V3. Orienta o } \\
\text { desenvolvimento } \\
\text { de políticas e } \\
\text { processos como } \\
\text { ativos estratégicos } \\
\text { ao longo do ciclo } \\
\text { de vida do negócio. }\end{array}$} & $\begin{array}{l}\text { Gerenciamento } \\
\text { do portfólio de } \\
\text { serviços }\end{array}$ & $\begin{array}{l}\text { Administração dos investimentos em } \\
\text { gerenciamento de serviços, objetivando } \\
\text { geração de valor para o negócio. }\end{array}$ \\
\hline & & $\begin{array}{l}\text { Gerenciamento } \\
\text { financeiro de } \mathrm{TI}\end{array}$ & $\begin{array}{l}\text { Quantificação, em termos financeiros, do } \\
\text { valor dos serviços de } \mathrm{TI} \text {, incluindo os ativos } \\
\text { que sustentam o provisionamento destes } \\
\text { serviços. }\end{array}$ \\
\hline & & $\begin{array}{l}\text { Gerenciamento } \\
\text { da demanda }\end{array}$ & $\begin{array}{l}\text { Entendimento dos padrões de atividade do } \\
\text { negócio e influência sobre a demanda do } \\
\text { cliente. }\end{array}$ \\
\hline \multirow{7}{*}{$\begin{array}{l}\text { Desenho de } \\
\text { serviço }\end{array}$} & \multirow{7}{*}{$\begin{array}{l}\text { Orienta sobre como } \\
\text { desenhar e criar } \\
\text { serviços de acordo } \\
\text { com a estratégia } \\
\text { concebida } \\
\text { anteriormente. }\end{array}$} & $\begin{array}{l}\text { Gerenciamento } \\
\text { do catálogo de } \\
\text { serviços }\end{array}$ & $\begin{array}{l}\text { Gerenciamento da informação contida no } \\
\text { catálogo, buscando garantir que esteja } \\
\text { correta e reflita os detalhes correntes. }\end{array}$ \\
\hline & & $\begin{array}{l}\text { Gerenciamento } \\
\text { de níveis de } \\
\text { serviço }\end{array}$ & $\begin{array}{l}\text { Negociação, definição e documentação de } \\
\text { acordos e metas. }\end{array}$ \\
\hline & & $\begin{array}{l}\text { Gerenciamento } \\
\text { de capacidade }\end{array}$ & $\begin{array}{l}\text { e que existe capacidade em todas } \\
\text { e TI a custos justificáveis. }\end{array}$ \\
\hline & & $\begin{array}{l}\text { Gerenciamento } \\
\text { de } \\
\text { disponibilidade }\end{array}$ & $\begin{array}{l}\text { Garantia de que o nível de disponibilidade } \\
\text { entregue seja igual ou maior às metas } \\
\text { acordadas. }\end{array}$ \\
\hline & & $\begin{array}{l}\text { Gerenciamento } \\
\text { de continuidade } \\
\text { de serviços }\end{array}$ & $\begin{array}{l}\text { Suporte ao processo de gerenciamento de } \\
\text { continuidade dos negócios em geral. Busca } \\
\text { manter a operação, mesmo que de forma } \\
\text { degradada dentro de um limite de tempo } \\
\text { acordado. }\end{array}$ \\
\hline & & $\begin{array}{l}\text { Gerenciamento } \\
\text { de segurança da } \\
\text { informação }\end{array}$ & $\begin{array}{l}\text { Alinhamento da segurança de } \mathrm{TI} \text { à } \\
\text { segurança do negócio e garantia de que a } \\
\text { segurança da informação seja efetivamente } \\
\text { gerenciada. }\end{array}$ \\
\hline & & $\begin{array}{l}\text { Gere } \\
\text { de fo }\end{array}$ & $\begin{array}{l}\text { Gerenciamento dos serviços entregues e } \\
\text { provisionamento de qualidade fim-a-fim. }\end{array}$ \\
\hline \multirow[t]{2}{*}{$\begin{array}{l}\text { Transição de } \\
\text { serviço }\end{array}$} & \multirow{2}{*}{$\begin{array}{l}\text { Orienta sobre como } \\
\text { colocar o serviço } \\
\text { em produção, } \\
\text { garantindo } \quad 0\end{array}$} & $\begin{array}{l}\text { Suporte re } \\
\text { planejamento da } \\
\text { transição }\end{array}$ & $\begin{array}{l}\text { Planejamento e controle dos recursos } \\
\text { necessários para colocar um serviço novo } \\
\text { ou modificado no ambiente de produção. }\end{array}$ \\
\hline & & Gerenciamento & mudanças \\
\hline
\end{tabular}




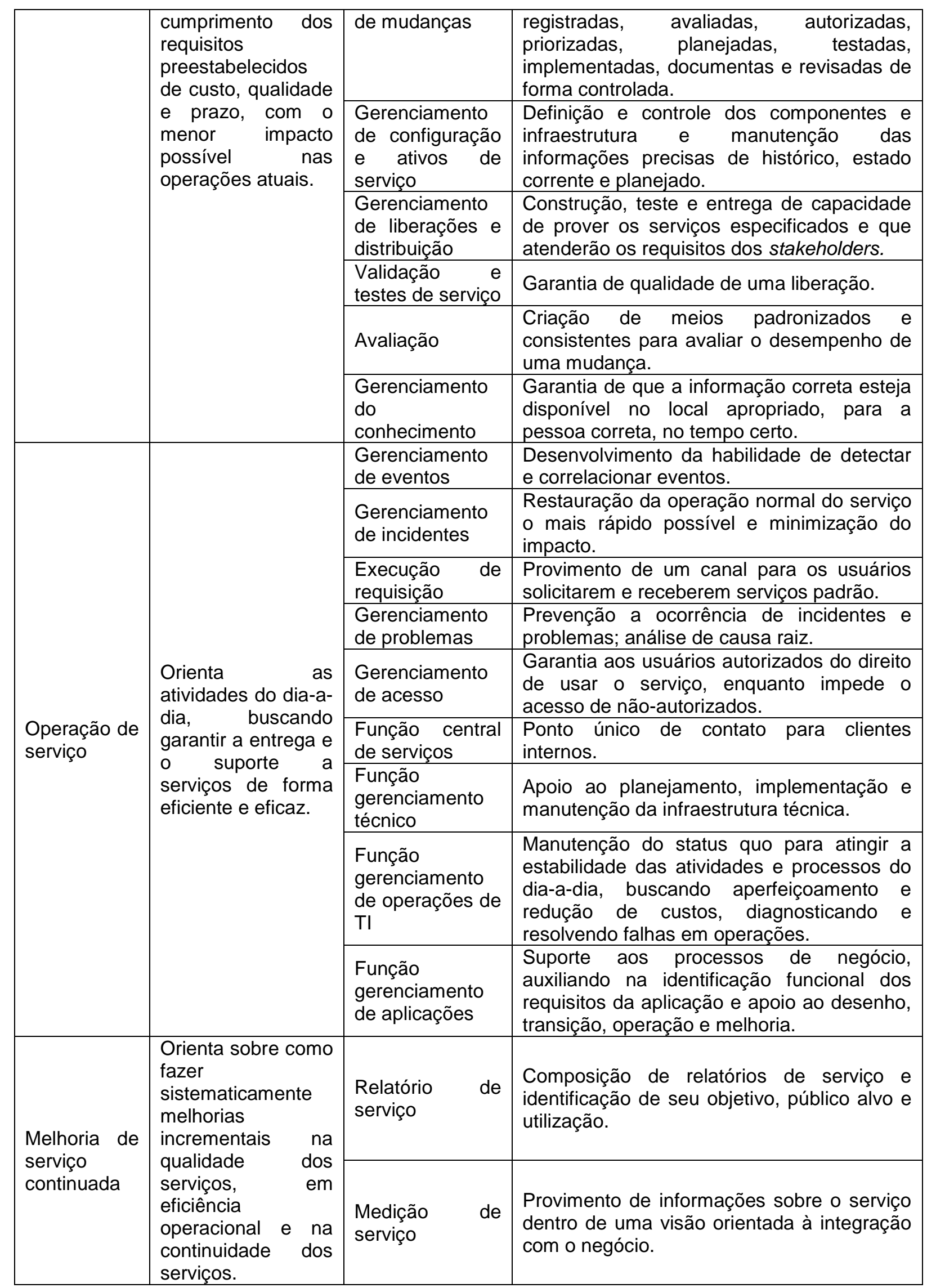


A ITIL é a biblioteca mais conhecida para gestão de serviços e é bastante utilizada em conjunto com outros modelos. A terceira versão da biblioteca incorporou itens mais estratégicos, o que deixou o modelo mais completo, mas também com maior sobreposição com outros modelos, sendo necessária uma maior análise para combinações entre eles.

A combinação COBIT-ITIL, por exemplo, tem sido bastante estudada na academia e entre as empresas (CLEMENTI, 2007, ITGI; OGC, 2008). A ITIL descreve, principalmente, os processos relativos a suporte e entrega de serviços do COBIT (domínio DS), mas não cobre todos os requisitos de controle descritos no COBIT para este domínio. Os outros domínios são tratados mais superficialmente, pois a biblioteca busca detalhar como implementar e quem será responsável. Desta forma, a combinação entre eles torna-se interessante no desenvolvimento da Governança de TI.

\subsection{ISO/IEC 20000}

A biblioteca ITIL é aceita no mundo todo como uma referência em melhores práticas para o gerenciamento de serviços de TI. No entanto, até pouco tempo atrás, não havia uma norma que comprovasse que determinada empresa estava ou não alinhada à ITIL. Em 2000, a BSI (British Standards Institution) publicou a primeira norma relacionada, a BS 15000. Em 2005, a ISO criou a ISO/IEC 20000, baseada na BS 15000 (ITSMF, 2006). Enquanto a ITIL provê melhores práticas, sendo o ponto de partida para melhorias de processos, a ISO 20000 é um padrão, sendo base para a realização de benchmarking de serviços de TI.

Apesar de não incluir formalmente a abordagem ITIL, a norma descreve um conjunto de processos de gerenciamento integrados alinhados e complementares aos processos definidos dentro da ITIL (ITSMF, 2006).

A parte 1 da norma (especificação) descreve o que deve ser levado em consideração na implementação do gerenciamento de serviços de $\mathrm{TI}$, sendo utilizada no processo de certificação. A Parte 2 (código de prática) é um guia prático para orientar as empresas a planejarem melhorias e a se prepararem para serem 
auditadas e certificadas na norma (FERNANDES; ABREU, 2008). A Figura 23 ilustra os processos de gerenciamento de serviços na visão da norma.

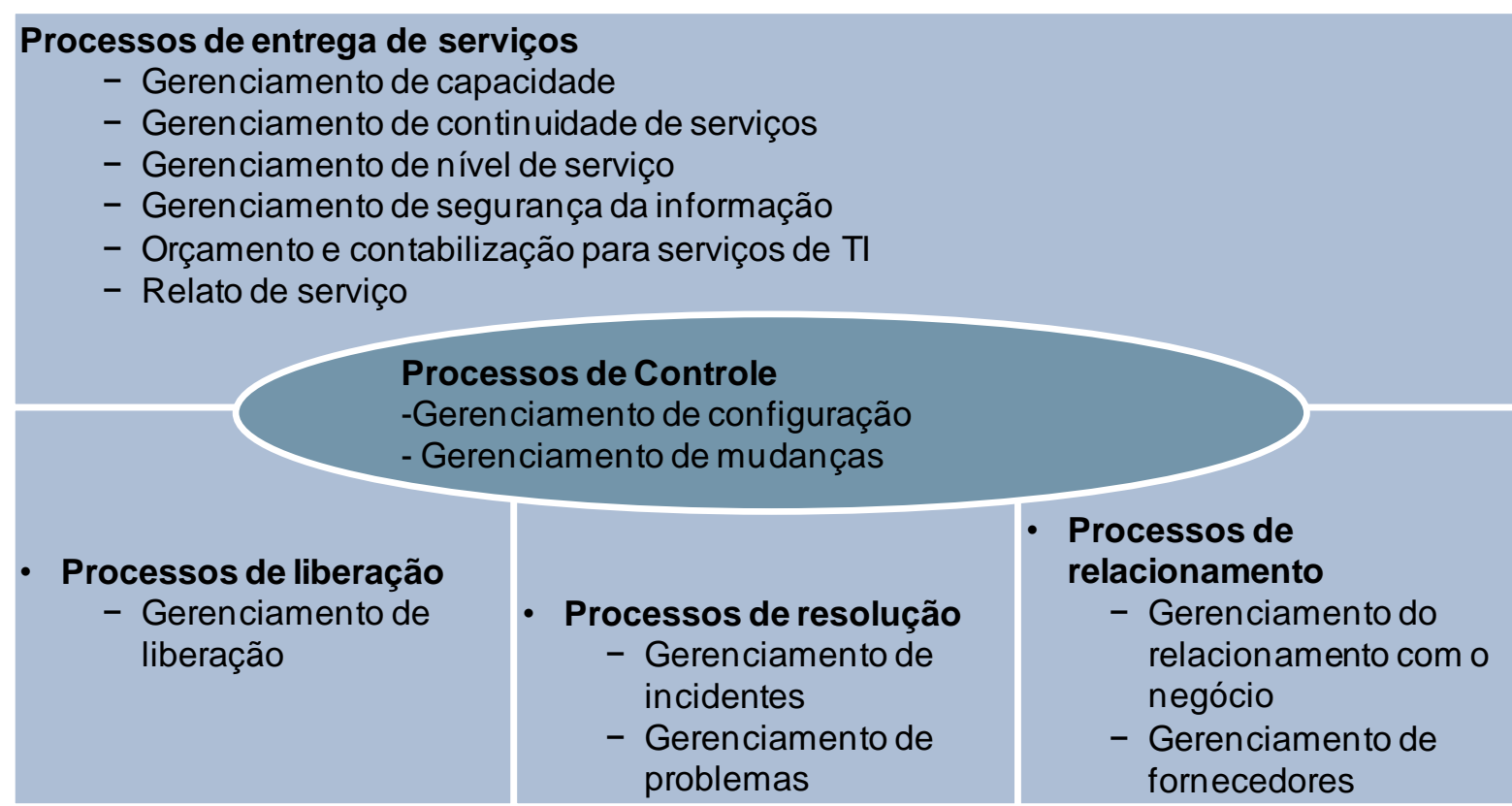

Figura 23: Processos ISO/IEC 20000 (adaptado de ISO, 2005 apud FERNANDES; ABREU, 2008)

A ISO 20000 pode ser utilizada em qualquer empresa que ofereça serviços de TI (interna ou externamente), além de poder ser utilizada em conjunto com outras normas, como a ISO 9001:2000 (qualidade) e a ISO/IEC 27001 (segurança da informação). Empresas certificadas em ISO 27001 atenderão aos requisitos de segurança da ISO 20000.

\subsection{ISO 27000}

A ISO 27001, derivada da BS7799-2:2002, provê um modelo para estabelecer, implantar, operar, monitorar, rever, manter e melhorar um Sistema de Gestão da Segurança da Informação (SGSI). Um SGSI pode ser definido como um sistema de gerenciamento utilizado para estabelecer e manter um ambiente seguro para a informação (ELOFF; ELOFF, 2003).

Um SGSI é análogo a um Sistema da Qualidade e é passível de certificação. Esta certificação se dá a partir das evidências (documentos e práticas) do conjunto de 
controles implantados e que devem ser continuamente executados e devidamente registrados.

Como a norma ISO 9001:2000, a ISO 27001:2005 foi construída sobre o modelo PDCA (Plan-Do-Check-Act) (MARTINS; SANTOS, 2005), bem como sobre o requisito de melhoria contínua (HUMPHREYS, 2006), como ilustra a Figura 24.

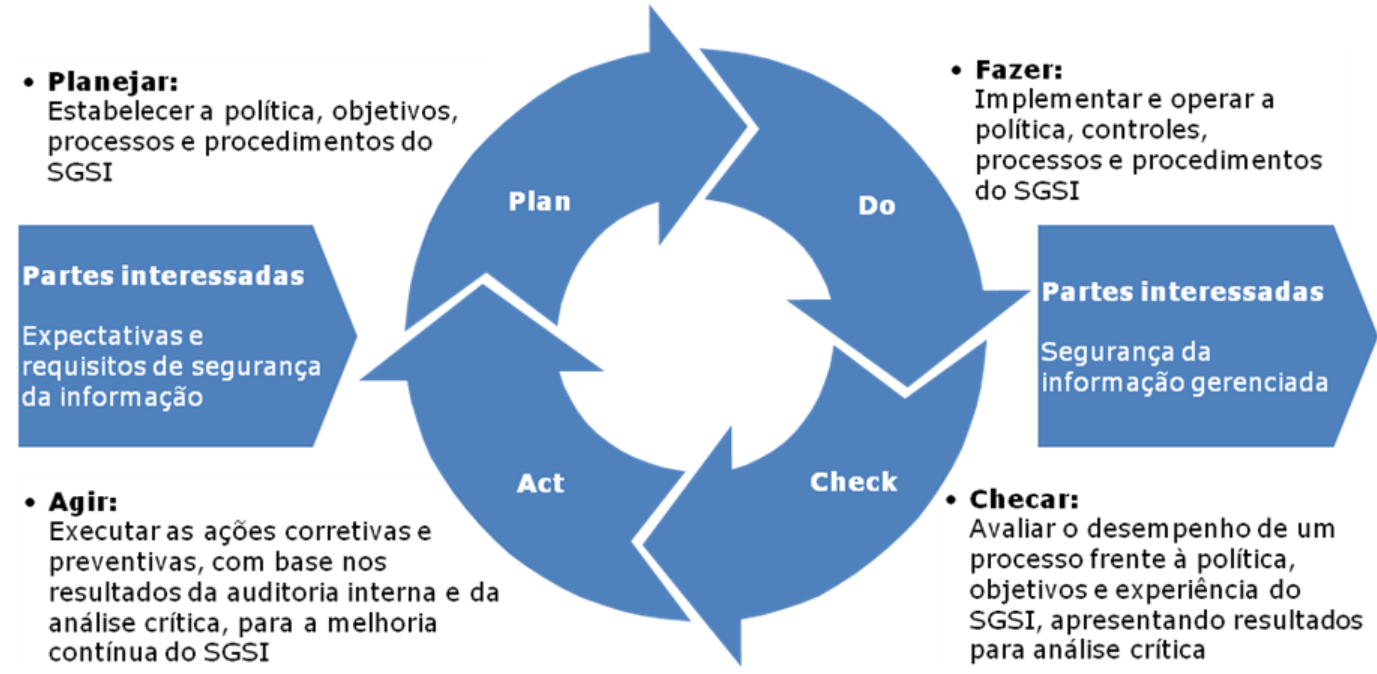

Figura 24 - PDCA (Adaptado de Fernandes e Abreu, 2008)

Atualmente, a série 27000 já contempla outras normas relacionadas à gestão de segurança da informação:

- ISO 27002: "Code of practice for information security management" (derivada da ISO 17799); estabelece as diretrizes e princípios gerais para iniciar, implantar, manter e melhorar a gestão da segurança da informação (substitui a ISO17799);

- ISO 27003 (em elaboração): "Information security management system implementation guidance"; fornece ajuda para a implantação de um SGSI;

- ISO 27004 (em elaboração): "Information security management measurement"; apresenta métodos para a avaliação e métricas de um SGSI;

- ISO 27005: "Information security risk management"; apresenta diretrizes para promover o gerenciamento de riscos de segurança da informação; 
- ISO 27006: "Requirements for bodies providing audit and certification of information security management systems"; guia para organizações que irão realizar a certificação de seus clientes (FERNANDES, ABREU, 2008).

Além da série 27000 , existem outras normas e padrões relacionados diretamente à segurança da informação, como a ISO/IEC TR 13335 (Guidelines for the Management of IT Security, GMITS), a BS25999 (gestão da continuidade do negócio), a ISO/IEC 15408 (Evaluation criteria for IT security, Common Criteria) e a ISO/IEC 27827 (Systems Security Engineering Capability Maturity Model, SSE$C M M$.

A série 27000 é muito conhecida e acaba tratando mais do que segurança da informação no âmbito de $\mathrm{Tl}$, incluindo aspectos de riscos, confidencialidade de documentos e acesso físico, por exemplo.

\subsubsection{7 eSCM-SP e eSCM-CL}

O eSCM-SP (The eSourcing Capability Model for Service Providers) e o eSCM-CL (The eSourcing Capability Model for Client Organizations) são modelos focados na gestão de outsourcing de projetos e serviços de TI, sendo o primeiro sob o ponto de vista das empresas prestadoras de serviços, e o segundo, sob o ponto de vista do cliente. Ambos foram criados pelo ITsqc (Information Technology Services Qualification Center) da Carnegie Mellon University (SOARES, 2008). O termo "eSourcing" refere-se à prestação de serviços habilitados por TI

O eSCM-SP possui oitenta e quatro práticas agrupadas em dez áreas de capacitação: gestão de riscos, gestão do conhecimento, gestão de pessoas, gestão da performance, gestão de ameaças, gestão da tecnologia, entrega do serviço, transferência do serviço, desenho e implementação do serviço, contratação (PINTO et al., 2005).

O ciclo de vida de sourcing (prestação do serviço) é divido em quatro blocos: iniciação, entrega, fechamento e contínua. Da mesma forma que outros modelos, este também possui cinco níveis de capacitação do fornecedor. 
O eSCM-CL tem por objetivo prover aos clientes um conjunto de melhores práticas para as atividades de sourcing, ajudar as organizações a estabelecer, gerenciar e melhorar suas relações de sourcing, ajudar os clientes a mitigar riscos, assegurar a satisfação dos interessados e avaliar suas próprias capacidades em serviços de sourcing de $\mathrm{TI}$.

O modelo possui noventa e cinco práticas agrupadas em dezessete áreas de capacitação: gestão da estratégia de sourcing, gestão da governança, gestão do relacionamento, gestão do valor, gestão da mudança organizacional, gestão de pessoas, gestão do conhecimento, gestão da tecnologia, gestão de ameaças, análise de oportunidades de sourcing, abordagem de sourcing, planejamento do sourcing, avaliação de fornecedor de serviço, acordos de serviços, transferência de serviços, gestão dos serviços contratados, encerramento do sourcing (SOARES, 2008).

O ciclo de vida de sourcing (prestação do serviço) é divido em cinco blocos: os quatro do eSCM-SP (iniciação, entrega, fechamento e contínua), mais a fase de análise, que contempla entender a situação atual, identificar oportunidade de sourcing, analisar as opções de sourcing e decidir ou não pelo sourcing (FERNANDES; ABREU, 2008).

Da mesma forma que outros modelos, este também possui cinco níveis de capacitação, que mostram o caminho de evolução do cliente de serviços rumo à excelência em gestão de sourcing.

O eSCM foi desenvolvido de forma a complementar outros modelos, como ITIL, COBIT, CMMi, entre outros, que não tratam, de forma integral, todas as questões críticas existentes na gestão da terceirização.

Um bom relacionamento de prestação de serviços demanda boas práticas por parte do cliente e por parte do fornecedor (MECENA, 2005). Com o eSCM, as empresas que provêm e as empresas que contratam serviços têm como desenvolver uma relação cliente - fornecedor melhor, gerando valor e reduzindo os riscos associados à terceirização. 
O modelo foca nas atividades relacionadas à terceirização, e não em todos os processos do cliente. Com isto, a combinação do eSCM com outros modelos também é bastante interessante. A ITIL, por exemplo, possui o processo de gerenciamento de fornecedores, que irá controlar a relação nas operações do dia-adia.

\subsection{PMBoK}

O PMBoK (Project Management Body of Knowledge) é um conhecido guia para gerenciamento de projetos. Gerenciamento de projetos é a aplicação de conhecimentos, habilidades, ferramentas e técnicas às atividades do projeto a fim de alcançar seus objetivos (PMI, 2004). O gerenciamento de projetos pode ser visto como um conjunto de práticas geralmente aceitas que estimulam governança, transparência e que podem fortalecer os vínculos entre estratégia e operação (ZAGUIR; MARTINS, 2006).

Um projeto é um empreendimento não repetitivo, caracterizado por uma sequência clara e lógica de eventos, com início, meio e fim, que se destina a atingir um objetivo claro e definido, sendo conduzido por pessoas dentro de parâmetros pré-definidos de tempo, custo, recursos envolvidos e qualidade (VARGAS, 2007).

O manual compreende cinco processos:

- Iniciação: define e autoriza o projeto ou uma fase do projeto;

- Planejamento: define ou refina os objetivos e planeja as ações necessárias para alcançar os objetivos e o escopo do projeto;

- Execução: integra pessoas e outros recursos para realizar o plano de gerenciamento do projeto;

- Monitoramento e controle: mede e monitora o progresso para identificar variações e tomar ações corretivas;

- Encerramento: formaliza a aceitação do produto, serviço ou resultado e conduz o projeto a um final ordenado. 
Agrupados nestes cinco processos, estão nove áreas de conhecimento. Estas nove áreas, por sua vez, agrupam quarenta e quatro processos, como ilustra a Figura 25.

O PMBoK pode ser aplicado em projetos de qualquer natureza. As empresas costumam desenvolver seus processos de gerenciamento de projetos baseados no conjunto de conhecimentos do PMBoK, buscando algo customizado às características de seus projetos.

Junto ao PMBoK, utiliza-se o OPM3 (Organizational Project Management Maturity Model) para avaliar a maturidade em gerenciamento de projetos. Maturidade em gerenciamento de projetos refere-se ao nível de sofisticação, intimidade e utilização das técnicas e procedimentos padrão destinados à execução de determinadas atividades do gerenciamento de projetos (JUCA JUNIOR; AMARAL, 2005).

O OPM3 considera três elementos básicos para sua implementação: conhecimento, avaliação e melhoria. $O$ modelo é baseado em um ciclo evolutivo de melhoria contínua, similar ao ciclo de Deming, ou PDCA (Plan-Do-Check-Act), sendo um bom guia para avaliar e planejar melhorias.

O PMBoK formaliza diversos conceitos em gerenciamento de projetos, como a própria definição de projeto e do seu ciclo de vida. O PMBoK não é uma metodologia, mas sim um conjunto de conhecimentos necessários para que se gerencie um projeto e, caso se deseje, seja desenvolvida uma metodologia de gerenciamento de projetos. 


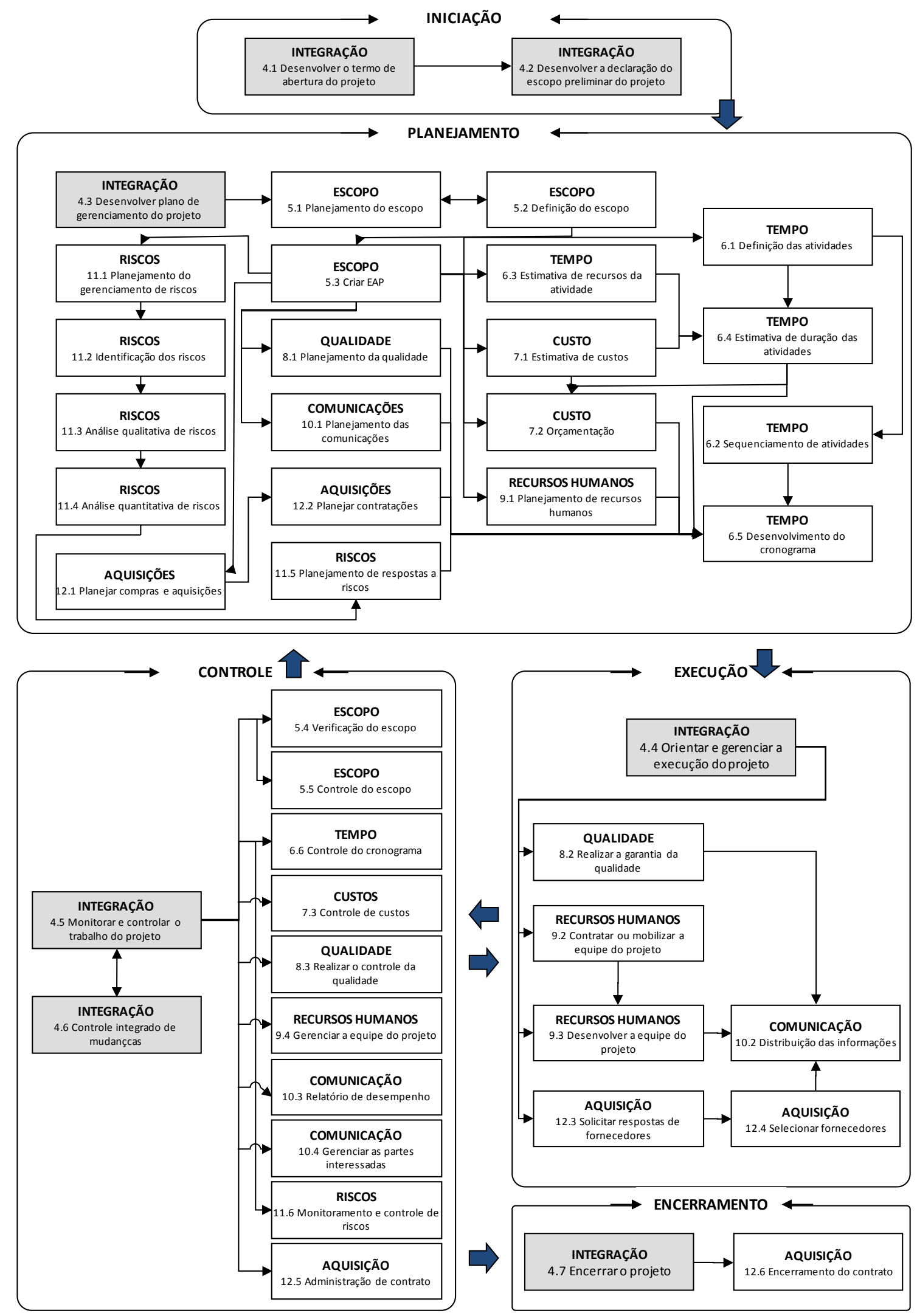

Figura 25 - Mapeamento entre os processos de gerenciamento de projetos e os grupos de processos de gerenciamento de projetos e as áreas de conhecimento (PMI, 2004) 


\subsection{PRINCE2}

A PRINCE (Projects IN Controlled Environments) é um método de gerenciamento de projetos especialmente popular na Europa e em alguns países asiáticos (QAI, s.d.). A PRINCE2 é baseada nos princípios do PMBoK (SIEGELAUB, 2004), mas diferentemente deste, que é um conjunto de conhecimentos, a PRINCE2 é, de fato, uma metodologia de gerenciamento de projetos (FERNANDES; ABREU, 2008). Os modelos podem ser vistos como complementares: enquanto o PMBoK é uma base de conhecimentos e boas práticas de gerenciamento de projetos, a PRINCE2 é um método de gerenciamento de projetos baseado em processos, orientando gerente e time na condução do projeto. O PMBOK Guide mostra "o que" é necessário fazer e a PRINCE2 mostra “como" fazer (RIBEIRO, 2010a).

A PRINCE2 é composta por oito processos e quarenta e cinco sub-processos, os quais definem as atividades que serão executadas ao longo do ciclo de vida do projeto. O modelo prevê também oito componentes que são como áreas de conhecimento que devem ser aplicadas de acordo com a necessidade, dentro das atividades de cada processo. A Figura 26 ilustra o relacionamento entre processos e componentes (ANGELO, 2008).

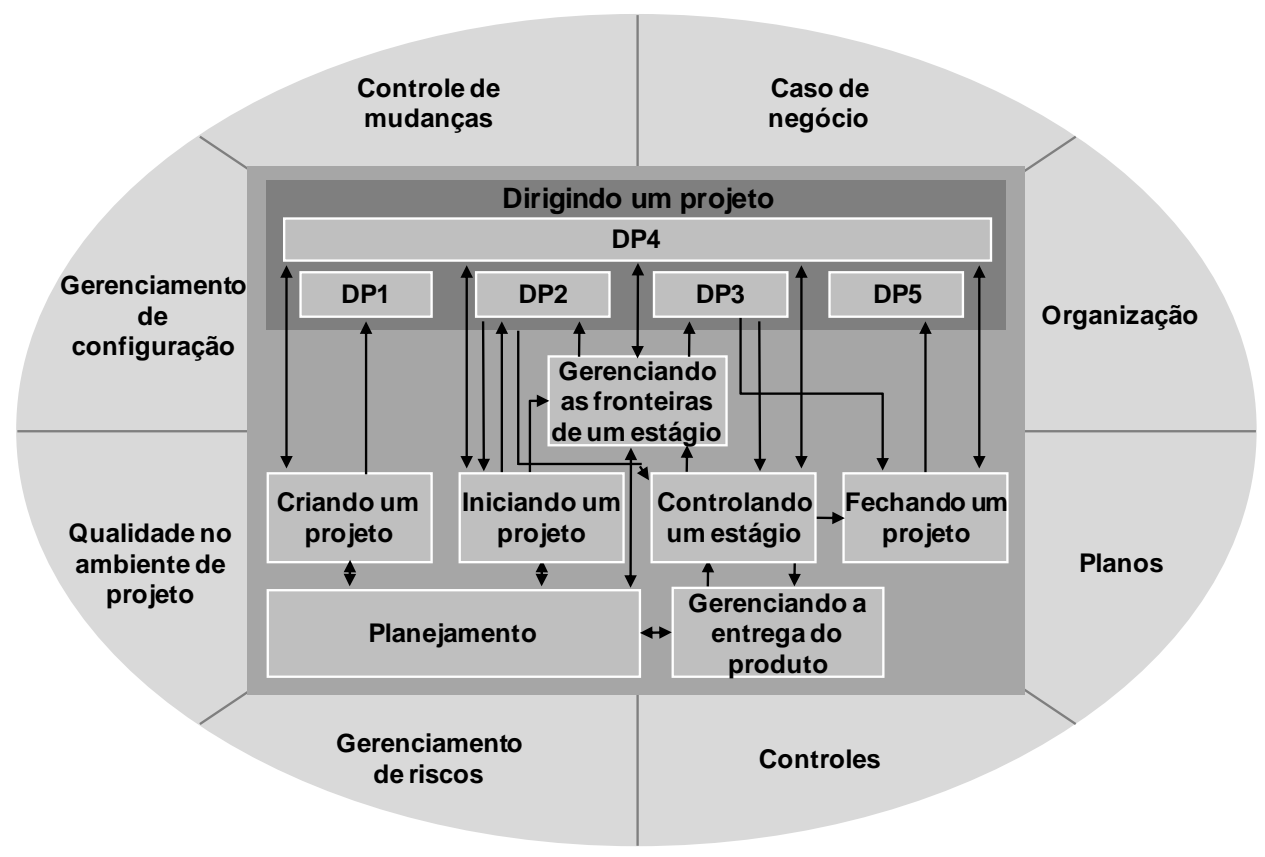

Figura 26 - Relacionamento entre processos e componentes na PRINCE2 (ANGELO, 2008) 
O modelo prevê três técnicas que auxiliam no planejamento e controle dos projetos:

- Planejamento baseado em produto: o planejamento e a definição do escopo são realizados a partir de uma estrutura denominada PBS (Product Breakdown Structure) muito similar à EAP (Estrutura Analítica de Projeto) do PMBoK, que ajuda na criação de pacotes de trabalho que facilitam a distribuição e o controle do trabalho para as equipes de desenvolvimento;

- Técnica de controle de mudanças: define os passos para o efetivo tratamento das mudanças solicitadas ao longo do projeto;

- Técnica de revisão da qualidade: processo estruturado para a revisão de qualidade (FERNANDES: ABREU, 2008).

Assim como é compatível com o PMBoK, a PRINCE2 também foi desenvolvida em conformidade com a ISO 9001, padrão para qualidade (SIEGELAUB, 2004).

A PRINCE2 é de caráter um pouco mais prático que o $\mathrm{PMBoK}$, sendo um método para gerenciamento de projetos, enquanto este é um corpo do conhecimento, utilizado para desenvolver métodos. A PRINCE2 possui, inclusive, ferramentas aplicáveis diretamente ao dia-a-dia do gerenciamento de projetos, como o caso de negócios, que também consta no Val IT como uma ferramenta para gestão de valor.

Da mesma forma que o PMBoK possui o modelo de maturidade OMP3, a PRINCE2 possui o P3M3 (Portfólio, Programme \& Project Management Maturity Model). O P3M3 possui como fundamento o $\mathrm{CMM}$ e, por isto, possui cinco níveis de maturidade: processo inicial; processo repetível; processo definido; processo gerenciado e processo otimizado. O P3M3 é empregado para avaliar o gerenciamento de projetos, programas e portfólio.

\subsection{Balanced Scorecard}

O BSC - Balanced Scorecard é uma forma abrangente de medição de desempenho (FAVARETTO, 2001) para planejamento e gestão da estratégia. O modelo surgiu através de uma pesquisa do Norton Institute, então um braço de pesquisa da KPMG 
sobre a medição de desempenho na organização do futuro. $O$ estudo foi motivado pela crença de que a medição de desempenho considerando apenas indicadores financeiros estava obsoleta. Por esta razão, o grupo de estudo passou a focalizar sua atenção para um scorecard multidimensional (FERNANDES; ABREU, 2008).

Os objetivos de curto e longo prazo são equilibrados através de quatro perspectivas:

- Financeira: trata dos resultados financeiros da empresa;

- Cliente: trata da satisfação, retenção e aquisição de clientes, segmentados por serviço;

- Processos internos: trata os processos como críticos para a entrega dos serviços/produtos;

- Aprendizado e crescimento: trata da satisfação interna e capacitação.

Cada perspectiva possui metas e cada meta possui objetivos, medidas, alvos e iniciativas.

As diferentes perspectivas da organização são concatenadas em um diagrama conhecido por mapa estratégico que descreve a estratégia da empresa relacionando objetivos distribuídos nas quatro dimensões (KALLÁS, 2003). É uma representação visual das relações de causa e efeito entre os objetivos estratégicos e representa como a empresa cria valor, sendo o "elo perdido" entre a formulação da estratégia e a sua execução.

O conceito do BSC tem sido aplicado nos processos de TI (GREMBERGEN, 2000). $\mathrm{Em} \mathrm{TI}$, o BSC deve ser usado durante o planejamento da $\mathrm{TI}$, assim como na gestão do dia-a-dia da realização da estratégia de TI (FERNANDES; ABREU, 2008).

São sugeridas quatro diferentes perspectivas para o BSC TI, como ilustra a Figura 27, a seguir: 


ORIENTAÇÃO A USUÁRIOS
Como os usuários vêem o departamento de TI?
Missão
Ser o fornecedor preferencial em sistemas de
informação
Estratégias
- fornecedor preferencial para aplicações
- fornecedor preferencial para operações
- parceria com usuários
- satisfação do usuário
EXCELÊNCIA OPERACIONAL
Qual eficientes e eficazes são os processos de TI?
Missão
Entregar aplicaçõese serviços de TI eficientese
eficazes
Estratégias
- desenvolvimentos eficientes e eficazes
operações eficientes e eficazes

CONTRIBUIÇÃO COM O NEGÓCIO
Como os gestores vêem o departamento de TI?
Missão
Obter uma contribuição justa do negócio para os
investimentos de TI
Estratégias
- controlar custos de TI
- valor dos projetos de TI para o negócio
- prover novas habilidades ao negócio
$\quad$ ORIENTAÇÃO PARA O FUTURO
Quão bem posicionada está a TI para atender a
$\quad$ necessidades futuras?
Missão
Desenvolver oportunidades para responder a
desafios futuros
Estratégias
- treinamento do pessoal de TI
- idade do portfolio de aplicações

Figura 27 - Padrão BSC TI (GREMBERGEN, 2000)

Cada uma dessas perspectivas deve ser traduzida em métricas para avaliar a situação atual e repetir a avaliação periodicamente. Os parâmetros devem estar mais relacionados aos objetivos do negócio do que aos objetivos organizacionais, o que leva a TI a pensar em termos de desempenho do negócio (KUMBAKARA, 2008).

Assim como para a empresa, para a área de TI é interessante usar o BSC para não avaliar os investimentos em $\mathrm{TI}$ apenas sob a perspectiva financeira. De acordo com LIMA et. al. (2009), na área de TI já existem várias aplicações do BSC por conta de sua adoção pela empresa, porém ainda há poucas informações sobre os resultados de sua aplicação. No entanto, os resultados de muitas empresas melhoram significativamente com a adoção de um BSC para TI.

O BSC é um dos modelos de desempenho mais difundidos. Dá foco ao que se busca e auxilia na implementação. O COBIT utiliza as perspectivas do BSC para derivar os objetivos do negócio e, então, definir os objetivos de TI. 


\subsection{Seis Sigma}

O Seis Sigma é uma metodologia para melhoria de qualidade de processos. O objetivo principal do modelo é a melhoria do desempenho do negócio através da melhoria do desempenho de processos, tendo como meta um processo que apresente 3,4 defeitos sobre um milhão ou o "sigma 6", que equivale a um rendimento de $99,9997 \%$ de resultados do processo isentos de defeitos. A metodologia Seis Sigma melhora qualquer processo de negócio através de constante revisão e ajuste no processo. A implantação do Seis Sigma utiliza como base a metodologia DMAIC (Define, Measure, Analyse, Improve and Control Definir, Medir, Analisar, Melhorar e Controlar) (LARSEN et al., 2006).

Para cada etapa do projeto são utilizadas ferramentas e técnicas de mercado, como diagrama de espinha de peixe (ou Diagrama de Ishikawa), testes de hipóteses, brainstorming, Balanced Scorecard e FMEA (Failure Mode and Effect Analysis), entre outros.

O modelo pode ser aplicado para projetos de melhoria de processos, gerenciamento do processo e para projetos de novos processos. Para TI, apesar de poucos dados sobre a aplicação de Seis Sigma, o modelo também pode ser utilizado.

Pode-se verificar que a metodologia DMAIC está alinhada com o processo de melhoria contínua da biblioteca ITIL v3, os chamados "7Rs": definir o que deve ser medido, o que pode ser medido, coletar dados, processar dados, analisar dados, apresentar e usar a informação. Pode-se também utilizar o conceito de melhoria contínua para o processo de gerenciamento de projetos para buscar reduzir os erros em projetos, utilizando, por exemplo, lições aprendidas.

Além disto, os processos da ITIL podem ser utilizados como entradas para o Seis Sigma. Por exemplo, estratégia do serviço, demanda e níveis de serviço entram na Definição; eventos, incidentes, capacidade, em Medição; problemas, continuidade, financeiro em Análise; mudanças e liberações, em Implementação; nível de serviço, capacidade, segurança, em Controle.

O Seis Sigma pode, ainda, ser utilizado para a melhoria de processos de gerenciamento de projetos. 
Existe também o "Lean" Seis Sigma, um modelo que combina o conceito da manufatura enxuta (lean), com foco na agilidade do processo, com o seis sigma, com foco na qualidade. O Lean Seis Sigma pode ser combinado, por exemplo, com - CMMi, gerando uma abordagem que integra métodos ágeis com desenho e desenvolvimento de processos para melhorar as habilidades de engenharia de software (SOFTWARE ENGINEERING PROCESS GROUP, 2008).

\subsection{TOGAF}

O TOGAF (The Open Group Architecture Framework) é um modelo composto por um método detalhado e uma série de ferramentas de suporte para o desenvolvimento de arquiteturas de $\mathrm{TI}$, permitindo o projeto, a avaliação e a construção da arquitetura corporativa e de TI mais compatível com as necessidades e características da organização (THE OPEN GROUP, 2002). Um dos objetivos do modelo é padronizar um método para o desenvolvimento de uma arquitetura empresarial, além de possibilitar a interoperabilidade entre arquiteturas e componentes e garantir a reutilização de componentes. O modelo pode ser usado junto com outros frameworks, como o Zachman Framework ou o Federal Enterprise Architecture (FEA), por exemplo.

Para o TOGAF, arquitetura tem dois significados, dependendo do contexto:

- Descrição formal de um sistema ou um plano bastante detalhado para guiar a sua implementação;

- A estrutura de componentes, seu interrelacionamento e os princípios e guias que direcionam seu desenho e evolução.

O ADM (Architecture Development Method) é o núcleo do modelo e consiste em um método iterativo para projeto e implantação da arquitetura escolhida. A Figura 28 ilustra o ADM. 


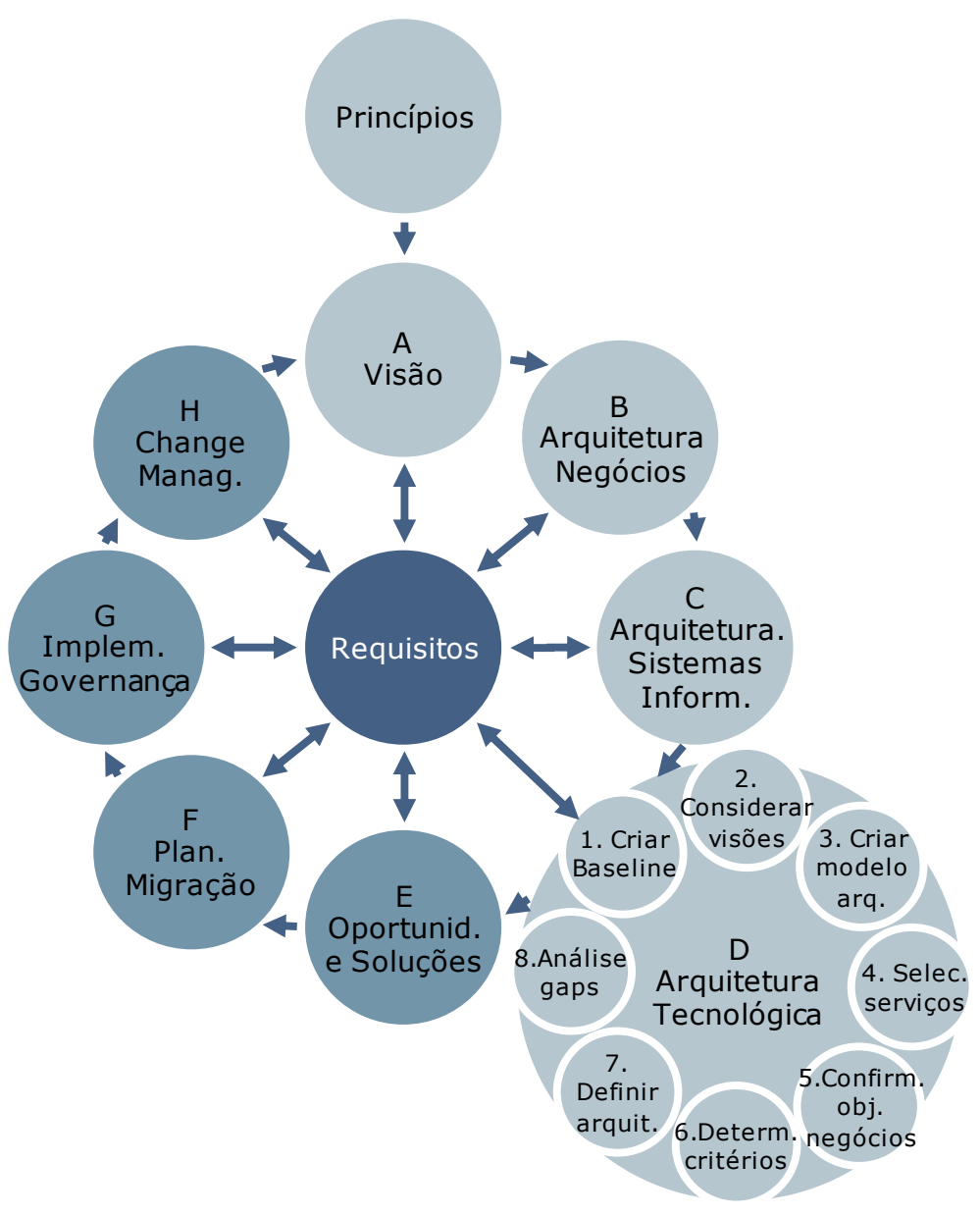

Figura 28 - TOGAF Architecture Development Method (adaptado de THE OPEN GROUP, 2009)

Junto a este método, podem ser utilizados os repositórios de arquiteturas e padrões do TOGAF, como:

- ADM Guidelines and Techniques, um conjunto de diretrizes sobre como utilizar o ADM, como aplicá-lo a projetos de diferentes tamanhos, como utilizar o TOGAF para SOA (Service-Oriented Architecture) etc.;

- Architecture Content Framework, um padrão para artefatos arquiteturais, componentes e entregáveis;

- Enterprise Continuum: discute taxonomias apropriadas e ferramentas para categorizar e armazenar as saídas das atividades referentes à arquitetura em uma empresa; 
- Reference Models: uma seleção de modelos de arquitetura de referência, incluindo a TOGAF Foundation Architecture e o modelo de referência de integração de sistemas III-RM;

- Architecture Capability Framework: diretrizes sobre como estabelecer e operar uma função de arquitetura dentro de uma empresa, incluindo processos, conhecimentos necessários, papeis e responsabilidades (KELLER, 2009).

Vários artefatos derivados de modelos de melhores práticas como COBIT, ITIL, CMMi etc. podem estar nos repositórios de padrões e serem empregados na implementação de arquiteturas relativas à TI (FERNANDES; ABREU, 2008).

O TOGAF pode ser utilizado para desenvolver arquiteturas para os mais diversos setores, utilizando um modelo combinado com melhores práticas de mercado e com os padrões da empresa. Seu principal componente é o ADM.

\subsection{ISO/IEC 38500}

Lançada em 2008, ISO/IEC 38500:2008 é um padrão internacional para Governança de TI que busca avaliar, direcionar e monitorar o uso da TI, aplicável a qualquer tipo de organização. A norma estabelece um modelo de Governança de TI e fornece aos gestores uma estrutura de princípios para avaliação, gestão e monitoramento de $\mathrm{Tl}$, auxiliando-os a encontrar um ponto de equilíbrio entre riscos e o retorno sobre investimentos (CALDER, 2008).

De acordo com Alberto (2010) alguns domínios relativos à Governança de Tl já possuem suas respectivas normas, como a ISO 20000 para Gerenciamento de Serviços de TI, a ISO 27001 para segurança da informação e a ISO 9000 para qualidade de processos. No entanto, reconheceu-se a necessidade de um padrão específico para governança.

A norma surgiu do esboço da ISO/IEC 29382 que define seis princípios para a governança (38500.ORG, 2008): 
- Responsabilidade: estabelecer responsabilidades facilmente compreensíveis para a Tl;

- Estratégia: planejar a TI para que ela ofereça o melhor suporte à organização;

- Aquisições: validar as aquisições de TI, buscando equilíbrio entre benefícios, oportunidades, custos e riscos, tanto no curto, quanto no longo prazo;

- Desempenho: garantir a melhor performance da TI sempre que necessário, medindo e monitorando;

- Conformidade: garantir a conformidade da TI junto à legislação e demais regulamentos, buscando transparência;

- Comportamento humano: garantir que a utilização dos recursos de TI respeitem os fatores humanos. (ALBERTO, 2010 e NASCIMENTO, 2009)

A norma descreve governança corporativa de maneira alinhada à OECD e define a Governança de $\mathrm{TI}$ como o sistema pelo qual o uso atual e futuro da Tl é dirigido e controlado para dar suporte à organização e monitorar seu uso para realizar os seus planos.

A norma é clara na distinção entre governança e gerenciamento. Gerenciamento é o sistema de controles e processos necessário para alcançar os objetivos estratégicos estabelecidos pela direção da empresa, sujeito às políticas e ao monitoramento impostos pela governança (TEIXEIRA, 2010).

A ISO/IEC 38500 pode ser aplicada em qualquer tipo de organização, independentemente do seu tamanho e serve de referência para implementar a Governança de $\mathrm{TI}$ de forma que permita avaliar, dirigir e monitorar o uso da $\mathrm{TI}$ (AMORIM, 2009). A Figura 29 ilustra o modelo do ciclo Avaliar-Dirigir-Monitorar da ISO 38500 . 


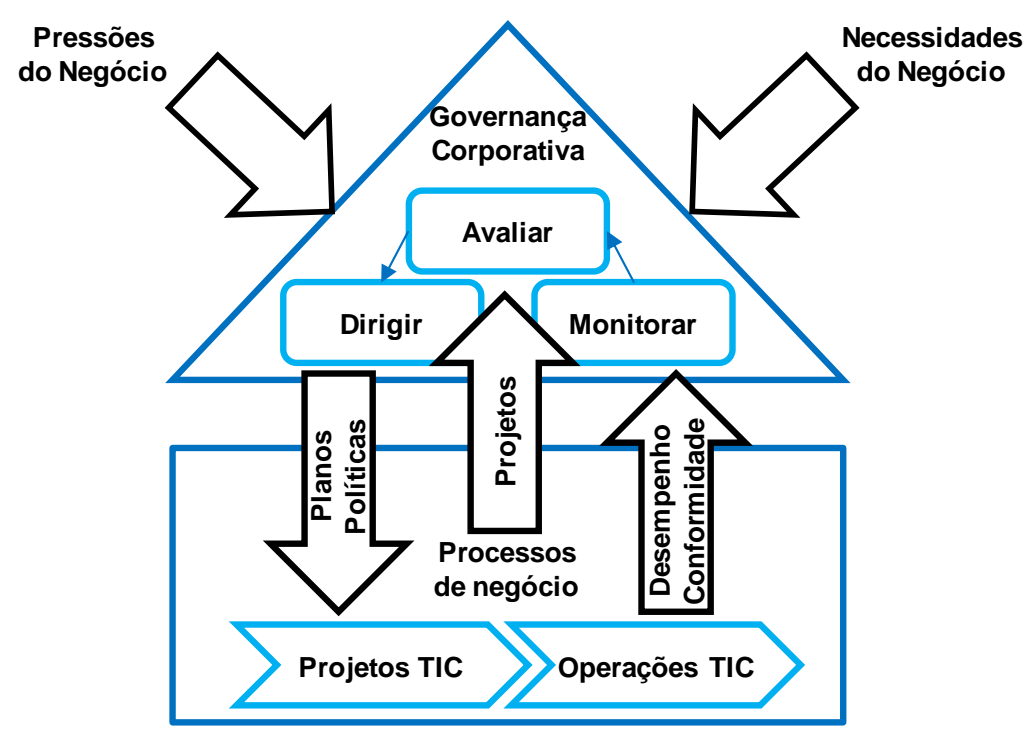

Figura 29 - Modelo do ciclo Avaliar-Dirigir-Monitorar para a Governança de TI de acordo com a ISO 38500 (TEIXEIRA, 2010)

Dada a pouca idade da norma, não são encontradas muitas referências acadêmicas e de mercado acerca da utilização. Os seis princípios e o ciclo avaliar-dirigirmonitorar são importantes aspectos a considerar no desenvolvimento de um modelo de Governança de TI e os modelos COBIT, ITIL e VAL IT, por exemplo, transformam os princípios da ISO 38500 em ações:

- Responsabilidade: COBIT e VAL IT;

- Estratégia: COBIT (mais especificamente, domínio PO) e Val IT;

- Aquisições: COBIT (mais especificamente, domínio AI) e VAL IT;

- Desempenho: COBIT (mais especificamente, DS e ME) e ITIL;

- Conformidade: COBIT e ITIL;

- Comportamento humano: COBIT.

Chaudhari (2010) comenta que, em sua forma atual, a ISO 38500 é um pouco incompleta para ser utilizada como padrão único, mas é uma boa forma de as empresas verificaram seu estado em Governança de TI. A ISO já planeja uma 
segunda versão da norma, que irá focar mais em direcionamentos para implementação.

\title{
2.1.4.2.14 Analise Comparativa Geral dos Modelos de Governança
}

\author{
Os modelos descritos dão o suporte necessário para que a Governança de TI possa
}

cumprir seus objetivos. Resumindo os principais modelos, tem-se o seguinte:

Tabela 4 - Modelos e melhores práticas de mercado: descrição e aplicabilidade

\begin{tabular}{|c|c|c|}
\hline Modelo & Descrição & Aplicabilidade \\
\hline BSC & $\begin{array}{l}\text { Balanced Scorecard, metodologia de planejamento } \\
\text { e gestão da estratégia. }\end{array}$ & $\begin{array}{l}\text { Apoio ao planejamento } \\
\text { estratégico de } \mathrm{Tl} \text { metas e } \\
\text { métricas. }\end{array}$ \\
\hline COBIT & $\begin{array}{l}\text { Control Objectives for Information and related } \\
\text { Technology, modelo para auditoria e controle de } \\
\text { processos de Tl. }\end{array}$ & $\begin{array}{l}\text { Alinhamento da TI ao negócio e } \\
\text { serviços de } \mathrm{TI} \text {, avaliação dos } \\
\text { processos. }\end{array}$ \\
\hline Val IT & Modelo para gestão do valor e investimentos de TI. & $\begin{array}{l}\text { Alinhamento da Tl ao negócio, } \\
\text { análise dos investimentos, } \\
\text { geração de valor. }\end{array}$ \\
\hline ISO 38500 & $\begin{array}{l}\text { Norma de Governança de TI que estabelece uma } \\
\text { estrutura de princípios para avaliação, gestão e } \\
\text { monitoramento de TI. }\end{array}$ & Governança de TI. \\
\hline ITIL v3 & $\begin{array}{l}\text { Information Technology Infrastructure Library, } \\
\text { conjunto de melhores práticas para definição da } \\
\text { estratégia, desenho, transição, operação e } \\
\text { melhoria contínua do serviço. }\end{array}$ & $\begin{array}{l}\text { Desenvolvimento de serviços de } \\
\text { TI e melhoria contínua. }\end{array}$ \\
\hline ISO 27000 & $\begin{array}{l}\text { Código de práticas para a gestão da segurança da } \\
\text { informação }\end{array}$ & $\begin{array}{l}\text { Desenvolvimento e operação de } \\
\text { processos de segurança de } \\
\text { informação. }\end{array}$ \\
\hline TOGAF & $\begin{array}{l}\text { The Open Group Architecture Framework, modelo } \\
\text { para desenvolvimento e implementação de } \\
\text { arquiteturas de negócio, aplicações e tecnologia. }\end{array}$ & $\begin{array}{lcr}\text { Arquitetura } & \text { empresarial } & - \\
\text { avaliação } & \text { do negócio } & \text { a } \\
\text { aspectos } & \text { técnicos } & \text { da } \\
\text { arquitetura. } & & \end{array}$ \\
\hline PMBoK & $\begin{array}{l}\text { Project Management Body of Knowledge, base de } \\
\text { conhecimento em gestão de projetos }\end{array}$ & $\begin{array}{l}\text { Implementação } \\
\text { gerenciamento de projetos. }\end{array}$ \\
\hline OPM3 & $\begin{array}{l}\text { Organizational Project Management } \\
\text { Model, um modelo de maturity } \\
\text { gerenciamento de projetos. }\end{array}$ & $\begin{array}{l}\text { Avaliação da maturidade em } \\
\text { gerenciamento de projetos } \\
\text { (relacionado ao PMBoK). }\end{array}$ \\
\hline PRINCE2 & $\begin{array}{l}\text { Project in Controlled Environments, metodologia } \\
\text { de gerenciamento de projetos }\end{array}$ & $\begin{array}{l}\text { Implementação } \\
\text { gerenciamento de projetos. }\end{array}$ \\
\hline P3M3 & $\begin{array}{l}\text { Portfólio, Programme \& Project Management } \\
\text { Maturity Model, modelo de maturidade para o } \\
\text { gerenciamento de projetos, programas e portfólio. }\end{array}$ & $\begin{array}{l}\text { Avaliação da maturidade em } \\
\text { gerenciamento de projetos } \\
\text { (relacionado à PRINCE2) }\end{array}$ \\
\hline CMMi & $\begin{array}{l}\text { Capability Maturity Model Integration, processos } \\
\text { para desenvolvimento de produtos e projetos de } \\
\text { software, para aquisição e serviços. }\end{array}$ & $\begin{array}{l}\text { Processos de } \quad \text { de, } \\
\text { desenvolvimento de software, } \\
\text { aquisições e serviços. }\end{array}$ \\
\hline eSCM-SP & $\begin{array}{l}\text { The eSourcing Capability Model for Service } \\
\text { Providers, trata de outsourcing em serviços que } \\
\text { usam TI de forma intensiva. }\end{array}$ & $\begin{array}{l}\text { Estratégia de outsourcing, } \\
\text { operação e controle de para } \\
\text { fornecimento de serviços. }\end{array}$ \\
\hline eSCM-CL & $\begin{array}{l}\text { The eSourcing Capability Model for Client } \\
\text { Organization, conjunto de práticas para que o } \\
\text { cliente defina a estratégia e o gerenciamento do } \\
\text { outsourcing de serviços de } \mathrm{TI} \text { ou fortemente }\end{array}$ & $\begin{array}{l}\text { Estratégia de outsourcing, } \\
\text { operação e controle de serviços } \\
\text { de terceiros. }\end{array}$ \\
\hline
\end{tabular}


A Figura 30 demonstra onde cada modelo se encaixa, conforme análise realizada acima. As ferramentas estão alocadas nas categorias em que predominam, mas também se encaixam em outras categorias em menor grau. A predominância é indicada pelas cores mais fortes - cores mais fracas indicam relação mais fraca e também pelos números - "1" indica relação mais forte.

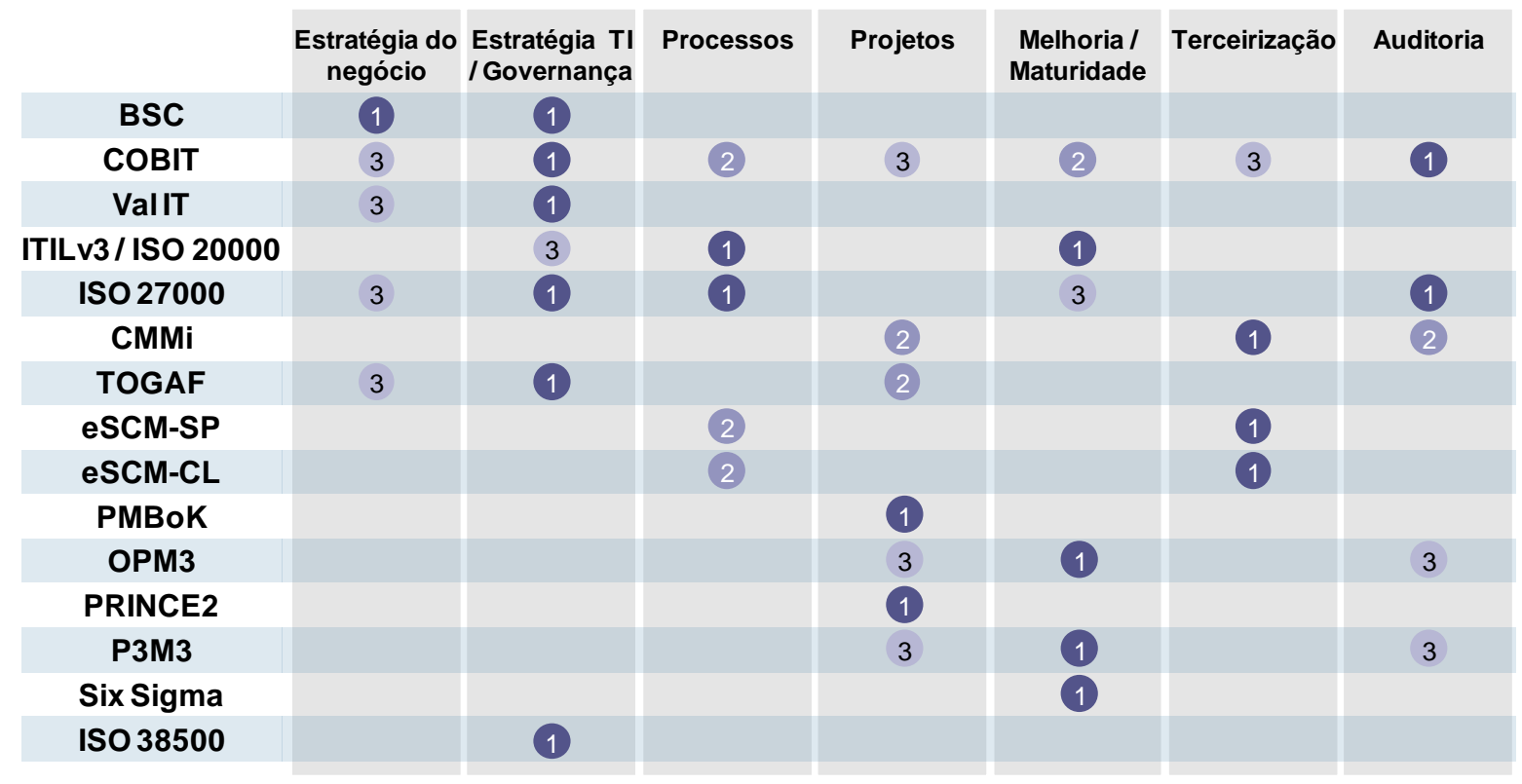

Figura 30 - Análise do âmbito de aplicação de cada melhor prática

O estudo "IT Governance Global Status Report - 2008" levantou dados sobre o uso dos modelos citados, como ilustrado na Figura 31. Os modelos mais utilizados, de acordo com a pesquisa, são a ITIL (que, de acordo com a pesquisa, não é exatamente um modelo de governança, mas sim um modelo de entrega de serviços) e a ISO 20000.

Esta mesma pesquisa detectou que o conhecimento a respeito do COBIT ultrapassa $50 \%$ dos entrevistados e a adoção gira em torno de 30\%. De 25 a 35\% dos entrevistados utilizam o COBIT de forma estrita e 50\% afirmam utilizá-lo como uma das fontes de referência (ITGI; PRICEWATERHOUSECOOPERS, 2008). 


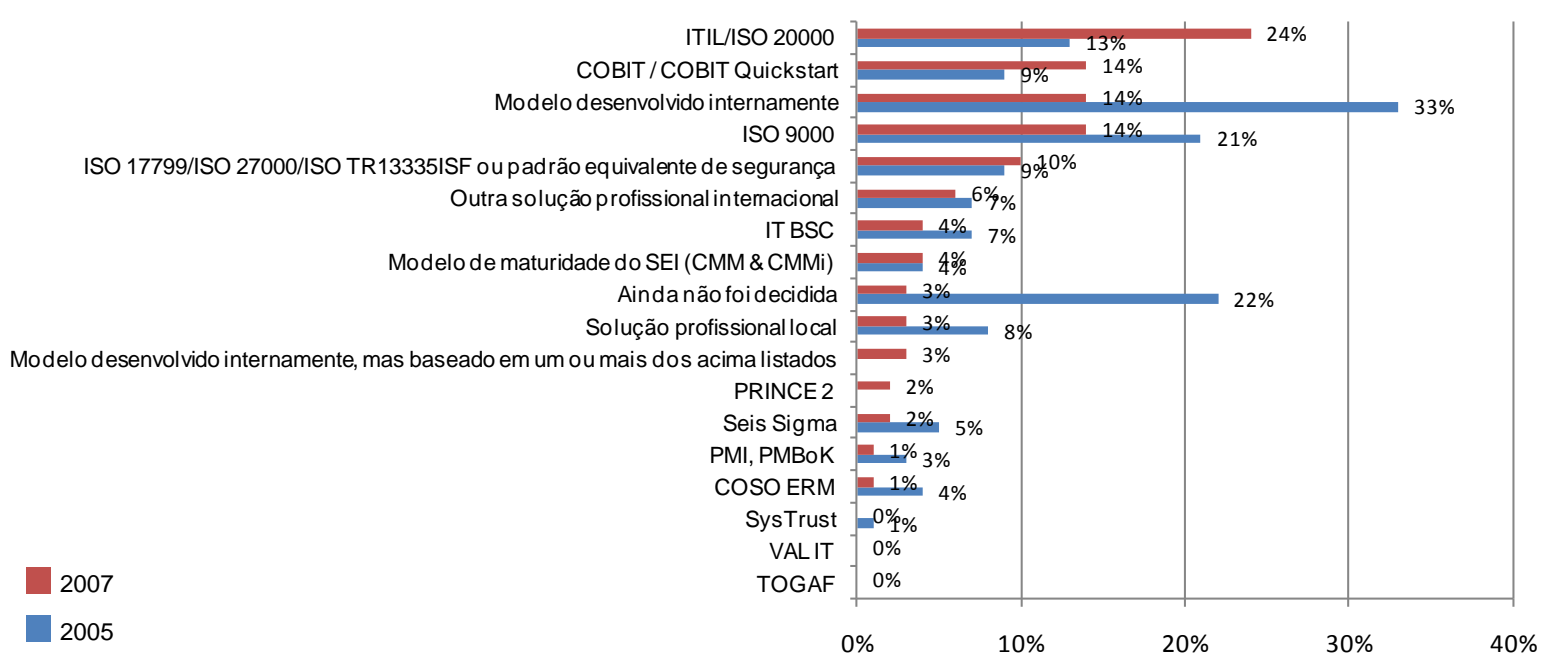

Figura 31 - Modelos de governança utilizados (ITGI; PRICEWATERHOUSECOOPERS, 2008)

Outra pesquisa também buscou levantar os modelos utilizados pelas empresas (RODRIGUES et al., 2009). A ITIL foi apontada como o modelo estrutural ou sistema de padronização de processos e atividades de TI mais adotado pelos seus executivos. O PMBoK e PRINCE2, o CobiT e as normas relacionadas à segurança da informação também são bastante utilizadas. Já o TOGAF, talvez por ser uma prática recente, ainda possui baixa utilização. A Figura 32 demonstra os resultados obtidos na pesquisa.

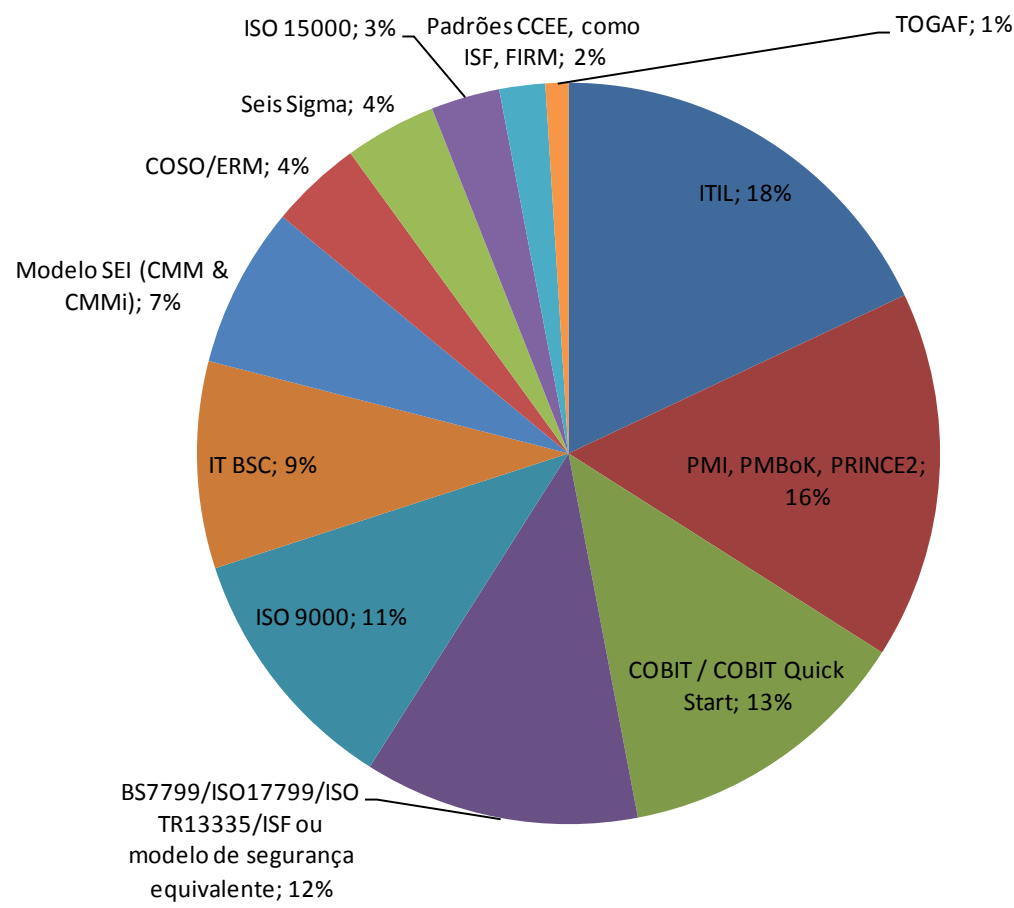

Figura 32 - Estruturas / processos de gestão (RODRIGUES et al., 2009) 
De maneira geral, as empresas podem criar seus próprios modelos ou adotar padrões combinados para atender a suas necessidades. Embora haja certa sobreposição entre os modelos, na maioria das vezes eles podem ser complementares (GAMA; MARTINELLO, 2006). De acordo com o estudo do ITGI e da PricewaterhouseCoopers (2008), as soluções internas geralmente são baseadas no COBIT, ITIL e ISO 9000 (padrão de qualidade).

2.4.1.3 Combinação de modelos de governança de $\mathrm{TI}$ e melhores práticas

Os pesquisadores têm uma opinião unânime de que uma estrutura ótima e universal de Governança de TI não existe (BROWN; GRANT, 2005), mas algumas combinações genéricas entre modelos e melhores práticas podem ser desenvolvidas, adaptando-as a cada realidade. Muitos trabalhos têm sido feitos com o intuito de criar as melhores soluções, customizadas à situação de cada empresa.

Clementi (2007) especifica em seu trabalho um método de criação de modelo de gerenciamento de serviços de $\mathrm{Tl}$ a partir de modelos existentes para auxiliar na implantação de uma gestão de serviços de TI mais eficiente e eficaz do que através da utilização isolada dos modelos adotados na sua construção.

Para testar o método, o autor utilizou dois dos modelos mais conhecidos, o COBIT e a ITIL, gerando o modelo GSS-COBITIL. Este modelo engloba os processos de gerenciamento de suporte de serviços de TI da versão dois da ITIL: gerenciamento de incidentes, gerenciamento de problemas, gerenciamento de configuração, gerenciamento de mudanças e gerenciamento de liberação.

O GSS-COBITIL, por combinar ferramentas de forma alinhada ao negócio, permite uma implantação mais consistente do gerenciamento de suporte de serviços de $\mathrm{TI}$, focando tanto em controle quanto em execução, de forma mais eficiente e eficaz (CLEMENTI, 2007).

Apesar de os exemplos utilizados serem COBIT e ITIL, o método é aplicável a outros modelos. A Figura 33 ilustra o método proposto. 


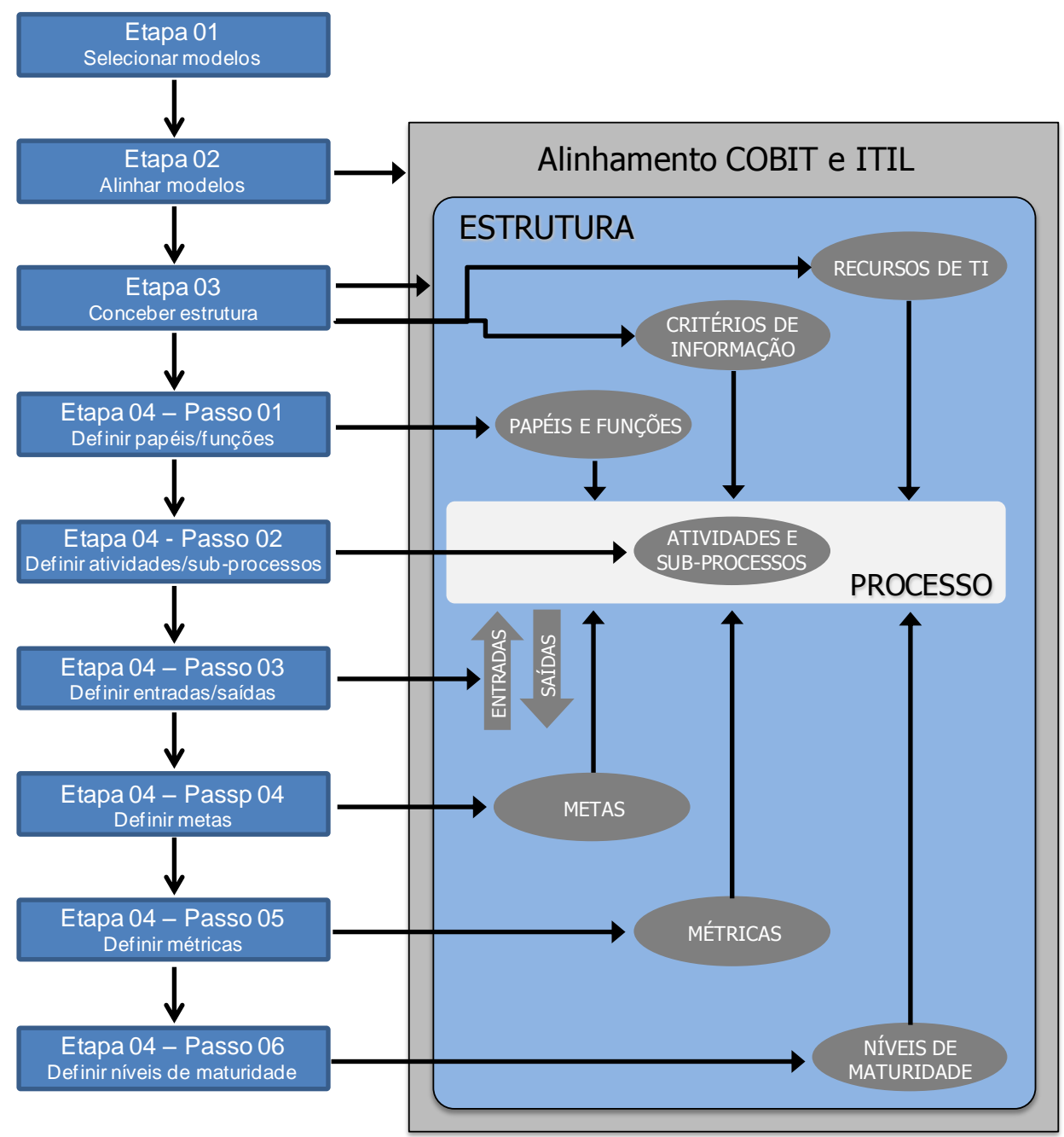

Figura 33 - Método de criação e estrutura do modelo proposto por Clementi (CLEMENTI, 2007)

O ITGI publica uma série de trabalhos que buscam alinhar diferentes modelos, como COBIT, ITIL e ISO 27002 (ITGI; OGC, 2008), COBIT e PMBoK, COBIT e TOGAF, entre outros (ISACA, s.d.). A Figura 34 ilustra um exemplo da relação apresentada nesta publicação. 
Domínio COBIT 4.1: Plan and Organize (PO)

PO2 Definir a arquitetura da informação

\begin{tabular}{|c|c|c|c|}
\hline COBIT 4.1 - Objetivo de Controle & Áreas Chave & ITIL V3 - Informação de suporte & $\begin{array}{l}\text { ISO/IEC 27002:2005 - Informação } \\
\text { de suporte }\end{array}$ \\
\hline $\begin{array}{l}\text { PO2.2 Dicionário de Dados } \\
\text { Corporativos e Regras de Sintaxe de } \\
\text { Dados }\end{array}$ & $\begin{array}{l}\text { - Dicionário de dados corporativo } \\
\text { - Entendimento comum dos dados }\end{array}$ & $\begin{array}{l}\text { - SD } 5.2 \text { Gerenciamento de dados e } \\
\text { informação } \\
\text { • SD } 7 \text { Considerações tecnológicas }\end{array}$ & $\begin{array}{l}\text { - 7.1.1.1 Inventário de ativos } \\
\text { - 11.1.1 Política de controle de } \\
\text { acesso }\end{array}$ \\
\hline $\begin{array}{l}\text { PO2.3 Esquema de Classificação de } \\
\text { Dados }\end{array}$ & $\begin{array}{l}\text { - Classes de informação } \\
\text { - Propriedade } \\
\text { - Retenção } \\
\text { - Regras de acesso } \\
\text { - Níveis de segurança para cada } \\
\text { classe de informação }\end{array}$ & $\begin{array}{l}\text { - SD } 5.2 \text { Gerenciamento de dados e } \\
\text { informação }\end{array}$ & $\begin{array}{l}\text { - } 7.2 .1 \text { Diretrizes de classificação } \\
\text { - 10.7.1 Gerenciamento de dados } \\
\text { removíveis } \\
\text { - 10.8.1 Políticas e procedimentos } \\
\text { para intercâmbio de informações } \\
\text { - 10.8.2 Acordos para intercâmbio } \\
\text { - 11.1.1 Política de controle de } \\
\text { acesso }\end{array}$ \\
\hline PO2.4 Gerenciamento de integridade & $\begin{array}{l}\text { - Integridade e consistência de } \\
\text { dados }\end{array}$ & $\begin{array}{l}\text { - SD } 5.2 \text { Gerenciamento de dados e } \\
\text { informação } \\
\text { - ST } 4.7 \text { Gerenciamento do } \\
\text { conhecimento }\end{array}$ & \\
\hline
\end{tabular}

Figura 34 - Exemplo de mapeamento COBIT - ITIL - ISO 27001 (ITGI, 2008)

Existem diversas outras publicações que buscam entender e mapear as relações entre melhores práticas. Van Sante e Ermers (2009) apresentam a ITIL e o TOGAF como modelos que podem ser complementares, como ilustram a Figura 35 e a Figura 36.

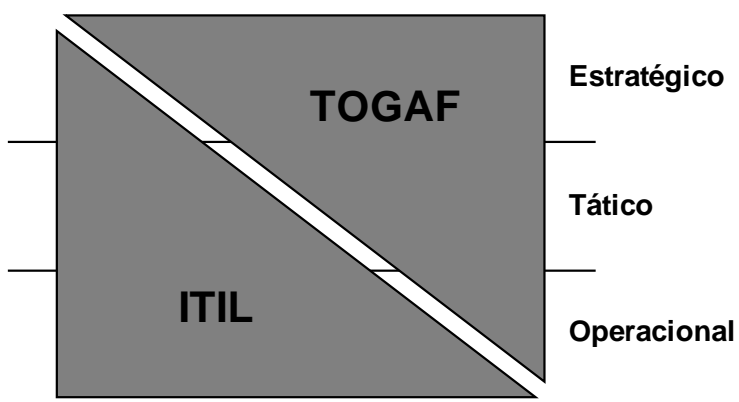

Figura 35 - Os domínios e papeis da ITIL e TOGAF dentro de uma organização (RADHAKRISHNAN, 2008 apud VAN SANTE; ERMERS, 2009)

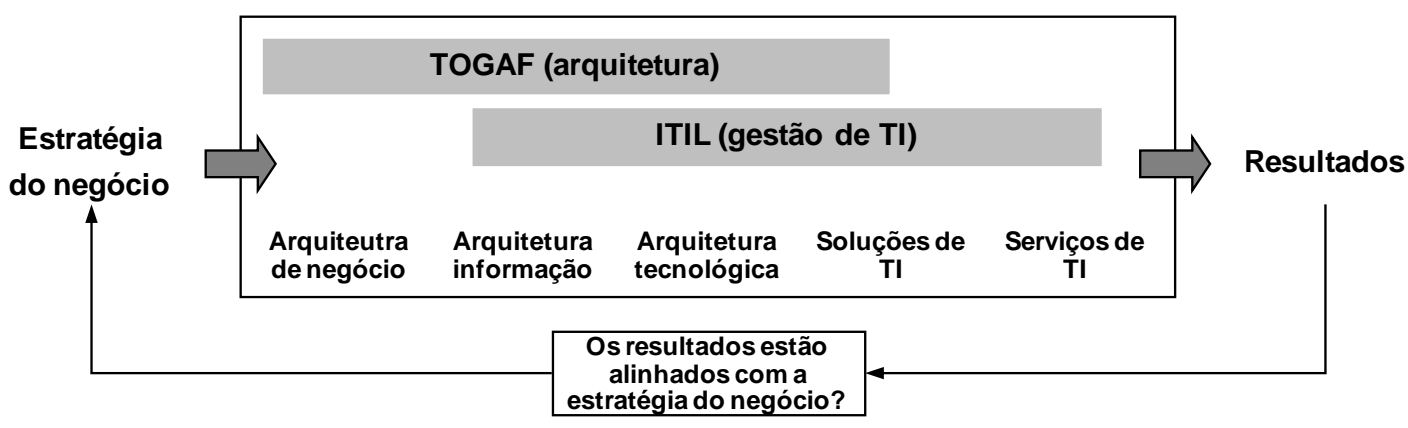

Figura 36 - Escopos da ITIL V3 e do TOGAF (VAN SANTE; ERMERS, 2009) 
O Val IT é apresentado por Voon e Salido (2009) como um modelo que estende e complementa o COBIT, como ilustra a Figura 37.

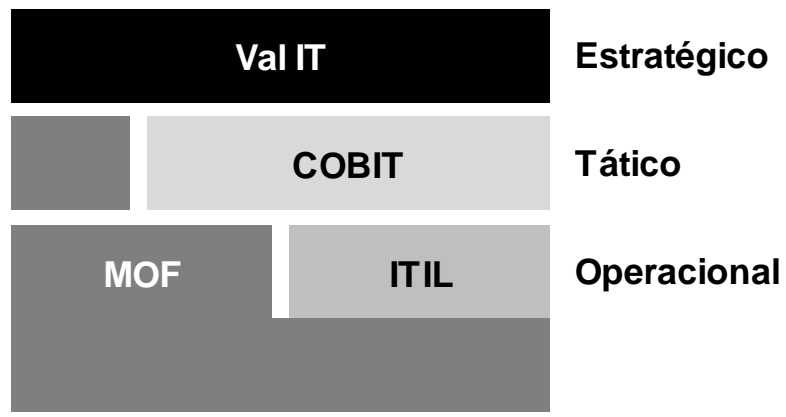

Figura 37 - COBIT e Val IT (VOON; SALIDO, 2009)

Sotille (2010) apresenta um paralelo entre o CMM e o PMBoK para projetos de software, como ilustra a Figura 38.

\begin{tabular}{|cc|}
\hline CMM - Nível 2 & PMBoK \\
\hline Gerência de Requisitos & Gerência do Escopo \\
\hline Planejamento de Projeto & Gerência do Tempo \\
\hline Acompanhamento e Supervisão & Gerência de Custo \\
\hline \hline Subcontratação & Gerência dos Riscos \\
\hline Garantia da Qualidade & Gerência das Comunicações \\
\hline \hline Gerência de Configuração & Gerência dos Recursos Humanos \\
\hline \hline
\end{tabular}

Figura 38 - CMM \& PMBoK (SOTILLE, 2010)

Toomey (2008) apresenta um estudo de caso em que a ISO 38500 é vista como a ligação que faltava para a criação da verdadeira Governança de $\mathrm{TI}$, em conjunto com outros modelos, como ilustra a Figura 39. 


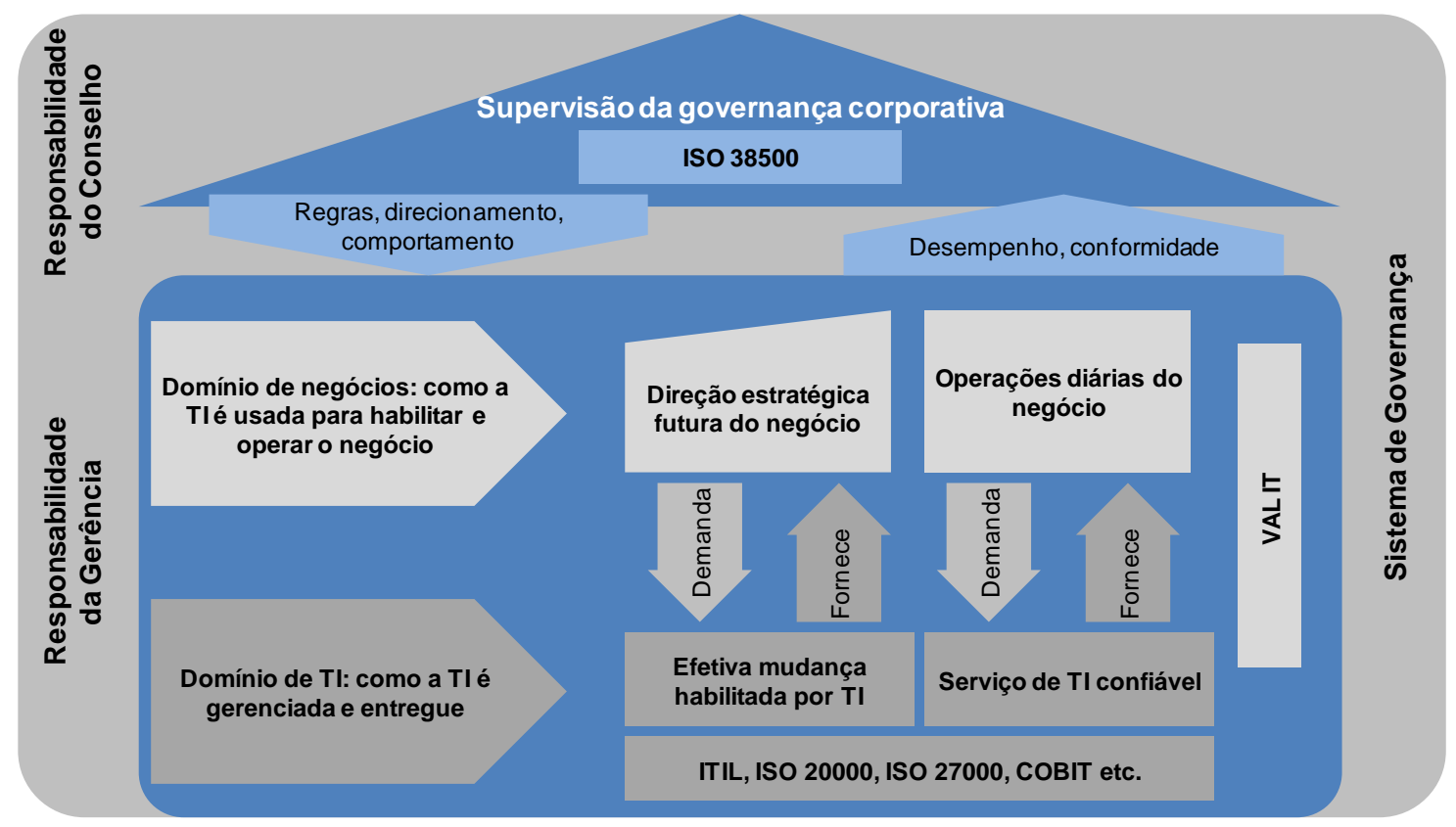

Figura 39 - Sistema de governança que integra supervisão da diretoria da empresa e tarefas gerenciais (TOOMEY, 2008)

Jesus (2007) apresenta um esquemático que une diversos modelos e os associa aos direcionadores estratégicos da empresa, como ilustra a Figura 40.

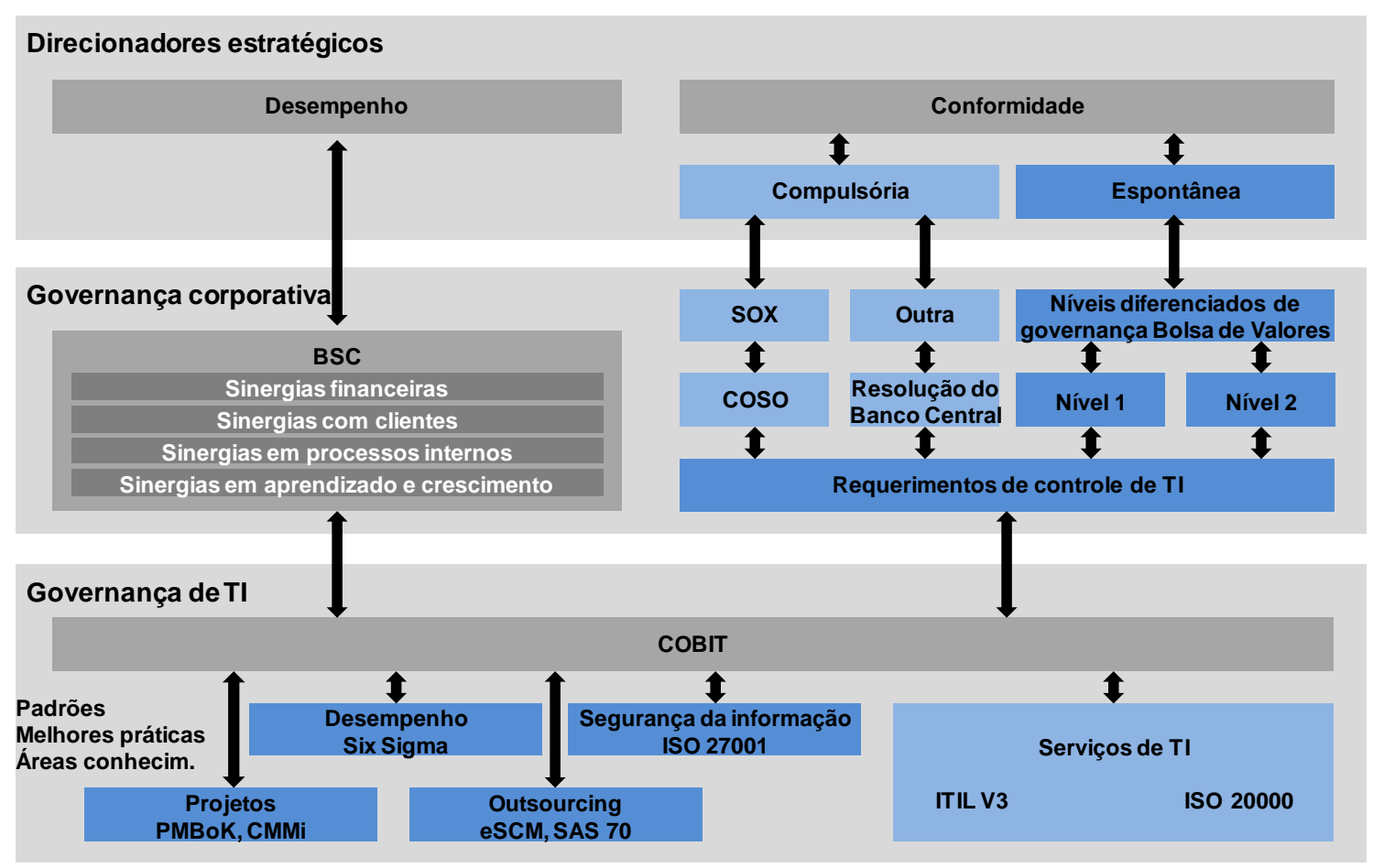

Figura 40 - Melhores práticas em Governança de TI (JESUS, 2007) 
O modelo de Calder-Moir (CALDER, 2008a) foi desenvolvido como uma maneira de organizar os desafios e ferramentas de governança TI através de um processo fima-fim que posiciona as ferramentas existentes em seis segmentos que representam os passos no processo, iniciando pela estratégia do negócio. Cada segmento é dividido em três camadas, sendo que os altos executivos da empresa se encontram na camada mais interna, avaliando as informações e tomando decisões e os analistas de TI estão na camada mais externa, lidando com as diferentes ferramentas para planejar, desenvolver, avaliar, controlar e entregar serviços de TI. A Figura 41 representa o modelo.

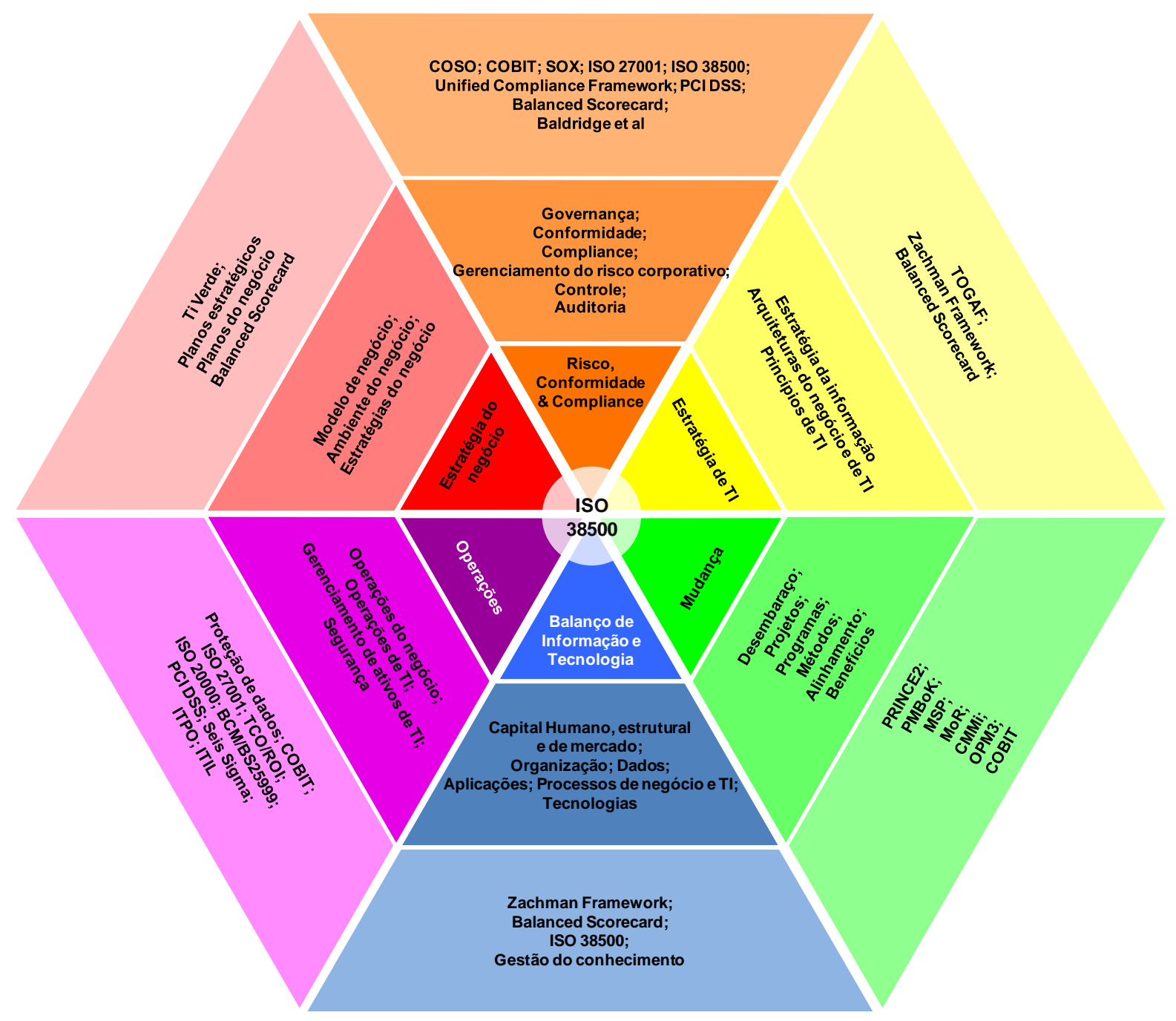

Figura 41 - Framework Calder-Moir (CALDER, 2008a)

A Governança de TI pode ser desenvolvida utilizando uma combinação de diversas estruturas, processos e mecanismos, diferentes para cada organização. É 
importante que um plano para sua implementação seja elaborado, e dentro deste plano é necessário desenvolver um modelo de Governança de $\mathrm{Tl}$, alinhado ao modelo de governança corporativa (ITGI, 2006a). Dentre os passos sugeridos por Carvalho (2009) e Grembergen et al. (2004) estão treinamento de colaboradores, análise da situação atual, escolha de um modelo de governança, alinhamento com o planejamento estratégico do negócio e alinhamento com processos existentes.

\subsection{Alinhamento entre tecnologia aplicada à produção e negócio e Governança de TI do escritório ao chão de fábrica}

Muitas soluções de $\mathrm{TI}$ vêm sendo utilizadas para apoio à manufatura, mas o histórico de diversos erros, distância dos usuários e falta de alinhamento com o negócio permanece (TAYLOR, 1998 apud FAVARETTO, 2001). Kumar (2005) comenta que nem todas as empresas que implementaram CIM (Computer Integrated Manufacturing) tiveram sucesso e apresenta alguns fatores críticos de sucesso para que projetos deste tipo alcancem seus objetivos:

1. Formulação de um plano de projeto simplificado e padronizado priorizando o design do sistema integrado de automação com uma meta específica alinhada ao negócio, um plano macro que direcione a alocação de recursos e a operação do dia-a-dia;

2. Desenvolvimento de uma estrutura organizacional com procedimentos efetivos de comunicação, coordenação, monitoramento e documentação, contando com o apoio da alta direção da empresa;

3. Formação de equipes com a experiência e a motivação necessárias para implementar soluções integradas com uma estrutura de trabalho bem definida e mecanismos efetivos de comunicação para reportar resultados e documentar os detalhes dos trabalhos;

4. Desenvolvimento de uma estrutura modular gerencial e de manufatura para facilitar os trabalhos em processos e projetos; 
5. Os módulos anteriormente citados devem ser integrados de alguma forma, buscando uma visão clara do sistema, comunicada para todos os envolvidos;

6. O desempenho do sistema deve ser avaliado e devem ser feitas modificações baseadas nas avaliações para manter a operação do sistema eficiente.

Souza e Pereira (2008) comentam que algumas publicações vêm mostrando que em muitas vezes as aplicações de automação não se subordinam a uma estratégia corporativa. Um destaque é para a falta de padronização e integração com os negócios da empresa, pois as soluções são geralmente desenvolvidas de forma isolada.

Em uma empresa do setor de manufatura, o planejamento da automação deve ser realizado de forma a buscar uma visão abrangente das necessidades do processo industrial. Dessa forma, assegura-se a funcionalidade e a integração entre os sistemas, evitando-se a implantação de sistemas isolados e incompatíveis. Este planejamento, devido à crescente integração entre o chão de fábrica e todos os níveis de gestão estratégica, tática e operacional das organizações, deve estar alinhado ao planejamento estratégico da organização e ao planejamento estratégico de sistemas (DANTAS; TÁVORA JUNIOR, 2003).

Junto à automação, a TI permite criar um ambiente integrado e estabelecer um fluxo de informação que coleta dados do processo de produção e os leva até os sistemas corporativos, provendo informações que suportarão a tomada de decisões e a gestão do negócio. No entanto, muitas companhias ainda possuem estruturas e processos separados entre TI e automação (FRASER; ZIMMERMANN, 2007). Além disto, os profissionais de automação nem sempre entendem o valor que a TI está entregando para o negócio e o valor percebido dos trabalhos conjuntos entre $\mathrm{TI}$ e automação ainda é baixo (MIKLOVIC, 2008).

As justificativas para a ainda existente separação são as diferentes características necessárias ao ambiente que suporta os processos de ambas as áreas. Em controle, os dados devem ser transmitidos em tempo real, e qualquer falha no sistema pode significar desde perdas financeiras até falhas de segurança para os operadores. Já no âmbito corporativo, a transmissão de dados, apesar de importante, pode levar alguns segundos. 
Um aspecto em que a TI e a automação claramente apresentam conflito é em como os sistemas devem ser suportados. Enquanto sistemas transacionais podem passar por janelas de manutenção no meio da noite ou nos finais de semana, plantas que rodam em regime $24 \times 7$ não permitem este tipo de operação e requerem suporte diretamente no local (SOMMER, 2008).

Por outro lado, as métricas utilizadas no chão de fábrica podem não suportar as metas de negócio. Um estudo de 2006 da MESA, "Metrics that matter" descobriu que apenas 3\% das indústrias possuem indicadores de chão de fábrica relacionados com métricas financeiras e de negócio (FRASER; ZIMMERMANN, 2007).

Para obter maiores vantagens competitivas, as empresas precisam modificar suas práticas, processos, estruturas e até mesmo a cultura para possibilitar a criação de sistemas de informação realmente integrados. A convergência tecnológica pode trazer uma série de benefícios econômicos e qualitativos que transcendem as áreas de $\mathrm{Tl}$ e automação, gerando benefícios para o negócio como um todo, como aumento da eficiência e lucratividade, redução de custos, redução de erros por entrada manual de dados de ambos os lados e redução de esforço duplicado de manter equipamentos e serviços separados (mão de obra e equipamentos).

A estrutura organizacional é um item essencial para o sucesso das implementações. É importante que se verifique se os recursos humanos atuais suportam o novo ambiente, quais qualificações são necessárias, qual será a divisão do trabalho e de responsabilidades e como o novo sistema será integrado aos sistemas existentes. (CHAN et al., 2001)

De acordo com Gifford (2011), algumas empresas de manufatura utilizam um grupo especializado: Tecnologia dos Sistemas de Manufatura, motivado pelo alto custo e da baixa integração de dados entre os sistemas isolados. Estas empresas inovadoras posicionaram este grupo entre a TI corporativa e a Engenharia de Manufatura, mas com autoridade real de abranger ambos os níveis. Dentro deste grupo, estão analistas de diferentes níveis que gerenciam plantas e processos, além de arquitetos que governam os sistemas de produção, como SCADA, sistemas de controle da produção, de agendamento de capacidade, de manutenção etc. Esta 
estrutura organizacional reduziu os custos com os sistemas através da integração, utilizando uma plataforma unificada.

O comprometimento da direção também é essencial, bem como o estabelecimento de indicadores na fase de planejamento. A escolha de tecnologias deve levar em consideração as necessidades da empresa e a avaliação deve levar em conta aspectos econômicos, analíticos (que consideram aspectos econômicos e outros aspectos menos tangíveis) e estratégicos. A avaliação dos aspectos estratégicos pode levar em conta a importância técnica da solução, os objetivos do negócio e a criação de vantagens competitivas.

Sistemas corporativos podem auxiliar as plantas a manter suas atividades alinhadas à estratégia da empresa, como demandas e mudanças nas especificações de produtos. A convergência de tecnologias, como sistemas operacionais e plataformas Ethernet, viabiliza certo grau de padronização e um suporte integrado, por exemplo. A segurança da informação implantada nos sistemas de TI pode também ser expandida para dados industriais, visto que são tanto ou mais críticos para o sucesso do negócio (FRASER; ZIMMERMANN, 2007).

De acordo com o estudo de Frase e Zimmermann (2007), diversas empresas já vêm vantagens na atuação sinérgica entre TI e manufatura. No entanto, de acordo com pesquisa realizada pela PricewaterhouseCoopers $(\mathrm{PwC})$ em conjunto com o IT Governance Institute (ITGI) (2008) em vinte e três países, a manufatura ainda é o setor que menos atribui importância para a Tl e também um dos setores que menos tem a Governança de TI implementada ou em implementação. Este mesmo estudo constatou que a comunicação de oportunidades de negócio pela TI para o negócio ainda é um ponto com importantes oportunidades de melhoria.

Dentre os problemas de TI apontados nesta pesquisa, estão falta de alinhamento, altos custos ou retornos não comprovados, problemas com terceiros e conhecimento da equipe.

Para reduzir problemas como estes, Fraser e Zimmermann (2007) sugerem algumas melhores práticas relacionadas à organização deste cenário convergente:

- Apoio da alta gerência; 
- Mecanismos de reporte mesclados, com um grupo TI-automação reportando tanto para a área de operações, quanto para a área de $\mathrm{TI}$, bem como a formalização de responsabilidades em comum ou, ao menos, sob os mesmos executivos;

- Incentivo à rotação funcional para aumentar conhecimentos e compreensão do trabalho do outro grupo;

- Separação de desenvolvimento e execução: equipes de projeto não devem estabelecer padrões, mas utilizar os padrões de um grupo multifuncional específico para este fim;

- Estabelecimento de princípios guia de design, por exemplo, em manufatura, um bom desenvolvimento deve permitir manutenção sem exigir desligamento do sistema;

- Padronização de arquiteturas e revisão periódica;

- Isolamento das redes: a rede de controle deve estar separada, para garantir os tempos de resposta e a confiabilidade; se possível, separar também software e hardware. É interessante o estabelecimento de padrões, mas isto não implica em uma rede única;

- Controle do ciclo de vida dos sistemas, pois, apesar de os sistemas de automação terem uma vida útil maior que os de $\mathrm{TI}$, a disciplina para atualizar e trocar antes do final do suporte pelo fornecedor é crucial para a confiabilidade;

- Gerenciamento da segurança de Tl;

- Gerenciamento de mudanças de TI: companhias estão adotando regras rígidas sobre o que pode ser modificado e quando para prevenir problemas que levam a paradas de produção; os processos formais para mudanças em TI e automação devem esta documentados; 
- Formalização dos processos de mudanças de automação para todas as modificações nas plantas, incluindo descrição da mudança, autorizações, testes, planos de volta em caso de problemas etc.;

- Participação do usuário final nos os times de projeto que lidarão com sistemas e dados tanto de TI quanto de controle;

- Equipes multifuncionais para garantir um completo entendimento das metas e desafios que ocorrem no planejamento do projeto e implementação;

- Simulação de resultados;

- Cuidado com o sub investimento, buscando garantir a viabilidade dos sistemas a longo prazo, bem como a manutenção das habilidades pessoais;

- Lições aprendidas, um levantamento ao final de cada projeto para verificar se os padrões, políticas ou procedimentos precisam ser revisados;

- Auditoria dos resultados para mostrar ao conselho da empresa ou aos responsáveis pelo controle financeiro o que foi realizado para garantir que o projeto vai atingir seus objetivos (FRASER; ZIMMERMANN, 2007).

Os pontos a serem observados e as boas práticas para um cenário integrado entre a tecnologia aplicada à produção e a tecnologia aplicada ao ambiente de escritório nos remetem à Governança de $\mathrm{TI}$, como a observância à estratégia da empresa e o alinhamento com esta, o apoio da alta gerência, as mudanças organizacionais necessárias, padronização de arquiteturas, definição de processos, medição etc.

Silva (2009) comenta que é possível estender a Governança de TI para as diversas funções de uma organização como a produção, o marketing e o desenvolvimento de produtos. A adoção da governança nestes âmbitos busca o estabelecimento de mecanismos para assegurar que os investimentos, entre eles, investimentos em informação, estejam alinhados à estratégia da empresa. No entanto, ainda são poucas as iniciativas como a do autor, que buscam estender a Governança de TI para o chão de fábrica, proporcionando uma estrutura decisória, de processos e mecanismos relacionais integrados. 
A governança da informação para a produção é um desafio, visto que a arquitetura deste ambiente ainda está em desenvolvimento. Um modelo de alinhamento de $\mathrm{TI}$ para a manufatura requer cuidados redobrados, pois existem diferentes necessidades entre o ambiente de TI corporativa e os sistemas de produção (SILVA, 2009).

\subsection{Considerações finais do capítulo}

Neste capítulo foram apresentados os conceitos necessários para a elaboração do modelo de Governança de TI do escritório ao chão de fábrica de uma empresa. Foram apresentados os conceitos de:

- Informação;

- Tecnologia da Informação (TI)

- Produção e integração entre os diferentes ambientes

- Governança de TI

- Modelos de Governança de TI: Weill e Ross (2006), Fernandes e Abreu (2008), Grembergen (2009) e Albertin e Albertin (2010)

- Melhores práticas (COBIT, Val IT, CMMI, ITIL, ISO/IEC 20000, ISO 27000, eSCM-SP e eSCM-CL, PMBoK, PRINCE2, BSC, Seis Sigma, TOGAF, ISO/IEC 38500

- Combinação entre melhores práticas e

- Alinhamento entre os diferentes ambientes.

Entender os benefícios e desafios desta integração, o que existe em comum, as melhores práticas e os modelos que podem servir como base para um modelo consolidado é uma importante etapa para a elaboração do modelo geral de Governança de TI. Na próxima seção será descrito o problema e os requisitos a serem considerados. 


\section{DESCRIÇÃO DO PROBLEMA E ESPECIFICAÇÃO DE REQUISITOS}

Um grande desafio em controlar as empresas de manufatura é encontrar uma forma de gerenciar a complexidade do ambiente industrial, que inclui vários pedidos relacionados a diversas variantes de produtos, produzidos por diferentes processos e muitos dados a serem processados ou compartilhados (Vernadat, 1996). Para implementar a Governança de $\mathrm{Tl}$ em uma empresa de manufatura envolvendo todos os seus ambientes, do escritório ao chão de fábrica, é proposto neste trabalho um modelo de Governança de TI.

Como modelo entende-se uma abstração da realidade expressa em termos de algum formalismo ou linguagem definido por alguns constructos (Vernadat, 1996). Em outras palavras, para um observador $B$, um objeto $A^{*}$ é um modelo de um objeto $A$ na medida em que $B$ pode utilizar $A^{*}$ para responder às perguntas que the interessam sobre A (Minsky, 1968).

Um modelo é expresso em alguma linguagem, sendo a mais formal, a matemática e a menos formal (e mais rica), a linguagem natural. Existem muitas linguagens para modelar, como símbolos, gráficos ou diagramas.

Para a composição do modelo proposto neste trabalho, foram considerados:

1. A classificação das ferramentas utilizadas nas indústrias em geral e suas diferentes características (vide Seção 3.1);

2. Os requisitos para um modelo de Governança de TI ser aplicável aos diferentes ambientes de uma indústria genérica (vide Seção 3.2);

3. A combinação dos diferentes modelos de Governança de $\mathrm{TI}$ e melhores práticas apresentados no referencial teórico atendendo os requisitos especificados anteriormente (vide Seção 4). 


\subsection{Classificação das ferramentas utilizadas em manufatura}

Existem diferentes classificações para as tecnologias utilizadas no ambiente industrial (SWAMIDASS; KOTTA, 1998, BOYER et al., 1997 apud ZHOU et al., 2009, CHAN et al., 2001, COSTA et al., 2000, MESA, s.d). Para este trabalho, será considerada a seguinte divisão, feita com base nos modelos de classificação existentes e considerando as características dos sistemas dentro dos diversos ambientes de uma indústria:

- Ferramentas para automação do chão de fábrica, como PLC (Programmable Logical Controller), sensores e atuadores, que devem funcionar ininterruptamente (visto que controlam a fabricação em si) e, caso falhem, devem ter sua manutenção efetuada imediatamente;

- Ferramentas para controle e operação da manufatura, como ferramentas para gerenciamento de processos, de qualidade e de mão de obra e que, assim como no caso anterior, devem funcionar ininterruptamente, visto que definem o que será produzido, onde e em que momento;

- Ferramentas para desenvolvimento de produtos e processos, como CAD e PLM, que podem parar para manutenções quando necessário, mas sem a ocorrência de paradas inesperadas, sobretudo em épocas de desenvolvimento de projetos, quando são ferramentas muito demandadas para atender às estratégias e datas da empresa, por exemplo;

- Ferramentas corporativas, como email e intranet, que estão distribuídas por toda a empresa e aceitam janelas de manutenção e toleram eventuais falhas, pois não controlam a produção e contam com meios alternativos de substituição (telefone, por exemplo).

\subsection{Requisitos para um modelo de Governança de $\mathrm{TI}$ aplicado à manufatura}

Entende-se por requisito uma função, restrição ou propriedade que deve ser fornecida, encontrada ou atendida para satisfazer às necessidades do usuário do 
sistema. Especificar um requisito é compreender o que deve ser feito e o que se espera como resultado (Macoratti, 2007). Neste trabalho, um conjunto de requisitos deve ser definido e correlacionado em um modelo, como realizou Bernardes (2005).

Um modelo de Governança de TI que abrange os sistemas corporativos, os sistemas de desenvolvimento de produtos e processos, e os sistemas para controle e operação da manufatura e os sistemas para automação do chão de fábrica tem como principal objetivo promover a integração organizacional, processual e tecnológica entre os diferentes ambientes de uma indústria, dentro do escopo de TI. O usuário do modelo seria a própria empresa, que o utilizaria para definir o que deve levar em consideração estratégica, tática e operacionalmente para obter um ambiente integrado.

Um modelo de Governança de TI deve, de maneira geral:

- Definir os direitos decisórios, formalizando e comunicando papeis e responsabilidades, de forma a deixar claro quem faz o quê, quem é responsável, quem é consultado e quem é informado (WEILL; ROSS, 2006);

- Definir estruturas de governança (arranjos) que busquem a otimização dos investimentos de toda a empresa, ao mesmo tempo evitando subinvestimento, o que pode acarretar problemas no médio e longo prazos;

- Estabelecer uma estrutura organizacional responsável pela Governança de TI que garanta que o modelo de governança seja implementado e sustentado de acordo com as estratégias e prioridades da empresa;

- Considerar o comportamento humano, visto que a governança envolve pessoas, além de mudanças em processos, mudanças culturais e tecnologias;

- Considerar a criação de uma arquitetura padrão para referência para todos os ambientes, bem como princípios-guia de design de arquitetura, garantindo agilidade e menores tempos de resposta de sistemas, além de reuso de sistemas e módulos e manutenção simplificada de sistemas; 
- Estabelecer diferentes equipes de projeto, para estabelecer padrões e para operações de forma que as especializações atendam aos requisitos de cada ambiente operacional da empresa, além de permitir melhor gerenciamento das atividades (é importante ter equipes que definam padrões, equipes que cuidem dos projetos e equipes que cuidem das operações do dia-a-dia, pois são tipos diferentes de atividades);

- Trabalhar com um portfólio de TI único, permitindo a visão consolidada de todos os tipos de projetos, infraestruturas e serviços, sejam do escritório ou do chão de fábrica, além do gerenciamento integrado da demanda;

- Estabelecer processos de gerenciamento de serviços para os diferentes ambientes da empresa, de forma que sejam consideradas as diferentes demandas;

- Considerar o gerenciamento de todos os ativos, como recomenda a biblioteca de melhores práticas ITIL, mesmo os de maior ciclo de vida, visto que uma indústria tem diferentes tipos de ativos, com características muito distintas;

- Viabilizar o gerenciamento de mudanças integrado de sistemas, verificando todos os impactos das mudanças de sistemas nos diferentes ambientes;

- Considerar as exigências de segurança da informação nos diferentes ambientes, dadas as diferentes características na forma de processar e fornecer as informações na cadeia de desenvolvimento e produção de uma indústria;

- Desenvolver mecanismos de emissão de relatórios de resultados (de projetos de sistemas e operações) integrados, permitindo uma visão holística do ambiente de forma que seja possível entender o impacto do trabalho de cada área no todo, incentivando o trabalho colaborativo; 
- Estabelecer uma estrutura de comunicação apropriada, considerando comitês, ferramentas online ou impressas e outros meios disponíveis para disseminar informação nos diferentes ambientes;

- Estabelecer mecanismos de relacionamento entre as diferentes áreas, para estabelecer uma comunicação clara e eficiente entre áreas com diferentes hábitos e práticas de trabalho;

- Considerar o levantamento de lições aprendidas em projetos e operações para a criação de uma base de conhecimento;

- Auditar os resultados de projetos e de operações, garantindo que as informações de toda a empresa, entre todos os sistemas, estão sendo transmitidas e utilizadas da forma correta, de acordo com as estratégias da empresa.

Um modelo integrado de Governança de TI deve, especificamente para o caso de chão de fábrica:

- Considerar aspectos do chão-de-fábrica nos princípios-guia de design de arquitetura de sistemas, como permitir manutenção sem desligamento do sistema no caso de equipamentos do chão de fábrica;

- Considerar regras especiais de segurança da informação para os sistemas de controle, pois eles apresentam características diferentes dos sistemas utilizados em escritório, como uma rede com protocolos diferentes dos conhecidos em Tl;

- Considerar que a infraestrutura dos sistemas de chão-de-fábrica deve ser tratada de forma isolada da rede em que transitam os dados corporativos e necessariamente ser redundante;

- Estabelecer regras de atendimento e manutenção local, que sejam mais rápidas que as utilizadas para o ambiente de escritório, para evitar, por exemplo, uma parada na linha de produção e garantir a eficiência operacional; 
- Considerar uma política de sobressalentes mais rígida para o chão-defábrica, dada a urgência na correção de incidentes neste ambiente;

- Estabelecer mecanismos de comunicação que sejam efetivos no chão-defábrica, visto que, por exemplo, nem todos os funcionários têm acesso a computadores durante $o$ expediente de trabalho.

\subsection{Considerações finais do capítulo}

Neste capítulo foi apresentado o problema de pesquisa, classificadas as ferramentas presentes em uma indústria e listados os requisitos que devem ser atendidos pelo modelo de Governança de TI para que seja integrado do escritório ao chão de fábrica.

Entender os diferentes ambientes presentes em uma indústria e os requisitos do modelo é uma importante etapa para o desenvolvimento do modelo, apresentado na próxima seção. 


\section{MODELO DE GOVERNANÇA DE TI PROPOSTO}

O modelo proposto tem por base o modelo de Weill e Ross (2006) em sua forma básica. O modelo de governança dos autores, mais estratégico, foi detalhado nos níveis tático e operacional e incorporou aspectos para atender aos requisitos apresentados na seção 3.3. As partes superiores do modelo são colocadas em prática pelas partes inferiores. Durante todo o processo de desenvolvimento, foram consideradas as características especiais da $\mathrm{Tl}$ e da manufatura, contempladas no levantamento de requisitos.

A estratégia e a organização da empresa definem os comportamentos desejáveis que motivam a governança corporativa. Weill e Ross (2006) afirmam que existem diferentes modelos de estratégia (disciplina de valor): excelência operacional, intimidade com o cliente e liderança em produtos.

Como está sendo tratado o ambiente industrial, dentro da estratégia da organização temos a estratégia de manufatura, que engloba a estratégia de automação. Em uma empresa do setor de manufatura, o planejamento da automação deve ser realizado de forma a buscar uma visão abrangente das necessidades do processo industrial. Dessa forma, assegura-se a funcionalidade e a integração entre os sistemas, evitando-se a implantação de sistemas isolados e incompatíveis. Este planejamento, devido à crescente integração entre o chão de fábrica e todos os níveis de gestão estratégica, tática e operacional da organização, deve estar alinhado ao planejamento estratégico da organização e ao planejamento estratégico de sistemas (DANTAS; TÁVORA JUNIOR, 2003). Este conjunto de estratégias é ponto de partida para a Governança de TI.

A organização e os comportamentos desejáveis de TI devem estar em harmonia com a estratégia e a organização da empresa. Os comportamentos desejáveis criam valor e são influenciados por diferentes fatores, como a cultura da empresa, a missão, os valores e as estruturas. Por exemplo, a empresa possui como parte de sua estratégia a eficiência operacional. Isto leva à organização e aos comportamentos desejáveis de centralização e padronização dos sistemas de TI. Este item não é objeto de estudo do presente trabalho. 
Neste modelo, propõe-se uma estrutura especializada por processo/tecnologia, visto que os negócios estão relacionados e a infraestrutura é compartilhada, ou seja, um modelo centralizado, com equipes compartilhadas entre unidades de negócio.

A estratégia da empresa deve ser harmonizada com os arranjos de $\mathrm{Tl}$, que atribuem direitos decisórios para as decisões-chave da Governança de $\mathrm{TI}$. Cada empresa irá definir arranjos de governança e atribuir os direitos decisórios de acordo com suas necessidades, mas, para o caso da Governança de TI aplicada às áreas de escritório ao chão de fábrica, sugere-se os seguintes arranjos para tomar decisões, com base na pesquisa apresentada por Weill e Ross (2006):

- Para os princípios de TI, que orientam as escolhas estratégicas (caso não existam, defini-los é uma tarefa de alinhamento) tem-se um duopólio, visto que habilita a tomada de decisões conjunta entre líderes do negócio e de TI, composto por representantes diretamente relacionados à $\mathrm{TI}$ e à automação. $\mathrm{O}$ duopólio é uma das melhores formas para decisões estratégicas;

- Para os investimentos, assim como para os princípios, sugere-se um duopólio, por ser uma das melhores formas para decisões estratégicas e permitir o envolvimento das áreas de negócio e de Tl;

- Para a arquitetura de TI, adota-se uma monarquia de TI, pois se trata de uma decisão mais técnica;

- Para a infraestrutura de TI, o mesmo que para a arquitetura, uma monarquia de $\mathrm{TI}$, para que a gestão seja mais centralizada, como é indicado para infraestruturas compartilhadas (conforme mencionado acima, um modelo especializado por processo/tecnologia);

- Para as aplicações de negócio, devem ser criados diversos duopólios entre TI e cada área de negócio, para decisões mais customizadas em menor tempo, concentrando-se diretamente nas necessidades das unidades de negócio. O duopólio permite melhor intercâmbio entre as áreas de negócio e $\mathrm{TI}$, habilitando uma tomada de decisões conjunta e consciente. 
Dentre as decisões a serem tomadas, foi incluída a "Arquitetura de Automação" organização lógica dos dados e aplicações de controle. Neste caso, deve existir um grupo do negócio específico para tratar do assunto e propõe-se a criação de uma estrutura de trabalho conjunta com a Arquitetura de TI como mecanismo, buscando a criação de uma arquitetura cada vez mais integrada para trabalhar da melhor forma com, por exemplo, o padrão Ethernet/IP, aplicado ao chão de fábrica.

Estes são pontos muito importantes, pois as estruturas de tomada de decisão são o primeiro passo na concepção da Governança de TI. Os direitos decisórios de TI devem estar claramente definidos e devem ser explicitamente comunicados.

Na sequencia, foi utilizado o trabalho de Albertin e Albertin (2010) para entender a relação entre os modelos de governança e os modelos de mercado, como COBIT e ITIL. De acordo com os autores, os modelos conhecidos de mercado são modelos de administração de TI, usados para implementar a governança. Ainda de acordo com Albertin e Albertin (2010), a Governança de TI precisa desenvolver uma estrutura que contemple algumas características, entre elas, os métodos que darão suporte para a administração de TI, como COBIT e ITIL. Desta forma, entende-se que o modelo de Governança de TI pode ser detalhado utilizando-se as práticas conhecidas de mercado.

Após este entendimento, foi utilizado o modelo de Grembergen e De Haes (2008) para a subdivisão do modelo de Weill e Ross (2006). Desta forma, a divisão dos mecanismos de Governança de TI sugerida é:

- Estruturas organizacionais, que farão ao arranjos acontecerem;

- Processos de alinhamento, que incluem melhores práticas que irão colocar a Governança de TI em prática, fazendo o alinhamento entre a estratégia e organização da empresa e os comportamentos desejáveis - os modelos de administração citados por Albertin e Albertin (2010);

- Mecanismos relacionais, que buscarão integrar a TI ao negócio via pessoas e abordagens de comunicação. 
Quanto à estrutura organizacional, as empresas que têm a Governança de TI mais eficaz mesclam diferentes tipos de organização. Estruturas usuais de tomadas de decisão envolvem um comitê administrativo executivo ou sênior, um comitê de executivos de $\mathrm{Tl}$, equipes de processo com membros de $\mathrm{Tl}$, gerentes de relacionamento entre negócios e $\mathrm{TI}$, comitês de arquitetura e de aprovação de capital (WEILL; ROSS, 2006). Dentre as estruturas, propõe-se as seguintes:

- Comitê estratégico de TI, que deve atuar junto ao conselho administrativo da empresa, tendo por responsabilidade manter a TI na agenda do conselho, e discutir princípios de $\mathrm{TI}$ e os investimentos. O envolvimento da $\mathrm{Tl}$ nos processos de decisão relevantes assegura o rápido atendimento das exigências do negócio;

- Comitê gestor (também conhecido como Steering Committee), uma equipe de representantes de diversas áreas de nível gerencial com a tarefa de ligar a estratégia de $\mathrm{TI}$ com a do negócio. O grupo tem por responsabilidade priorizar, avaliar custos e alocar recursos (em alguns casos, para tornar estes comitês menos burocráticos, as empresas selecionam os projetos que serão discutidos por eles, como alguma exceção ou um investimento que ultrapassa determinado valor). Também é muito importante a comunicação, dando visibilidade para as iniciativas de $\mathrm{TI}$, além de ser uma forma de harmonizar objetivos entre $\mathrm{TI}$ e unidades de negócio. É importante que o nível executivo tenha conhecimento das tecnologias, técnicas de gestão, riscos e benefícios de cada uma;

- Equipe de arquitetura responsável por, a partir dos princípios do negócio, definir uma arquitetura comum a toda a empresa, englobando a arquitetura de TI e a arquitetura de controle, do chão de fábrica;

- Equipe de serviços de TI responsável pelas operações do dia-a-dia para toda a empresa;

- Equipe de segurança responsável pela monitoração e controle das políticas de segurança da informação e os mecanismos a serem usados para colocálas em prática; 
- Equipe de projeto compostos por um gerente de projetos, um gerente de relacionamento (explicado a seguir) e representantes das áreas, responsáveis pelo planejamento, execução e controle dos projetos relacionados à $\mathrm{Tl}$, bem como pela identificação das demandas de TI.

Além destas estruturas, Fernandes e Abreu (2008) comentam que uma nova estrutura vem sendo apresentada, o "Escritório do CIO". Esta é uma área que oferece suporte diretamente ao $\mathrm{ClO}$ e pode ser subdividida em gestão da conformidade (auditorias, gestão de não conformidades), gestão financeira da $\mathrm{TI}$ (orçamentos, custos, relatórios, estudo de viabilidade financeira), gestão de fornecedores (contratações, elaboração de solicitações de informações e propostas, gestão dos contratos, controle de faturas, gestão do desempenho do fornecedor), gestão de pessoas (recrutamento e seleção, programa de treinamentos, plano de carreira, banco de horas, controle de férias), planejamento da TI (planejamento de $\mathrm{TI}$, prospecção tecnológica, planejamento e implantação de melhorias), gestão do portfólio de TI (elaboração e gestão do portfólio, monitoramento de projetos e serviços) e outros serviços (apresentações, eventos, "endomarketing", relatórios gerenciais, desenvolvimentos dos processos do escritório, gestão de ativos, serviços e níveis de serviço do escritório).

Com isto, tem-se diferentes estruturas que colocam em prática os arranjos recomendados para o setor de manufatura.

Neste ponto, utilizou-se o modelo de Fernandes e Abreu (2008) para detalhar a parte tática do modelo quanto aos processos de alinhamento.

O plano estratégico de $\mathrm{TI}$ direciona os recursos de $\mathrm{TI}$ de acordo com a estratégia do negócio e, no caso da manufatura, engloba os direcionamentos relacionados à automação. O plano é importante por melhorar o entendimento dos envolvidos quanto às oportunidades e limitações de $\mathrm{TI}$, identificar o desempenho atual, a capacidade e necessidade de recursos humanos e esclarecer o nível de investimento necessário. Este plano pode incluir estratégias para os próximos anos (cinco anos, por exemplo) e trabalhará em conjunto com o portfólio de $\mathrm{TI}$, servindo como entrada e recebendo as saídas deste. Deve incluir aspectos estratégicos de arquitetura e terceirização, definidos nos respectivos processos, descritos a seguir. 
O portfólio de $\mathrm{TI}$ direciona o relacionamento com clientes internos e fornecedores, orientando 0 atendimento a demandas. $O$ portfólio trata de ativos, programas (conjunto de projetos), projetos e serviços e inclui o catálogo de $\mathrm{TI}$, os serviços futuros e até mesmo os que deixaram de existir. O catálogo é um banco de dados com informações sobre todos os serviços de $\mathrm{TI}$, incluindo informações sobre o relacionamento do serviço com os processos de negócio e os recursos técnicos relacionados.

Este processo gera entradas para o processo de decisão e investimento que prioriza projetos, decide quanto será investido, quantifica financeiramente 0 valor dos serviços de $\mathrm{Tl}$ e dos ativos que sustentam o serviço, bem como documenta e acorda o valor dos serviços recebidos pelos clientes e habilitar a modelagem e o gerenciamento da demanda.

processo de gerenciamento de investimento tem como entradas as metas estratégicas e de desempenho e os casos de negócio, desenvolvidos pelas áreas interessadas, que os defendem perante a alta direção da companhia. A alta direção utiliza o portfólio de $\mathrm{TI}$ e as diretrizes da empresa para avaliar os investimentos propostos e tomar as decisões sobre os projetos que serão priorizados.

O cálculo dos valores dos serviços entregues por TI permitirão também realizar uma comparação com os valores propostos por prestadores de serviço terceirizados, viabilizando a realização de avaliações importantes de redução de custos. Dentro deste processo discute-se também se haverá e, em caso positivo, como será realizado o mecanismo de cobrança reversa, ou seja, se os usuários vão pagar e quanto o vão pelos serviços de TI.

Desta forma, temos a estrutura parcial descrita na Figura 42. 


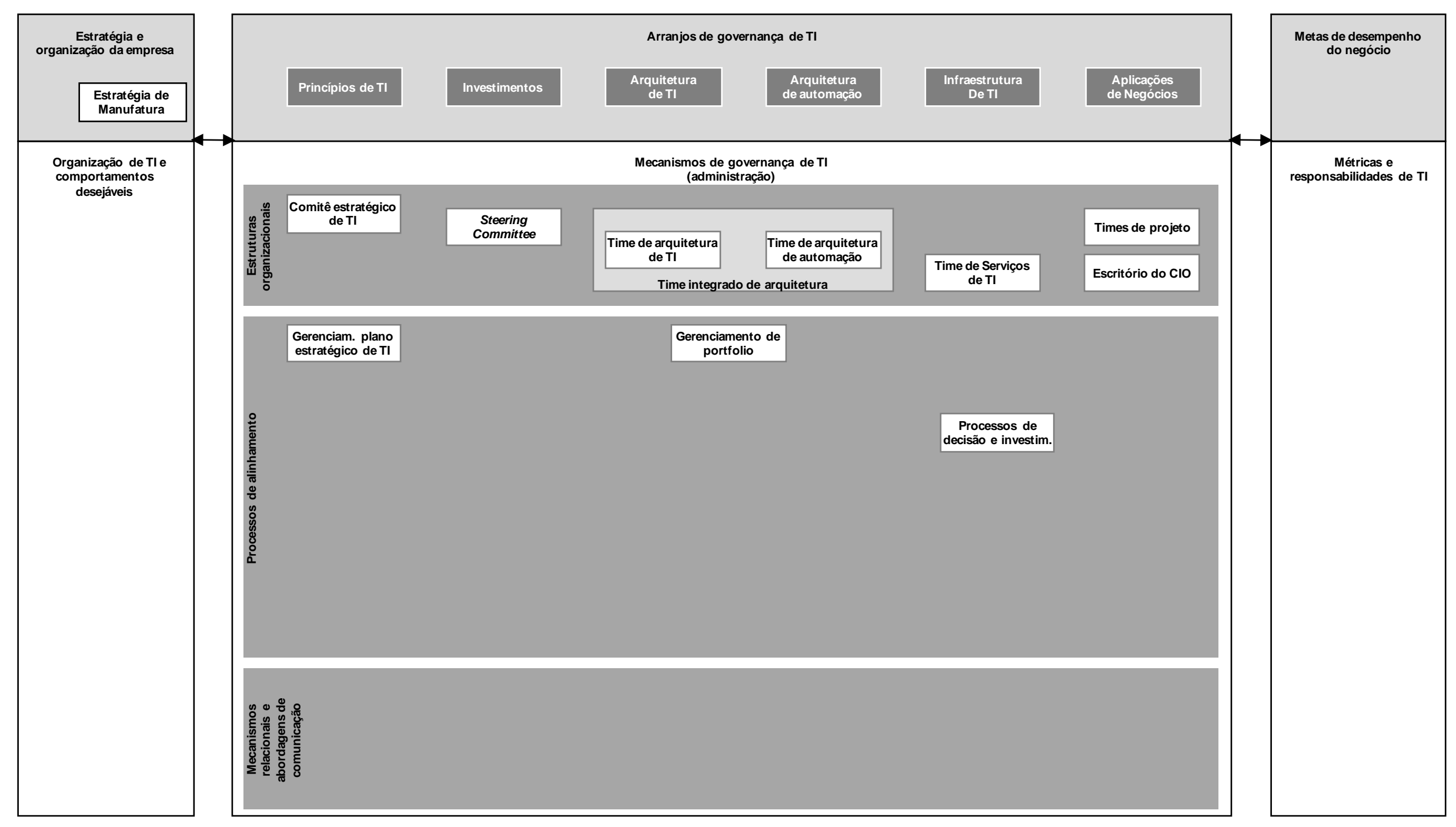

Figura 42 - Primeiro modelo parcial 
Com esta estrutura parcial, os modelos de administração de TI descritos na seção 2.4.1.2 e os aspectos dos modelos de integração descritos na seção 2.3.4.1 foram empregados para detalhar melhor as partes tática e operacional, de forma que o modelo atinja seu objetivo e que a empresa que o utilize seja capaz de definir o que levar em consideração estratégica, tática e operacionalmente para obter um ambiente integrado de Governança de TI. A Figura 43 descreve como o detalhamento foi realizado.

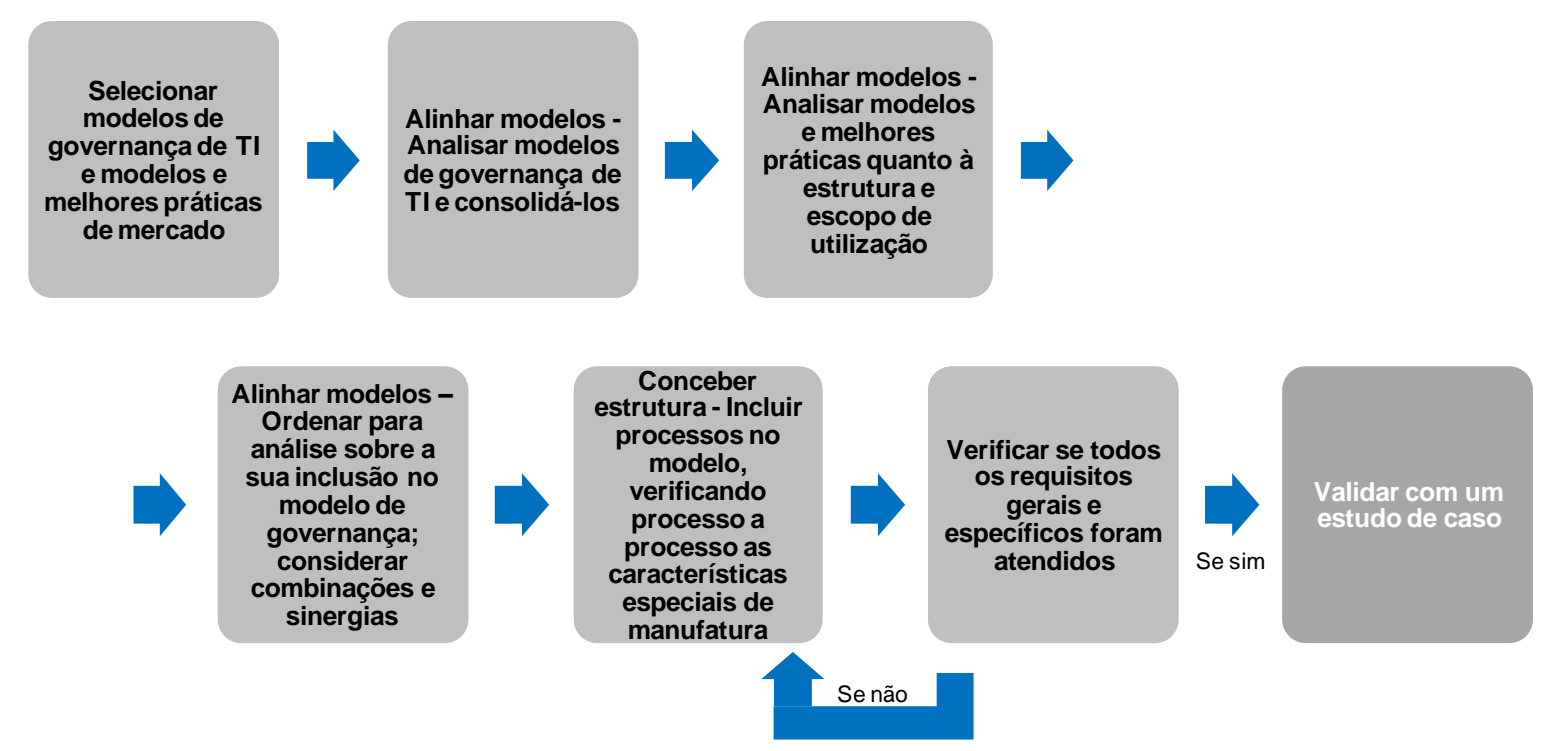

Figura 43 - Detalhamento das etapas para desenvolvimento do modelo

O primeiro, o segundo e o terceiro passos descritos na figura já foram realizados (selecionar modelos de Governança de $\mathrm{Tl}$ e modelos e melhores práticas de mercado, alinhar modelos - analisar modelos de Governança de TI e consolidá-los, alinhar modelos - analisar modelos e melhores práticas quanto à estrutura e âmbito de utilização).

No passo quatro, primeiramente, foram analisados COBIT (Control Objectives for Information and related Technology), Val IT e ISO 38500, modelos que têm uma relação mais direta com Governança de TI. Na sequencia, foram avaliados ITIL (Information Technology Infrastructure Library), ISO 27000, TOGAF (The Open Group Architecture Framework), PMBoK (Project Management Body of Knowledge) e PRINCE2 (Project in Controlled Environments), conhecidos mecanismos que apoiam a Governança de TI em aspectos mais operacionais e tecnológicos. Depois, 
foram analisados eSCM (The eSourcing Capability Model) e CMMi (Capability Maturity Model Integration) que, neste caso, estão relacionados com a prestação de serviços de TI por terceiros para a indústria e, por fim, OPM3 (Organizational Project Management Maturity Model) e P3M3 (Portfólio, Programme \& Project Management Maturity Model), BSC (Balanced Scorecard) e Seis Sigma, relacionados às metas, métricas e melhoria contínua.

\section{1. $\quad$ Análise do COBIT}

Como mencionado na seção 2.4.1.2, um dos benefícios primários do COBIT é integrar outras melhores práticas, como ilustrado na Figura 40. Por este motivo, o detalhamento da estrutura começou pela verificação do que os trinta e quatro processos do COBIT sugerem, o que já está considerado até o momento na estrutura em construção e o que é importante incluir.

A Tabela 5 lista os trinta e quatro processos agrupados em seus domínios e relaciona o que precisa ser incluído na estrutura parcial descrita anteriormente.

É importante considerar que o COBIT é um modelo que teve início na área de negócio, migrando, posteriormente, também para a área de TI. Está alinhado ao BSC (Balanced Scorecard), sendo que as metas de negócio listadas no modelo têm como referência as quatro perspectivas do BSC: "financeira", "cliente", "processos internos", "aprendizado e crescimento".

Tabela 5 - Domínios e processos do COBIT e o que é necessário incluir no modelo em construção

\begin{tabular}{|c|c|c|}
\hline Domínio & Processo & Ação \\
\hline \multirow[t]{3}{*}{ PO } & $\begin{array}{l}\text { PO1 - Definir um } \\
\text { plano estratégico de } \\
\text { TI }\end{array}$ & $\begin{array}{l}\text { O plano é sugerido por Fernandes e Abreu (2008) e já está } \\
\text { considerado na estrutura. } \\
\text { Este processo também contempla o gerenciamento do valor de } \\
\text { TI, incluindo casos de negócio e a avaliação destes casos de } \\
\text { negócio, aspectos detalhados a seguir utilizando o Val IT. } \\
\text { Contempla, também, o gerenciamento do portfólio, já incluído } \\
\text { no modelo. }\end{array}$ \\
\hline & $\begin{array}{lr}\text { PO2 - Definir } & \text { a } \\
\text { arquitetura } & \text { da } \\
\text { informação } & \end{array}$ & $\begin{array}{l}\text { Deve ser incluído um processo para gerenciar a arquitetura, } \\
\text { buscando padronização, agilidade e segurança das } \\
\text { informações. }\end{array}$ \\
\hline & $\begin{array}{ll}\text { PO3 - Determinar as } \\
\text { diretrizes } & \text { de } \\
\text { tecnologia } & \end{array}$ & $\begin{array}{l}\text { A direção tecnológica pode ser definida com base nos princípios } \\
\text { de TI, deve ser contemplada no plano estratégico de TI e estar } \\
\text { de acordo com a arquitetura empresarial. Relacionado a este } \\
\text { processo está também a criação de um conselho de arquitetura, } \\
\text { já contemplado na estrutura parcial. }\end{array}$ \\
\hline
\end{tabular}




\begin{tabular}{|c|c|c|}
\hline & $\begin{array}{lr}\text { PO4 - Definir } & \text { os } \\
\text { processos, } & \text { a } \\
\text { organização e os } & \text { os } \\
\text { relacionamentos de } \mathrm{TI}\end{array}$ & $\begin{array}{l}\text { Este processo trata das estruturas de pessoal que devem } \\
\text { existir, incluindo comitê estratégico, comitês combinados entre } \\
\text { TI e o negócio para priorização dos recursos de TI, de risco, } \\
\text { qualidade e segurança de Tl. Estas três últimas estruturas } \\
\text { podem ser consideradas dentro da estrutura Escritório do CIO. }\end{array}$ \\
\hline & $\begin{array}{l}\text { PO5 - Gerenciar o } \\
\text { investimento de TI }\end{array}$ & $\begin{array}{l}\text { Este processo sugere que seja estabelecida uma estrutura } \\
\text { combinada entre TI e o negócio para gerenciar programas de } \\
\text { investimentos em TI, incluindo custos, benefícios e priorização. } \\
\text { No modelo proposto, esta função é exercida por um steering } \\
\text { comittee e gerenciada pelo processo de decisão e investimento. }\end{array}$ \\
\hline & 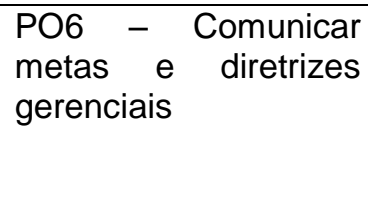 & $\begin{array}{l}\text { Deve ser incluído um processo para gerenciar um programa } \\
\text { de comunicação contínuo para conscientizar e garantir o } \\
\text { entendimento da direção tecnológica, das políticas e riscos } \\
\text { de TI. Este ponto pode ser considerado dentro da } \\
\text { subdivisão de mecanismos relacionais. }\end{array}$ \\
\hline & $\begin{array}{l}\text { PO7 - Gerenciar os } \\
\text { recursos humanos de } \\
\text { TI }\end{array}$ & $\begin{array}{l}\text { Deve ser incluído um processo que considera } \\
\text { recrutamento, treinamento, avaliação de desempenho, } \\
\text { promoção e desligamento de pessoal de TI, garantindo a } \\
\text { execução das atividades da melhor forma e até mesmo a } \\
\text { segurança das informações. }\end{array}$ \\
\hline & $\begin{array}{l}\text { PO8 - Gerenciar a } \\
\text { qualidade }\end{array}$ & $\begin{array}{l}\text { Deve ser estabelecido um processo para monitorar o } \\
\text { desempenho (com entradas dos processos presentes na } \\
\text { coluna da esquerda do modelo) e melhorar continuamente } \\
\text { os processos e serviços de TI. }\end{array}$ \\
\hline & $\begin{array}{l}\text { PO9 - Avaliar e } \\
\text { gerenciar os riscos de } \\
\text { TI }\end{array}$ & $\begin{array}{l}\text { Deve ser desenvolvida uma estrutura para gerenciamento } \\
\text { de risco alinhada ao gerenciamento de risco corporativo. }\end{array}$ \\
\hline & $\begin{array}{l}\text { PO10 - Gerenciar } \\
\text { projetos }\end{array}$ & $\begin{array}{l}\text { Deve ser estabelecida uma estrutura para gerenciamento de } \\
\text { todos os projetos de TI. }\end{array}$ \\
\hline Al & $\begin{array}{ll}\text { Al1 - Identificar } & \text { as } \\
\text { soluções } & \text { de } \\
\text { automação } & \end{array}$ & $\begin{array}{l}\text { Deve ser estabelecido um processo que considere as } \\
\text { necessidades, viabilidade, riscos e custo-benefício de uma } \\
\text { nova aplicação para decidir se ela será comprada ou } \\
\text { desenvolvida. Este processo será incluído dentro de outros } \\
\text { processos do modelo. }\end{array}$ \\
\hline & $\begin{array}{l}\text { Al2 - Adquirir } \mathrm{e} \\
\text { manter os softwares }\end{array}$ & $\begin{array}{l}\text { Deve ser estabelecido um processo de desenvolvimento } \\
\text { que contemple o cumprimento de prazos e otimização de } \\
\text { custos, segregando as funções de desenvolvimento, teste e } \\
\text { operação. Este processo será incluído dentro de outros } \\
\text { processos do modelo. }\end{array}$ \\
\hline & $\begin{array}{ll}\text { Al3 - Adquirir } & \mathrm{e} \\
\text { manter } & \mathrm{a} \\
\text { infraestrutura } & \\
\text { tecnológica } & \end{array}$ & $\begin{array}{l}\text { Deve ser estabelecido um processo que trate da } \\
\text { infraestrutura necessária para as aplicações de negócio de } \\
\text { acordo com a arquitetura de TI, fortemente ligado ao } \\
\text { monitoramento da capacidade existente - o que vai definir, } \\
\text { por exemplo, se é necessário adquirir mais recursos para } \\
\text { determinado projeto. Este processo será incluído dentro de } \\
\text { outros processos do modelo. }\end{array}$ \\
\hline & $\begin{array}{l}\text { Al4 - Possibilitar a } \\
\text { operação e uso }\end{array}$ & $\begin{array}{l}\text { Deve ser estabelecido um processo que trate da } \\
\text { disponibilização de conhecimento sobre novos sistemas } \\
\text { por meio de documentação e treinamentos. }\end{array}$ \\
\hline & $\begin{array}{l}\text { Al5 - Adquirir recursos } \\
\text { de TI }\end{array}$ & $\begin{array}{l}\text { Deve ser estabelecido um processo que contemple } \\
\text { procedimentos para aquisição, seleção de fornecedores e } \\
\text { contratos. Este processo será incluído dentro de outros } \\
\text { processos do modelo. }\end{array}$ \\
\hline & $\begin{array}{l}\text { Al6 - } \text { Gerenciar } \\
\text { mudanças }\end{array}$ & $\begin{array}{l}\text { Deve ser estabelecido um processo de gerenciamento de } \\
\text { mudanças em sistemas e serviços. }\end{array}$ \\
\hline & $\begin{array}{l}\text { Al7 - Instalar } \quad \text { e } \\
\text { certificar soluções } \\
\text { mudanças }\end{array}$ & $\begin{array}{l}\text { Deve ser estabelecido um processo de gerenciamento de } \\
\text { liberações, incluindo testes, instruções de implantação e } \\
\text { migração. }\end{array}$ \\
\hline
\end{tabular}




\begin{tabular}{|c|c|c|}
\hline \multirow[t]{13}{*}{$\overline{D S}$} & $\begin{array}{llr}\text { DS1 - } & \text { Definir } & \text { e } \\
\text { gerenciar } & \text { níveis } & \text { de } \\
\text { serviços } & & \end{array}$ & $\begin{array}{l}\text { Deve ser estabelecido um processo para definição dos } \\
\text { níveis de serviço, monitoramento e divulgação de } \\
\text { resultados destes níveis. }\end{array}$ \\
\hline & $\begin{array}{l}\text { DS2 - Gerenciar } \\
\text { serviços terceirizados }\end{array}$ & $\begin{array}{l}\text { Deve ser estabelecido um processo para gestão de } \\
\text { fornecedores, incluindo o monitoramento dos serviços. }\end{array}$ \\
\hline & $\begin{array}{l}\text { DS3 - Gerenciar } \\
\text { desempenho } \\
\text { capacidade }\end{array}$ & $\begin{array}{l}\text { Deve ser estabelecido um processo de gerenciamento de } \\
\text { desempenho e capacidade, incluindo a previsão de } \\
\text { necessidades futuras, de forma a garantir que os recursos } \\
\text { de TI estejam sempre disponíveis. }\end{array}$ \\
\hline & $\begin{array}{l}\text { DS4 - Assegurar a } \\
\text { continuidade dos } \\
\text { serviços }\end{array}$ & $\begin{array}{l}\text { Deve ser estabelecido um processo que garanta a } \\
\text { continuidade dos serviços de TI incluindo o } \\
\text { desenvolvimento e testes de um plano de continuidade de } \\
\text { TI, armazenamento de cópias de segurança e treinamentos } \\
\text { periódicos visando minimizar a probabilidade e o impacto } \\
\text { da interrupção de um serviço chave. }\end{array}$ \\
\hline & $\begin{array}{l}\text { DS5 - Garantir a } \\
\begin{array}{l}\text { segurança } \\
\text { sistemas }\end{array} \text { dos }\end{array}$ & $\begin{array}{l}\text { Deve ser estabelecido um processo de gestão da segurança } \\
\text { da informação de forma a proteger todos os ativos de Tl e } \\
\text { minimizar o impacto de incidentes de segurança. }\end{array}$ \\
\hline & $\begin{array}{l}\text { DS6 - Identificar e } \\
\text { alocar custos }\end{array}$ & $\begin{array}{l}\text { Deve ser estabelecido um processo para alocação dos } \\
\text { custos de } \mathrm{Tl} \text {, oferecendo maior visibilidade sobre o uso dos } \\
\text { serviços pelo negócio. }\end{array}$ \\
\hline & $\begin{array}{l}\text { DS7 - Educar e treinar } \\
\text { os usuários }\end{array}$ & $\begin{array}{l}\text { Deve ser estabelecido um processo para identificação de } \\
\text { necessidades de treinamentos, execução e medição dos } \\
\text { resultados tanto para funcionários de Tl, quanto para } \\
\text { funcionários das áreas de negócio. }\end{array}$ \\
\hline & $\begin{array}{l}\text { DS8 - Gerenciar a } \\
\text { central de serviço e } \\
\text { os incidentes }\end{array}$ & $\begin{array}{l}\text { Deve ser criada uma central de serviços e estabelecido um } \\
\text { processo de gerenciamento de solicitações e incidentes } \\
\text { para resolver os chamados o mais rapidamente possível. }\end{array}$ \\
\hline & $\begin{array}{l}\text { DS9 - Gerenciar a } \\
\text { configuração }\end{array}$ & $\begin{array}{l}\text { Deve ser estabelecido um processo para criação e } \\
\text { manutenção de um repositório de configuração de } \\
\text { hardware e software. }\end{array}$ \\
\hline & $\begin{array}{l}\text { DS10 - Gerenciar os } \\
\text { problemas }\end{array}$ & $\begin{array}{l}\text { Deve ser estabelecido um processo de gerenciamento de } \\
\text { problemas que trabalhe com a identificação e classificação } \\
\text { dos problemas, análise de causas-raiz e resolução. }\end{array}$ \\
\hline & $\begin{array}{l}\text { DS11 - Gerenciar os } \\
\text { dados }\end{array}$ & $\begin{array}{l}\text { Deve ser estabelecido um processo para gerenciamento } \\
\text { dos dados, incluindo cópia de segurança, recuperação de } \\
\text { dados e o devido descarte de mídias. Este processo será } \\
\text { incluído dentro de outros processos do modelo. }\end{array}$ \\
\hline & $\begin{array}{l}\text { DS12 - Gerenciar o } \\
\text { ambiente físico }\end{array}$ & $\begin{array}{l}\text { Deve ser estabelecido um processo de gerenciamento do } \\
\text { ambiente físico para proteger os ativos e os dados contra } \\
\text { acesso indevido, danos ou roubo. Este processo será } \\
\text { incluído dentro de outros processos do modelo. }\end{array}$ \\
\hline & $\begin{array}{l}\text { DS13 - Gerenciar as } \\
\text { operações }\end{array}$ & $\begin{array}{l}\text { Deve ser estabelecido um processo para gerenciar as } \\
\text { operações, incluindo o monitoramento de infraestrutura e a } \\
\text { manutenção preventiva de hardware. Este processo será } \\
\text { incluído dentro de outros processos do modelo. }\end{array}$ \\
\hline \multirow[t]{3}{*}{ ME } & $\begin{array}{l}\text { ME1 - Monitorar e } \\
\text { avaliar o desempenho } \\
\text { de TI }\end{array}$ & $\begin{array}{l}\text { Deve ser estabelecido um processo de monitoramento, } \\
\text { incluindo a definição dos indicadores, os meios de } \\
\text { divulgação dos resultados e a implementação de ações de } \\
\text { melhoria. }\end{array}$ \\
\hline & $\begin{array}{l}\text { ME2 - Monitorar e } \\
\text { avaliar os controles } \\
\text { internos }\end{array}$ & $\begin{array}{l}\text { Deve ser estabelecido um processo para monitorar os } \\
\text { controles internos de atividades de Tl e identificar ações de } \\
\text { melhoria. }\end{array}$ \\
\hline & $\begin{array}{l}\text { ME3 - Assegurar a } \\
\text { conformidade com } \\
\text { requisitos externos }\end{array}$ & $\begin{array}{l}\text { Deve ser estabelecido um processo para identificar leis, } \\
\text { regulamentações e contratos e otimizar processos para } \\
\text { reduzir o risco de não-conformidade. }\end{array}$ \\
\hline
\end{tabular}




\begin{tabular}{|l|l|l|}
\hline $\begin{array}{l}\text { ME4 - Prover avernança de TI } \\
\text { Gove processo trata do estabelecimento de uma estrutura de }\end{array}$ & $\begin{array}{l}\text { Este } \\
\text { Governança de TI integrada à governança corporativa, além da } \\
\text { realização de auditorias independentes do status da } \\
\text { Governança de TI. }\end{array}$ \\
\hline
\end{tabular}

\subsection{Análise do Val IT}

O Val IT, por estender o COBIT, foi utilizado na sequência, para verificar quais outros processos deveriam ser incluídos ou detalhados. Para facilitar o entendimento de como o Val IT será colocado em prática, iniciou-se a análise pelo domínio de gerenciamento do investimento, conforme descrito na Tabela 6.

O Val IT diferencia projeto, programa e portfólio. O modelo define projeto como um conjunto estruturado de atividades que buscam entregar uma nova habilidade, que não é suficiente para atingir um resultado para o negócio. Um programa é um conjunto de projetos interrelacionados suficientes para atingir um resultado para o negócio (esta é a unidade de trabalho dos processos do Val IT). Um portfólio é um conjunto de programas de investimento, serviços, projetos, ativos ou recursos de TI. O principal interesse do Val IT é o portfólio de investimentos - os demais, são de maior interesse dentro do contexto do COBIT.

Tabela 6 - Domínio "Investment Management" (IM) e respectivos processos do VAL IT e o que é necessário incluir no modelo

\begin{tabular}{|c|c|c|}
\hline Domínio & Processo & Ação \\
\hline \multirow[t]{4}{*}{ IM } & $\begin{array}{l}\text { IM1 - Desenvolver e } \\
\text { avaliar o caso de } \\
\text { negócio do conceito } \\
\text { inicial de programa } \\
\text { (conjunto de projetos) }\end{array}$ & $\begin{array}{l}\text { Identificar uma nova oportunidade, desenvolver o caso de } \\
\text { negócios e avaliá-lo. } \\
\text { A identificação da nova oportunidade pode ser feita por qualquer } \\
\text { área da empresa. O caso de negócio inicial deve conter os } \\
\text { benefícios quantitativos e qualitativos esperados, como estes } \\
\text { benefícios serão medidos, investimentos previstos em todo o } \\
\text { clico de vida do programa, riscos e potenciais impactos. Avaliar } \\
\text { o caso de negócio preliminar e discutir se ele tem potencial para } \\
\text { ser detalhado em um caso de negócios completo. }\end{array}$ \\
\hline & $\begin{array}{l}\text { IM2 - Entender o } \\
\text { programa candidato e } \\
\text { as alternativas de } \\
\text { implementação }\end{array}$ & $\begin{array}{l}\text { Utilização de métodos e técnicas apropriados para entender e } \\
\text { documentar um entendimento comum sobre a proposta e suas } \\
\text { alternativas de implementação. }\end{array}$ \\
\hline & $\begin{array}{l}\text { IM3 - Desenvolver o } \\
\text { plano do programa }\end{array}$ & $\begin{array}{l}\text { Definir e documentar todos os projetos necessários para o } \\
\text { programa, incluindo projetos fora da área de TI. Especificar } \\
\text { recursos necessários, incluindo pessoal, origem da verba, tempo } \\
\text { e interdependências com outros projetos. }\end{array}$ \\
\hline & $\begin{array}{l}\text { IM4 - Desenvolver } \\
\text { análise de custos e } \\
\text { benefícios para todo o } \\
\text { ciclo de vida do } \\
\text { programa }\end{array}$ & $\begin{array}{l}\text { Identificar custos e benefícios, definir metas e como serão } \\
\text { medidas, obter aprovação associados a um programa. }\end{array}$ \\
\hline
\end{tabular}




\begin{tabular}{|l|l|l|}
\hline $\begin{array}{l}\text { IM5 - Desenvolver o } \\
\text { caso de negócios } \\
\text { completo }\end{array}$ & $\begin{array}{l}\text { Desenvolver o caso de negócios completo, detalhando escopo, } \\
\text { objetivos, dependências, riscos, marcos do projeto, custos e } \\
\text { benefícios. Obter aprovação do caso de negócios detalhado. }\end{array}$ \\
\hline $\begin{array}{l}\text { IM6 - Lançamento e e } \\
\text { gestão do programa }\end{array}$ & $\begin{array}{l}\text { Planejar, gerenciar e acompanhar/gerenciar benefícios obtidos. } \\
\text { IM7 Atualizar } \\
\text { portfólios } \\
\text { operacionais }\end{array}$ & $\begin{array}{l}\text { Atualizar os portfólios afetados pelos programas de } \\
\text { investimento, incluindo portfólio de projetos, serviços, } \\
\text { aplicações, ativos etc. }\end{array}$ \\
\hline $\begin{array}{l}\text { IM8 - Atualizar o caso } \\
\text { de negócios }\end{array}$ & $\begin{array}{l}\text { Utilizar o caso de negócios durante o desenvolvimento do } \\
\text { programa para que ele reflita as atuais mudanças, custos e } \\
\text { benefícios alcançados pela implementação do programa. }\end{array}$ \\
\hline $\begin{array}{l}\text { IM9 - Monitoramento } \\
\text { e divulgação de } \\
\text { informações sobre onalor, } \\
\text { programa }\end{array}$ & $\begin{array}{l}\text { Monitorar e reportar desempenho e potencial de entregar valor, } \\
\text { gastos e riscos. }\end{array}$ \\
\hline $\begin{array}{l}\text { IM10 - Retirar o } \\
\text { programa }\end{array}$ & $\begin{array}{l}\text { Retirar o programa do portfólio de investimentos ativo de forma } \\
\text { estruturada e garantindo que os benefícios esperados sejam } \\
\text { obtidos, mas o monitoramento deve continuar até que o } \\
\text { programa tenha se tornado um serviço contínuo. Mesmo assim, } \\
\text { sabe-se que pode demandar novos investimentos no futuro. }\end{array}$ \\
\hline
\end{tabular}

Os processos acima descritos são tratados como sub-processos de "Decisão e Investimento", com forte ligação com o PO5 do COBIT e com o gerenciamento do projeto.

É importante considerar que o modelo diferencia a pessoa que fará o gerenciamento do projeto (gerente de projetos), da pessoa que fará o gerenciamento do programa (gerente do programa), das funções que suportam ambos - PMO (Project Management Office) e PgMO (Programme Management Office). Pode-se, então, considerar dois processos: gerenciamento de programas e gerenciamento de projetos.

O processo de "Decisão e Investimento" deve contemplar o Caso de Negócios, que dará visibilidade sobre o valor de determinado projeto ou serviço para o negócio, o que é muito importante para justificar investimentos e trabalhar como sugerido no Val IT:

1. Elaboração de um caso de negócio inicial;

2. Avaliação do caso de negócio e estudo de alternativas;

3. Detalhamento do planejamento do programa;

4. Análise de custos e benefícios; 
5. Se aprovado, detalhamento do caso de negócios;

6. Gerenciamento do programa;

7. Atualização de portfólios;

8. Utilização do caso de negócios durante o desenvolvimento do programa;

9. Monitoramento e reporte sobre o programa;

10. Retirar o programa.

Passando ao domínio de gerenciamento do portfólio, tem-se os processos descritos na Tabela 7.

Tabela 7 - Domínio "Portfólio Management" (PM) e respectivos processos do VAL IT e o que é necessário incluir no modelo

\begin{tabular}{|c|c|c|}
\hline Domínio & Processo & Ação \\
\hline \multirow[t]{6}{*}{ PM } & $\begin{array}{l}\text { PM1 - Estabelecer } \\
\text { orientação estratégica } \\
\text { e meta de mix de } \\
\text { investimentos }\end{array}$ & $\begin{array}{l}\text { Revisar e garantir que a visão e os princípios de negócio sejam } \\
\text { conhecidos e que os investimentos de TI estejam alinhados a } \\
\text { eles. Identificar oportunidade em que a TI possa suportar a } \\
\text { estratégia do negócio. Definir um mix (conjunto combinado) } \\
\text { apropriado de investimentos. } \\
\text { Traduzir as estratégias e metas do negócio em estratégias e } \\
\text { metas de TI. }\end{array}$ \\
\hline & $\begin{array}{l}\text { PM2 - Determinar } \\
\text { disponibilidade e fonte } \\
\text { de recursos }\end{array}$ & Entender os recursos disponíveis, fontes e o que já foi gasto. \\
\hline & $\begin{array}{l}\text { PM3 - Gerenciar a } \\
\text { disponibilidade de } \\
\text { recursos humanos }\end{array}$ & $\begin{array}{l}\text { Criar e manter um inventário de recursos humanos do negócio e } \\
\text { de TI, entender a demanda atual e futura, identificar deficiências, } \\
\text { possuir um plano tático de recursos humanos. }\end{array}$ \\
\hline & $\begin{array}{l}\text { PM4 - Avaliar e } \\
\text { selecionar programas } \\
\text { para financiar }\end{array}$ & $\begin{array}{l}\text { Avaliar e atribuir pontuação relativa para cada programa, criar } \\
\text { uma visão global da carteira de investimento, tomar as decisões } \\
\text { de investimentos e comunicar, especificar marcos de projeto e } \\
\text { alocar fundos para os programas selecionados, ajustar metas, } \\
\text { previsões e orçamentos, incorporar despesas de programa em } \\
\text { mecanismos de cobrança reversa. }\end{array}$ \\
\hline & $\begin{array}{lr}\text { PM5 - Monitorar } & \text { e } \\
\text { informar sobre } & \text { o } \\
\text { desempenho } & \text { do } \\
\text { portfólio } & \text { de } \\
\text { investimento } & \end{array}$ & Prover visão geral dos investimentos para a direção da empresa. \\
\hline & $\begin{array}{ll}\text { PM6 - Otimizar } & 0 \\
\text { desempenho } & \text { do } \\
\text { portfólio } & \text { de } \\
\text { investimento } & \end{array}$ & $\begin{array}{l}\text { Revisar o portfólio de investimento, identificar sinergias, eliminar } \\
\text { duplicações entre programas, identificar e mitigar riscos. } \\
\text { Repriorizar o portfólio quando necessário. }\end{array}$ \\
\hline
\end{tabular}

Os processos PM1, PM2, PM4, PM5 e PM6 são tratados dentro do processo de "Gerenciamento de Portfólio". A parte "Traduzir as estratégias e metas do negócio 
em estratégias e metas de Tl" entrará na coluna da direita do modelo sugerido, em métricas e responsabilidades de $\mathrm{TI}$. $\mathrm{O}$ processo $\mathrm{PM} 3$ está relacionado ao gerenciamento de recursos humanos, que deve ser considerado no modelo.

Por fim, tem-se o domínio de gerenciamento de valor, mais alto nível, cujos processos e sua utilização no modelo proposto são descritos na Tabela 8 , a seguir.

Tabela 8 - Domínio "Value Governance" (VG) e respectivos processos do VAL IT e o que é necessário incluir no modelo

\begin{tabular}{|c|c|c|}
\hline Domínio & Processo & Ação \\
\hline \multirow[t]{6}{*}{ VG } & $\begin{array}{l}\text { VG1 - Estabelecer } \\
\text { liderança informada e } \\
\text { comprometida }\end{array}$ & $\begin{array}{l}\text { Todos os executivos devem entender aspectos estratégicos da } \\
\text { TI e Governança de TI. Estabelecer um fórum de lideranças que } \\
\text { ajudarão a alta direção da empresa a entender e discutir } \\
\text { oportunidades que surgem com as novas tecnologias. Definir e } \\
\text { comunicar o que é valor para a empresa. Garantir alinhamento e } \\
\text { integração entre o negócio e TI através de metas chave de } \\
\text { negócio. } \\
\text { O Comitê estratégico de TI tem este papel. }\end{array}$ \\
\hline & $\begin{array}{l}\text { VG2 - Definir e } \\
\text { implementar } \\
\text { processos }\end{array}$ & $\begin{array}{l}\text { Definir um modelo global de governança e analisar os processos } \\
\text { atuais frente a este modelo, identificar e priorizar requisitos de } \\
\text { processos, definir e documentar processos, estabelecer, } \\
\text { implementar e comunicar papeis e responsabilidades, } \\
\text { estabelecer estruturas organizacionais. }\end{array}$ \\
\hline & $\begin{array}{ll}\text { VG3 - Definir } & \text { as } \\
\text { características } & \text { do } \\
\text { portfólio } & \end{array}$ & $\begin{array}{l}\text { Definir os tipos de portfólio. O Val IT preocupa-se com o portfólio } \\
\text { de investimentos, enquanto o COBIT trata dos portfólios de } \\
\text { projetos, serviços, ativos e recursos. Definir categorias para os } \\
\text { itens do portfólio - o de investimentos, por exemplo, pode ser } \\
\text { categorizado em "mandatório", "continuidade ou sustentação", } \\
\text { ou outros como "estratégico" (para criar novos produtos / } \\
\text { serviços e entrar em novos mercados), "transformação" (para } \\
\text { obter vantagem competitiva ou inovação), "transacional" (para } \\
\text { processar transações de forma mais eficiente). Desenvolver e } \\
\text { comunicar critérios de avaliação, atribuir pesos, definir critérios } \\
\text { de acompanhamento do valor gerado ao negócio. }\end{array}$ \\
\hline & $\begin{array}{lr}\text { VG4 - Alinhar } & \text { e } \\
\text { integrar a gestão de } \\
\text { valor com } & \text { o } \\
\text { planejamento } & \\
\text { financeiro } & \text { da } \\
\text { empresa. } & \end{array}$ & $\begin{array}{l}\text { Entender práticas de orçamentação da empresa, definir práticas } \\
\text { necessárias para geração de valor, identificar mudanças } \\
\text { necessárias, definir estrutura e conteúdo do caso de negócios, } \\
\text { revisar as práticas. Isto deve estar incluído no processo de } \\
\text { decisão e investimento. }\end{array}$ \\
\hline & $\begin{array}{l}\text { VG5 - Estabelecer } \\
\text { monitoramento efetivo } \\
\text { da governança }\end{array}$ & $\begin{array}{l}\text { Identificar métricas a serem monitoradas, definir processos para } \\
\text { captura dos dados e divulgação de informações, identificar e } \\
\text { monitorar ações de melhoria de processos. Isto será detalhado } \\
\text { na coluna da direita do modelo que está em desenvolvimento. }\end{array}$ \\
\hline & $\begin{array}{l}\text { VG6 - Melhorar } \\
\text { continuamente as } \\
\text { práticas de gestão de } \\
\text { valor }\end{array}$ & $\begin{array}{l}\text { Revisar as lições aprendidas de gerenciamento de valor, } \\
\text { planejar, implementar e monitorar mudanças nos domínios de } \\
\text { gerenciamento de valor, do portfólio e de investimentos. Isto } \\
\text { será detalhado na coluna da direita do modelo que está em } \\
\text { desenvolvimento. }\end{array}$ \\
\hline
\end{tabular}

Desta forma, temos a segunda estrutura parcial descrita na Figura 44. 


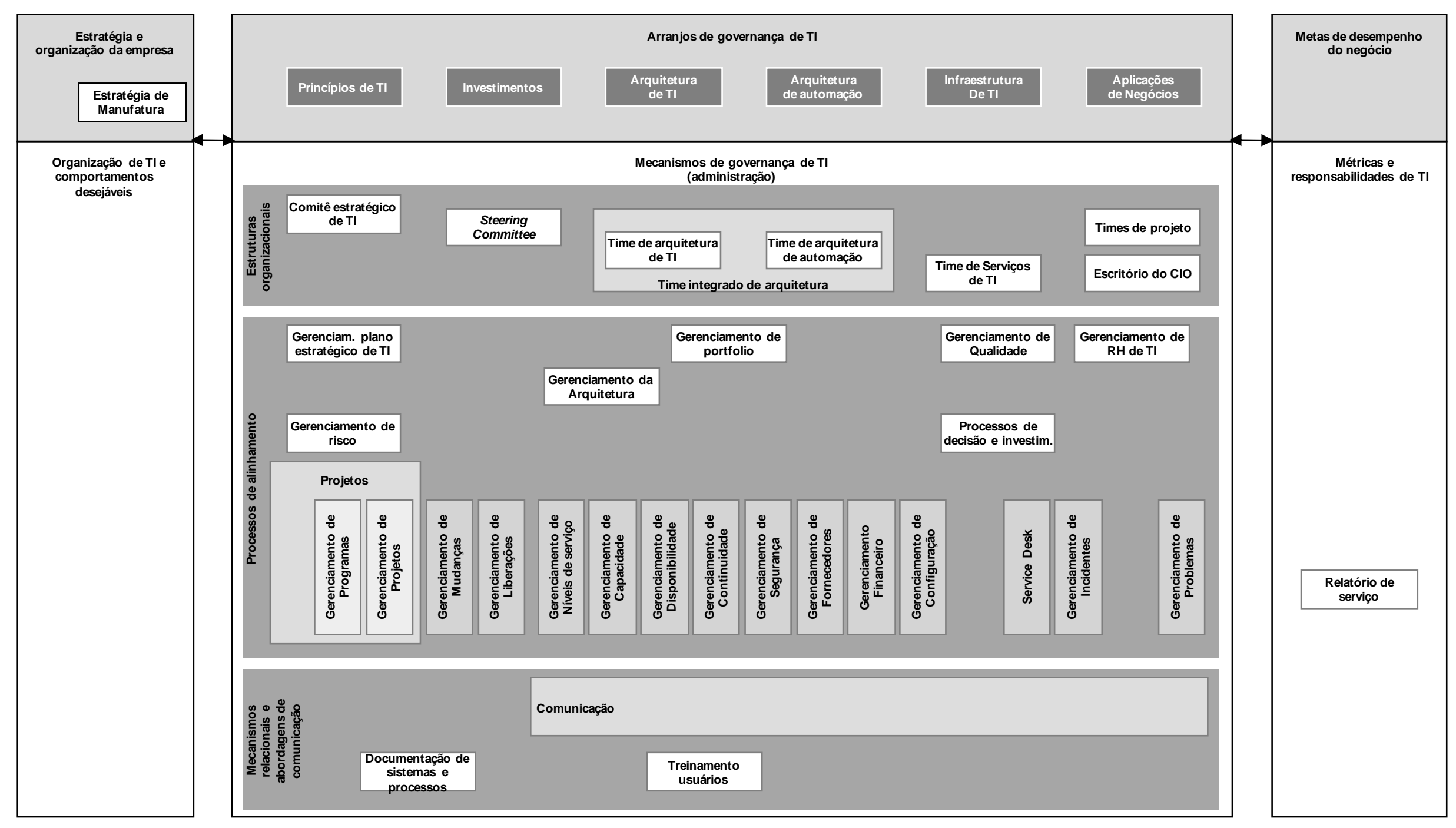

Figura 44 - Modelo parcial de Governança de TI, envolvendo COBIT, Val IT e outros 


\subsection{Detalhamento de acordo com ITIL, ISO 27000, PMBoK, PRINCE2 e TOGAF}

Ao analisar com detalhes cada um dos demais processos que devem ser incluídos ou detalhados no modelo, observa-se uma forte relação com os modelos ITIL e ISO 27000 , sendo que os processos, por vezes, apresentam sobreposição, como pode ser verificado no trabalho de mapeamento de ITGI e OGC (2008). Além deles, observa-se referência também ao TOGAF e aos modelos relacionados a gerenciamento de projetos - PMBoK e PRINCE2. Estes modelos foram utilizados para detalhar cada processo, conforme descrito a seguir.

O portfólio precisa de um processo que o gerencie e, entre ele e o processo de decisão e investimento, é importante gerenciar a demanda, como sugerido na ITIL, que irá capturar as necessidades e consolidá-las. Sem um mecanismo eficaz para controlar as demandas, a TI terá problemas com um número maior de demandas do que recursos para atendê-las - ou, até mesmo, poderá ter problemas com capacidade ociosa. O gerenciamento de demanda irá gerar entradas para o processo de decisão e investimento. Este processo irá capturar as necessidades e consolidá-las. Sem um mecanismo eficaz para controlar as demandas, a TI terá problemas com um número maior de demandas do que recursos para atendê-las.

Sugere-se aqui que o processo de gerenciamento da demanda capture as solicitações das áreas de negócio por meio dos casos de negócios, incorporando a elaboração do caso inicial, avaliação e estudo de alternativas, detalhamento do planejamento e análise de custos e benefícios, passando, então, para o processo de decisão e investimento, que irá aprovar (ou não) o caso de negócios, detalhar, gerenciar o programa e efetivamente investir no programa aprovado.

Para gerenciar os riscos, deve-se buscar a referência que o negócio utiliza para gerenciar os riscos corporativos e trabalhar no contexto de riscos da $\mathrm{Tl}$, identificando os eventos, avaliando os riscos e desenvolvendo respostas a eles. O plano de gerenciamento de riscos deve ser constantemente monitorado e modificado quando necessário. O COBIT, a ITIL e o PMBOK possuem referências sobre como mitigar ou mesmo evitar riscos em TI. A ISACA possui um modelo específico para riscos, o 
Risk IT. Enquanto o COBIT provê uma série de controles para mitigar ou evitar riscos em TI, o Risk IT provê um modelo para identificar e gerenciar os riscos de TI.

Uma ferramenta importante dentro deste escopo é a Análise de Impacto aos Negócios (Business Impact Analysis, BIA, também mencionada na série ISO 27000 e na ITIL) que irá quantificar os riscos associados à TI, calculando o impacto para o negócio referente à perda de um serviço. Esta análise é também entrada para os processos de riscos associados à segurança da informação e à operação. Sugerese um processo único, integrado, com a visão dos riscos da $\mathrm{Tl}$ em todos os seus âmbitos de atuação.

A partir deste ponto, sugere-se dividir as ações de $\mathrm{Tl}$ em duas partes: projetos e operações, como na ISO 38500, e uma terceira divisão, entre as duas, para contemplar os processos de transição.

\subsubsection{Gerenciamento de projetos}

Os projetos são esforços temporários empreendidos para criar um produto, serviço ou resultado exclusivo. Propõe-se a utilização do PMBoK, alinhado ao método PRINCE2 (o PMBoK trata de "o quê" deve ser feito e a PRINCE2, "como", materializando as boas práticas sugeridas pelo PMI). Dentro do contexto de gerenciamento de projetos estão incluídas, também, as aquisições necessárias, o que permite uma associação com os processos Al1, Al2, Al3 e, principalmente, Al5 do COBIT, relacionados a aquisições, contratações (com todo o processo de seleção) e treinamentos em projetos, além do processo de gerenciamento de projetos propriamente dito, o PO10.

O modelo proposto contempla alguns componentes da PRINCE2, como gerenciamento de configuração, controle de mudanças e os casos de negócios já mencionados anteriormente.

Os projetos tratam de novas implementações ou expansões da infraestrutura e sistemas existentes. Neste ponto, sugere-se a divisão dos projetos nas categorias 
citadas anteriormente de sistemas existentes em indústrias, pois as categorias possuem diferentes características de projeto:

- Ferramentas para automação, cujos projetos devem ser realizados de forma conjunta entre a TI e a área de automação, geralmente críticos para o negócio;

- Ferramentas para controle e operação da manufatura, cujos projetos também devem ser realizados em conjunto por TI e automação;

- Ferramentas para desenvolvimento de produtos e processos que devem ter seus projetos realizados por TI junto às áreas de negócio envolvidas;

- Ferramentas corporativas, cuja implantação deve consultar as áreas da empresa, mas é realizada, basicamente, por TI.

O gerenciamento de projetos, portanto, é interessante que possua processos diferentes entre estes três ambientes, utilizando o PMBoK e a PRINCE2 como referência. Contudo, o gerenciamento de programas pode ser único, para permitir uma visão consolidada do portfólio e todas as análises necessárias.

\subsubsection{Transição e Operações}

A parte de transições refere-se ao final da implantação de projetos (entrada em "produção"), enquanto a parte de operações trata de processos e atividades do diaa-dia para manter sistemas e infraestruturas em perfeito funcionamento. $O$ sequenciamento dos processos será feito de acordo com o ciclo de vida proposto na ITIL, tornando mais prático o entendimento dos processos: desenho, transição e operação. Neste ponto, sugere-se também a divisão nas categorias semelhantes às de projetos, pois cada uma tem suas necessidades especiais neste âmbito:

- Ferramentas para automação do chão de fábrica, mais críticas, que não permitem paradas, devem ter redes isoladas das demais, redundâncias e manutenção local; 
- Ferramentas para controle e operação da manufatura, que também não permitem paradas, devem ter redes isoladas das demais, redundâncias e manutenção local;

- Ferramentas para desenvolvimento de produtos e processos que têm sua criticidade variável de acordo com as áreas;

- Ferramentas corporativas, para a empresa toda.

Esta divisão é feita para assegurar os diferentes tratamentos que cada ambiente deve receber da $\mathrm{Tl}$, com diferentes exigências.

\subsubsection{Gerenciamento de níveis de serviço}

O gerenciamento de níveis de serviço (ou Service Level Agreement, SLA) mencionado no COBIT e na ITIL, negocia, define e documenta os acordos de nível de serviço entre a $\mathrm{Tl}$ e o negócio, para atendimento de solicitações e incidentes. Sugere-se aqui um processo único, integrado, mas que considere as diferentes necessidades dos quatro tipos de ambientes supracitados, constituindo uma estrutura multinível:

- O nível corporativo, que cobre assuntos referentes a toda a estrutura da empresa, tratando de ferramentas corporativas, como o e-mail;

- O nível do cliente, que cobre serviços referentes a uma unidade do negócio específica, para todos os serviço utilizados. Neste caso, encaixa-se o chão de fábrica, pois os serviços de $\mathrm{Tl}$ podem receber os níveis de serviço diferenciados que garantirão a continuidade das operações;

- O nível do serviço, que trata de todos os assuntos relevantes para um serviço específico, utilizado por determinada unidade de negócio. Como exemplo, pode-se citar o caso das ferramentas de produto, processo e gestão do negócio, cujos níveis de serviço podem variar entre áreas de negócio. 
É importante destacar que, além dos SLA, tem-se também os OLA (Operational Level Agreement), ou nível de serviço operacional, que tratam dos serviços de outras áreas para a TI. Por exemplo, para a compra de um hardware, a TI só pode se comprometer com algum nível de serviço caso haja um OLA com a área de compras, garantindo a entrega do equipamento. Existem, ainda, os Contratos de Apoio (Underpinning Contracts, UC), entre a TI e seus fornecedores. É importante que a TI, ao discutir os SLA, estabeleça os contratos adjacentes necessários para garantir o cumprimento das metas.

\subsubsection{Gerenciamento de capacidade}

O processo de gerenciamento da capacidade de serviços e recursos mencionado no COBIT e na ITIL busca garantir capacidade a custos justificáveis e leva em conta a demanda da empresa, que inclui, por exemplo, os níveis de serviço acordados. Sugere-se um processo único que verifique a capacidade geral de TI de acordo com indicadores provindos de monitoramento. Exemplos de indicadores: quantidade de vezes por mês que a utilização da memória de determinada máquina ultrapassa $90 \%$ ou volume ocupado em determinado disco.

\subsubsection{Gerenciamento de disponibilidade}

Para garantir que os níveis de serviço acordados sejam cumpridos, a disponibilidade deve ser gerenciada. Este processo está junto ao gerenciamento de capacidade no COBIT, mas na ITIL é um processo independente. O processo de gerenciamento de disponibilidade busca otimizar a capacidade de infraestrutura, auxiliando na entrega dos serviços de $\mathrm{Tl}$, sustentando a disponibilidade a um custo aceitável. $\mathrm{O}$ processo monitora e analisa tendências, combinando os requisitos do negócio com a capacidade da infraestrutura em atendê-los, e propõe melhorias caso não atenda.

A disponibilidade inclui a quantidade relativa de tempo em que o serviço esteve operando, índices de confiabilidade (como tempo médio entre falhas e tempo médio 
entre incidentes de sistema) e índices de sustentabilidade (como tempo médio para recuperar o serviço). Sugere-se um processo único que considere os respectivos níveis de serviço.

\subsubsection{Gerenciamento de continuidade}

O gerenciamento de continuidade tem por objetivo garantir a continuidade dos serviços de $\mathrm{TI}$ com base no que o negócio considera importante. A análise de impacto aos negócios, descrita anteriormente, é entrada para este processo. Considera-se que pode haver apenas um processo, igual para todos os ambientes, contanto que se considere as criticidades de cada sistema na análise.

\subsubsection{Gerenciamento de segurança}

O gerenciamento de segurança busca garantir a confidencialidade, integridade e disponibilidade dos ativos e serviços de TI de acordo com a política de segurança e a análise de impacto aos negócios (Business Impact Analysis, BIA) desenvolvidos em conjunto com a direção da empresa. Neste modelo, propõe-se tratar a segurança de acordo com a ISO 27002, cujos onze temas principais são:

- Política de segurança da informação;

- Organização da segurança da informação, com os processos básicos necessários para a gestão da segurança;

- Gestão de ativos, que busca o tratamento adequado da informação;

- Segurança de recursos humanos, antes, durante e depois do período de contrato;

- Segurança física e do meio ambiente, que trata da entrada e saída segura de pessoas e recursos;

- Gerenciamento de operações e comunicações, que inclui a documentação de processos e práticas seguras de utilização de sistemas; 
- Controle de acessos, que restringe e controla os acessos aos sistemas;

- Aquisição, desenvolvimento e manutenção de sistemas, que trata da análise de requisitos de segurança, testes e aceitação de novos sistemas;

- Gestão de incidentes de segurança, de forma alinhada à gestão de incidentes de TI, explicada a seguir;

- Gestão de continuidade de negócios, que, a partir da análise de impacto ao negócio (BIA) mencionada anteriormente, estrutura e estabelece planos de continuidade;

- Conformidade, que identifica as legislações aplicáveis e busca a conformidade com normas internas e externas.

O gerenciamento de segurança acaba sendo mais amplo que a $\mathrm{TI}$, tratando de temas como confidencialidade de documentos e acesso físico. Este processo de gerenciamento de segurança mais amplo engloba o processo sugerido na ITIL e os processos DS5, DS11 e DS12 do COBIT.

Visto que a segurança deve começar pela definição de uma política de segurança da informação elaborada em conjunto com representantes das áreas de negócio, sugere-se separar a política (mais estratégica) das operações. A política deve ser desenvolvida pela equipe de segurança, especialistas no assunto, em conjunto com o Comitê Gestor (Steering committee), que traz a visão do negócio para a política.

No gerenciamento de segurança no dia-a-dia, sugere-se a divisão dos processos em duas partes, tendo uma específica para a automação do chão de fábrica, utilizando a ISA-99. A ISA-99 foi criada com o objetivo de permitir que as redes de controle utilizem a tecnologia e experiência da segurança da informação por meio de soluções práticas que não causem problemas e inclui todas as aplicações do chão de fábrica. 


\subsubsection{Gerenciamento de fornecedores}

O processo de gerenciamento de fornecedores tem por objetivo gerenciar os contratos de serviços. Isto inclui todo o ciclo de vida de um contrato: seleção de fornecedores, manutenção de uma base de fornecedores classificados, avaliação de contratos, negociação e aprovação, revisão, renovação e encerramento. Este processo está relacionado ao DS2 do COBIT. Aqui se sugere um processo único, pois, conforme sugerido por Ramirez e Zucareli (s.d), a gestão de contratos de terceiros é interessante que seja centralizada.

\subsubsection{Gerenciamento financeiro}

Dentro das operações do dia-a-dia, também deve-se realizar o gerenciamento financeiro operacional (gerenciamento dos custos das operações, mencionado no COBIT e na ITIL), apurando e analisando os custos (por usuário, por serviço) e efetuando a cobrança (faturamento e cobrança dos serviços de $\mathrm{TI}$ ) de acordo com a estratégia pré-definida. Este processo também pode ser único, tratando de forma centralizada a apuração dos custos.

\subsubsection{Gerenciamento de mudanças}

Tratando de transição, tem-se o gerenciamento de mudanças, o gerenciamento de liberações e o gerenciamento de configuração. $O$ gerenciamento de mudanças (associado ao processo Al6 do COBIT) busca garantir que as mudanças sejam registradas, avaliadas, autorizadas, priorizadas, planejadas, testadas, implementadas, documentadas e revisadas. É importante que as mudanças sejam categorizadas para auxiliar na priorização. Os tipos usuais são:

- Mudança normal, como uma implementação planejada final de um projeto;

- Mudança emergencial, como uma mudança decorrente de um incidente que impacta a empresa e 
- Mudança padrão, como uma instalação de software em computador de usuário.

Esta última é tratada no gerenciamento de requisições, pois refere-se a pedidos usuais dentro de um ambiente empresarial.

Para garantir que as mudanças tenham a avaliação adequada sob o ponto de vista técnico e de negócio, pode-se criar um comitê responsável. É importante que este gerenciamento seja realizado de maneira integrada, para avaliar todos os impactos de forma holística. Além disso, deve-se considerar que qualquer mudança implica em impacto e risco, mas o risco deve ser controlado e o impacto, reduzido.

O processo de gerenciamento de mudanças possui uma relação com gerenciamento de projetos, pois a mudança é um processo temporário que poderá criar um novo serviço ou produto, ou seja, um novo projeto. É importante que este gerenciamento seja realizado de maneira integrada, para avaliar todos os impactos de forma holística.

\subsubsection{Gerenciamento de liberações}

Associado ao gerenciamento de mudanças está o gerenciamento de liberações (ligado ao processo Al7 do COBIT), que trata da construção, teste e entrega de serviços. O processo busca garantir a proteção do ambiente de produção e visa assegurar a consistência, estabilidade, disponibilidade e continuidade dos serviços de TI. Sugere-se um processo distinto para cada um dos ambientes, pois as características de entrega nos quatro ambientes acima descritos são bem diferentes - as mudanças são avaliadas em conjunto. Por exemplo, uma liberação em ambiente de controle e operação da produção deve considerar as janelas da manutenção da planta, enquanto a liberação de sistemas corporativos deve considerar, por exemplo, a semana do fechamento financeiro. 


\subsubsection{Gerenciamento de configuração}

O gerenciamento de configuração trata da definição e controle dos ativos, mantendo registros atualizados de hardware, software, documentos e pessoal de suporte. É importante que estes dados sejam armazenados em uma biblioteca segura.

No modelo proposto, sugere-se incluir este processo na parte de operações do diaa-dia e dividir o gerenciamento de configuração em três partes também, para obter um melhor controle. A política de sobressalentes também é considerada neste processo e, para o caso do chão de fábrica, deve ser mais rígida, pois garantirá a não parada da produção.

O gerenciamento de configuração também acompanha todo o ciclo de vida de um ativo e é um importante processo de apoio aos demais processos de TI. Sugere-se dividir o gerenciamento de configuração em quatro partes também, para melhor controle dos ativos e para incorporar as diferentes políticas necessárias

\subsubsection{Gerenciamento de eventos}

O gerenciamento de eventos, relacionado ao processo DS13 do COBIT, busca detectar, correlacionar e agir frente a algum evento pré-determinado. Os eventos podem ser apenas informativos, de prevenção ou exceção, que deve ser tratado o quanto antes pela equipe de gerenciamento de incidentes (explicado a seguir). Este processo precisa ser incluído no modelo e sugere-se um processo específico para o chão de fábrica, com procedimentos distintos para detecção mais rápida de eventos, que contam com a colaboração dos operadores que estão na linha de produção.

\subsubsection{Service Desk}

Como ponto único de contato entre os clientes e a TI deve haver uma central de serviços integrada, capaz de receber os chamados de diferentes áreas com 
diferentes necessidades e tomar as devidas providências. Este primeiro nível de atendimento é muito importante por ser a primeira impressão do usuário quanto ao atendimento de TI.

A equipe desta área deve ter os conhecimentos necessários para atender a qualquer chamado da maneira correta, oferecendo uma abordagem global e especialista ao mesmo tempo. Estruturas centralizadas de atendimento são as mais usuais, recomendadas em grande parte das melhores práticas ("ponto único de contato").

\subsubsection{Gerenciamento de incidentes}

O gerenciamento de incidentes tem por objetivo restaurar o serviço o mais rápido possível, registrando, categorizando, priorizando, diagnosticando, investigando, resolvendo e encerrando o incidente. Associados à resolução do incidente, estão os níveis de serviço, definindo as prioridades de resolução e recebendo os índices de níveis de serviço relacionados a incidentes registrados.

Um incidente, para ser resolvido no menor tempo possível, precisa de uma equipe com conhecimentos e recursos necessários para solucioná-lo. Neste aspecto, o mecanismo de escalonamento é muito importante - se o primeiro nível não resolve, existe um segundo nível mais especializado.

Sugere-se no modelo a divisão do gerenciamento de incidentes em três, com um especifico para os sistemas de controle e operação, outro para os sistemas de controle e outro para os sistemas corporativos e de desenho de produto e processo. Nos dois primeiros casos, deve haver uma equipe local para atendimento e um processo diferenciado, mais rápido, para atender aos níveis de serviço que costumam ser muito mais exigentes.

\subsubsection{Gerenciamento de requisições}

As mesmas equipes de gerenciamento de incidentes podem tratar das requisições, controladas pelo processo de gerenciamento de requisições, que nada mais são 
que mudanças padrão, pré-aprovadas. Este processo trata também os pedidos de informação e reclamações.

\subsubsection{Gerenciamento de problemas}

Para prevenir incidentes e problemas maiores, eliminar recorrências e diminuir os impactos daqueles eventos que não podem ser prevenidos, existe o gerenciamento de problemas, que busca analisar e entender as causas raízes dos acontecimentos importantes. Os erros conhecidos são armazenados em uma base de dados de erros conhecidos e, enquanto não há uma solução definitiva, deve-se definir uma ação de contorno. Ao final do processo, é importante que hajam lições aprendidas e sejam identificadas eventuais necessidades de mudança. Sugere-se um processo único de estudo dos problemas e reutilização das análises, independentemente do ambiente sistêmico.

\subsubsection{Arquitetura}

Ainda falta detalhar o processo de gerenciamento da arquitetura corporativa (envolvendo todos os ambientes). O ADM (Architecture Development Method), núcleo do TOGAF, é um método iterativo para desenvolvimento e implantação da arquitetura escolhida e uma boa referência para o desenvolvimento de arquiteturas em manufatura também.

Quando se fala em arquitetura empresarial, inclui-se a arquitetura de processos de negócio, que deve ser baseada na estratégia e visão da empresa, além da arquitetura de dados, aplicações e infraestrutura. Para detalhar a arquitetura de dados atendendo aos requisitos do chão de fábrica, a parte 2 da ISA 95 pode entrar como referência para o modelo de Governança de TI proposto para definir dados e estruturas. A arquitetura de aplicações também pode utilizar a ISA 95 como referência. Já a parte de infraestrutura não tem relação direta com a ISA 95, mas esta pode ser utilizada para analisar ou definir a infraestrutura necessária. 
De acordo com os requisitos necessários para o nosso modelo, é importante que sejam desenvolvidos princípios-guia de design (como permitir manutenção sem desligamento do sistema) e que as arquiteturas sejam o mais padronizadas o possível, reduzindo custos e tempo de desenvolvimento e facilitando o suporte. $O$ uso do TOGAF relaciona-se aos processos PO2 e PO3, além do Al1 ("Identificar as soluções de automação") do COBIT.

\subsubsection{Qualidade}

O processo de gerenciamento da qualidade deve captar os dados de monitoramento de projetos, serviços e de metas em geral e buscar melhorar continuamente os processos e serviços de $\mathrm{TI}$, para garantir que estão atendendo aos níveis de serviço esperados. Pode incluir também a verificação da satisfação do cliente.

\subsubsection{Recursos Humanos}

É importante que haja um processo de gerenciamento de recursos humanos de TI que trate de recrutamento, treinamento, avaliação de desempenho, promoção e desligamento de pessoal de TI, garantindo a execução das atividades da melhor forma e até mesmo a segurança das informações. A parte específica de treinamento é tratada na seção de mecanismos relacionais.

Este processo deve possuir, também, um catálogo de pessoal e conhecimentos, entender a demanda atual e futura de pessoal, identificar deficiências na equipe e planejar como supri-las. Com isto, atende-se aos processos PO7 do COBIT e PM3 do Val IT.

Algumas empresas promovem a rotação de funções ("job rotation") entre áreas, seja com pessoal sênior de $\mathrm{TI}$ assumindo posições chave de negócio ou como parte do plano de carreira dos profissionais. 


\subsection{Detalhamento de acordo com eSCM-SP / eSCM-CL e CMMi}

Dos modelos mais utilizados pelo mercado, ainda precisam ser analisados eSCM-SP / eSCM-CL, CMMi, OPM3 / P3M3, BSC e Seis Sigma.

\subsubsection{Terceirização}

O eSCM refere-se à estratégia de terceirização, um importante item que precisa ser incluído no modelo proposto, que irá nortear o relacionamento com fornecedores. No caso estudado, este ponto pode ser trabalhado tendo por base o eSCM-CL (cliente), pois se trata de uma empresa de manufatura. O CMMi-ACQ também pode ser utilizado.

A partir da estratégia geral de $\mathrm{TI}$, dos princípios de $\mathrm{TI}$, desenvolve-se os objetivos e a estratégia de terceirização - sourcing ${ }^{8}$ (que inclui a estratégia de aquisições) que serão entradas também para o portfólio de TI.

O modelo possui noventa e cinco práticas agrupadas em dezessete áreas de capacitação:

1. Gestão da estratégia de sourcing.

2. Gestão da governança.

3. Gestão do relacionamento.

4. Gestão do valor.

5. Gestão da mudança organizacional.

6. Gestão de pessoas.

\footnotetext{
${ }^{8}$ Sourcing refere-se ao processo de escolher fontes para realizar atividades necessárias ao negócio. O outsourcing refere-se à contratação de um terceiro; o insourcing refere-se a desenvolver as atividades internamente; o multisourcing refere-se a escolher diversas fontes para as diferentes atividades.
} 
7. Gestão do conhecimento.

8. Gestão da tecnologia.

9. Gestão de ameaças.

10. Análise de oportunidades de sourcing.

11. Abordagem de sourcing.

12. Planejamento do sourcing.

13. Avaliação de fornecedor de serviço.

14. Acordos de serviços.

15. Transferência de serviços.

16. Gestão dos serviços contratados.

17. Encerramento do sourcing (SOARES, 2008).

Da mesma forma que outros modelos, este também possui cinco níveis de capacitação, que mostram o caminho de evolução do cliente de serviços rumo à excelência em gestão de sourcing:

- Nível 1 - Desempenhando o sourcing;

- Nível 2 - Gestão consistente do sourcing;

- Nível 3 - Gerenciamento organizacional do desempenho do sourcing;

- Nível 4 - Aperfeiçoar o valor gerado proativamente;

- Nível 5 - Sustentando a Excelência.

Dentre as áreas de capacitação, verifica-se a sobreposição com outros modelos de administração de $\mathrm{TI}$, ou seja, pode-se utilizá-los de maneira complementar ao eSCM. É possível, por exemplo, verificar um paralelo deste processo com o Al2 do 
COBIT (adquirir e manter os softwares). Utilizar o eSCM (ou o CMMi), do ponto de vista interno, permite melhores serviços, qualidade e confiabilidade.

O CMMi-DEV, utilizado para o processo de desenvolvimento de software, é utilizado em empresas que desenvolvem software, o que não é o caso de aplicação do modelo de governança proposto.

Os modelos OPM3 / P3M3, BSC e Seis Sigma são relacionados com a coluna da esquerda do modelo (métricas e responsabilidades de $\mathrm{TI}$ ) e serão tratadas a seguir.

\subsection{Detalhamento dos mecanismos relacionais e abordagens de comunicação}

Ainda precisam ser detalhados no modelo os aspectos de mecanismos relacionais e abordagens de comunicação.

\subsubsection{Gerentes de relacionamento}

Quanto aos mecanismos relacionais e abordagens de comunicação, sugere-se a determinação de um gerente de relacionamento, como feito por Weill e Ross (2006) - uma pessoa de TI responsável por atender determinadas áreas de negócio e estabelecer a comunicação entre a área de negócio e a área de $\mathrm{TI}$ para as discussões necessárias. Esta pessoa seria da área de $\mathrm{TI}$ e faria parte das equipes de projetos, gerenciando-os. É um mecanismo popular para a implementação de arranjos do tipo duopólio.

\subsubsection{Planejamento de comunicação}

Os mecanismos de comunicação são, também, valiosos e destinam-se a difundir decisões e processos de Governança de TI, além de comportamentos desejáveis. Deve haver um planejamento da comunicação de $\mathrm{Tl}$ e sugere-se incluir neste plano as seguintes ferramentas: 
- Comunicados da alta gerência que esclareçam prioridades;

- Treinamento dos gerentes de relacionamento para comunicação dos motivos da Governança de TI às áreas de negócio;

- Comunicação via web de políticas, padrões e indicadores de TI.

Além disso, podem ser realizadas campanhas de conscientização periódicas sobre estratégia e Governança de TI, e, também, sobre riscos e políticas de TI, conforme sugerido no processo PO6 do COBIT.

Sugere-se incluir neste modelo mecanismos de comunicação de TI que sejam efetivos no chão-de-fábrica, considerando que nem todos os funcionários têm acesso a computadores durante o expediente de trabalho. Estes mecanismos podem incluir folhetos, avisos em murais, manuais impressos disponibilizados em locais determinados e reuniões rápidas.

\subsubsection{Planejamento de treinamentos}

Treinamentos podem fazer parte dos mecanismos relacionais, buscando, além de estreitar o relacionamento da TI com o negócio, esclarecer e disseminar o uso das ferramentas e serviços disponibilizados da melhor maneira. Isto inclui o treinamento de usuários, como mencionado no processo DS7 do COBIT e treinamento em projetos e gerenciamento de liberações, como mencionado no processo Al7, e do pessoal de $\mathrm{TI}$.

Treinamentos conjuntos das equipes também podem ser realizados, permitindo maior intercâmbio e entendimentos das necessidades de cada parte. Estes treinamentos cruzados podem tanto ser convites a pessoas-chave de outra área para participação em treinamentos, quanto turmas combinadas para treinamento em determinado assunto.

Workshops podem ser realizados com o intuito de discutir os processos das áreas e compartilhar como o trabalho de uma afeta 0 trabalho da outra. Tão importante quanto os processos são as pessoas neles envolvidas. $O$ 
relacionamento/comunicação é fator essencial para o alinhamento e trabalho colaborativo.

\subsubsection{Documentação de sistemas e processos}

Relacionada aos treinamentos, está também a documentação de TI, que possibilita a operação e uso dos sistemas (como sugerido o Al4 do COBIT), além da documentação de sistemas e processos.

\subsection{Metas de desempenho do negócio}

As metas de desempenho do negócio serão entradas para a definição das métricas e responsabilidades de $\mathrm{Tl}$, importantes para auferir o quanto a $\mathrm{TI}$ está atendendo ao negócio e levantar o que pode ser melhorado. Como entradas para estes processos, devem estar também as metas de produção.

\subsection{Métricas e responsabilidades de TI}

Quanto às métricas, um dos aspectos que pode auxiliar na atuação conjunta entre as áreas é a existência de indicadores compartilhados de objetivos entre as áreas.

Muitos dirigentes concentram-se nos indicadores e problemas específicos de suas áreas. As métricas raramente consideram um cenário integrado, com a TI medindo custos de suporte e disponibilidade de equipamentos e a automação focando em questões que podem impactar a produção. A gestão integrada dos indicadores poderá retroalimentar o modelo como um todo, apontando quais ações são necessárias para melhorar o desempenho do negócio. Seriam exemplos de indicadores compartilhados a quantidade de incidentes ocorrida no chão de fábrica, a quantidade de mudanças planejadas e implementadas em conjunto, a quantidade de projetos conjuntos concluídos dentro do prazo e custo previsto. 
O BSC-TI (Balanced Scorecard) pode ser utilizado para isto. As quatro perspectivas do modelo são:

- Contribuição para o negócio: como a direção da empresa vê o departamento de TI;

- Orientação a usuários: como os usuários vêm o departamento de TI;

- Excelência operacional: quão eficazes e eficientes são os processos de TI e

- Orientação para o futuro: quão bem a TI está posicionada para atender às futuras necessidades da empresa.

COBIT pode ser utilizado em conjunto de duas formas:

- Avaliando a maturidade dos processos internos, dentro da perspectiva de excelência operacional;

- Como base para a definição dos indicadores dentro de cada perspectiva. Primeiro, consulta-se os objetivos de negócio e, então, se faz a ligação com os objetivos de TI (ligação presente no COBIT). Com isto em mãos, consultase se os processos atendem aos objetivos identificados de $\mathrm{Tl}$ e quais indicadores são listados dentro de cada um desses processos.

O OPM3 e o P3M3 também podem ser utilizados em conjunto para a definição de metas e métricas relacionadas ao gerenciamento dos projetos de Tl.

Cada uma das perspectivas do BSC-TI deve ser traduzida em métricas para avaliar a situação atual e repetir a avaliação periodicamente, segundo um processo de melhoria contínua. O método DMAIC do Seis Sigma pode auxiliar neste processo: Definir, Medir, Analisar, Melhorar e Controlar. O Seis Sigma ajuda a melhorar e inovar no processo, construindo qualidade em torno de processos e pessoas. Podese também utilizar os conceitos de "Lean" para tornar os processos mais eficientes e eficazes.

O processo de Relatório de Serviço está associado ao ciclo acima mencionado e é responsável pela geração e fornecimento de relatórios sobre os resultados 
alcançados e o desenvolvimento nos níveis de serviços. É necessário que formato, conteúdo e frequência dos relatórios sejam acordados entre TI e o negócio.

\subsection{Modelo proposto}

Chega-se, portanto, ao modelo completo descrito na Figura 45. Com estes processos, temos o conjunto sugerido de acordo com as melhores práticas/referências de todos os processos que precisam ser trabalhados para a criação de um modelo integrado que atenda aos diferentes requisitos de uma indústria. São também atendidos os seis requisitos da ISO 38500 e os requisitos listados na seção 3.2, conforme detalha a Tabela 9.

Tabela 9 - Atendimento aos requisitos

\begin{tabular}{|c|c|}
\hline Requisito Geral & Atendimento ao requisito \\
\hline $\begin{array}{l}\text { Definir os direitos decisórios, formalizando e } \\
\text { comunicando papeis e responsabilidades, de forma a } \\
\text { deixar claro quem faz o quê, quem é responsável, } \\
\text { quem é consultado e quem é informado. }\end{array}$ & $\begin{array}{l}\text { A definição dos arquétipos descreve } \\
\text { combinações de pessoas que tomam } \\
\text { decisões ou contribuem para a tomada de } \\
\text { decisões de } \mathrm{TI} \text { dentro das empresas. As } \\
\text { estruturas organizacionais propostas } \\
\text { colocam estes arquétipos em prática. }\end{array}$ \\
\hline $\begin{array}{l}\text { Definir estruturas de governança que busquem a } \\
\text { otimização dos investimentos de toda a empresa, e } \\
\text { ao mesmo tempo evitem investimento em valor } \\
\text { inferior ao necessário, o que pode acarretar } \\
\text { problemas no médio e longo prazos. }\end{array}$ & $\begin{array}{l}\text { O processo de Gerenciamento do Portfólio } \\
\text { em conjunto com os processos de } \\
\text { Gerenciamento de Demanda e Decisão e } \\
\text { Investimento fazem com que as áreas } \\
\text { trabalhem os investimentos em conjunto e, } \\
\text { ao mesmo tempo, considerem as } \\
\text { necessidades da empresa. }\end{array}$ \\
\hline $\begin{array}{l}\text { Estabelecer uma estrutura responsável pela } \\
\text { Governança de TI que garanta que o modelo de } \\
\text { governança seja implementado e sustentado de } \\
\text { acordo com as estratégias e prioridades da empresa. }\end{array}$ & $\begin{array}{l}\text { O escritório do ClO tem esta atribuição, } \\
\text { dentre outras. }\end{array}$ \\
\hline $\begin{array}{l}\text { Considerar o comportamento humano, visto que a } \\
\text { governança envolve, além de mudanças em } \\
\text { processos, mudanças culturais. }\end{array}$ & $\begin{array}{l}\text { Os mecanismos relacionais tratam do } \\
\text { relacionamento entre pessoas (e áreas) e as } \\
\text { abordagens de comunicação levam a TI a } \\
\text { todos que dela dependem. }\end{array}$ \\
\hline $\begin{array}{l}\text { Considerar a criação de uma arquitetura padrão de } \\
\text { referência para todos os ambientes, bem como } \\
\text { princípios-guia de design, garantindo agilidade e } \\
\text { menores tempos de resposta, além de reuso e } \\
\text { manutenção simplificada. }\end{array}$ & $\begin{array}{l}\text { A equipe de arquitetura integrada (TI + } \\
\text { automação) tem o papel de definir a } \\
\text { arquitetura e cuidar do processo. }\end{array}$ \\
\hline $\begin{array}{l}\text { Estabelecer diferentes equipes: para projetos; para } \\
\text { estabelecer padrões; para operações, de forma que } \\
\text { as especializações atendam aos requisitos de cada } \\
\text { ambiente, além de permitir melhor gerenciamento } \\
\text { das atividades. }\end{array}$ & $\begin{array}{l}\text { O modelo considera estruturas específicas } \\
\text { para projeto, segurança, serviços e demais } \\
\text { atividades da área de TI. }\end{array}$ \\
\hline $\begin{array}{l}\text { Trabalhar com um portfólio de TI único, permitindo a } \\
\text { visão de todos os tipos de projetos, infraestruturas e } \\
\text { serviços, sejam do escritório ou do chão de fábrica, } \\
\text { além do gerenciamento integrado da demanda. }\end{array}$ & $\begin{array}{l}\text { Requisito atendido pelos processos de } \\
\text { Gerenciamento do Portfólio } \\
\text { Gerenciamento de Demanda. }\end{array}$ \\
\hline
\end{tabular}




\begin{tabular}{|c|c|}
\hline $\begin{array}{l}\text { Estabelecer processos de gerenciamento de } \\
\text { serviços para os diferentes ambientes, } \\
\text { considerando-se as diferentes demandas específicas } \\
\text { de cada ambiente. }\end{array}$ & $\begin{array}{l}\text { Os processos de transição e operação são } \\
\text { divididos, quando necessário, entre os } \\
\text { diferentes ambientes que existem em uma } \\
\text { indústria. }\end{array}$ \\
\hline $\begin{array}{l}\text { Considerar o gerenciamento de todos os ativos, } \\
\text { mesmo os de maior ciclo de vida, visto que uma } \\
\text { indústria tem diferentes tipos de ativos, com } \\
\text { características muito distintas. }\end{array}$ & $\begin{array}{l}\text { G Gerenciamento de Configuração é } \\
\text { dividido entre os diferentes ambientes de } \\
\text { forma a considerar os diferentes ciclos de } \\
\text { vida. }\end{array}$ \\
\hline $\begin{array}{l}\text { Viabilizar o gerenciamento de mudanças integrado, } \\
\text { verificando-se todos os impactos decorrentes das } \\
\text { mudanças nos diferentes ambientes. }\end{array}$ & $\begin{array}{l}\text { O Gerenciamento de Mudanças proposto é } \\
\text { único. }\end{array}$ \\
\hline $\begin{array}{l}\text { Considerar as exigências de segurança da } \\
\text { informação nos diferentes ambientes, dadas as } \\
\text { diferentes características na forma de processar e } \\
\text { fornecer as informações na cadeia. }\end{array}$ & $\begin{array}{l}\text { O Gerenciamento de Segurança proposto é } \\
\text { dividido em duas partes, um para os } \\
\text { ambientes corporativo, de desenho de } \\
\text { produto e processo e de gestão da produção } \\
\text { e o outro específico para os sistemas de } \\
\text { controle, que possuem diferentes } \\
\text { características e nem sempre suportam os } \\
\text { mecanismos utilizados nos demais sistemas. }\end{array}$ \\
\hline $\begin{array}{l}\text { Desenvolver mecanismos de emissão de relatórios } \\
\text { de resultados (de projetos e operações) integrados, } \\
\text { permitindo uma visão holística do ambiente de forma } \\
\text { que seja possível entender o impacto do trabalho de } \\
\text { cada área no todo, incentivando o trabalho } \\
\text { colaborativo. }\end{array}$ & $\begin{array}{l}\text { O modelo propõe indicadores } \\
\text { compartilhados, além do BSC-TI (Balanced } \\
\text { ScoreCard - Information Technology) e } \\
\text { relatórios de serviço para todos os } \\
\text { ambientes. }\end{array}$ \\
\hline $\begin{array}{l}\text { Estabelecer uma estrutura de comunicação } \\
\text { apropriada, considerando comitês, ferramentas e } \\
\text { outros meios disponíveis para atingir os diferentes } \\
\text { ambientes. }\end{array}$ & $\begin{array}{l}\text { ntes abordagens de } \\
\text { atender a todos os } \\
\text { tria. }\end{array}$ \\
\hline $\begin{array}{l}\text { Estabelecer mecanismos de relacionamento entre as } \\
\text { diferentes áreas, visto que têm diferentes hábitos e } \\
\text { práticas de trabalho. }\end{array}$ & $\begin{array}{l}\text { Os gerentes de relacionamento, as } \\
\text { campanhas de conscientização, os } \\
\text { treinamentos conjuntos e os workshops } \\
\text { buscam estabelecer este relacionamento. }\end{array}$ \\
\hline $\begin{array}{l}\text { Considerar o levantamento de lições aprendidas em } \\
\text { projetos e operações para a criação de uma base de } \\
\text { conhecimento. }\end{array}$ & $\begin{array}{l}\text { Isto será considerado dentro do processo de } \\
\text { melhoria contínua. }\end{array}$ \\
\hline $\begin{array}{l}\text { Auditar os resultados de projetos e de operações, } \\
\text { garantindo que as informações estão sendo } \\
\text { transmitidas e utilizadas da forma correta. }\end{array}$ & $\begin{array}{l}\text { processos } \\
\text { Sontínua. }\end{array}$ \\
\hline Requisito Específico Chão de Fábrica & sito \\
\hline $\begin{array}{l}\text { Considerar aspectos do chão-de-fábrica nos } \\
\text { princípios-guia de design, como permitir manutenção } \\
\text { sem desligamento do sistema no caso de } \\
\text { equipamentos do chão de fábrica. }\end{array}$ & $\begin{array}{l}\text { O time de arquitetura integrado proposto é } \\
\text { responsável pelo processo de arquitetura e, } \\
\text { por possuir membros das diferentes áreas, } \\
\text { irá considerar as diferentes necessidades e } \\
\text { atende a este requisito. }\end{array}$ \\
\hline $\begin{array}{l}\text { Considerar regras especiais de segurança da } \\
\text { informação para os sistemas de controle, pois eles } \\
\text { apresentam características diferentes dos sistemas } \\
\text { utilizados em escritório. }\end{array}$ & $\begin{array}{l}\text { Conforme mencionado, o modelo propõe um } \\
\text { processo distinto para o chão de fábrica. }\end{array}$ \\
\hline $\begin{array}{l}\text { Considerar que a infraestrutura dos sistemas de } \\
\text { chão-de-fábrica deve ser controlada de forma isolada } \\
\text { e necessariamente ser redundante. }\end{array}$ & $\begin{array}{l}\text { A infraestrutura isolada e redundante é um } \\
\text { princípio tratado pela equipe integrada de } \\
\text { arquitetura. }\end{array}$ \\
\hline $\begin{array}{l}\text { Estabelecer regras de atendimento e manutenção } \\
\text { local, mas rápidas que as utilizadas para o ambiente } \\
\text { de escritório. }\end{array}$ & $\begin{array}{l}\text { O Gerenciamento de Incidentes é dividido } \\
\text { em diferentes partes para atender a este } \\
\text { requisito. }\end{array}$ \\
\hline $\begin{array}{l}\text { Considerar uma política de sobressalentes mais } \\
\text { rígida para o chão-de-fábrica, dada a urgência na } \\
\text { correção de incidentes neste ambiente. }\end{array}$ & $\begin{array}{l}\text { O Gerenciamento de Configuração separado } \\
\text { para cada ambiente busca garantir esta } \\
\text { diferenciação. }\end{array}$ \\
\hline Estabelecer mecanismos de comunicação que sejam & O modelo propõe um processo específico de \\
\hline
\end{tabular}


efetivos no chão-de-fábrica, visto que, por exemplo, comunicação no chão de fábrica.

nem todos os funcionários têm acesso a

computadores durante o expediente de trabalho.

\subsection{Considerações finais do capítulo}

Neste capítulo foi apresentado o modelo integrado proposto. A empresa que o utilizar será capaz de definir o que levar em consideração estratégica, tática e operacionalmente para obter um ambiente de Governança de TI único, do escritório ao chão de fábrica. Não se espera que um modelo deste porte seja implementado em apenas uma etapa, mas que sirva de base para um projeto maior, de diversas fases.

Nas próximas seções, descrevem-se o estudo de caso realizado para testar este modelo e as análises do estudo. 


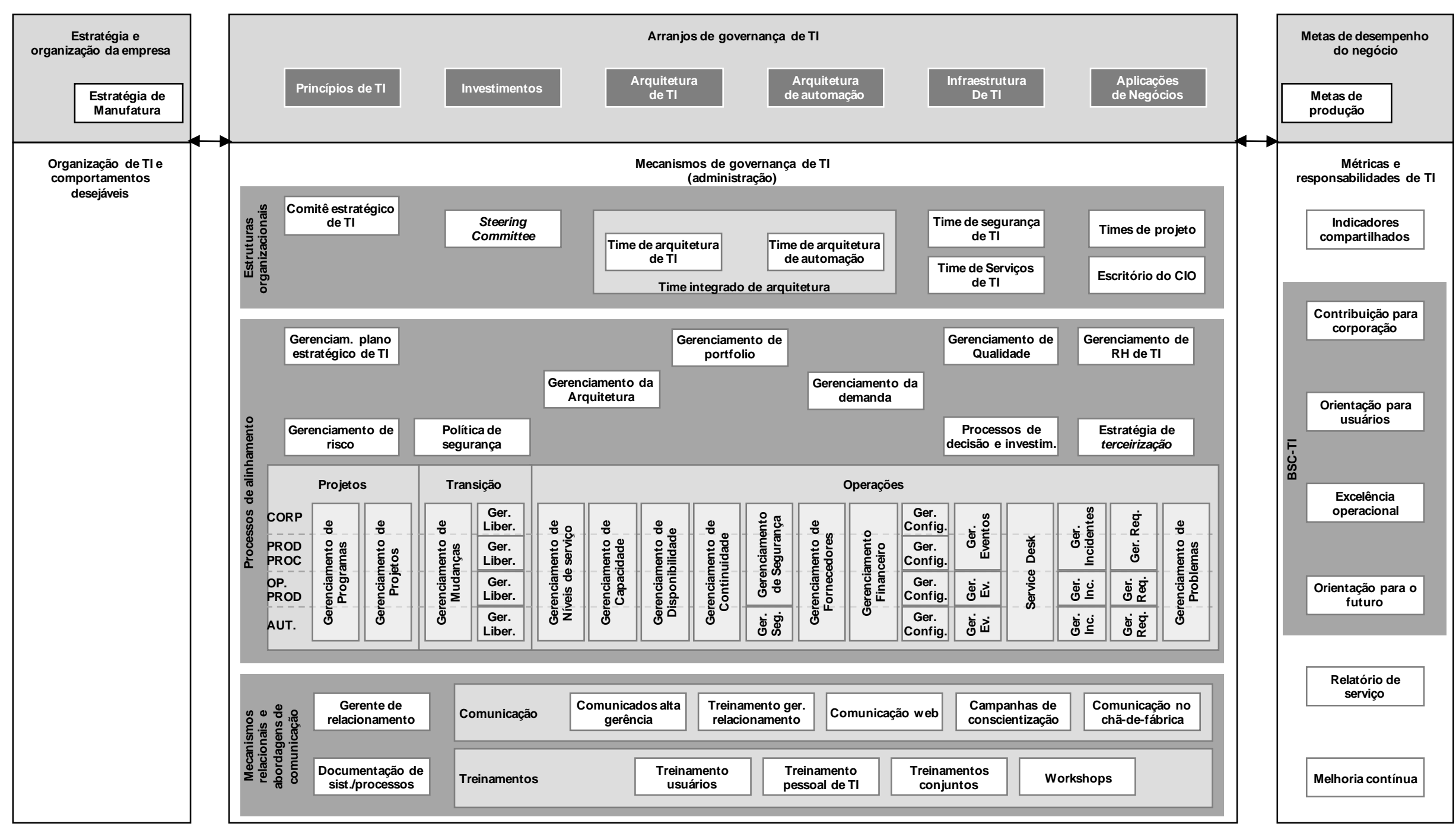

Figura 45 - Modelo proposto 


\section{ESTUDO DE CASO}

O modelo sugerido tem por objetivo responder à pergunta "como integrar a Governança de $\mathrm{Tl}$ através de um modelo, considerando sua utilização em processos corporativos e de produção?".

Para validar o modelo proposto, é utilizado o estudo de caso de uma empresa que produz carros. Este capítulo tem por objetivo descrever a situação atual na empresa estudada para possibilitar a validação do modelo proposto. Os tópicos abordados neste capítulo são os seguintes:

- Indústria automobilística: apresentação do segmento e histórico;

- Tecnologia da Informação na indústria automobilística: como a TI tem sido empregada neste segmento;

- Empresa estudada: apresentação da empresa Carros, histórico e estratégia;

- TI na empresa Carros: como a TI é vista e utilizada para suportar as operações da empresa Carros;

- Estado atual da Governança de TI na empresa estudada: como é a Governança de TI na Carros, de acordo com cada item do modelo proposto;

- Estado desejado da Governança de TI na empresa estudada e como a empresa pretende alcançá-lo: o que a Carros tem por meta para a Governança de $\mathrm{Tl}$ e como pretende alcançar esta meta.

Para fins de elaboração deste estudo de caso, foram entrevistadas 26 pessoas distribuídas como descreve a Tabela 10.

Tabela 10 - Entrevistados e respectivas áreas

\begin{tabular}{|c|l|}
\hline Quantidade & Área \\
\hline 1 & CIO (duas entrevistas) \\
\hline 7 & $\begin{array}{l}\text { Gerentes de relacionamento da TI com o negócio: um supervisor, um } \\
\text { proveniente da área de negócio, quatro que lidam com as áreas de desenho de } \\
\text { produto e processo e um que lida com a área de automação. }\end{array}$ \\
\hline 5 & $\begin{array}{l}\text { Especialistas da área de serviços de TI, sendo um oriundo da área de } \\
\text { Manutenção do chão de fábrica, um que trata de arquitetura, um que trata de } \\
\text { segurança, um que trata de processos de serviços e outros que atendem a } \\
\text { incidentes e problemas das áreas de desenho de produto e processo. }\end{array}$ \\
\hline
\end{tabular}




\begin{tabular}{|c|c|}
\hline 5 & $\begin{array}{l}\text { Analistas e supervisor que trabalham com assuntos relacionados à estrutura } \\
\text { proposta no modelo "Escritório do CIO" (riscos, Governança de TI, projetos, } \\
\text { treinamentos). }\end{array}$ \\
\hline 1 & Supervisor que trabalha com finanças dentro da área de $\mathrm{TI}$. \\
\hline 1 & $\begin{array}{l}\text { Supervisor responsável por projetos consultivos de gestão em toda a empresa, } \\
\text { respondendo por questões de TI dentro destas consultorias. }\end{array}$ \\
\hline 6 & $\begin{array}{l}\text { Áreas de negócio (inclui automação, áreas responsáveis por desenho de } \\
\text { produtos e processos e outras áreas). }\end{array}$ \\
\hline \multicolumn{2}{|r|}{ Total $=26$ entrevistados de diferentes níveis hierárquicos, áreas e funções } \\
\hline
\end{tabular}

O período de realização das entrevistas foi de maio a agosto de 2011. As perguntas da pesquisa foram validadas pelo CIO. Para tornar o estudo de caso mais robusto, foram levadas em conta as observações diretas, análises documentais, informações obtidas nas entrevistas e verificações das informações com diferentes entrevistados.

O protocolo utilizado para balizar as entrevistas é descrito na Figura 46. As perguntas foram feitas de acordo com as responsabilidades do entrevistado.

Além deste protocolo, foram utilizadas perguntas sugeridas por Weill e Ross (2006) para atribuir uma nota à Governança de TI da empresa, conforme ilustra a Figura 47. 


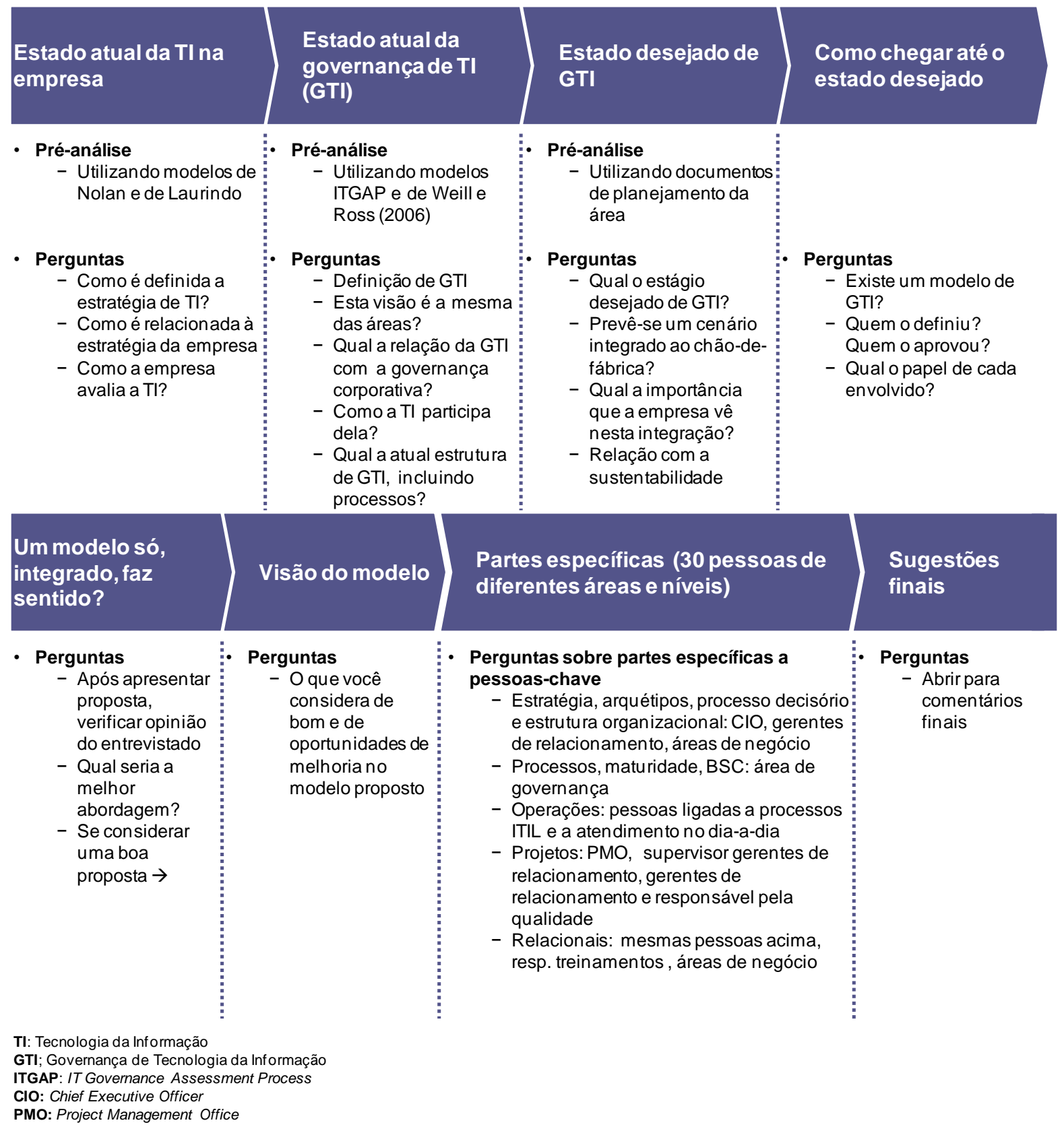

Figura 46 - Protocolo utilizado nas entrevistas 
1. Qual a importância dos seguintes resultados de sua governança de TI, numa escala de 1 (Sem importância) a 5 (Muito importante)?

- Uso da TI com boa relação custo/benefício

- Uso eficaz da TI para o crescimento

- Uso eficaz da TI para a utilização de ativos

- Uso eficaz da TI para a flexibilidade dos negócios

2. Qual a influência da governança de Tl em seu negócio nas seguintes medidas de sucesso, numa escala de 1 (Sem sucesso) a 5 (Muito bem0 ucedida)?

- Uso da TI com boa relação custo/benefício

- Uso eficaz da TI para o crescimento

- Uso eficaz da TI para a utilização de ativos

- Uso eficaz da TI para a flexibilidade dos negócios

3. Quais as áreas em que a governança de TI funciona melhor? Por quê?

4. Quais as áreas em que a governança de TI não é eficaz? Por quê?

Figura 47 - Perguntas para avaliar a Governança de TI (WEILL; ROSS, 2006)

A seguir, são apresentados: a história da indústria automobilística; o desenvolvimento da Tecnologia da Informação neste setor; a empresa em que foi realizado o estudo de caso; e as informações que foram levantadas.

\subsection{A indústria automobilística}

A história do automóvel começou em 1886, quando Carl Benz entrou com o pedido de patente de seu carro motorizado, um triciclo equipado com motor de combustão. Em paralelo, Nikolaus August Otto já havia patenteado, em 1876, um motor batizado com seu nome e, em 1892, Rudolf Diesel entrou com o pedido de patente de sua versão de motor de combustão.

As primeiras fábricas de automóveis surgiram por volta de 1890 na Europa e nos Estados Unidos e, em 1913, Henry Ford iniciou a produção em massa do Ford T, através de uma linha de montagem.

O paradigma da Ford predominou até 1970, quando o modelo Toyota de produção o suplantou. Neste modelo, predomina a filosofia "Just-in-time", que busca operar com estoque zero, além de ser dada uma especial atenção à qualidade e a zero-defeito (ULRICH, 2011). 
Atualmente, os principais desafios da indústria automobilística relacionam-se à alta competitividade, excesso de capacidade de fabricação, alianças e fusões complexas, concorrência global, estagnação da demanda, redução na lealdade pela marca, legislação (ambiental, segurança), aquisição de matéria prima e custos com energia (SCHWARZ, 2008).

\subsubsection{Brasil}

O primeiro veículo motorizado chegou ao Brasil em 1891 pelas mãos de Alberto Santos Dumont. As primeiras indústrias automotivas do Brasil vieram de outros países logo depois, no início do século XX.

O setor passou, então, por diversas dificuldades, como conseqüência da Segunda Grande Guerra e da desatualização tecnológica em relação ao resto do mundo, mas. Contudo, nos anos 50, com incentivos do governo brasileiro, passou por uma revolução (GOVERNO DO ESTADO DE SÃO PAULO, s.d.). Desde então, mesmo passando por diversas crises, como a crise do petróleo, a crise da produção versus a demanda, em que se produzia mais do que se vendia e a grande crise mundial de 2008, a indústria automotiva tem tido um papel muito importante na economia brasileira.

O setor automotivo é um dos maiores do país, correspondendo a cerca $23 \%$ do PIB (Produto Interno Bruto) industrial e 5\% do PIB nacional e empregando 1,5 milhão de pessoas, direta e indiretamente (seguros, peças, combustíveis, ruas e estradas, venda e revenda etc.) (ANFAVEA, 2010). O Brasil é o quarto maior mercado automotivo do mundo (atrás de Estados Unidos, China e Japão), tendo emplacado mais de três milhões de carros e comerciais leves nacionais e importados em 2010 (FENABRAVE, 2010). Ainda assim, o setor tem muitas oportunidades de crescimento, visto que $61 \%$ das famílias brasileiras ainda não têm um automóvel e a razão veículos/pessoas é um para sete, enquanto em países como os Estados Unidos, por exemplo, esta razão é um para um (RIBEIRO, 2010).

É uma indústria não totalmente madura: muitas novidades surgem e as direções podem mudar muito, principalmente por conta da tecnologia. Nos próximos anos, 
mais novidades são esperadas, dada a crescente competitividade, principalmente com a chegada das montadoras chinesas, além das maiores exigências com a segurança veicular e conectividade (comunicação via Internet). Com isto, não apenas o preço, mas a emoção do consumidor tem sido trabalhada nesta indústria, sendo o carro uma forma de expressar status e personalidade, de forma que o desafio agora é maior: menor custo, maior quantidade de funcionalidades, qualidade e segurança.

\subsection{A Tecnologia da Informação na indústria automobilística}

A indústria automotiva tem utilizado a Tecnologia da Informação (TI) em diversas aplicações. Diferentes contribuições vieram de diferentes países, mas o desenvolvimento de técnicas de controle de qualidade e produção enxuta das indústrias japonesas trouxe uma forma de relacionamento muito mais colaborativa entre montadora e fornecedores e tem uma importância particular para a transformação da TI na indústria automotiva. As inovações permitiram a produção de carros de alta qualidade e menores custos.

A indústria americana, por sua vez, traçou estratégias mais diretamente dependentes da $\mathrm{TI}$, e a grande mudança veio com o desenvolvimento do Controle Numérico Computadorizado (CNC - Computer Numerical Control) que viabilizou ferramentas que podiam ser programadas para produzir formas geométricas específicas e precisas, além de permitir um alto volume de produção. A habilidade de programar robôs para realizar tarefas repetitivas permitiu a expansão deles em diversas partes da indústria, aumentando a produtividade e reduzindo, por exemplo, riscos de segurança para funcionários.

Este ambiente foi aprimorado com as ferramentas de CAD/CAM (Computer Aided Design / Computer Aided Manufacturing), inicialmente utilizadas para automatizar os desenhos, que passaram a ser capazes de produzir programas para ferramentas CNC (Computer Numerical Control).

Hoje em dia, é possível desenvolver um carro, simular as suas características reais, criar processos virtuais e executar uma série de testes antes de construções físicas, 
reduzindo drasticamente os custos com experimentos, além de agilizar o desenvolvimento de produtos e processos.

Além disto, existem também as ferramentas que emergiram das estratégias japonesas, como o MRP (Materials Requirement Planning), utilizado para controlar o inventário e auxiliar na logística fina do processo produtivo que hoje também já passou a ser integrado aos sistemas ERP (Enterprise Resource Planning), utilizados no controle e no planejamento estratégico dentro da indústria.

Estes desenvolvimentos não causaram tanto impacto quanto a revolução japonesa de qualidade e produção enxuta, mas seus efeitos acumulados são muito importantes, trazendo muita eficiência ao processo produtivo, redução de custos, mais qualidade e segurança.

\subsection{A Empresa Estudada}

A empresa "Carros", pertencente ao grupo multinacional "Z", está presente no Brasil há diversas décadas e emprega milhares de funcionários, estando entre as maiores empresas do país. A companhia tem investido muito no Brasil e está entre as líderes de seu segmento.

A empresa possui um detalhado mapa de processos de negócio que se divide em quatro grandes partes e tem como grande meta a lucratividade em um cenário de crescimento econômico variável e altamente competitivo. Além disto, existe uma grande preocupação com a qualidade dos produtos e com a sustentabilidade.

A empresa Carros utiliza o BSC (Balanced Scorecard) como apoio à execução de sua estratégia, tendo criado um mapa estratégico próprio, que baliza as ações de todas as áreas da empresa. 


\subsection{A TI na empresa Carros}

A área de TI na empresa possui um importante papel, visto que muitos processos de negócio dela dependem e as estratégias necessitam da $\mathrm{Tl}$ para serem concretizadas. Organizacionalmente, a área está abaixo da diretoria de Finanças.

A estratégia da $\mathrm{Tl}$ está relacionada à otimização dos processos internos através da implementação de melhores práticas, reduzindo custos operacionais. A missão da área envolve a integração dos processos de negócio através da utilização de sistemas de TI buscando a eficiência do negócio.

A área possui um plano de negócios que descreve a estratégia de $\mathrm{Tl}$, as áreas e as ações esperadas para os próximos cinco ano. Este documento foi elaborado por uma iniciativa da própria área e é divulgado a todas as áreas de negócio da empresa para que tenham as informações necessárias quanto às aquisições de $\mathrm{Tl}$, atual desempenho e capacidade, portfólio de projetos de TI etc.

\subsection{Estado atual da Governança de TI na empresa estudada}

A governança corporativa, na visão da empresa, é um conjunto de responsabilidades e práticas exercidas pela alta direção provendo direcionamento estratégico e garantindo que os objetivos sejam atingidos, gerenciando riscos e garantindo que os recursos da empresa sejam utilizados de forma correta. A empresa possui uma área responsável pela governança corporativa, riscos e conformidade que busca trabalhar de forma alinhada à matriz da empresa.

A Governança de TI é reconhecida como uma parte da governança corporativa, tendo a equipe utilizado o COBIT como base, priorizando alguns processos de Planejamento e Organização (PO). A Governança de TI é definida no plano de negócios de TI como uma fusão de uma série de disciplinas de gerenciamento, e implica em um sistema no qual todos os envolvidos têm as informações necessárias para tomada de decisões. Uma Governança de TI eficaz permite que a TI suporte as metas do negócio, otimize os investimentos de $\mathrm{Tl}$ e gerencie de forma correta os riscos e oportunidades de TI. 
Alguns entrevistados, principalmente das áreas de negócio ficaram bastante em dúvida em responder. De acordo com os entrevistados da área de $\mathrm{TI}$, as áreas de negócio não conhecem o conceito de Governança de TI. Algumas pessoas das áreas de negócio, principalmente aquelas ligadas aos projetos de $\mathrm{TI}$ da área têm um certo conhecimento, mas nada aprofundado.

A nota da Governança de TI, seguindo o método proposto por Weill e Ross (2006) descrito na Figura 47, captada nas entrevistas foi aproximadamente 54. De acordo com o estudo realizado pelos autores a nota média é 69 , com as empresas de melhor desempenho apresentando notas em torno de 75 . Isto ocorre porque Governança de TI da Carros está em desenvolvimento e a tendência é que esta nota aumente no decorrer dos anos.

Os princípios de TI, declarações de alto nível sobre como a Tl é utilizada no negócio, uma das cinco decisões relacionadas à Governança de TI, não estão formalizados. Mesmo não formalizados, alguns princípios implícitos existem, como:

- A área de TI é responsável pelo planejamento de todos os projetos. A execução dos projetos de Tl e das operações de Tl é realizada por terceiros;

- Os processos e arquiteturas de TI tanto da área corporativa como da área de produção são padronizados em alinhamento com a matriz;

- O controle de custos é uma prática constante;e

- A eficiência operacional é uma meta com fins no aprimoramento da qualidade dos serviços realizados, a otimização de recursos, e redução de custos.

Também não existe um modelo formalizado de Governança de $\mathrm{Tl}$ e os papeis e as responsabilidades não estão, formalmente, definidos para todos os processos de TI.

De acordo com a área, os principais desafios da Governança de TI na empresa envolvem:

- Definição de processos e a melhoria contínua com base em melhores práticas, como COBIT, ITIL, ISO e CMMi; 
- Implementação eficiente de gerenciamento de projetos (atingindo escopo e respeitando prazo, orçamento e qualidade esperada);

- Gerenciamento de fornecedores garantindo eficiência dos serviços e conformidade com as regras da empresa;

- Garantia de qualidade em projetos e serviços (grau em que o projeto ou serviço atende as necessidades);

- Identificação prévia de riscos de TI e de negócios e gerenciamento dos mesmos;

- Definição e gerenciamento de objetivos de TI para contribuir com as metas do BSC corporativo.

A empresa utiliza principalmente o COBIT como referência para a implementação de TI e para melhoria de processos e serviços.

\subsubsection{Estratégia de manufatura}

A estratégia de manufatura influencia a demanda por produção e a estratégia de criação de produtos, a criação de novos carros ou novas versões de carros existentes. Não existe uma estratégia de automação - os projetos são reativos, demandados de acordo com as necessidades de novos processos e produtos. Em breve será definida uma estratégia de automação com base no que o Grupo Z já está fazendo e levando-se em conta a evolução das tecnologias. Nenhuma dessas estratégias está ligada diretamente à estratégia de TI, mas a TI trabalha para suportá-las.

\subsubsection{Organização de TI e comportamentos desejáveis}

Dentre os comportamentos desejáveis da área estão centralização de infraestruturas, utilização máxima de padrões do Grupo Z para arquitetura e 
aplicações, buscando facilitar o compartilhamento e a integração, procedimentos padronizados de operações e projetos.

\subsubsection{Arranjos de Governança de TI}

$\mathrm{Na}$ empresa Carros existem diferentes arranjos para as diferentes decisões de Governança de TI:

- Para os princípios de TI não existe um arranjo (ou arranjo do tipo "anarquia"), pois os princípios ainda não são definidos;

- Para os investimentos de TI, conta-se com três partes (um "tripólio"): todas as áreas de negócio, Tl e Finanças (que engloba a área de TI) nos momentos de priorização e decisão;

- Para as aplicações de negócio, a área de negócio interessada e a TI trabalham juntas para transformar a demanda em projeto, ou seja, tem-se um duopólio;

- Para a arquitetura de TI utiliza-se a monarquia de TI, pois é o grupo que detém o conhecimento técnico necessário;

- Para a infraestrutura de TI utiliza-se também a monarquia de TI, pois é o grupo que detém o conhecimento técnico necessário;

- Para a arquitetura de automação, existe um grupo relacionado ao planejamento da automação ("PLANPROD") que decide o que é melhor e contrata fornecedores para 0 desenvolvimento $e$, para os sistemas específicos do chão de fábrica, solicita apenas pontos de rede à TI. Quando se trata de um sistema de informação a ser utilizado no chão de fábrica, esse grupo trabalha em conjunto com a TI (duopólio), mas a arquitetura de controle em si é decidida por eles, seguindo padrões do Grupo Z (monarquia de automação). É importante destacar que a arquitetura usada em robôs e ilhas de produção é pouco discutida com TI, vindo os padrões da matriz do Grupo Z. 
5.5.4 Mecanismos de Governança de TI - Estruturas organizacionais

A área de $\mathrm{TI}$ é composta pelo $\mathrm{ClO}$ e pelas equipes de Relacionamento com as áreas de negócio, Serviços de TI, Finanças de TI e Governança de TI.

A área de relacionamento com as áreas de negócio é responsável pelo relacionamento entre $\mathrm{TI}$ e o negócio, dividida de acordo com os processos do negócio, atuando em linha com as diretrizes da matriz da companhia. Os gerentes de relacionamento, junto com as áreas, formam duopólios que discutem as necessidades de aplicações (posteriormente discutidas e priorizadas em um steering committee próprio para decidir investimentos). São também responsáveis pelo gerenciamento dos projetos de $\mathrm{TI}$ para as áreas, desde a iniciação até o encerramento e pelo relacionamento da $\mathrm{TI}$ com a área, sendo o principal ponto de contato (exceto para chamados do dia-a-dia, para os quais existe uma central de atendimento). Os gerentes de relacionamento devem conhecer os processos das respectivas áreas de negócio, preocupando-se com a evolução da área.

A área de Serviços de TI é responsável por toda a infraestrutura de TI da companhia. O grupo é dividido em duas equipes:

- O que atende ao dia-a-dia da empresa, suportando as aplicações do negócio (atuando ligadas ou não ao ERP e; com segurança); trabalhando com melhores práticas e indicadores de desempenho; e telecomunicações/redes. Este grupo lida com incidentes, problemas, gerenciamento de acessos e de mudanças, por exemplo e

- O que lida com a tecnologia e seu direcionamento, tratando de projetos específicos de TI. Este grupo realiza projetos de TI para todas as áreas da empresa, suportando as áreas de negócio em projetos de infraestrutura (telecomunicações, redes e datacenter). São também responsáveis por gerenciar a capacidade, a continuidade dos serviços, os ativos e pela relação com prestadores de serviço que suportam a infraestrutura de TI. Este segundo grupo forma uma monarquia de $\mathrm{TI}$ para decisões quanto à infraestrutura. 
Dentro do primeiro grupo estão profissionais que suportam as aplicações, muitas vezes exercendo o papel de contato principal da TI com as áreas de negócio para problemas do dia-a-dia. Controlam chamados, cobram providências e auxiliam o grupo de gerentes de relacionamento nas decisões técnicas.

Dentro de Serviços de TI estão também o CTO (Chief Technology Officer) e o CISO (Chief Information Security Officer). O primeiro é responsável pela arquitetura da informação, formando uma monarquia de TI para decisões quanto à arquitetura de $\mathrm{TI}$, sempre tomadas com base nos padrões da matriz. O segundo é responsável pela segurança da informação, política e processos relacionados.

A área de Finanças de TI trabalha bem próxima à área de Governança de Tl e é responsável pelos controles financeiros e aprovações específicos da área de TI.

A área de Governança de TI é responsável por definir, implementar e melhorar processos baseados em modelos de mercado como COBIT, ITIL, ISO 27001 e CMMi, gerenciar o portfólio de projetos, gerenciar contratos, gerenciar as habilidades do pessoal de TI ("skills"), garantir a qualidade em projetos e serviços, identificar riscos e gerenciá-los, definir e gerenciar os objetivos de TI para que estejam de acordo com o BSC corporativo, garantindo a conformidade.

Não existe um comitê estratégico de TI formalizado atuando junto ao conselho administrativo da empresa. O $\mathrm{ClO}$ representa a $\mathrm{Tl}$ em reuniões mais estratégicas e, por vezes, o vice-presidente de Finanças representa a área, visto que a TI está dentro de Finanças na estrutura organizacional da empresa.

Existe um comitê gestor de Tl composto pelos executivos de $\mathrm{Tl}$ e executivos das áreas de negócio. Este fórum discute investimentos e priorização de projetos, além de outros aspectos como estratégia de TI e formação de equipe para projetos especiais. Este é o grupo que toma as principais decisões de TI da Carros, seguindo um direcional dado pela matriz do Grupo Z.

As decisões em âmbito de projeto são tomadas pelos gerentes de relacionamento em conjunto com as áreas de negócio e as decisões técnicas de TI são tomadas pelo grupo de Serviços de TI. Ambas as equipes se reportam ao $\mathrm{ClO}$ que apresenta os principais resultados ao comitê gestor periodicamente. 
5.5.5 Mecanismos de Governança de TI - Processos de alinhamento

Esta seção será detalhada de acordo as sub-divisões do modelo de Governança de TI proposto neste trabalho.

\section{Plano estratégico de TI}

Como mencionado anteriormente, a área possui um plano estratégico de TI que consolida anualmente as estratégias de $\mathrm{TI}$, suas metas e projetos previstos de cada área. Alimentando este plano estratégico, existe um planejamento de projetos para os próximos cinco anos, priorizado em conjunto com as áreas de negócio.

\section{Gerenciamento de Riscos}

Quando ao gerenciamento de risco, a empresa entende que se trata da habilidade de prever, antecipar e controlar riscos operacionais, seguindo o que é planejado para os próximos cinco anos. O risco está sempre associado a uma probabilidade de ocorrência e ao impacto causado. O gerenciamento de riscos tem por objetivo aumentar o valor da companhia, garantir os resultados esperados, reduzir custos, entre outros.

Os riscos de toda a empresa são classificados e os principais devem conter um plano de ação e serem monitorados. Os processos de gerenciamento de riscos são alinhados dentro de todo o Grupo Z e surgiram por solicitação do conselho fiscal e administrativo da matriz. O comitê gestor de TI monitora os riscos da área. Associados aos riscos, existem projetos para reduzi-los ou eliminá-los. Dentro da TI, de acordo com o levantamento de risco da empresa, a $\mathrm{TI}$ aceita o risco, o trabalha e reporta. Ainda não houve uma avaliação dos riscos pela própria TI.

O modelo existente hoje é voltado para indicadores qualitativos e acabou começando com itens relacionados à segurança da informação, o que é bastante 
comum. Está em construção uma nova análise de risco para a TI, ampliando a atual para incluir outros aspectos específicos da área. Este novo modelo contempla impacto no negócio, dimensões de segurança da informação e cenário do risco (sistema ou ambiente, ameaça, duração, efeito) de forma quantitativa, permitindo uma comparação entre o "preço" do risco e o "preço" da solução.

Associados ao gerenciamento de riscos estão os aspectos de conformidade. Entende-se que fazem parte da governança de $\mathrm{Tl}$ e que relacionam-se a documentação, políticas e processos internos, certificações para suportar auditorias e evitar fraudes.

\section{Segurança}

A empresa possui uma política de segurança de TI válida para todo o Grupo Z, definida de acordo com ISO 27001 e publicada na intranet da empresa, para que todos os funcionários possam acessar. Esta política é definida pela matriz do Grupo $Z$, sendo que cada filial do grupo adiciona um ou outro adendo que julga importante.

Apoiando a política de segurança da informação, existem as diretrizes de segurança que detalham as políticas e resumem os padrões para grupos de usuários específicos.Existem ainda os procedimentos de segurança, como as especificações técnicas de segurança para arquitetura e para desenvolvimento. As diretrizes e os procedimentos são desenvolvidos pela empresa Carros no Brasil.

Dentro do processo de gerenciamento da segurança da informação existe um grupo mundial que reporta incidentes de segurança para que as outras plantas da empresa possam tomar as providências necessárias em conjunto com seus fornecedores de TI.

O grupo responsável pela segurança de $\mathrm{TI}$ trabalha com os sistemas corporativos e parte dos sistemas de produção, atuando até o sistema de controle da produção, mas muito pouco junto ao chão de fábrica, que trabalha independente - mas todo e qualquer equipamento ligado à rede corporativa deve estar condizente com as diretrizes de segurança. Pretende-se unificar esta atuação. 
Não existem processos definidos de segurança no chão de fábrica e alguns problemas ocorrem por este fato e porque as redes ainda não estão completamente segregadas, um projeto em desenvolvimento. Serão três redes: uma corporativa, uma para controle e operação da produção e uma de controle, com pontos de contato controlados por mecanismos de segurança, como sugere a ISA-99, mas não se utiliza este padrão explicitamente (o padrão que está sendo implementado foi definido pela matriz do Grupo Z).

\section{Arquitetura}

Quanto à arquitetura, o principal responsável no Brasil é o CTO. O Grupo Z busca padronização e economias de escala e possui um guia com o mapa da arquitetura e os padrões que servem como base para todos os projetos de TI. Este guia é periodicamente revisado para incluir as novas tecnologias e atender às diferentes demandas do Grupo.

Este mapa é definido por um grêmio de arquitetura composto por representantes de diversos países. As propostas deste grupo são levadas àqueles que atendem às áreas de negócio para a decisão final.

Neste mapa, os sistemas de desenho de produtos e processos e os sistemas de informação utilizados no chão de fábrica, como o sistema que controla a produção, são vistos como sistemas específicos dos respectivos processo de negócio e, portanto, devem seguir os padrões de desenvolvimento do Grupo. Os sistemas de controle não estão contemplados, mas as redes de informação e seus protocolos estão.

Além deste guia de padrões, existe, para cada macro-processo de negócio, um guia estratégico de aplicações. Este guia contém todos os sistemas utilizados pelo grupo, os respectivos âmbitos de utilização (local / mundial) e os planos para cada um (desenvolver / descontinuar). 
Existe também um comitê separado por regiões que recebe todos os projetos e os avalia tecnicamente para verificar se estão de acordo com os padrões esperados e se existem sinergias entre os diferentes projetos.

Quanto à arquitetura do chão de fábrica, o responsável é o grupo de planejamento de automação.

Não existe um comitê formalizado entre esta área e a TI, mas as equipes trabalham integradas, principalmente em relação ao sistema que controla a produção (“PRODCONTROL").

O PRODCONTROL é um sistema do Grupo $Z$ que, junto às informações técnicas do produto, realiza o planejamento da produção- seria uma parte de um MES, além de um sistema que gerencia as instalações, responsabilidade do grupo PLANPROD.

Trabalhando em conjunto com o sistema de controle da produção, existe um ERP com um módulo que reporta quantidades no final da linha de produção; um módulo de materiais que gerencia a cadeira produtiva (relacionado à logística); um módulo de qualidade, que gera relatórios voltados para partes específicas da produção e um módulo de manutenção, que gerencia ativos, incidentes com estes ativos e gera relatórios (o sistema que controla incidentes da TI corporativa é separado deste ambiente).

As redes de escritório e do sistema que controla a produção no chão de fábrica estão sendo segregadas com o uso de mecanismos específicos de segurança. As redes de controle já utilizam um padrão compatível com o Ethernet (Profinet), mas a atuação de TI vai até o PLC. A partir do PLC, as redes de controle ficam todas sob os cuidados do grupo PLANPROD.

A arquitetura segue boas práticas do Grupo Z, com sub-redes por processo e considerando a segurança das operações. A interface com TI conta com o uso de firewall e este é gerenciado por TI, seguindo partes da ISA-99. 


\section{Gerenciamento do portfólio}

O processo de gerenciamento do portfólio tem como entradas os projetos selecionados pelo comitê gestor, priorizados de acordo com a estratégia de TI, os requisitos de negócio e a infraestrutura. Cada projeto é gerenciado seguindo-se partes do PMBoK e o nível de controle de cada projeto depende do custo e do tempo de desenvolvimento. Não existe uma metodologia própria, customizada de gerenciamento de projetos..

O conjunto de todos os projetos correntes é controlado por uma sub-área da área de Governança de TI que busca estruturar formas de facilitar o gerenciamento dos projetos, evitando erros, poupando tempo e custo, avaliando sinergias entre projetos. Ao encerrar um projeto, o entregável passa para a área de Serviços de TI, responsável pela sustentação do ambiente (por manter o sistema em funcionamento).

Não existe um catálogo de serviços definido da área de TI para o negócio, mas existem catálogos de serviço dos fornecedores para a TI.

Os projetos de automação são gerenciados fora do Portfólio de TI pelo grupo PLANPROD.

\section{Gerenciamento da demanda}

Para receber e avaliar as demandas das áreas de negócio, existe um processo anual que trata dos projetos demandados para o ano seguinte. A demanda deve ser traduzida pela área de negócio, em conjunto com o respectivo gerente de relacionamento de $\mathrm{TI}$, em um caso de negócios. Este é o primeiro passo para a consolidação do portfólio de TI.

O caso de negócios deve detalhar a demanda, os riscos e benefícios associados ao projeto (ou à não execução do mesmo) e, em uma segunda fase, deve conter a infraestrutura, hardware, software e serviços de TI necessários para realizá-lo, já com uma ideia de custo. Todos os casos de negócio são reunidos, classificados 
como investimento ou serviço puro (como desenvolvimento de sistemas) e passam para uma fase de classificação e priorização.

O gerenciamento de demanda de automação é feito de forma segregada pelo grupo PLANPROD.

\section{Decisão e investimento}

Para priorizar os projetos, todos os projetos identificados pelo processo de gerenciamento de demanda são analisados quanto a risco e benefício e inseridos em uma matriz que possibilita a comparação entre eles. Com a formação da matriz que prioriza os projetos, determina-se quais serão desenvolvidos de acordo com a verba disponibilizada pela companhia para o próximo ano. Este é um processo conhecido pelas áreas de negócio e realizado já há diversos anos, sendo, inclusive, suportado pelo ERP da empresa.

Os projetos de automação passam por um fórum distinto dos projetos de $\mathrm{TI}$, sob responsabilidade do grupo PLANPROD.

\section{Gerenciamento da qualidade}

O processo de gerenciamento de qualidade em TI está sendo implementado com o auxílio do COBIT. A área lida com a qualidade em diferentes âmbitos:

- Em projetos, junto com o PMO. Enquanto a área de PMO define os métodos de gerenciamento de projetos, a área de qualidade verifica o alinhamento de planos com resultados - recursos, tempo e entregáveis,devendo participar das reuniões de situação geral dos projetos, o que ainda não é realizado;

- Nos processo seletivos dos fornecedores com uma matriz de seleção, principalmente referindo-se aos grandes fornecedores;

- Controle nos níveis de serviço / atendimento, fazendo uma verificação amostral da qualidade dos relatórios. 
Está em estudo uma pesquisa de qualidade pela central de atendimento para verificar a satisfação dos clientes internos. A área também auxilia no monitoramento de indicadores de serviços.

\section{Recursos Humanos}

As políticas de recursos humanos $(\mathrm{RH})$ ficam sob a responsabilidade do $\mathrm{RH}$ corporativo, sendo esta área responsável pela contratação, retenção e demissão do pessoal de TI. A área de $\mathrm{TI}$ pode participar dos processos seletivos para acompanhar.

Não existe plano de carreira explicitamente definido e não existe job rotation corporativo. Existe um mapa de conhecimentos necessários para cada cargo.

Os recursos humanos de automação são gerenciados da mesma forma (procedimento corporativo).

\section{Estratégia de Sourcing}

A empresa Carros possui uma estrutura multisourcing dividida pelos tipos de sistemas ERP e não ERP. A área pretende melhorar seus processos com base no COBIT.

Apesar de não existir uma estratégia explícita de terceirização, há um direcional para terceirizar aqueles serviços considerados comuns, como serviços de impressão e central de atendimento.

A estratégia de terceirização da automação é separada, mas segue os mesmos princípios básicos da estratégia não formalizada seguida por $\mathrm{Tl}$ : o desenvolvimento é feito por empresas especializadas e a Carros gerencia os projetos e a integração. 
5.5.5.1 Mecanismos de Governança de TI - Processos de alinhamento - Processos de Gerenciamento de Projetos

Os projetos em TI são gerenciados de acordo com o PMBoK. Atualmente, está em estudo a elaboração de um novo método,, mais simples e mais fácil de ser aplicado.

Dentro da área de Governança de TI, existe um grupo de PMO, responsável por auxiliar em todos os projetos e controlar o portfólio de projetos. Existe também um repositório central de projetos. Esta área também irá auxiliar a $\mathrm{TI}$ a incorporar outras melhores práticas à elaboração de casos de negócio, ao gerenciamento dos projetos e a controlar cada uma das nove áreas presentes no PMBoK.

Quanto ao gerenciamento do portfólio de projetos, a área é responsável por gerenciar todo o portfólio, buscando integração e colaboração entre os projetos, para otimizar recursos humanos e financeiros. Periodicamente é elaborado um painel para controle geral dos projetos presentes no portfólio.

As fases dos projetos são divididas da seguinte forma para todos os projetos da empresa:

- Preparação do projeto: inicialização, definição do escopo, planejamento e aprovação financeira;

- Execução: compras, desenho, desenvolvimento, testes e instalação;

- Preparação final e liberação para uso: testes integrados, treinamentos, liberação para uso.

Um processo muito bem estabelecido é o que envolve aquisições dentro dos projetos da empresa Carros, incluindo o uso de uma ferramenta integrada.

$\mathrm{Na}$ Carros, as áreas devem trabalhar em conjunto nos projetos - precisam trabalhar juntos o gerente de relacionamento, a área de negócio, e as áreas técnicas de TI. Houve uma iniciativa de formar um comitê de gerentes de relacionamento para discutir os casos de negócio e procurar sinergias entre projetos de diferentes áreas, mas a iniciativa foi paralisada. 
Os projetos de automação também seguem as melhores práticas de mercado, mas são gerenciados de forma independente da área de TI pelo grupo PLANPROD.

5.5.5.2 Mecanismos de Governança de TI - Processos de alinhamento - Operações

\section{Níveis de serviço}

Os níveis de serviço são definidos de acordo com a severidade de cada sistema, definida em conjunto com as áreas usuárias, a criticidade do incidente e quantos usuários são afetados.

Existem níveis de serviço definidos para todos os prestadores de serviço e está prevista a aplicação de multas no caso de não cumprimento de SLAs. Existe um processo e uma ferramenta para controle dos indicadores, que tratam de:

- Disponibilidade de aplicações, medida mensalmente e de acordo três diferentes classes de serviço;

- Tempo de resposta a incidentes, medido com base no tempo máximo por aplicação e de acordo com três diferentes classes de serviço;

- Tempo de resolução de incidente, medido com base no tempo máximo por aplicação e de acordo com três diferentes classes de serviço;

- Tempo de resolução de problemas, medido com base no tempo máximo de todas as aplicações;

- Tempo médio entre falhas, medido mensalmente, com base em três diferentes classes de serviço;

- Mudanças abortadas com relação a todas as aplicações;

- Incidentes resultantes de mudanças implementadas, considerando todas as aplicações; 
- Satisfação do cliente interno quanto a serviços para todas as aplicações.

Espera-se que a cada nova aplicação, o responsável pelo projeto já estude os tempos de atendimento e como funcionará o suporte à nova aplicação, definindo a severidade junto à área de negócio envolvida.

Para o chão de fábrica, a TI responde pelos níveis de serviço da aplicação que controla a produção PRODCONTROL que possui uma célula de serviços terceirizada in loco. As ferramentas de automação têm um processo distinto de gerenciamento dos níveis de serviço, realizado pelo grupo PLANPROD.

\section{Capacidade}

A capacidade de $\mathrm{TI}$ é monitorada com o auxílio de uma ferramenta pelos prestadores de serviço e reportada à empresa periodicamente. Não existem procedimentos estabelecidos para avisos quanto à capacidade e quanto a previsões de capacidade e desenvolvimento de um plano. Para o sistema PRODCONTROL, a célula responsável monitora a capacidade com um processo próprio e toma ações juntamente à TI quando necessário.

Para os sistemas de automação, a capacidade é dada pela capacidade de produção e é gerenciada pela equipe de automação PLANPROD.

\section{Disponibilidade e Eventos}

A disponibilidade das aplicações e infraestrutura é monitorada por prestadores de serviço. Uma ferramenta de gerenciamento de eventos e falhas está sendo implementada em todo o Grupo Z.

No chão de fábrica, existe uma célula de monitoramento 24 horas para o sistema PRODCONTROL. Esta mesma célula é responsável pela resolução de incidentes no chão de fábrica e acionam os responsáveis quando necessário. 
No entanto, esta célula atua apenas para este sistema específico e não para todos os sistemas lá presentes. Mesmo sendo uma célula específica, não realiza nada sem consultar a área de $\mathrm{TI}$, que tem todo o controle.

Já os sistemas de automação têm a disponibilidade gerenciada pela equipe de automação PLANPROD e os eventos são monitorados pelos próprios funcionários da linha de produção - existem alarmes nos equipamentos.

\section{Segurança}

Existe um grupo responsável exclusivamente pelo gerenciamento de segurança e de acesso. Este grupo suporta as operações do dia-a-dia e o desenvolvimento de todos os projetos de Tl. Existe um grupo mundial que reporta incidentes de segurança para todas as plantas do Grupo Z, de forma que possam atuar de forma preventiva, com erros que ocorreram em outras localidades.

O grupo de segurança atende a todos os sistemas de TI até o PRODCONTROL, mas os sistemas de chão de fábrica não são totalmente suportados, não havendo processos definidos. Estes sistemas possuem poucos mecanismos de segurança nativos, o que demandaria mais controle

\section{Continuidade}

Um plano de recuperação de desastres está sendo definido.Será utilizada uma análise de impacto aos negócios (BIA), mas ainda não foi desenvolvida.

O backup e a recuperação de arquivos são realizados por um provedor de serviço com o auxílio de uma ferramenta e de acordo com as políticas definidas pela empresa em conjunto com as áreas de negócio. O mesmo provedor de serviços é responsável pelo descarte das informações.

Não existe plano de recuperação de desastres em automação - existem outras plantas de produção, mas nada semelhante a um plano de continuidade. 


\section{Fornecedores}

Baseando-se na ITIL, o time conduz reuniões diárias, semanais e mensais com os fornecedores para melhorar os serviços, acompanhar os resultados e os níveis de serviço.

Apesar de o processo de aquisições ser bem estabelecido dentro dos projetos da empresa Carros, processos para modificar e encerrar contratos ainda precisam ser formalizados e comunicados, tanto em TI, quanto em automação.

\section{Financeiro}

Existem procedimentos corporativos para controle dos custos de cada área, com ferramentas de apoio. Os custos são reportados e existem metas e métricas para gerenciar o processo.

Já existem mecanismos de cobrança reversa para custos de impressão, telefonia e acesso à internet. A área tem por meta informar às áreas o custo por usuário. Para os demais serviços, ainda não existem mecanismos de cobrança reversa, mas a empresa já estuda esta possibilidade. A criação de um catálogo de serviços pode auxiliar.

Não foram reportados mecanismos de controle de custos em automação, mas também não existem serviços compartilhados entre diversas áreas.

\section{Mudanças}

O processo de gerenciamento de mudanças é definido e formalizado e conta com uma ferramenta de apoio para cadastro e controle. Existe um comitê responsável pelas mudanças e semanalmente ocorre uma reunião deste comitê. Neste comitê participam o responsável pelo processo de gerenciamento de mudanças, os envolvidos com os projetos a serem discutidos (tanto da empresa, quanto de 
fornecedores) e incentiva-se a participação de outros profissionais da área de TI para que avaliem o impacto das mudanças nos sistemas sob sua responsabilidade.

Este comitê trata de toda e qualquer mudança de TI e, antes da reunião semanal, é enviada uma agenda com todas as mudanças que serão discutidas. Desta forma, os profissionais de TI podem verificar o que será discutido e, mesmo que não haja um sistema de sua responsabilidade, podem avaliar os impactos. Os procedimentos para submissão, aprovação e controle das mudanças são conhecidos.

As mudanças avaliadas são relacionadas a mudanças em sistemas (mudanças em documentos, por exemplo, não são analisadas) e são classificadas em:

- Pré-definida: soluções de contorno, mudanças simples e já testadas;

- Minor: impacto e risco baixos;

- Major: impacto ou risco alto, geralmente afeta mais de uma aplicação;

- Emergencial: relacionada a algum distúrbio iminente em um ou mais processos de negócio.

Recentemente, o processo foi revisto para incorporar melhorias, entre elas, procedimentos para agilizar a implementação de mudanças "minor" e facilitar o trabalho de avaliação do $\mathrm{CAB}$, havendo uma avaliação no início do projeto e outra ao final.

Uma outra melhoria que se entende que possa ser incorporada é a avaliação por pacotes de melhorias de um mesmo sistema que podem, por estarem em um mesmo ambiente, mesmo que tratem de funcionalidade diferentes, afetar umas às outras.

Para o sistema PRODCONTROL, as mudanças também são levadas ao CAB, mas apenas para informação: as janelas de execução são programadas de forma emergencial, pois este sistema não pode parar, visto que impacta diretamente na produção. 
Os sistemas de automação têm suas mudanças planejadas e aprovadas pela equipe PLANPROD e não passam pelo CAB de TI.

\section{Liberações}

Na empresa Carros, o mesmo comitê que verifica as mudanças, planeja a liberação, libera na reunião do $\mathrm{CAB}$ (em que participam profissionais de outras áreas da $\mathrm{TI}$ ) e acompanha os resultados (o que foi feito, o que foi abortado). Entende-se que o $\mathrm{CAB}$ hoje, sem as modificações recentemente planejadas, trate muito mais de liberações do que de mudanças, pois avalia o que será feito apenas no final do ciclo.

Existem procedimentos definidos de retorno e testes para mudanças "major", mas estuda-se melhorar o processo de testes para todas as mudanças. As mudanças “major" também contam com acompanhamento pós-implementação.

São controlados indicadores de mudanças abortadas (aprovadas e não implementadas por algum motivo) e incidentes gerados por mudanças liberadas.

Para os sistemas corporativos, a liberação é feita apenas pela área de $\mathrm{TI}$, com testes da própria área (especialista responsável); os sistemas de desenho de produto e processo contam com um processo diferenciado, pois devem incluir os testes realizados pelos usuários finais, que entendem do processo de negócio suportado por aquele sistema; para o sistema PRODCONTROL, as mudanças são apenas informadas no CAB e o processo de liberação é feito de forma emergencial pela célula responsável com o acompanhamento de TI. Os demais sistemas do chão-de-fábrica possuem processo próprio, sem passar pelo CAB.

\section{Configuração}

O controle de inventário dos equipamentos corporativos é de responsabilidade de cada área de negócio (controle das máquinas, do que está instalado, qual o usuário responsável, prazos de garantia etc.). O mesmo vale para a equipe de automação que controla os equipamentos de TI no chão de fábrica. 
Recentemente, foi implementada uma ferramenta dedicada para isto que é capaz de realizar levantamentos em toda a rede corporativa da empresa, permitindo que o controle seja realizado pela área de TI (hardware, softwares instalados, utilização destes softwares). Existe uma iniciativa para criar e manter uma CMDB, mas ainda não existe um processo definido.

O gerenciamento de configuração dos sistemas de automação é realizado pelas equipes de manutenção que trabalham no chão-de-fábrica.

\section{Service Desk}

O service desk é o ponto de contato dos usuários de TI para suporte e requisições. Ele é responsável por receber, cadastrar e resolver as solicitações relacionadas a aplicações, hardware, rede, infraestrutura, impressoras etc. Os usuários podem entrar em contato através de um ramal ou por email.

Existe um service desk geral (sistemas corporativos e de desenho de produtos e processos), um específico para o ERP, um específico para o sistema que controla a produção e um para executivos (uma demanda cultural do Grupo Z). Este específico para o sistema que controla a produção, bem como seu modelo de atendimento, é padrão em todas as plantas do Grupo Z. O específico para o ERP foi criado durante o projeto e seria provisório, mas permaneceu e hoje apresenta vantagens e desvantagens: o atendimento é especializado, mas o usuário não sabe às vezes para qual deve ligar.

Existem indicadores definidos para o service desk, como taxa de resolução no primeiro contato, tempo máximo de resolução, taxa de reabertura de chamados, tempo máximo de espera no atendimento, tempo máximo para resposta por email.

O service desk ainda não é preparado para receber todo tipo de chamado (chamados de sistemas de desenho de processos, principalmente, por serem novos na empresa, ainda não são de domínio da central de atendimento), mas isto está em processo de melhoria. Os sistemas de automação não possuem uma central de atendimento, pois os próprios monitores da linha de produção acionam diretamente a equipe de manutenção responsável. 


\section{Incidentes}

Existe um processo definido e formalizado de gerenciamento de incidentes que conta com o suporte de uma ferramenta para cadastro e controle. O processo também contempla escalação de incidentes para os grupos responsáveis, comunicação de situação aos usuários finais e reporte de métricas para o grupo responsável. Existem métricas definidas para controle dos incidentes:

- Tempo de resolução, de acordo com a severidade do incidente, definido com base na criticidade da aplicação, impacto e quantidade de usuários afetados;

- Tempo de resposta, também de acordo com a severidade do incidente;

- Porcentagem de incidentes reabertos.

Para os sistemas de desenho de produto e processo estão sendo criadas estruturas de atendimento específicas dentro do processo existente (grupos solucionadores, para os quais são encaminhados os tickets abertos na central de atendimento). Algumas aplicações desenvolvidas na matriz do Grupo Z possuem um processo distinto de suporte, direto com a matriz, havendo na filial pessoas responsáveis por atividades de administração destes sistemas, como inclusão e exclusão de usuários

Conforme mencionado anteriormente, para o sistema PRODCONTROL, existe uma célula de monitoramento 24 horas responsável pela resolução de incidentes e acionamento dos responsáveis quando necessário. Esta célula trata apenas do sistema de controle de produção de carros e é um modelo utilizado em todas as plantas do Grupo Z.

Para os demais ativos do chão de fábrica, existem também plantonistas que atendem localmente. Quando ocorre um incidente, trabalha-se para resolver o incidente e, depois, o monitor responsável pelo trecho da linha de produção afetado cadastra a ocorrência no módulo de manutenção do ERP, para garantir que está tudo registrado, mas que, ao mesmo tempo, o atendimento seja o mais rápido possível. Estes plantonistas são profissionais da própria empresa, não terceirizados e não existem SLAs definidos para este atendimento. 


\section{Requisições}

Para o ambiente corporativo, para os sistemas de desenho de produtos e processos, para o sistema PRODCONTROL e para as redes de TI por toda a fábrica, as requisições são cadastradas e gerenciadas como os incidentes. Quando as requisições ultrapassam um determinado número de horas, abre-se uma solicitação de serviço. Para esta última categoria, está em discussão a implantação de indicadores, pois ainda não existem.

Para os demais sistemas do chão de fábrica, existe um processo diferente e as pequenas requisições são enviadas por sistema ao grupo responsável pela manutenção da planta. Quando são solicitações maiores, são tratadas como projetos pelo grupo PLANPROD.

\section{Problemas}

O processo de gerenciamento de problemas é definido e conta com o trabalho dos provedores de serviço para a análise de causa raiz. O processo é o mesmo para o ambiente corporativo e de desenho de produto e processo.

Para o sistema PRODCONTROL, a célula possui um processo particular, mais ágil para a análise dos problemas, que conta com o trabalho da célula especializada.

Para os demais sistemas de chão de fábrica, existe um processo próprio, de responsabilidade do grupo PLANPROD. 


\subsubsection{Mecanismos relacionais e abordagens de comunicação}

\section{Gerentes de relacionamento}

A área dos gerentes de relacionamento descrita anteriormente reúne os gerentes de relacionamento da área de $\mathrm{TI}$, responsáveis pelo atendimento às áreas de negócio. Este profissional deve conhecer o negócio da área que atende e oferecer soluções de forma pró-ativa. Esta pessoa deve estar preocupada com os projetos e as soluções de longo prazo.

No entanto, na empresa existe uma figura em algumas áreas de negócio que tem um trabalho essencial de relacionamento com o gerente de relacionamento e representação de sua área. Esta função não é oficializada e não tem uma denominação, mas seria algo como um ponto focal ou um segundo gerente de relacionamento na área de negócio que consolida e discute os projetos com o BRM. Nem todas as áreas possuem e aquelas que não possuem, apresentam maiores problemas de relacionamento.

\section{Comunicação}

A comunicação é vista como um dos grandes problemas da área, mas tem importância reconhecida. As dificuldades de comunicação são internas e externas. Para as externas, um catálogo de serviços pode ajudar. Internamente, entende-se ser necessário incentivar melhor a comunicação sobre o que deve ser feito (estratégias, procedimentos) e feedbacks. Os procedimentos da área não são todos comunicados e, tanto a área, quanto as áreas de negócio, entendem que este é um ponto a ser trabalhado, além da criação de uma estratégia global de comunicação.

Existe um canal de comunicação da área com a empresa toda através da intranet da empresa. Este canal de comunicação é usado para divulgar formulários, políticas de segurança, projetos. Algumas partes estão desatualizadas, mas existe um projeto de atualização geral, tanto de conteúdo, quanto de tecnologia. 
O plano de negócio da área também é uma forma de comunicação. Recentemente foi criado um jornal de circulação interna mensal para divulgar qualquer assunto de TI.

Em 2009, foram estipuladas reuniões periódicas de TI com as áreas explicando as definições de $\mathrm{TI}$, planejamento estratégico de sistemas e processos. Isto facilitou muito o trabalho entre as áreas, pois as áreas de negócio estavam informadas e ficavam mais próximas da área de TI. No entanto, este projeto foi paralisado e não se chegou a discutir projetos.

\section{Treinamento}

As necessidades de treinamento das áreas de negócio são identificadas e informadas pelos usuários finais e gerentes. No caso de grandes projetos, o próprio time responsável identifica a necessidade. Estas necessidades são identificadas de maneira ad-hoc, visto que não existe um processo estabelecido para isto.

Os treinamentos da área de $\mathrm{TI}$ são selecionados pelos próprios funcionários e revisados pelos gestores, não havendo um processo ou plano de treinamento definido para formação em cada cargo. A lista de cada área é de responsabilidade de um coordenador de treinamento (existe um em cada área) e o $\mathrm{RH}$ consolida e providencia a contratação dos treinamentos.

Não existe uma cobrança por colocar em prática os treinamentos, fazendo com que o conhecimento seja efetivamente utilizado dentro da área.

\subsubsection{Metas de desempenho do negócio}

O Grupo possui metas audaciosas para os próximos anos. Para colocar estas metas em prática, a empresa possui um mapa estratégico baseado no BSC com as perspectivas financeira, cliente, interna e potencial e crescimento. 


\subsubsection{Métricas e responsabilidades de $\mathrm{TI}$}

A área de $\mathrm{Tl}$ está alinhada à empresa neste sentido e possui metas para a área, com base no BSC corporativo, segregado das metas do grupo PLANPROD.

As metas relacionam-se a metas financeiras, satisfação dos clientes internos, padronização e otimização de processos e sistemas de TI, disponibilidade de sistemas relacionados aos processos produtivos, gerenciamento de projetos cronograma, treinamento e comunicação, índice de satisfação interno. Este BSC de TI não é o BSC-TI descrito anteriormente na seção sobre modelos de mercado e melhores práticas.

Recentemente, foi realizado um levantamento completo da maturidade dos 34 processos de acordo com o COBIT. Para cada processo, existe uma meta de maturidade três ou quatro. Como próximo passo, está a definição de prioridade entre os processos.

A satisfação dos usuários com a área de TI é medida anualmente por uma pesquisa realizada por uma consultoria externa. Esta pesquisa chega a uma nota final que a área trabalha para aumentar ano a ano e mostra os principais pontos de melhoria da área sob a ótica das áreas de negócio. Para cada um destes pontos é traçado um plano de ação para o próximo ano, que tem surtido efeito no índice da pesquisa.

\section{Melhoria contínua}

Ainda não existe um plano de melhoria contínua - cada profissional, em sua área de atuação, é responsável por melhorar os processos e possui relatórios dos fornecedores e com eles realizam reuniões, mas não existe um processo único, consolidado. Hoje em dia, existem iniciativas principalmente relacionadas aos processos de fornecedores.

A revisão de processos internos costuma ser feita através de um programa corporativo de melhoria de processos voltado para melhorias rápidas. Um processo a ser revisto é sugerido pela empresa, pela diretoria da área ou pelos próprios 
funcionários (passando pela aprovação da diretoria). Para a revisão, são reunidos representantes dos envolvidos munidos de autonomia para modificar o processo.

Além deste programa de melhorias rápidas, existe um que trata de melhorias maiores, processos mais complexos. Dentro deste programa, dois grandes projetos foram realizados para a área de TI utilizando os processos do COBIT como base. Neste programa, quem toma as decisões por modificações nos processos é a alta direção da área ou até mesmo da empresa. Este programa pode gerar necessidades de melhorias rápidas, tratadas pelo outro programa mencionado acima.

\subsection{Estado desejado da Governança de TI na empresa estudada e como a empresa pretende alcançá-lo}

Não existe um modelo de governança explícito, nem tanto um modelo integrado do escritório ao chão de fábrica. No entanto, a área de TI da empresa Carros tem trabalhado muito em sua reestruturação e entende ser necessário um modelo de governança integrado, uma referência, nem muito específico, nem muito complexo. Recentemente, um trabalho de definição de papeis e responsabilidades tem sido desenvolvido.

Para o porte da empresa, entende-se que o modelo acabará sendo complexo. Este modelo deve ter sua implementação muito bem planejada, verificando o que deve ser implementado, o que eventualmente precisa ser adaptado e quando.

Até o momento, a meta da área é, a partir de um levantamento dos níveis de maturidade de acordo com o COBIT, elevar a maturidade dos processos para 3 ou 4, dependendo do nível atual de maturidade. Esta já é uma meta bastante audaciosa, dado o trabalho necessário para elevar a maturidade dos processos que, na maioria das empresas, giram em torno do nível 2, se não menos.

Entende-se que a área de Governança de TI é a responsável pelo estabelecimento dos processos, evolução nos níveis de maturidade e desenvolvimento e implementação de um modelo de Governança de TI. 


\subsection{Considerações finais do capítulo}

Neste capítulo foi apresentado o estudo de caso realizado na empresa Carros, em busca da validação do modelo proposto. Foram apresentados o estado atual da Governança de TI na Carros e o estado desejado, descrevendo o que a empresa realiza em cada parte do modelo proposto.

No próximo capitulo, é realizada a análise do estudo de caso como ferramenta para a validação do modelo proposto. 


\section{VALIDAÇÃO DO MODELO PROPOSTO}

principal objetivo deste capítulo é apresentar a validação do Modelo de Governança de TI aplicado do escritório ao chão de fábrica.

Esta validação é feita por meio de:

- Análise do atendimento aos requisitos especificados para o modelo de Governança de TI;

- Análise crítica dos resultados da aplicação do modelo proposto para um estudo de caso. No caso particular desta dissertação, este estudo focou a indústria automobilística;

- Análise da aplicabilidade do modelo proposto a outros setores da indústria.

\subsection{Análise de Requisitos}

No Capítulo 3.2, foram descritos os principais requisitos que deveriam ser atendidos pelo modelo de Governança de TI extensível para a área de manufatura a ser proposto.

No Capítulo 4, foi apresentado o modelo de Governança de TI do escritório ao chão de fábrica proposto e discutidos quais e como os requisitos levantados no Capítulo 3.2 eram atendidos.

Tendo isto em vista, pode-se dizer que o Modelo de Governança:

- Atende a todos os requisitos gerais elicitados;

- Atende a todos os requisitos específicos do chão de fábrica.

Comparando com outros modelos existentes no que concerne ao atendimento de requisitos, pode-se dizer que o modelo contemplou os aspectos de integração dos diferentes ambientes de uma empresa de manufatura, o que não é tratado diretamente pelos modelos de Governança de TI e melhores práticas de mercado. 


\title{
6.2. Análise do Uso do Modelo Proposto para o Estudo de Caso
}

\author{
A Tabela 11, a seguir, apresenta uma síntese das principais características da
} Carros levantadas no estudo de caso.

Tabela 11 - Síntese do estudo de caso da Carros

\begin{tabular}{|c|c|}
\hline Tópicos & Análise \\
\hline Governança de TI & $\begin{array}{l}\text { A definição de governança existente no plano de negócios está parcialmente } \\
\text { alinhada às definições acadêmicas. A área de TI da empresa Carros também } \\
\text { pode trabalhar no alinhamento do conceito entre seus colaboradores. Alinhar } \\
\text { o conceito é uma forma de aprimorar o modelo de governança. } \\
\text { As áreas de negócio não conhecem bem o conceito - os dirigentes que } \\
\text { recebem o plano de negócios têm esta informação, mas ela nem sempre } \\
\text { chega até os analistas. }\end{array}$ \\
\hline Princípios de TI & $\begin{array}{l}\text { Os princípios de TI não estão formalizados, mas existem de forma implícita. A } \\
\text { área está sendo reestruturada e entende-se que este ponto é algo a ser } \\
\text { tratado, juntamente com a revisão da missão da área, de forma a alinhar } \\
\text { ainda mais a TI com o negócio. De acordo com Weill e Ross (2006), a } \\
\text { definição dos princípios já é uma atividade importante de alinhamento. }\end{array}$ \\
\hline $\begin{array}{l}\text { Modelo de } \\
\text { Governança de TI }\end{array}$ & $\begin{array}{l}\text { A empresa não possui um modelo de governança explícito, mas, por ter } \\
\text { iniciado o trabalho de governança com o COBIT (o que é indicado em } \\
\text { publicações como um bom modelo para começar a implementar a } \\
\text { Governança de TI, além de possuir como um de seus benefícios primários a } \\
\text { integração de outros modelos) já possui diversos processos definidos ou em } \\
\text { definição de acordo com o que sugere o modelo proposto. Além do COBIT, } \\
\text { também são bastante utilizados a ITIL e o PMBoK, bem como o BSC } \\
\text { corporativamente. A área também entende como desafios da Governança de } \\
\text { TI uma série de aspectos importantes que estão incorporados no modelo } \\
\text { sugerido. }\end{array}$ \\
\hline Estratégias & Análise \\
\hline Estratégia de $\mathrm{TI}$ & $\begin{array}{l}\text { A estratégia de Tl é importante fator nas demais decisões e processos de } \\
\text { Governança de TI. }\end{array}$ \\
\hline $\begin{array}{l}\text { Estratégia de } \\
\text { Manufatura }\end{array}$ & $\begin{array}{l}\text { A estratégia de automação está sendo definida e será importante entrada para } \\
\text { os projetos, tanto os que são realizados de forma independente pela área de } \\
\text { automação, quanto aqueles que demandam interação com a área de TI. }\end{array}$ \\
\hline Arranjos & Análise \\
\hline $\begin{array}{ll}\text { Arranjos } & \text { de } \\
\text { governança }\end{array}$ & $\begin{array}{l}\text { Os arranjos da Carros são semelhantes aos sugeridos pelo modelo: } \\
\text { - Para os princípios, ainda não há; } \\
\text { - Para os investimentos de TI, um "tripólio"; } \\
\text { - Para as aplicações de negócio, duopólio; } \\
\text { - Para a arquitetura de TI, monarquia de TI; } \\
\text { - Para a infraestrutura de TI, monarquia de TI; } \\
\text { - Para a arquitetura de automação, monarquia de automação. }\end{array}$ \\
\hline Estrutura & Análise \\
\hline $\begin{array}{l}\text { Comitê estratégico } \\
\text { de TI }\end{array}$ & $\begin{array}{l}\text { Não existe um comitê estratégico de TI formalizado atuando junto ao conselho } \\
\text { administrativo da empresa, mas este papel é desempenhado pelo ClO e, por } \\
\text { vezes, pelo vice-presidente de Finanças, fazendo com que a TI esteja } \\
\text { presente na agenda da alta direção da empresa. } \\
\text { Além de manter a TI na agenda da alta administração, Albertin e Albertin } \\
\text { (2010) comentam que é interessante que o diretor de TI participe de alguns } \\
\text { comitês, juntamente com os outros diretores da empresa e das unidades de } \\
\text { negócio para ter conhecimento das estratégias da organização e do } \\
\text { planejamento futuro. Levando em consideração as características da }\end{array}$ \\
\hline
\end{tabular}




\begin{tabular}{|c|c|}
\hline & $\begin{array}{l}\text { organização como tamanho, investimento e crescimento, juntamente com a } \\
\text { visão e a estratégia, o diretor de TI tem melhores condições de planejar a } \\
\text { Governança de TI. A Carros está desenvolvendo este ponto. } \\
\text { Estas ações estratégicas não incluem a automação, tratada por outra área da } \\
\text { Carros. }\end{array}$ \\
\hline $\begin{array}{l}\text { Comitê gestor de } \mathrm{TI} \\
\text { (Steering } \\
\text { Committee) }\end{array}$ & $\begin{array}{l}\text { O comitê gestor de TI foi recentemente reformulado e está alinhado ao que é } \\
\text { sugerido no modelo. É importante que as áreas de negócio realizem } \\
\text { internamente a comunicação do que é discutido e do que precisa ser levado } \\
\text { às reuniões deste grupo, além das decisões serem comunicadas dentre os } \\
\text { analistas de TI. Este comitê gestor não trata de assuntos de automação, } \\
\text { tratados por outro comitê. }\end{array}$ \\
\hline $\begin{array}{l}\text { Time de arquitetura } \\
\text { integrado }\end{array}$ & $\begin{array}{l}\text { Não existe um time de arquitetura integrado, mas os grupos de } \mathrm{TI} \text { e de } \\
\text { automação trabalham em conjunto, principalmente em relação ao sistema que } \\
\text { controla a produção. Os sistemas de automação são totalmente controlados } \\
\text { pelo grupo de automação, que apenas demanda da TI pontos de rede, por } \\
\text { exemplo. A empresa pode considerar a criação do grupo de manufatura } \\
\text { especializado sugerido por Gifford (2011), entre o grupo de TI e o grupo de } \\
\text { automação. Dentro deste grupo ficam analistas de diferentes níveis que } \\
\text { gerenciam plantas e processos, além de arquitetos que governam os sistemas } \\
\text { de produção, como SCADA, sistemas de controle da produção, de } \\
\text { agendamento de capacidade, de manutenção etc. em busca de uma } \\
\text { plataforma integrada. }\end{array}$ \\
\hline $\begin{array}{l}\text { Time } \\
\text { de TI }\end{array}$ & $\begin{array}{l}\text { Estrutura alinhada ao que é sugerido no modelo para os ambientes } \\
\text { corporativo, de desenho de produto e processo e de controle da produção. A } \\
\text { segurança no ambiente de automação é tratada pela equipe de automação, } \\
\text { seguindo diretrizes da matriz do Grupo Z. }\end{array}$ \\
\hline $\begin{array}{l}\text { Time de serviços } \\
\text { de TI }\end{array}$ & $\begin{array}{l}\text { Dentro do time de serviços sugerido no modelo, a empresa Carros conta com } \\
\text { um time responsável pela operação específica das aplicações, mas com } \\
\text { função distinta da operação da infraestrutura. É um modelo interessante para } \\
\text { uma empresa do porte da Carros, mas que, na própria empresa Carros, ainda } \\
\text { precisa de ajustes, com a definição clara dos papeis e responsabilidades } \\
\text { deste grupo e do grupo de gerentes de relacionamento. } \\
\text { O sistema que controla a produção possui um time específico e o ambiente de } \\
\text { automação é atendido pelo time de manutenção da planta. }\end{array}$ \\
\hline Times de projeto & $\begin{array}{l}\text { da projeto possui seu time que envolve a área de negócio quando se trata } \\
\text { um projeto de aplicações de negócio. O ambiente de automação também } \\
\text { balha com times de projeto, formado por pessoas da própria área e } \\
\text { necedores. }\end{array}$ \\
\hline Escritório do $\mathrm{ClO}$ & $\begin{array}{l}\text { O escritório do } \mathrm{ClO} \text {, apesar de não possuir esta denominação, trata de } \\
\text { conformidade, gerenciamento financeiro de TI, fornecedores, pessoas, } \\
\text { planejamento de TI, gestão do portfólio, desenvolvimento de processos, } \\
\text { gestão dos serviços e comunicação. Aspectos relacionados à automação são } \\
\text { tratados pelo time específico. }\end{array}$ \\
\hline & \\
\hline $\begin{array}{l}\text { Plano estratégico } \\
\text { de TI }\end{array}$ & $\begin{array}{l}\text { A Carros possui um plano divulgado que melhora o entendimento dos } \\
\text { envolvidos quanto às oportunidades e limitações de TI, identifica o } \\
\text { desempenho atual, a capacidade e aspectos estratégicos de arquitetura. Não } \\
\text { são contemplados recursos humanos e terceirização, nem aspectos da } \\
\text { automação. }\end{array}$ \\
\hline $\begin{array}{l}\text { Gerenciamento de } \\
\text { Riscos }\end{array}$ & $\begin{array}{l}\text { Existe um processo de gerenciamento de riscos alinhado ao gerenciamento } \\
\text { de riscos corporativo e está em processo de melhoria. } \\
\text { O gerenciamento de riscos da automação é feito separadamente do } \\
\text { gerenciamento de riscos de } \mathrm{Tl} \text {, mas o processo corporativo é o mesmo. }\end{array}$ \\
\hline $\begin{array}{l}\text { Política } \\
\text { Segurança }\end{array}$ & $\begin{array}{l}\text { A Política de Segurança segue a norma internacional ISO } 27001 \text { e é comum } \\
\text { em todas as filiais do Grupo Z, permitindo intercâmbio de práticas e } \\
\text { informações. }\end{array}$ \\
\hline Arquitetura & $\begin{array}{l}\text { O processo de definição é de responsabilidade da matriz do Grupo Z. O livro } \\
\text { de referência é conhecido, mas, ainda assim, poderia ser melhor divulgado } \\
\text { aos responsáveis pelas definições de projetos junto às áreas de negócio. A }\end{array}$ \\
\hline
\end{tabular}




\begin{tabular}{|c|c|}
\hline & $\begin{array}{l}\text { automação, apesar de dever utilizar o livro de referência como base, possui } \\
\text { um processo de definição de arquitetura completamente distinto, o que pode } \\
\text { trazer alguns conflitos tecnológicos. } \\
\text { O processo de definição da arquitetura de TI deve garantir padronização, } \\
\text { agilidade e segurança das informações. Neste ponto, o processo de } \\
\text { arquitetura apresenta certa sobreposição ao processo de definição dos } \\
\text { procedimentos de segurança. Na empresa Carros, a arquitetura de TI vai até } \\
\text { o sistema que controla a produção, mas já existem alguns conflitos a partir } \\
\text { deste ponto que precisam ser discutidos com a automação - é o caso de uma } \\
\text { tecnologia sem fio muito utilizada nos equipamentos de produção, mas } \\
\text { considerada uma rede não segura por TI. }\end{array}$ \\
\hline $\begin{array}{l}\text { Gerenciamento do } \\
\text { Portfólio }\end{array}$ & $\begin{array}{l}\text { O portfólio é focado em investimentos e conta com uma categorização, } \\
\text { conforme sugere o Val IT. O Val IT sugere que o portfólio de TI seja otimizado, } \\
\text { identificando sinergias e duplicações entre programas. A área realiza isto } \\
\text { dentro de seu calendário de elaboração e aprovação de casos de negócios e } \\
\text { o comitê que avalia tecnicamente os projetos na região também avalia } \\
\text { sinergias. } \\
\text { A área precisa ainda criar um catálogo de serviços que, de preferência, } \\
\text { contenha os valores por serviços para cobrança reversa. } \\
\text { Os projetos de automação são tratados separado deste portfólio de TI pela } \\
\text { área responsável. }\end{array}$ \\
\hline $\begin{array}{l}\text { Gerenciamento da } \\
\text { Demanda }\end{array}$ & $\begin{array}{l}\text { Conduzido pelos gerentes de relacionamento e seus superiores, alinhado com } \\
\text { as práticas da matriz. Os casos de negócio desenvolvidos pelas áreas em } \\
\text { conjunto com TI estão de acordo com o que é sugerido em relação a } \\
\text { conteúdo, além de possuírem duas etapas: uma inicial e uma detalhada, e } \\
\text { estarem alinhados ao BSC corporativo. A etapa detalhada deve vir após } \\
\text { aprovação, para evitar que se trabalhe em algo que não é necessário. Este } \\
\text { aspecto está sendo endereçado na melhoria do processo atual. } \\
\text { A demanda de projetos de automação é tratada pela área de automação em } \\
\text { separado. }\end{array}$ \\
\hline $\begin{array}{l}\text { Decisão } \\
\text { Investimento }\end{array}$ & $\begin{array}{l}\text { Processo conhecido pelas áreas de negócio, mas cujos resultados, de acordo } \\
\text { com os entrevistados, poderiam ser melhor divulgados. As áreas carecem de } \\
\text { explicação sobre os critérios utilizados para as decisões, mas este é um ponto } \\
\text { divulgado na reunião do comitê gestor, o que pode indicar que a comunicação } \\
\text { dentro das áreas de negócio pode ser melhorada. }\end{array}$ \\
\hline Qualidade & $\begin{array}{l}\text { Está sendo definido para ser aplicado a projetos, serviços, processo seletivo } \\
\text { de fornecedores e pesquisa com clientes. É importante que o processo } \\
\text { seletivo de fornecedores contemple pequenas e grandes empresas e que } \\
\text { considere as peculiaridades de compra de serviços - as empresas conhecem } \\
\text { bem a compra de bens materiais, mas a aquisição de serviços é mais } \\
\text { complicada e, muitas vezes, intangível. }\end{array}$ \\
\hline Recursos Humanos & $\begin{array}{l}\text { Sob responsabilidade do RH. Este processo também deve incluir um catálogo } \\
\text { de pessoal e conhecimentos, entender a demanda atual e futura e planejar } \\
\text { como supri-la. Quem faz este planejamento hoje é o } \mathrm{ClO} \text {. }\end{array}$ \\
\hline Terceirização & $\begin{array}{l}\text { Caminho em direção ao multisourcing, seguindo práticas de mercado. } \\
\text { Estratégia poderia ser formalizada, além de divulgada às áreas de negócio. }\end{array}$ \\
\hline $\begin{array}{l}\text { Programas } \\
\text { Projetos }\end{array}$ & $\begin{array}{l}\text { A empresa possui divisão em projetos e portfólio. Pode trabalhar para } \\
\text { melhorar o entendimento e o uso de agrupamentos em programas, mesmo } \\
\text { incluindo projetos não TI. Para os projetos também podem ser estabelecidas } \\
\text { métricas além de financeiras e pode-se estabelecer, por exemplo, OLAs com } \\
\text { áreas internas, como Compras. } \\
\text { A área de PMO está trabalhando na definição de uma metodologia e na } \\
\text { criação de documentos padronizados para auxiliar no gerenciamento dos } \\
\text { projetos pelos gerentes de relacionamento e já conta com um painel de } \\
\text { projetos para controle consolidado. }\end{array}$ \\
\hline $\begin{array}{l}\text { Gerenciamento de } \\
\text { níveis de serviço }\end{array}$ & $\begin{array}{l}\text { O processo é definido e igual para os ambientes corporativo, de desenho de } \\
\text { produto e processo e de controle da produção. O gerenciamento de níveis de } \\
\text { serviço do ambiente de automação não é alinhado ao gerenciamento dos } \\
\text { demais ambientes. }\end{array}$ \\
\hline
\end{tabular}




\begin{tabular}{|c|c|}
\hline $\begin{array}{l}\text { Gerenciamento de } \\
\text { capacidade }\end{array}$ & $\begin{array}{l}\text { O gerenciamento de capacidade não é definido por completo, visto que hoje } \\
\text { possui apenas a captação dos dados provindos de monitoramento, sem } \\
\text { formalizar as análises e planos de ações necessárias. Para o sistema que } \\
\text { controla a produção, existe um processo específico executado pela célula } \\
\text { responsável pelo sistema e para os sistemas de automação existe um terceiro } \\
\text { processo, diferente. }\end{array}$ \\
\hline $\begin{array}{l}\text { Gerenciamento de } \\
\text { Disponibilidade } \\
\text { Eventos }\end{array}$ & $\begin{array}{l}\text { O gerenciamento de disponibilidade é dividido em três: um para sistemas } \\
\text { corporativos e de desenho de produto e processo, outro para o sistema de } \\
\text { informação que controla a produção e outro para os sistemas de automação, } \\
\text { realizado na própria linha de produção. }\end{array}$ \\
\hline $\begin{array}{l}\text { Gerenciamento de } \\
\text { Segurança }\end{array}$ & $\begin{array}{l}\text { Para os sistemas corporativos, de desenho de produto e processo e para o } \\
\text { sistema que controla a produção, o processo é o mesmo, baseado na ISO } \\
27000 \text { e alinhado ao Grupo Z. Ainda precisa incorporar processos de } \\
\text { segurança no chão de fábrica, garantindo o controle e a segurança. }\end{array}$ \\
\hline $\begin{array}{l}\text { Gerenciamento de } \\
\text { Continuidade }\end{array}$ & $\begin{array}{l}\text { Em desenvolvimento em conjunto com as áreas de negócio, mas sem } \\
\text { considerar o ambiente de automação. É importante que a análise de impacto } \\
\text { aos negócios seja desenvolvida em conjunto com as áreas de negócio e } \\
\text { considere todas as necessidades. }\end{array}$ \\
\hline $\begin{array}{l}\text { Gerenciamento de } \\
\text { Fornecedores }\end{array}$ & $\begin{array}{l}\text { O gerenciamento de fornecedores é divido em duas partes: contratação e } \\
\text { operação. A parte da operação é acompanhada por TI, com reuniões } \\
\text { periódicas de acompanhamento. A parte de contratação é realizada pela área } \\
\text { de Compras, sendo que a TI não tem os catálogos de fornecedores e nem os } \\
\text { qualifica, apenas avalia tecnicamente as propostas. Contanto que Compras } \\
\text { trabalhe de maneira alinhada à área de TI, não é um problema que detenha } \\
\text { estes processos. Os processos para modificar e encerrar contratos precisam } \\
\text { ser formalizados e comunicados. }\end{array}$ \\
\hline $\begin{array}{l}\text { Gerenciamento } \\
\text { Financeiro }\end{array}$ & $\begin{array}{l}\text { O gerenciamento financeiro é o mesmo para os ambientes corporativo, de } \\
\text { desenho de produto e processo e de controle da produção. A empresa já } \\
\text { pensa em expandir os mecanismos de cobrança reversa. Para o ambiente de } \\
\text { automação, não há contabilização deste tipo. }\end{array}$ \\
\hline $\begin{array}{l}\text { Gerenciamento de } \\
\text { Mudanças }\end{array}$ & $\begin{array}{l}\text { O gerenciamento de mudanças é estabelecido e já passa por revisões para } \\
\text { melhoria. Pode-se incorporar a avaliação por pacotes de melhorias. Todas as } \\
\text { mudanças no sistema que controla a produção são feitas de forma } \\
\text { emergencial, mas o processo é o mesmo que as mudanças emergenciais dos } \\
\text { demais ambientes. Para os sistemas de controle, pode ser incorporada a } \\
\text { prática. }\end{array}$ \\
\hline $\begin{array}{l}\text { Gerenciamento de } \\
\text { Liberações }\end{array}$ & $\begin{array}{l}\text { O gerenciamento de liberações hoje é feito junto com o de mudanças } \\
\text { (instruçães de implantação e migração). Não há um processo de testes } \\
\text { padronizado, mas os aceites dos usuários já possuem processo definido e } \\
\text { formulários desenvolvidos. Hoje em dia, os processos são diferentes entre os } \\
\text { ambientes corporativo, de desenho de produto e processo, do sistema que } \\
\text { controla a produção e do ambiente de automação. }\end{array}$ \\
\hline $\begin{array}{l}\text { Gerenciamento de } \\
\text { Configuração }\end{array}$ & $\begin{array}{l}\text { O processo de gerenciamento de configuração está sendo criado com o } \\
\text { auxílio de uma ferramenta, trazendo a responsabilidade para a TI (hoje é } \\
\text { realizado, em sua maioria, pelas áreas de forma manual). Esta base, além de } \\
\text { inventário, deve fazer correlações entre os diferentes itens de configuração, } \\
\text { auxiliando os demais processos. O processo também deve contemplar a } \\
\text { política de sobressalentes para cada um dos ambientes. } \\
\text { O ambiente de automação não está incluído neste processo, mas possui um } \\
\text { processo próprio. }\end{array}$ \\
\hline Service Desk & $\begin{array}{l}\text { O modelo sugere que haja um único ponto de contato, mas a empresa pode } \\
\text { avaliar a existência de outros conforme sua cultura. Hoje, a Carros possui } \\
\text { uma para os sistemas corporativos e de desenho de produto e processo, um } \\
\text { para o ERP, outro para o sistema que controla a produção e, para os sistemas } \\
\text { de automacão, o contato é direto com a equipe de manutencão de planta. }\end{array}$ \\
\hline $\begin{array}{l}\text { Gerenciamento } \\
\text { Incidentes }\end{array}$ & $\begin{array}{l}\text { O gerenciamento de incidentes tem um processo definido e conhecido para os } \\
\text { sistemas corporativos. Pode passar por melhorias, principalmente nos roteiros } \\
\text { utilizados pelos atendentes, para que os incidentes sejam resolvidos no } \\
\text { primeiro nível ou, caso necessário, sejam encaminhados aos grupos corretos }\end{array}$ \\
\hline
\end{tabular}




\begin{tabular}{|c|c|}
\hline & $\begin{array}{l}\text { rapidamente. Os usuários também devem ser informados sobre a melhor } \\
\text { forma de abrir os chamados, auxiliando no correto encaminhamento. } \\
\text { Para os sistemas de desenho de produto e processo, está em } \\
\text { desenvolvimento um processo diferenciado, em que grupos específicos serão } \\
\text { responsáveis pelos chamados destes ambientes. Este ponto se diferencia do } \\
\text { proposto no modelo. } \\
\text { O sistema de controle da produção possui um processo diferenciado, atendido } \\
\text { pela célula específica e o ambiente de automação possui ainda um outro } \\
\text { processo, em que se atua primeiro e, depois, se cadastra o incidentes, além } \\
\text { de ser executado por uma outra equipe local (manutenção de planta). }\end{array}$ \\
\hline $\begin{array}{l}\text { Gerenciamento de } \\
\text { Requisições }\end{array}$ & $\begin{array}{l}\text { Semelhante ao gerenciamento de incidentes, dividido entre os quatro } \\
\text { ambientes. }\end{array}$ \\
\hline $\begin{array}{l}\text { Gerenciamento de } \\
\text { Problemas }\end{array}$ & $\begin{array}{l}\text { O gerenciamento de problemas tem sido realizado conforme sugerido no } \\
\text { modelo, semelhante para sistemas corporativos e de desenho de produto e } \\
\text { processo, mas o sistema que controla a produção e o ambiente de automação } \\
\text { possuem processos distintos. }\end{array}$ \\
\hline $\begin{array}{l}\text { Mecanismo } \\
\text { relacional ou } \\
\text { abordagem de } \\
\text { comunicação }\end{array}$ & Análise \\
\hline $\begin{array}{lr}\text { Gerente } & \text { de } \\
\text { relacionamento } & \mathrm{e} \\
\text { treinamento } & \text { do } \\
\text { gerente } & \text { de } \\
\text { relacionamento } & \end{array}$ & $\begin{array}{l}\text { O modelo de gerentes de relacionamento está de acordo com o que é } \\
\text { sugerido no modelo. É importante também que a empresa Carros estude a } \\
\text { formalização da função de "segundo gerente de relacionamento" (na área de } \\
\text { negócio) para que todas as áreas possuam este importante ponto de contato, } \\
\text { além de um padrão de trabalho comum. } \\
\text { A área de automação não possui a figura de gerente de relacionamento, mas } \\
\text { possui gerentes de projetos. }\end{array}$ \\
\hline $\begin{array}{l}\text { Planejamento de } \\
\text { comunicação }\end{array}$ & $\begin{array}{l}\text { A área de TI da Carros pode avaliar o desenvolvimento de um plano completo } \\
\text { de comunicação, além da criação de um catálogo de serviços para que toda a } \\
\text { empresa tenha claros os serviços que a TI presta internamente. }\end{array}$ \\
\hline $\begin{array}{lr}\text { Planejamento } & \text { de } \\
\text { comunicação } & - \\
\text { Treinamento } & \text { dos } \\
\text { gerentes } & \text { de } \\
\text { relacionamento } & \end{array}$ & $\begin{array}{l}\text { É importante que seja desenvolvido um padrão básico de relacionamento com } \\
\text { as áreas para que o atendimento seja mais parecido entre as áreas, não } \\
\text { dependendo tanto de indivíduos, além do treinamento destes gerentes na } \\
\text { comunicação da estratégia de TI. }\end{array}$ \\
\hline $\begin{array}{lr}\text { Planejamento } & \text { de } \\
\text { comunicação } & - \\
\text { Comunicados alta } \\
\text { gerência }\end{array}$ & $\begin{array}{l}\text { A comunicação da alta direção de TI já é realizada para a alta direção das } \\
\text { outras áreas. Podem ser estudadas formas de comunicação para outros } \\
\text { níveis da empresa. }\end{array}$ \\
\hline $\begin{array}{l}\text { Planejamento de } \\
\text { comunicação } \\
\text { Comunicação web }\end{array}$ & $\begin{array}{l}\text { A empresa Carros já trabalha na comunicação web e trabalha na } \\
\text { implementação de uma ferramenta mais moderna. }\end{array}$ \\
\hline $\begin{array}{lr}\text { Planejamento } & \text { de } \\
\text { comunicação } & - \\
\text { Campanhas de } \\
\text { conscientização }\end{array}$ & $\begin{array}{l}\text { A Carros já utiliza emails e informativos que abrem nos computadores para } \\
\text { divulgar políticas e paradas de manutenção. A Carros pode estudar o retorno } \\
\text { das reuniões periódicas de } \mathrm{TI} \text { com as áreas. }\end{array}$ \\
\hline $\begin{array}{lr}\text { Planejamento } & \text { de } \\
\text { comunicação } & - \\
\text { Comunicação no } \\
\text { chão-de-fábrica }\end{array}$ & $\begin{array}{l}\text { A área de TI pode estudar formas de comunicação dos projetos e das } \\
\text { operações junto à área de automação. Pode-se iniciar por procedimentos de } \\
\text { segurança neste ambiente, onde ocorrem alguns problemas atualmente. }\end{array}$ \\
\hline $\begin{array}{l}\text { Planejamento } \\
\text { treinamentos }\end{array}$ & $\begin{array}{l}\text { Não existe um planejamento global estabelecido. } \\
\text { A área de automação possui seu próprio processo de treinamentos. }\end{array}$ \\
\hline $\begin{array}{l}\text { Planejamento } \\
\text { treinamentos } \\
\text { Treinamento } \\
\text { usuários }\end{array}$ & $\begin{array}{l}\text { Os treinamentos são solicitados pelas áreas de negocio ou são realizados em } \\
\text { época de projetos, não havendo um plano geral de treinamentos. }\end{array}$ \\
\hline $\begin{array}{l}\text { Planejamento } \\
\text { treinamentos } \\
\text { Treinamento }\end{array}$ & $\begin{array}{l}\text { Diversos treinamentos são disponibilizados ao pessoal da área. Não existe um } \\
\text { plano geral de treinamento de } \mathrm{TI} \text {, sendo que cada funcionário seleciona seus } \\
\text { treinamentos e os gestores validam. Também não existe um mecanismo de }\end{array}$ \\
\hline
\end{tabular}




\begin{tabular}{|c|c|}
\hline pessoal de $\mathrm{TI}$ & $\begin{array}{l}\text { cobrança por colocar em prática os treinamentos. Pode-se também formar } \\
\text { grupos de estudo. }\end{array}$ \\
\hline $\begin{array}{l}\text { Planejamento } \\
\text { treinamentos } \\
\text { Treinamentos } \\
\text { conjuntos }\end{array}$ & $\begin{array}{l}\text { Em alguns treinamentos participam pessoas de } \mathrm{Tl} \text { e das áreas de negócio, } \\
\text { mas não existe um programa estabelecido de treinamento conjunto. Podem } \\
\text { ser incentivados treinamentos conjuntos de Tl e área de negócio, se não em } \\
\text { temas técnicos, em temas comportamentais. }\end{array}$ \\
\hline $\begin{array}{l}\text { Planejamento } \\
\text { treinamentos } \\
\text { Workshops }\end{array}$ & $\begin{array}{l}\text { Não existe uma programação de workshops definida. A empresa Carros } \\
\text { também pode estudar a retomada das reuniões periódicas entre TI e área, } \\
\text { incorporando a discussão sobre os processos e o relacionamento entre o } \\
\text { trabalho da área e da TI (workshops) com controle da efetiva realização } \\
\text { (podem ser vistas como parte das campanhas de conscientização). É um } \\
\text { mecanismo que faz com que as áreas vejam o trabalho da TI e a TI entenda } \\
\text { melhor as áreas. }\end{array}$ \\
\hline $\begin{array}{lr}\text { Documentação } & \text { de } \\
\text { processos } & \text { e } \\
\text { sistemas } & \end{array}$ & $\begin{array}{l}\text { A Carros possui processos para documentação sistemas e serviços. Os } \\
\text { processos ainda não são todos documentados, mas já se reconhece esta } \\
\text { necessidades. }\end{array}$ \\
\hline $\begin{array}{l}\text { Metas de } \\
\text { desempenho do } \\
\text { negócio }\end{array}$ & Análise \\
\hline $\begin{array}{lr}\text { Metas } & \text { de } \\
\text { desempenho do } \\
\text { negócio e metas de } \\
\text { produção }\end{array}$ & $\begin{array}{l}\text { A empresa é referência quanto a metas de desempenho do negócio, tanto } \\
\text { pelas metas audaciosas, quanto pelo mapa estratégico com base no BSC, } \\
\text { incluindo as metas de produção. }\end{array}$ \\
\hline $\begin{array}{l}\text { Métricas e } \\
\text { responsabilidades } \\
\text { de TI }\end{array}$ & Análise \\
\hline $\begin{array}{l}\text { Indicadores } \\
\text { compartilhados }\end{array}$ & $\begin{array}{l}\text { De forma geral, a empresa deve buscar as metas do BSC, mas não existem } \\
\text { no nível mais operacional. }\end{array}$ \\
\hline BSC-TI & $\begin{array}{l}\text { A área já possui metas alinhadas ao BSC corporativo. Apesar de não usar o } \\
\text { BSC-TI, já considera suas perspectivas dentre suas metas (contribuição com } \\
\text { o negócio: como a direção da empresa vê o departamento de TI; orientação a } \\
\text { usuários: como os usuários vêm o departamento de Tl; excelência } \\
\text { operacional: quão eficazes e eficientes são os processos de Tl; orientação } \\
\text { para o futuro: quão bem a TI está posicionada para atender às futuras } \\
\text { necessidades da empresa). } \\
\text { A área de automação também possui indicadores ligados ao BSC corporativo, } \\
\text { mas não relacionados a TI. }\end{array}$ \\
\hline $\begin{array}{l}\text { Relatório } \\
\text { serviço }\end{array}$ & $\begin{array}{l}\text { Processo de acordo com o que é sugerido no modelo, com relatórios pré- } \\
\text { definidos para os serviços. A área pode estudar formas de divulgar mais estes } \\
\text { resultados. }\end{array}$ \\
\hline Melhoria contínua & $\begin{array}{l}\text { Apesar de não existir um plano de melhoria contínua - o que poderia ser } \\
\text { implementado pela área, existe o programa corporativo de melhoria de } \\
\text { processos e uma meta atrelada ao BSC de realização de determinado número } \\
\text { de revisões. Os processos a serem revisados devem ser divulgados a todos } \\
\text { os funcionários para que aqueles que possam colaborar, saibam quando irão } \\
\text { acontecer as reuniões. } \\
\text { Além deste programa de melhoria rápida de processos, existe o que trata de } \\
\text { melhorias maiores e processos mais complexos e que já realizou um trabalho } \\
\text { na própria área de TI. Pode-se ser melhorada a divulgação dos resultados e } \\
\text { implementações. } \\
\text { A área de automação também participa destes programas corporativos, mas } \\
\text { separada da área de TI. }\end{array}$ \\
\hline
\end{tabular}

Para validar o modelo proposto, a Tabela 12 lista os requisitos e o atendimento a eles frente à situação atual da Carros. 
Tabela 12 - Validação dos requisitos

\begin{tabular}{l}
\hline Requisito Geral \\
\hline Definir os direitos decisórios, formalizando e \\
comunicando papeis e responsabilidades, de \\
forma a deixar claro quem faz o quê, quem é \\
responsável, quem é consultado e quem é \\
informado \\
\hline Definir estruturas de governança que busquem \\
otimização dos investimentos de toda a empresa, \\
ao mesmo tempo evitando subinvestimento, o \\
que pode acarretar problemas no médio e longo \\
prazos
\end{tabular}

Estabelecer uma estrutura responsável pela Governança de TI que garanta que o modelo de governança seja implementado e sustentado de acordo com as estratégias e prioridades da empresa

Considerar o comportamento humano, visto que a governança envolve, além de mudanças em processos, mudanças culturais

Considerar a criação de uma arquitetura padrão para referência para todos os ambientes, bem como princípios-guia de design, garantindo agilidade e menores tempos de resposta, além de reuso e manutenção simplificada

Estabelecer diferentes times para projeto, para estabelecer padrões e para operações, de forma que as especializações atendam aos requisitos de cada ambiente, além de permitir melhor gerenciamento das atividades

Trabalhar com um portfólio de TI único, permitindo a visão de todos os tipos de projetos, infraestruturas e serviços, sejam do escritório ou do chão de fábrica, além do gerenciamento integrado da demanda

Estabelecer processos de gerenciamento de serviços para os diferentes ambientes, de forma que sejam consideradas as diferentes demandas

Considerar o gerenciamento de todos os ativos, mesmo os de maior ciclo de vida, visto que uma indústria tem diferentes tipos de ativos, com características muito distintas

Viabilizar 0 gerenciamento de mudanças integrado, verificando todos os impactos das mudanças nos diferentes ambientes

Considerar as exigências de segurança da informação nos diferentes ambientes, dadas as diferentes características na forma de processar e fornecer as informações

Desenvolver mecanismos de reporte de resultados (de projetos e operações) integrados, permitindo uma visão holística do ambiente de forma que seja possível entender o impacto do

\section{Atendimento ao requisito atualmente}

Em desenvolvimento pela implantação do PO4 do COBIT, além das estruturas organizacionais existentes e dos arranjos.

Os processos de gerenciamento do portfólio, de demanda e decisão e investimento que a Carros possui atendem a este requisito em conjunto com os casos de negócio (em que se justificam necessidades e riscos de não atendimento, por exemplo).

Estrutura existente dentro do "escritório do ClO" existente na Carros, mas que não abrange automação.

A Carros possui algumas práticas, como os gerentes de relacionamento e treinamentos.

A Carros possui o livro de padrões, que não inclui o ambiente de automação como um todo (apenas rede e protocolos).

A automação possui suas próprias melhores práticas, definidas também pela matriz.

A Carros possui estruturas conforme sugerido no modelo.

O gerenciamento do portfólio congrega todos os projetos de TI, não tratando dos projetos de automação.

\section{A Carros possui diversos processos} desenvolvidos com base no COBIT e na ITIL.

A Carros está trabalhando em ferramenta e processo de gerenciamento de configuração.

O ambiente de automação possui processo próprio, separado.

O gerenciamento de mudanças é integrado, exceto pelo ambiente de automação.

O gerenciamento de segurança nos ambientes corporativo, de desenho de produto e processo e de gerenciamento da produção contam com processos padronizados e de acordo com práticas de mercado e da matriz do Grupo Z. O ambiente de automação ainda não possui processos definidos, mas segue a arquitetura definida pela matriz que incorpora algumas práticas de segurança na rede.

A Carros baseia seus indicadores no BSC corporativo e pode trabalhar nos indicadores compartilhados em nível mais operacional. 


\begin{tabular}{|c|c|}
\hline $\begin{array}{l}\text { balho de cada área no todo, incentivando } 0 \\
\text { balho colaborativo }\end{array}$ & \\
\hline $\begin{array}{l}\text { Estabelecer uma estrutura de comunicação } \\
\text { apropriada, considerando comitês, ferramentas e } \\
\text { outros meios disponíveis para atingir os diferentes } \\
\text { ambientes }\end{array}$ & $\begin{array}{l}\text { A Carros precisa trabalhar a comunicação em } \\
\text { todos os ambientes, mas já possui algumas } \\
\text { práticas. }\end{array}$ \\
\hline $\begin{array}{l}\text { Estabelecer mecanismos de relacionamento entre } \\
\text { as diferentes áreas, visto que têm diferentes } \\
\text { hábitos e práticas de trabalho }\end{array}$ & $\begin{array}{llr}\text { A Carros já possui os gerentes } & \text { de } \\
\text { relacionamento e pode trabalhar nas } & \text { nampanar } \\
\text { campanhas de conscientização, nos } \\
\text { treinamentos conjuntos e nos workshops para } \\
\text { estabelecer este relacionamento. }\end{array}$ \\
\hline $\begin{array}{l}\text { Considerar o levantamento de lições aprendidas } \\
\text { em projetos e operações para a criação de uma } \\
\text { base de conhecimento }\end{array}$ & $\begin{array}{l}\text { A Carros ainda não possui nada formalizado, } \\
\text { mas as lições aprendidas em projetos serão } \\
\text { consideradas na nova metodologia de } \\
\text { gerenciamento de projetos e as operações } \\
\text { possuem os relatórios com planos de ação, } \\
\text { atendendo parcialmente. }\end{array}$ \\
\hline $\begin{array}{l}\text { Auditar os resultados de projetos e de } \\
\text { garantindo que as informações e } \\
\text { transmitidas e utilizadas da forma corr }\end{array}$ & $\begin{array}{l}\text { A Carros passa por diversas auditorias e possui } \\
\text { indicadores formalizados para reporte. }\end{array}$ \\
\hline Requisito Específico Chão de Fábrica & Aten \\
\hline $\begin{array}{l}\text { Considerar aspectos do chão-de-fábrica nos } \\
\text { princípios-guia de design, como permitir } \\
\text { manutenção sem desligamento do sistema no } \\
\text { caso de equipamentos do chão de fábrica }\end{array}$ & $\begin{array}{l}\text { A Carros possui o livro de padrões, que não } \\
\text { incluir o ambiente de automação (apenas rede e } \\
\text { protocolos), mas a automação recebe da matriz } \\
\text { do Grupo Z as instruções de arquitetura. }\end{array}$ \\
\hline $\begin{array}{l}\text { Considerar regras especiais de segurança da } \\
\text { informação para os sistemas de controle, pois } \\
\text { eles apresentam características diferentes dos } \\
\text { sistemas utilizados em escritório }\end{array}$ & $\begin{array}{l}\text { A Carros considera que existem requisitos } \\
\text { especiais, está desenvolvendo seus processos } \\
\text { de segurança para o chão de fábrica, e já } \\
\text { considera aspectos relacionados à arquitetura, } \\
\text { como a segregação de redes. }\end{array}$ \\
\hline $\begin{array}{l}\text { Considerar que a infraestrutura dos sistemas de } \\
\text { chão-de-fábrica deve ser controlada de forma } \\
\text { isolada e necessariamente ser redundante }\end{array}$ & $\begin{array}{l}\text { A rede para o chão de fábrica está sendo } \\
\text { segregada e é um dos princípios de arquitetura, } \\
\text { além da redundância. As redes de controle são } \\
\text { segregadas. }\end{array}$ \\
\hline $\begin{array}{l}\text { Estabelecer regras de atendimento e manutenção } \\
\text { local, mais rápidas que as utilizadas para o } \\
\text { ambiente de escritório }\end{array}$ & $\begin{array}{l}\text { O gerenciamento de incidentes para o sistema } \\
\text { que controla a produção e para o ambiente de } \\
\text { automação é diferenciado. Na Carros, ele } \\
\text { também é diferenciado entre os sistemas } \\
\text { corporativos e de desenho de produto e } \\
\text { processo. }\end{array}$ \\
\hline $\begin{array}{l}\text { Considerar uma política de sobressalentes mais } \\
\text { rígida para o chão-de-fábrica, dada a urgência na } \\
\text { correção de incidentes neste ambiente }\end{array}$ & O chão de fabrica possui processo próprio. \\
\hline $\begin{array}{l}\text { Estabelecer mecanismos de comunicação que } \\
\text { sejam efetivos no chão-de-fábrica, visto que, por } \\
\text { exemplo, nem todos os funcionários têm acesso a } \\
\text { computadores durante o expediente de trabalho }\end{array}$ & $\begin{array}{l}\text { A área de TI da Carros precisa desenvolver } \\
\text { mecanismos de comunicação no chão de } \\
\text { fabrica, tanto para aspectos de TI, quanto de } \\
\text { automação. }\end{array}$ \\
\hline
\end{tabular}

\subsection{Análise do Estudo de Caso}

A empresa Carros, utilizando o COBIT e priorizando os processos que julga mais importantes está desenvolvendo seu modelo de governança. 
Existem diversas oportunidades de melhoria, principalmente no que se refere à integração com o chão de fabrica e à implementação de processos neste ambiente, mas pode-se dizer que o modelo de Governança de TI sugerido neste trabalho é válido para o caso da Carros, visto que todos os tópicos possuem paralelo na empresa.

Alguns aspectos levantados no estudo de caso podem ser avaliados para melhoria do modelo:

- Utilização de mais de um Service Desk;

- Estabelecimento do "segundo gerente de relacionamento" nas áreas de negócio.

\subsection{Análise da Aplicabilidade do Modelo de Governança Proposto para Outros Setores da Indústria}

Visto que todas as outras indústrias possuem características gerais de ambientes e requisitos semelhantes (linha de produção e sistemas de controle, sistemas para desenvolvimento de produtos e processos, sistemas corporativos e sistemas de gerenciamento do que é produzido), o modelo também é válido para outras empresas com as mesmas características.

\subsection{Principais Considerações do Capítulo}

Neste capítulo foi apresentada a validação do modelo proposto considerando o atendimento aos requisitos especificados anteriormente, além da análise crítica da aplicação do modelo para um estudo de caso e da aplicação do modelo em outras indústrias.

No próximo capítulo, são apresentadas as considerações finais do presente trabalho. 


\section{CONSIDERAÇÕES FINAIS}

A TI tende a se tornar cada vez mais estratégica nas empresas. Como o ClO da General Motors declarou na Information Week, Carr (2003) pode até estar correto em dizer que a TI não importa, mas a melhoria de processos de negócio, vantagem competitiva, otimização e sucesso dos negócios importam e não são commodities. Para facilitar estas mudanças nos negócios, a tecnologia pode ser um fator de diferenciação, mesmo que se deseje gastar o mínimo possível com TI (EVANS, 2003 apud DE HAES, 2008).

Quase 70\% dos executivos participantes da pesquisa "IT's unmet potential" realizada pela McKinsey (ROBERT; SIKES, 2008) apontam a TI como uma das três principais alavancas para vantagens competitivas, mas relatam que o desempenho da $\mathrm{TI}$ ainda precisa de muitas melhorias.

Empresas que integram suas funções e tecnologias usualmente isoladas (como CAD e MRP) são melhores em agilidade, serviço ao cliente, introdução de novos produtos e melhoria de qualidade que suas semelhantes não integradas (YUSUF, 1998 apud FAVARETTO, 2001).

A empresa Carros ainda não possui um modelo explícito de Governança de TI, mas entende a importância do assunto e de ter um modelo integrado. Toda organização tem um modelo de Governança de TI, implícita ou explicitamente. No entanto, as empresas de melhor performance, trabalham para desenvolver ou melhorar a sua arquitetura de governança (PETERSON, 2004; WEILL; ROSS, 2006).

A Carros precisa estudar a implantação de um modelo mais abrangente de Governança de TI. O Val IT declara a importância de se definir um modelo global de Governança de TI e analisar os processos frente a este modelo, identificar e priorizar requisitos de processos, definir e documentar processos, estabelecer, implementar e comunicar papeis e responsabilidade e estabelecer estruturas organizacionais. De acordo com Meyer (2004) existem boas e más formas de governança: se bem desenhada, a governança faz com que pessoas, infraestrutura e capital da empresa trabalhem de forma harmoniosa em conjunto; por outro lado, se mal concebida, a governança leva a um cenário não produtivo, burocrático e cansativo aos envolvidos. 
O modelo proposto neste trabalho busca integrar os diferentes requisitos da $\mathrm{TI}$ corporativa e da TI aplicada ao chão de fábrica, estabelecendo uma estrutura única e uma linguagem comum, agregando as melhores práticas do mercado.

Comparando-se o modelo sugerido com o que existe hoje na empresa Carros, verificou-se que é possível criar um modelo de Governança de TI integrado, que atende aos requisitos elicitados, de forma que foi respondida a pergunta de pesquisa "como integrar a Governança de $\mathrm{Tl}$ através de um modelo, considerando sua utilização em processos corporativos e de produção?".

A grande contribuição do trabalho é o modelo de Governança de TI para o ambiente integrado de TI e chão de fábrica, levando-se em consideração a parte estratégica, tática e operacional do negócio.

No entanto, modelos são simplificações do mundo real e sua interpretação e adaptação devem estar alinhadas com os objetivos da empresa. Sugere-se este modelo para empresas de manufatura, pois atende a requisitos de integração da $\mathrm{TI}$ corporativa com o chão de fábrica de médio a grande porte. Empresas grandes, e medias geralmente, possuem um orçamento maior para a Governança de TI e precisam de uma combinação de mecanismos mais rica por conta da complexidade organizacional - uma montadora, por exemplo, possui geralmente um portfólio de mais de três ou quatro mil aplicações (KELLER, 2009). De acordo com Bowen et al. (2007), organizações complexas requerem múltiplas estruturas de tomada de decisões, o que leva a maiores chances de ocorrerem contradições e desalinhamentos.

No entanto, é muito importante considerar que uma Governança de Tl efetiva não é atingida do dia para a noite (RAU, 2004) e não se espera que um modelo do porte sugerido seja implementado em apenas uma etapa, mas que sirva de base para um projeto maior, desenvolvido diversas fases. É importante avaliar a distância da situação atual até a situação desejada, traçar estratégias de melhoria, priorizar os processos que a empresa julgar mais importantes e medir os resultados. Além disto, esta implementação envolve mudanças culturais e novos processos e é importante que a alta gerência apoie e participe da mudança, além de evitar que a iniciativa seja percebida como a criação de mais burocracias (ITGI, 2008). 


\subsection{Principais contribuições}

As principais contribuições deste trabalho foram:

- Análise e descrição dos modelos para integração tecnológica na seção 2.3.4.1;

- Análises de todos os modelos de Governança de TI e definição consolidada de Governança de TI na seção 2.4.1;

- Análise e descrição do alinhamento entre tecnologia aplicada à produção e negócio e Governança de TI do escritório ao chão de fábrica na seção 2.5, um âmbito de pesquisa que ainda precisa ser melhor explorado;

- Análise do âmbito de utilização das melhores práticas de mercado e consolidação na Figura 30;

- O modelo de Governança de TI para o ambiente integrado de TI e chão de fábrica, levando-se em consideração a parte estratégica, tática e operacional do negócio, a principal contribuição deste trabalho e

- O estudo de caso em empresa real e significativa, demonstrando aspectos positivos e negativos do dia-a-dia das indústrias.

\subsection{Limitações e trabalhos futuros}

Uma limitação deste trabalho refere-se ao grau de detalhamento dos processos. Para definir um modelo do porte sugerido neste trabalho, é necessário iniciá-lo em um nível mais macro em termos de detalhes para, depois, detalhar cada processo.

Outra limitação refere-se ao fato de o estudo exploratório ter sido baseado em opinião dos respondentes, e, segundo Yin (2005), podem "ocorrer imprecisões devido à memória fraca do entrevistado" ou "o entrevistado dá ao entrevistador o que ele quer ouvir". Em função disto, trabalhos futuros poderiam utilizar 
metodologias que procurem minimizar, ou até mesmo eliminar, os problemas levantados.

Como outra possibilidade de pesquisa futura, sugere-se o desenvolvimento de um método de implementação do modelo, bem como o detalhamento de processos de acordo com as prioridades de implementação de cada empresa, além do estudo exploratório em outras empresas, em busca de ajustes e refinamentos do modelo.

\subsection{Inovação deste trabalho}

Este trabalho trouxe uma inovação para o campo da Governança de TI: a consideração de arranjos, estruturas, processos, mecanismos relacionais e abordagens de comunicação, metas e métricas para o ambiente de automação, onde os requisitos e as tecnologias são distintas das conhecidas nos tradicionais ambientes de $\mathrm{TI}$, além de ser um trabalho que integrou diversos modelos.

Além disto, o modelo pode ser aplicado em outras indústrias, pois as demais empresas do ramo de manufatura possuem características gerais de ambientes e requisitos semelhantes. 


\section{REFERÊNCIAS}

38500.ORG. ISO 38500 IT Governance Standard. Disponível em <http://www.38500.org/>. Acesso em 09 de julho de 2010.

ADACHI, E. S. Governança de TI: análise crítica das práticas existentes em uma empresa estatal do setor de TI. 2008. 143p. Dissertação (Mestrado) - Engenharia de Produção, Universidade Federal do Rio Grande do Sul, Porto Alegre, 2008. Disponível em: <http://www.lume.ufrgs.br/bitstream/handle/10183/14822/000667045.pdf?sequence=1>. Acesso em 13 mai. 2011.

ALBERTIN, R. M. M; ALBERTIN, A. L. Estratégia de governança de tecnologia da informação: estrutura e práticas. 1aㅡ Edição. Rio de Janeiro: Elsevier, 2010. 232p.

ALBERTO, L. C. S. ISO 38500 - Um novo padrão para a Governança de TI. Blog GR Tips, 2010. Disponível em <http://www.virtue.com.br/blog/?p=47>. Acesso em 09 de julho de 2010.

ALMEIDA, A. CMMI for Services: apresentação. 2009. Disponível em: $<\mathrm{http}: / /$ www.alessandroalmeida.com/files/Palestra.CMMlforServices_4oEdicao.pdf>. Acesso em 23 mar. 2011.

AMORIM, W. W. C. C. Framework OpenGMP: uma proposta para gerenciar multiprojetos em uma estrutura organizacional em rede. 2009. 147p. Dissertação (Mestrado) - Centro de Informática, Universidade Federal de Pernambuco, Recife, 2009. Disponível em: < http://www.di.ufpe.br/ hermano/download/dissertacoes/DissertacaoOpenGMPWilnaraAmorim.pdf>.

Acesso em 07 jul. 2010.

ANFAVEA. Anuário ANFAVEA 2010. Disponível em: <www.anfavea.com.br/anuario.html>. Acesso em: 02 jun. 2011.

ANGELO, A. S. Entendendo o PRINCE2 ${ }^{\text {TM }}$. Revista MundoPM, Maio/2008. Disponível em <http://www.mundopm.com.br/noticia.jsp?id=264>. Acesso em 08 jul. 2010.

BERNARDES, M. C.; MOREIRA, E. S. Um modelo para inclusão da governança da segurança da informação no escopo da governança organizacional. In: SIMPÓSIO EM SEGURANÇA EM INFORMÁTICA, 7, 2005, São Paulo. Anais eletrônicos... São Paulo, 2005. Disponível em: < ftp://linorg.cirp.usp.br/pub1/SSI/SSI2005/artigos/14275.pdf>. Acesso em 13 abr. 2011.

BM\&FBOVESPA. São Paulo. Home page BM\&F Bovespa. Disponível em: <http://www.bmfbovespa.com.br >. Acesso em: 11 de abril de 2010.

BOWEN, P. L.; CHEUNG M. D.; ROHDE F. H. Enhancing IT governance practices: A model and case study of an organization's efforts. International Journal of Accounting Information Systems, vol. 8, n. 3, p. 191-221, 2007.

BRAGANZA, A. Rethinking the data-information-knowledge hierarchy: towards a case-based model. International Journal of Information Management, n. 24, p. 347-356, 2004.

BROWN, J. S., DUGUID, P. Organizational learning and communities-of-practice: Towards a unified view of working, learning, and innovation. Organization Science, 2(1), p. 40-57, 1991.

BROWN, A. E.; GRANT, G. G. Framing the Frameworks: A Review of IT Governance Research. Communications of the AIS, Vol. 15, artigo 38, 2005.

CALDER, A. ISO/IEC 38500: The IT Governance Standard. 1ª Edição. Reino Unido: IT Governance Publishing, 2008. 52p.

CALDER, A. The Calder-Moir IT Governance Framework - Overview. Reino Unido: IT Governance Publishing, 2008a. 5p. 
CARR, N.G. IT doesn't matter. Harvard Business Review, v.81, n. 5, p. 41-49, 2003.

CARR, N.G. The End of Corporate Computing. Sloan Management Review, v. 46, n. 3, p. 67-73, Primavera, 2005.

CARVALHO, T. C. M. B. TI Tecnologia da Informação - Tempo de Inovação. 1a Edição. São Paulo: M.Books, 2009. 460p.

CHAN, F. T. S.; CHAN, M. H.; LAU, H.;IP, R. W. L. Investment appraisal techniques for advanced manufacturing technology (AMT): a literature review. International Journal of Manufacturing Technology and Management, 12/1, p. 35-47, 2001.

CHAUDHARI, Y. ISO 38500 versus COBIT: What is the right choice? Search CIO, 2010. Disponível em: <http://searchcio.techtarget.in/news/1516291/ISO-38500-versus-COBIT-What-is-theright-choices. Acesso em 02 mai. 2011.

CHEN, D. Enterprise-control system integration - an international standard. International Journal of Production Research, 43: 20, p. 4335-4357, 2005.

CHIAVENATO, I. Introdução à Teoria Geral da Administração. 3ª Edição. São Paulo: McGraw-Hill do Brasil, 2004. 520p.

CLEMENTI, S. O modelo GSS-COBITIL para gerenciamento de suporte de serviços de tecnologia da informação. 2007. 201p. Tese (Doutorado) - Escola Politécnica, Universidade de São Paulo, São Paulo, 2007.

COSTA, S. E. G; PLATTS, K. W.; FLEURY, A. Advanced Manufacturing Technology: defining the object and positioning it as an element of manufacturing strategy. In: INTERNATIONAL CONFERENCE ON INDUSTRIAL ENGINEERING AND OPERATIONS MANAGEMENT, 6., 2000, São Paulo. Anais Eletrônicos... São Paulo: ICIEOM, 2000. Disponível em: <http://www.abepro.org.br/biblioteca/ENEGEP2000_10280.PDF>. Acesso em: 22 out. 2010.

DANTAS, M. G.; TÁVORA JUNIOR, J. L. Planejamento estratégico da automação industrial em uma perspectiva de alinhamento estratégico. In: ENCONTRO NACIONAL DE ENGENHARIA DE PRODUÇÃO, 23., 2003, Ouro Preto. Anais eletrônicos... Ouro Preto, MG: ENEGEP, 2003. Disponível em: < http://www.abepro.org.br/biblioteca/ENEGEP2003_TR0702_1694.pdf>. Acesso em: 23. out. 2010 .

DRENNAN, M. P. Information intensive industries in metropolitan areas of the United States of America. Environment and Planning A, v. 21, p. 1603-1618, 1989.

ELOFF, J.; M. ELOFF. Information Security Management - A New Paradigm. In: ANNUAL RESEARCH CONFERENCE OF THE SOUTH AFRICAN INSTITUTE OF COMPUTER SCIENTISTS AND INFORMATION TECHNOLOGISTS. Anais eletrônicos... Pretoria: SAICSIT, 2003. Disponível em: < http://portal.acm.org/citation.cfm?id=954028>. Acesso em: 23 mai. 2009.

FAVARETTO, F. Uma contribuição ao processo de gestão da produção pelo uso da coleta automática de dados de chão de fábrica. 2001. 235p. Tese (Doutorado) - Escola de Engenharia de São Carlos, Universidade de São Paulo, São Carlos, 2001. Disponível em: < http://www.teses.usp.br/teses/disponiveis/18/18135/tde-09102001-133342/en.php>. Acesso em: 21 abr. 2010.

FENABRAVE. Informativo FENABRAVE Emplacamentos. 2010. Disponível em: $<$ http://www.fenabrave.com.br/principal/home/?sistema=conteudos|conteudo\&id_conteudo=1\#conteud o>. Acesso em 12 de julho de 2011.

FERNANDES, A. A.; ABREU, V. F. Implantando a Governança de TI - da Estratégia à Gestão dos Processos e Serviços. 2º Edição. Rio de Janeiro: Brasport, 2008. 480p. 
FRANCALANCI, C.; MAGGIOLINI, P. Mesuring the financial benefits of IT investments on coordination. In: GRENBERGEN, W. V. Information systems evaluation management. Reino Unido: IRM Press, 2002. p. 54-74.

FRASER, J.; ZIMMERMANN, R. IT Controls engineering convergence. Furthers manufacturer's success. Rockwell Automation, Mllwalkee, EUA, 2007.

GAMA, F. A; MARTINELLO, M. Governança de Tecnologia da Informação: Um Estudo em Empresas Brasileiras. In: SIMPÓSIO FUCAPE DE PRODUÇÃO CIENTÍFICA, 4., 2006, Vitória. Anais Eletrônicos... Vitória: $\quad$ FUCAPE, 2006.2 Disponível em: $<$ http://www.fucape.br/_admin/upload/prod_cientifica/gama\%20-

\%20governanca\%20de\%20tecnologia\%20de\%20informacao.pdf>. Acesso em 13 abr. 2010.

GIFFORD, C. When Worlds Collide in Manufacturing operations: ISA 95 Best practices Book 2.0. Research Triangle Park: International Society of Automation, 2011. 256p.

GOVERNO DO ESTADO DE SÃO PAULO. Indústria Automobilística. São Paulo. Disponível em: $<$ http://www.saopaulo.sp.gov.br/conhecasp/historia_republica-industria-automobilistica $>$.Acesso em 01. Jun. 2011.

GREMBERGEN, W. V. The balanced scorecard and IT governance. Information Systems Control Journal, v. 2, p. 40-43, 2000.

GREMBERGEN, W. V.; HAES, S.; GULDENTOPS, E. Structures, processes and relational mechanisms for IT governance. In: GREMBERGEN, W. V. Strategies for Information Technology Governance. Reino Unido: Idea Group Publishing, 2004. p. 14-49.

GREMBERGEN, W. V.; DE HAES, S. Implementing Information Technology Governance: Models, Practices and Cases. ${ }^{1}{ }^{a}$ Edição. Hershey: IGI Publishing, 2008. 350p.

GREMBERGEN, W. V.; DE HAES, S. Enterprise Governance of Information Technology Achieving Strategic Alignement and Value. 1ㄹ Edição. Nova York: Springer Science and Business Media, 2009. 234p.

GROOVER, M. P. Automation, production systems, and computer-integrated manufacturing. $3^{\mathrm{a}}$ Edição. Nova Jersey: Pearson Education, 2008. 880p.

GUEDES, L. A.; BEZERRA, C.; FEIJÓ, R.; EIDELWEIN, M. E.; CUNHA, D. M.; COSTA, B.; SOUZA, A. Ambiente computacional para desenvolvimento de aplicações de monitoramento e análise de processos na indústria do petróleo. In: RIO OIL \& GAS EXPO AND CONFERENCE, 2008, Rio de Janeiro. Anais Eletrônicos... Rio de Janeiro: 2008. Disponível em: < http://www.sigaa.ufrn.br/sigaa/verProducao?idProducao $=92535 \& k e y=d 2229 \mathrm{~d} 875 \mathrm{db} 2775 \mathrm{fc} 9 \mathrm{dea} 94 \mathrm{cb} 1$ 4770e7>. Acesso em 20 abr. 2010.

HENDERSON, J. C.; VENKATRAMAN, N. Strategic Alignement: Leveraging Information Technology For Transforming Organizations. IBM Systems Journal. v.32, n.1, p. 4-16, 1993.

HOLLENDER, M. Collaborative Process Automation Systems. 1ª Edição. Research Triangle Park: ISA Publishing, 2009. 408p.

HUMPHREY, J.; SCHMITZ, H. Governance in Global Value Chains. In: SCHMITZ, H. Local enterprises in the global economy: issues of governance and upgrading. Cheltenham: Edward Elgar, 2004, p. 95-108.

HUMPHREYS, T. How to implement an ISO/IEC 27001 information security management system. ISO Management Systems, p. 40-44, Mai-Jun, 2006.

IBGC. Home page IBGC - Instituto Brasileiro de Governança Corporativa. Disponível em $<$ http://www.ibgc.org.br >. Acesso em: 28 de julho de 2010. 
ISACA. Val IT - $\quad$ Unlocking the Technology Investments: apresentação. 2009. Disponível em <http://www.isaca.org/KnowledgeCenter/Val-IT-IT-Value-Delivery-/Documents/Val-IT-Overview.ppt>. Acesso em 06 de julho de 2010.

The Val IT Framework 2.0: apresentação.Bogotá, 2009b. Disponível em: <http://www.isacabogota.net/Metodologias/VALIT.pdf>. Acesso em 15 de setembro de 2010.

ISACA. Home page da ISACA. Disponível em: <www.isaca.org.br>. Acesso em: 14 ago. 2010.

ITGI - INFORMATION TECHNOLOGY GOVERNANCE INSTITUTE. CobiT 4.0: control objectives, management guidelines, maturity models. Rolling Meadows: ITGI, 2005. 194 p. Disponível em: <http://www.itgi.org>. Acesso em: 07 mar. 2009.

Board Briefing on IT governance. Rolling Meadows: ITGI, 2006a. 73p. Disponível em: <http://www.itgi.org >. Acesso em: 18 jul. 2010.

Enterprise Value: Governance of IT Investments. Rolling Meadows: ITGI, 2006b. 28p. Disponível em <http://www.isaca.org/Knowledge-Center/Val-IT-IT-Value-Delivery-/Documents/VAL-ITbusiness-case.pdf>. Acesso em 17 de setembro de 2010.

CobiT 4.1: framework, control objectives, management guidelines, maturity models. Rolling Meadows: ITGI. 2007. 213 p. Disponível em: <http://www.isaca.org>. Acesso em: 07 mar. 2009.

Enterprise Value: Governance of IT Investments, The Val IT Framework 2.0. Rolling Meadows: ITGl, 2008. 116p. Disponível em: <http://www.isaca.org>. Acesso em: 23 jul. 2011.

ITGI - INFORMATION TECHNOLOGY GOVERNANCE INSTITUTE; OGC - OFFICE OF GOVERNMENT COMMERCE. Aligning COBIT 4.1, ITIL V3 and ISO/IEC 27002 for Business Benefits. 2008. 131p. Disponível em: <http://www.isaca.org>. Acesso em: 13 mar. 2010.

ITGI - INFORMATION TECHNOLOGY GOVERNANCE INSTITUTE; PRICEWATERHOUSECOOPERS. IT Governance Global Status Report. Rolling Meadows: ITGI, 2008. 73p. Disponível em: < http://www.isaca.org/Knowledge-Center/Research/Documents/GlobalStatus-Report---2008.pdf>. Acesso em: 21 mai. 2010.

ITSMF - IT SERVICE MANAGEMENT FORUM. ISO/IEC 20000, a pocket guide. Zeewolde: Van Haren Publishing, 2006. 71p.

An Introductory Overview of ITIL V3. Reino Unido: ITSMF. 2007. 58p. Disponível em <http://www.itsmfi.org/files/itSMF_ITILV3_Intro_Overview_0.pdf>. Acesso em 05 mar. 2009.

JESUS, R. Governança de TI: apresentação. Rio de Janeiro, 2007. Disponível em <http://www.sucesurj.com.br/download/FuturolTIL200707/Comunicacao\%20e\%20GovernancaTI\%20\%202.pdf>. Acesso em 15 de agosto de 2010.

JUCA JUNIOR, A. S.; AMARAL, D. C. Estudos de Caso de Maturidade em Gestão de Projetos em Empresas de Base Tecnológica. XXV ENCONTRO NACIONAL DE ENGENHARIA DE PRODUÇÃO ENEGEP. Anais Eletrônicos... Porto Alegre, RS: ENEGEP, 2005. Disponível em: < http://www.abepro.org.br/biblioteca/ENEGEP2005_Enegep0504_1632.pdf>. Acesso em 25 jun. 2010.

KALLÁS, D. Balanced Scorecard: aplicação e impactos. Um estudo com jogos de empresa. 2003. 217p. Dissertação (Mestrado) - Faculdade de Economia, Administração e Contabilidade, Universidade de São Paulo, São Paulo, 2003. Disponível em: $<$ http://www.teses.usp.br/teses/disponiveis/12/12139/tde-23082004132438/publico/Dissertacao_Kallas.pdf>. Acesso em: 02 jul. 2010.

KALINOWSKI, M.; SANTOS, G.; REINEHR, S.; MONTONI, M.; ROCHA, A. R., WEBER, K. C.; TRAVASSOS, G. H. MPS.BR: Promovendo a Adoção de Boas Práticas de Engenharia de Software pela Indústria Brasileira. XIII CONGRESSO IBERO AMERICANO DE ENGENHARIA DE SOFTWARE 
- CIBSE. Anais Eletrônicos... Cuenca, Equador: CIBSE, 2010. Disponível em: $<$ http://www.softex.br/portal/softexweb/uploadDocuments/CIBSE2010_MPSBR_CameraReady.pdf>. Acesso em: 20 de setembro de 2010.

KAPLAN, R. S.; NORTON, D. P. The balanced scorecard: translating strategy into action. Boston: Harvard Business School Press, 1996. 326p.

KELLER, W. TOGAF 9 Quick Start Guide for Enterprise Architects. Berlin: Wolfgang Keller, 2009. 59p. Disponível em <http://www.objectarchitects.biz/TOGAF9/TOGAF9QuickstartGuideV10c.pdf>. Acesso em 20 de janeiro de 2011.

KITAGAWA, C. H. Nível de adesão de empresas latino-americanas aos princípios de governança corporativa recomendados. 2007. 240p. Dissertação (Mestrado) - Faculdade de Economia, Administração e Contabilidade, Universidade de São Paulo, Ribeirão Preto, 2007. Disponível em: <http://www.teses.usp.br/teses/disponiveis/96/96133/tde-25042008-151237/es.php>. Acesso em 08 jun. 2010.

KUMAR, K. D.; KARUNAMOORTHY, L.; ROTH, H.; MIRNALINEE, T. T. Computers in manufacturing: towards successful implementation of integrated automation system. Technovation, n. 25, p. 477-488, 2005.

KUMBAKARA, N. Managed IT services: the role of IT standards. Information Management \& Computer Security, v. 16, n. 4, p.336-59, 2008.

LARSEN, M. H.; PEDERSEN, M. K.; ANDERSEN, K. V. IT Governance - Reviewing 17 IT Governance Tools and Analysing the Case of Novozymes A/S. In: HAWAll INTERNATIONAL CONFERENCE ON SYSTEM SCIENCES, 39., 2006. Anais Eletrônicos... Hawaii: HICSS, 2006. Disponível em: < http://www.cioindex.com/nm/articlefiles/60442-itgovernanceframeworks.pdf>. Acesso em: 28 jun. 2010.

LAURINDO, F. J. B. Um estudo sobre a avaliação da eficácia da tecnologia da informação nas organizações. 2000. 197p. Tese (Doutorado) - Escola Politécnica, Universidade de São Paulo, São Paulo, 2000.

LIMA, A. C.; SANTOS, L. B.; LUCIANO, M. B. Avaliação da importância do uso de um BSC para TI. 2009. 58p. Trabalho de Curso (MBA em Governança de TI) - Universidade Católica de Brasília, Brasília, 2009. Disponível em: <http://bdjur.stj.gov.br/xmlui/handle/2011/26513>. Acesso em 01 jul. 2010.

MACORATTI, J. C. Conceitos : Especificação de requisitos. Macoratti.net, 2007. Disponível em < http://www.macoratti.net/07/12/net_fer.htm>. Acesso em 12 de abril de 2011.

MANZINI, E.J. Entrevista semi-estruturada: análise de objetivos e de roteiros. In: SEMINÁRIO INTERNACIONAL SOBRE PESQUISA E ESTUDOS QUALITATIVOS, 2, 2004. Anais eletrônicos... Bauru, Brasil: A pesquisa qualitativa em debate, 2004. Disponível em: <http://www.sepq.org.br/llsipeq/anais/pdf/gt3/04.pdf>. Acesso em 09 set. 2011.

MARTINS, P. G.; LAUGENI, F. P. Administração da produção. São Paulo: Saraiva, 2006. 562p.

MARTINS, A. B.; SANTOS. C.A.S. Uma Metodologia para implantação de um Sistema de Gestão de Segurança da Informação. Revista de Gestão e Tecnologia e Sistema de Informação. v. 2, n. 2, p. 121-136, 2005.

MECENA, S. Modelos eSCM e o processo de aquisição: apresentação. 2005. Disponível em: <http://golden.softex.br/portal/softexweb/uploadDocuments/Sergio_Mecena_UFRJCOPPE_eSCM_W AS_SP_3_8_05.pdf>. Acesso em 05 mai. 2011.

MESA. Home page MESA - Manufacturing Enterprise Solutions Association. Disponível em: <http://www.mesa.org >. Acesso em 30 set. 2010. 
MEYER, N. D. Systemic IS governance: an introduction. Information Systems Management Journal, v.21, n.4, p.23-34, Outono, 2004.

MIGUEL, P. A. C. Estudo de caso na engenharia de produção: estruturação e recomendações para sua condução. Revista Produção, v. 17, n. 1, p. 216-229, 2007.

MIKLOVIC, D. Survey With ISA Reveals Automation IT Ownership Trends. GARTNER, 2008. 21p. Disponível em: <http://www.gartner.com/DisplayDocument?doc_cd=155335\&ref=g_fromdoc $>$. Acesso em: 24 mai. 2010.

MINSKY, M. Matter, Mind and Models. In: INTERNATIONAL FEDERATION OF INFORMATION PROCESSING CONGRESS, 1., p. 45-49 1968, Cambridge, MA. Anais... Cambridge: 1968. . Reimpresso em Semantic Information Processing, MIT Press, 1968.

MORAES, R. O; LAURINDO, F. J. B. Um Estudo de Caso da Gestão de Portfolio de Projetos de Tecnologia de Informação. Gestão \& Produção, v. 10, n. 3, p. 312-328, 2003.

MORORÓ, B. O. Modelagem sistêmica do processo de melhoria contínua de processos industriais utilizando o método Seis Sigma e Redes de Petri. 2008. 175p. Dissertação (Mestrado) - Escola Politécnica, Universidade de São Paulo, São Paulo, 2008. Disopnível em: < http://www.teses.usp.br/teses/disponiveis/3/3152/tde-29012009-

103220/publico/Dissertacao_MororoPosDefesa.pdf>. Acesso em: 05 jul. 2010.

NAGALINGAM S. V. CIM - Still the Solution for Manufacturing Industry. Robotics and Computer Integrated Manufacturing, 24(3), p. 332-344. 2008.

NASCIMENTO, J. Governança de TI e ISO/IEC 38500. Blog GSTI, 2009. Disponível em $<$ http://gsti.blogspot.com/2009/11/governanca-de-TI-e-isoiec-38500.html>. Acesso em 09 de julho de 2010.

PALENA, N; THAPA, S; BOYCE, C. Preparing a Case Study: A Guide for Designing and Conducting a Case Study for Evaluation Input. Pathfinder International Tool Series - Monitoring and Evaluation - $1, \quad 2006$. Disponível em: < http://www.pathfind.org/site/DocServer/m_e_tool_series_case_study.pdf $>$. Acesso em: 03 dez. 2010.

PANETTO, H; MOLINA, A. Enterprise Integration and Interoperability in Manufacturing Systems: trends and issues. Journal of Computers in Industry, 59/7, p. 641-646. 2008.

PEREIRA, M. M. M. A maturidade em gerenciamento de projetos e sua contribuição para a seleção de projetos de acordo com a estratégia organizacional. 2009. 126p. Dissertação (Mestrado) - Escola Politécnica, Universidade de São Paulo, São Paulo, 2009. Disponível em: < http://www.teses.usp.br/teses/disponiveis/3/3135/tde-01042009-

101859/publico/PEREIRA_MMM_Dissertacao.pdf>. Acesso em 18 jun. 2010.

PETERSON, R. R. Crafting Information Technology Governance. Information Systems Management, v. 21, p.7-23 Outono, 2004

PINTO, F. C. R; CAMEIRA, R. F.; CLEMENTE, R. G.; CAULLIRAUX, H. M. Outsourcing Global: Sistemas de Automação de Serviços Profissionais e Modelo de Certificação de Serviços Habilitados por Tecnologia da Informação. In: ENCONTRO NACIONAL DE ENGENHARIA DE PRODUÇÃO, 25., 2005. Anais Eletrônicos... Porto Alegre, RS, 2005. Disponível em: < http://www.abepro.org.br/biblioteca/ENEGEP2005_Enegep0901_1652.pdf>. Acesso em 05. Mai 2010.

PMI - PROJECT MANAGEMENT INSTITUTE. Guia PMBOK: um guia do conjunto de conhecimentos em gerenciamento de projetos. Pensilvânia: Project Management Institute. 2004. $405 p$.

PORTER, M. E.; MILLAR, V. How information gives you competitive advantage. Harvard Business Review, v. 63, n.4, p. 149-160, Jul-Ago, 1985. 
QAI - QAI GLOBAL SERVICE. PMBoK®, OPM3 ${ }^{\circledR}$, PRINCE2 ${ }^{\circledR}$. Disponível em $<$ http://www.qaiglobal.com/qgs/Content.asp?ID=913>. Acesso em 07 de julho de 2010.

RAMIREZ, J.C.; ZUCARELLI, G. Você tem a organização de TI certa para suportar sua estratégia de negócio? Disponível em: $<$ http://www.bain.es/bainweb/PDFs/cms/Public/Voce_tem_organizacao_de_TI_certa_Portuguese.pdf> . Acesso em: 18 abr. 2010.

RAU, K.G. Effective governance of IT: design, objectives, roles, and relationships. Information Systems Management, v.21, p.35-42, Outono, 2004.

RIBEIRO, M. Veículo ainda é sonho para 61\% das famílias. O Estado de São Paulo, 21 mar. 2010a. Disponível em: <http://www.estadao.com.br/estadaodehoje/20100321/not_imp527145,0.php> Acesso em 01 jun. 2011.

RIBEIRO, R. Qual é melhor, PRINCE2 ou PMBOK Guide? 2R Projetos, 2010b. Disponível em <http://www.2rprojetos.com/2010/03/29/qual-e-melhorprince2-ou-pmbok-guide>. Acesso em 08 de julho de 2010.

RODRIGUES, L. C.; MACCARI, E. A.; SIMÕES, S. A. O desenho da gestão da tecnologia da informação nas $\mathbf{1 0 0}$ maiores empresas na visão dos executivos de TI. Revista de Gestão da Tecnologia e Sistemas de Informação. v. 6, n. 3, p. 483-506, 2009.

SCHWARZ, M. Trends in the Automotive Industry Implications on Supply Chain Management. Cisco, San Jose, 2008.2 Disponível $\quad$ em: <http://www.cisco.com/web/about/ac79/docs/wp/ctd/Auto_Trends_WP_FINAL.pdf>. Acesso em: 03 abr. 2011.

SEI. Home Page SEI - Software Engineering Institute. Disponível em: <http://www.sei.cmu.edu/cmmi/tools/index.cfm>. Acesso em 05 mai. 2011.

SIEGELAUB, J. M. How PRINCE2 $®$ Can Complement PMBOK and Your PMP. PMI/ Westchester Chapter. 2004. Disponível em: <http://www.pmiwestchester.org/downloads/Prince2PMBOK.pdf>. Acesso em 07 de julho de 2010.

SILVA, E. B. Estendendo os limites da governança de tecnologia da informação até o chão de fábrica. 2009. 97p. Dissertação (Mestrado) - Centro Universitário da FEl, São Bernardo, 2009.Disponível em: <http://www.fei.edu.br/Download\%20de\%20Pesquisas/FEl-PD-002ElcioBrito.pdf>. Acesso em: 22 set. 2009.

SIMONSSON, M.; JOHNSON, P. Defining IT Governance: a consolidation of literature. EARP Working Paper, Suécia, 2005. Disponível em: $<$ http://citeseerx.ist.psu.edu/viewdoc/summary?doi=10.1.1.64.6388>. Acesso em: 30 jun. 2010.

SINGER, B. ISA - SP-99 Update: apresentação. 2006. Disponível em: <http://www.isa.org/link/SP99ppt>.Acesso em 23 abr. 2011.

SOARES, H. F. Importação de tecnologia gerencial para gestão do fornecimento de serviços de TI: um estudo sobre a aplicabilidade do modelo eSourcing Capability Model ao contexto institucional brasileiro. 2008. 144p. Dissertação (Mestrado) - Faculdade de Economia, Administração e Contabilidade, Universidade de São Paulo, São Paulo, 2008.Disponível em: $<$ http://www.teses.usp.br/teses/disponiveis/12/12139/tde-07102008-115552/pt-br.php>. Acesso em: 25 jun. 2010.

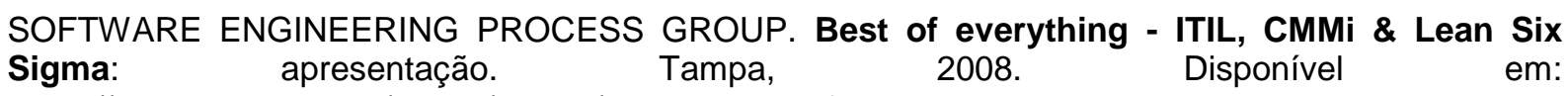
<http://www.sei.cmu.edu/library/assets/Banerjee08.pdf>. Acesso em 14 de julho de 2010. 
SOMMER, S. A marriage made in automation IT. 2008. 2p. Disponível em: < http://www.automationfederation.org/InTechTemplate.cfm?Section=Workforce_Development\&templat $\mathrm{e}=/$ ContentManagement/ContentDisplay.cfm\&ContentID=70858>. Acesso em: 24 mai. 2010.

SOTILLE, M. Comparação PMBoK \& CMM + CMMi: apresentação. Disponível em <http://www.pmtech.com.br/artigos/PMBOK\&CMM+CMMI.pdf>. Acesso em 07 de julho de 2010.

SOUZA, M.; PEREIRA, S.L. Tecnologia da informação como ferramenta de suporte a decisão e gestão nos processos de automação das instalações operacionais de saneamento. In: CONFERÊNCIA INTERNACIONAL DE APLICAÇÕES INDUSTRIAIS, 8., 2008, Poços de Caldas. Anais Eletrônicos... Poços de Caldas, MG: Induscon, 2008. Disponível em: < http://www.labplan.ufsc.br/congressos/Induscon\%202008/pdfs/40544.pdf>. Acesso em 18 abr. 2010.

SUN, H. Current and future patterns of using advanced manufacturing technologies. Technovation, 20, p. 631-641, 2000.

SWAMIDASS, P.M.; KOTHAS, S. Explaining manufacturing technology use, firm size and performance using a multidimensional view of technology. Journal of Operation Management, 17, p. 23-27. 1998.

TEIXEIRA, C. ISO $\mathbf{3 8 5 0 0}$ Visão Geral: apresentação. 2010. Disponível em: <http://www.slideshare.net/carlos_jmt/iso-38500-viso-geral>. Acesso em 10 jul. de 2010.

THE OPEN GROUP. The Open Group Architecture Framework (TOGAF) Version 7: apresentação. Reino Unido, 2002. Disponível em <http://www.enterprisearchitecture.info/Images/Documents/Intro\%20TOGAF\%20v7.pdf>. Acesso em 15 jul. de 2010.

The Open Group Architectural Framework (TOGAF) Version 9. Reino Unido: The Open Group, 2009. Disponível em: <http://pubs.opengroup.org/architecture/togaf9-doc/arch/>. Acesso em: 15 jul. 2010.

TOOMEY, M. Corporate Governance of IT: ISO 38500 Case Study: apresentação. Canberra, 2008. Disponível

<http://www.infonomics.com.au/Web\%20Content/Documents/itSMF_Canberra_Presentation_-

em: ISO_38500_Case_Study.pdf>. Acesso em 15 de agosto de 2010.

ULRICH, K. Há 125 anos Carl Benz solicitava patente do primeiro automóvel. Disponivel em: <http://www.dw-world.de/dw/article/0,,14799147,00.html>. Acesso em 11 de abril de 2011.

UNGER, K. Manufacturer's needs not changing but acronyms are. 2001. Disponível em: < http://www.isa.org/InTechTemplate.cfm?Section=InTech\&template=/ContentManagement/ContentDis play.cfm\&ContentID=723>. Acesso em: 25 abr. 2010.

VAN SANTE, T; ERMERS, J. TOGAF ${ }^{\mathrm{TM}} 9$ and ITIL $®$ V3 - Two Frameworks Whitepaper. 2009. Disponível em: <http://www.best-managementpractice.com/gempdf/White_Paper_TOGAF_9_ITIL_V3_Sept09.pdf >. Acesso em 15 de julho de 2010.

VARGAS, R. Manual prático do plano de projeto: utilizando o PMBoK Guide. 3ํeㄹção. Rio de Janeiro: Brasport, 2007. 256p.

VERNADAT, F.B. Enterprise Modelling and Integration: Principles and Applications. Londres: Chapman \& Hall, 1996.13p.

VOON, P.; SALIDO, J. MOF to COBIT/Val IT Comparison and Cross-Implementation Guide. 2009. Disponível em: <http://download.microsoft.com/download/7/3/0/7305B0C4-F874-448B-A4557949A6DFD966/MOF_COBIT-VallT_Cross-Impl_Guide_Final.pdf>. Acesso em 15 de julho de 2010.

WEBB, P.; POLLARD, C.; RIDLEY, G. Attemting to Define IT Governance. In: HAWAll INTERNATIONAL CONFERENCE ON SYSTEM SCIENCES, 39., 2006, Hawaii. Anais Eletrônicos... 
Hawaii: HICSS, 2006. Disponível em: <http://dl.acm.org/citation.cfm?id=1109716.1110022>. Acesso em: 03 jun. 2010.

WEILL, P. Don't Just Lead, Govern - How Top-Performing Firms govern IT. MIS Quarterly Executive, (3)1, p. 1-17. 2004.

WEILL, P.; ROSS, J. W. Governança de TI, tecnologia da informação. 1a Edição. São Paulo: M. Books do Brasil Editora Ltda., 2006. 290p.

YIN, R. K. Estudo de caso: planejamento e métodos. 3를 Edição. Porto Alegre: Bookman, 2005. 212p.

ZAGUIR, N. A.; MARTINS, M. R. Revisão crítica do OPM3: um estudo de redundâncias. In: ENCONTRO NACIONAL DE ENGENHARIA DE PRODUÇÃO, 26., 2006. Anais Eletrônicos... Fortaleza, CE: ENEGEP: 2006. Disponível em: < http://www.abepro.org.br/biblioteca/ENEGEP2006_TR550371_8500.pdf>. Acesso em 06 mai. 2010.

ZHOU, H.; LEONG, G. K.; JONSSON, P.; SUM, C. A comparative study of advanced manufacturing technology and manufacturing infrastructure investments in Singapore and Sweden. International Journal of Production Economics, n. 120, p. 42-53. 2009. 


\section{GLOSSÁRIO}

\begin{tabular}{|c|c|}
\hline Termo & Definição \\
\hline $\mathrm{TI}$ (ou TIC) & $\begin{array}{l}\text { Tecnologia da Informação, recentemente também denominada TIC, } \\
\text { Tecnologia da Informação e Comunicação. Neste trabalho, será utilizado o } \\
\text { termo TI para designar o conjunto de recursos tecnológicos e } \\
\text { computacionais para geração e uso da informação incluindo o uso de } \\
\text { hardware e software, telecomunicações, automaçâo, recursos multimídia e } \\
\text { todos os outros recursos e pessoal. }\end{array}$ \\
\hline Governança de TI & $\begin{array}{l}\text { Sistema pelo qual a organização de } \mathrm{TI} \text { é dirigida, incluindo direitos } \\
\text { decisórios, estruturas organizacionais, responsabilidades, processos, } \\
\text { mecanismos de relacionamento e mecanismos de monitoramento de } \\
\text { métricas, de forma que a TI possa atuar de forma congruente com o } \\
\text { negócio, agregando valor, sustentando e ampliando os objetivos e as } \\
\text { estratégias organizacionais. Não se trata, portanto, apenas da implantação } \\
\text { de modelos das chamadas melhores práticas de mercado. }\end{array}$ \\
\hline Alinham & $\begin{array}{l}\text { De acordo com o COBIT (ITGI, 2007, p. 09), alinhamento trata de "garantir a } \\
\text { ligação entre os planos de negócios e de TI, definindo, mantendo e } \\
\text { validando a proposta de valor de TI, alinhando as operações de TI com as } \\
\text { operações da organização". }\end{array}$ \\
\hline Escritório & $\begin{array}{l}\text { Ambiente corporativo que possui como sistemas o email, editores de texto, } \\
\text { de planilhas e apresentações, intranet e todos os demais sistemas utilizados } \\
\text { em computadores por toda a empresa. }\end{array}$ \\
\hline Chão de Fábrica & $\begin{array}{l}\text { Ambiente de produção que possui como sistemas de controle da produção e } \\
\text { do ambiente de automação, por meio de sensores, redes de controle e } \\
\text { robôs, por exemplo. }\end{array}$ \\
\hline Automação & $\begin{array}{l}\text { Groover (2008) define automação como a tecnologia pela qual um processo } \\
\text { ou procedimento é realizado sem intervenção humana. É implementada } \\
\text { usando um conjunto de instruções e um sistema de controle que as executa. }\end{array}$ \\
\hline Modelo & $\begin{array}{l}\text { Abstração da realidade expressa em termos de algum formalismo ou } \\
\text { linguagem definido por alguns constructos (Vernadat, 1996). Em outras } \\
\text { palavras, para um observador } B \text {, um objeto } A^{*} \text { é um modelo de um objeto } A \\
\text { na medida em que B pode utilizar } A^{*} \text { para responder às perguntas que lhe } \\
\text { interessam sobre } A \text { (Minsky, 1968). } \\
\text { Um modelo é expresso em alguma linguagem, sendo a mais formal, a } \\
\text { matemática e a menos formal (e mais rica), a linguagem natural. Existem } \\
\text { muitas linguagens para modelar, como símbolos, gráficos ou diagramas, } \\
\text { como o modelo entidade-relacionamento. }\end{array}$ \\
\hline
\end{tabular}

